UNIVERSIDADE DE SÃO PAULO

ESCOLA DE ENFERMAGEM DE RIBEIRÃO PRETO

JULIANA COELHO PINA

ABORDAGEM HIERARQUIZADA PARA A IDENTIFICAÇÃO DE FATORES ASSOCIADOS À HOSPITALIZAÇÃO POR PNEUMONIA, EM MENORES DE CINCO ANOS DE IDADE: ESTUDO CASO-CONTROLE

Ribeirão Preto 


\section{ABORDAGEM HIERARQUIZADA PARA A IDENTIFICAÇÃO DE FATORES ASSOCIADOS À HOSPITALIZAÇÃO POR PNEUMONIA, EM MENORES DE CINCO ANOS DE IDADE: ESTUDO CASO-CONTROLE}

Tese apresentada à Escola de Enfermagem de Ribeirão Preto da Universidade de São Paulo, para obtenção do título de Doutor em Ciências, Programa de Pós-Graduação Enfermagem em Saúde Pública.

Linha de Pesquisa: Assistência à criança e ao adolescente.

Orientador: Profa. Dra. Débora Falleiros de Mello

Co-orientador: Profa. Dra. Suzana Alves de Moraes

Ribeirão Preto 
AUTORIZO A REPRODUÇÃO E DIVULGAÇÃO TOTAL OU PARCIAL DESTE TRABALHO, POR QUALQUER MEIO CONVENCIONAL OU ELETRÔNICO, PARA FINS DE ESTUDO E PESQUISA, DESDE QUE CITADA A FONTE.

FICHA CATALOGRÁFICA

Pina, Juliana Coelho.

Abordagem hierarquizada para a identificação de fatores associados à hospitalização por pneumonia, em menores de cinco anos de idade: estudo caso-controle.

Ribeirão Preto, 2013.

181 p. : il. ; $30 \mathrm{~cm}$.

Tese de Doutorado apresentada à Escola de Enfermagem de Ribeirão Preto / USP.

Área de Concentração: Enfermagem em Saúde Pública.

Orientador: Profa. Dra. Débora Falleiros de Mello

Co-orientador: Profa. Dra. Suzana Alves de Moraes

1. criança. 2. pneumonia. 3. hospitalização. 4. atenção primária à saúde. 5 . epidemiologia. 6. estudos caso-controle. 
PINA, Juliana Coelho

ABORDAGEM HIERARQUIZADA PARA A IDENTIFICAÇÃO DE FATORES ASSOCIADOS À HOSPITALIZAÇÃO POR PNEUMONIA, EM MENORES DE CINCO ANOS DE IDADE: ESTUDO CASO-CONTROLE

Tese apresentada à Escola de Enfermagem de Ribeirão Preto da Universidade de São Paulo, para a obtenção do título de Doutor em Ciências, Programa de Pós-Graduação Enfermagem em Saúde Pública.

Aprovado em:

\section{Banca Examinadora}

Prof. Dr.

Instituição:

Assinatura:

Prof. Dr.

Instituição:

Assinatura:

Prof. Dr.

Instituição:

Assinatura:

Prof. Dr.

Instituição:

Assinatura:

Prof. Dr.

Instituição: Assinatura: 


\section{AGRADECIMENTOS}

À Profa. Dra. Débora Falleiros de Mello, não somente pela orientação desde a iniciação científica, mas pela amizade e pela partilha - do conhecimento em enfermagem em saúde da criança e da própria vida.

À Profa. Dra. Suzana Alves de Moraes, pela orientação, pelo aprendizado em Epidemiologia, pelo apoio nos momentos difíceis e pela amizade.

À Dra. Isabel Cristina Martins de Freitas, pela amizade e por toda sua valiosa contribuição a este trabalho.

Às bolsistas de apoio técnico desta pesquisa - Letícia Pancieri e Michele Cristina de Carvalho - pelo envolvimento, pró-atividade e excelência no trabalho desenvolvido.

À equipe de coleta de dados desta pesquisa, pelo compromisso e responsabilidade na realização do trabalho de campo.

À Fundação de Amparo à Pesquisa do Estado de São Paulo, pelo apoio financeiro para a realização desta pesquisa.

À Chefia do Departamento Materno-Infantil e Saúde Pública e à Área de Saúde da Criança e do Adolescente, por viabilizar minha disponibilidade para o desenvolvimento deste trabalho.

Às Profa. Dra. Maria Cândida de Carvalho Furtado e Profa. Dra. Maria José Bistafa Pereira, pelas contribuições relativas ao instrumento PCATool.

À Dra. Miyeko Hayashida, pela assessoria no gerenciamento do banco de dados do PCATool.

Às amigas e companheiras de trabalho e pós-graduação: Aline Okido, Daniela Pimentel, Patricia Curvo, Paula Chuprouski e Raquel Vivancos. 
A todos que, direta ou indiretamente, contribuíram para a realização deste trabalho.

À minha família: meus pais Orivaldo e Cecília, meu irmão Marcelo e meu sobrinho João Pedro - pelo amor, zelo e apoio.

A Deus, pelo eterno aprendizado... 


\section{RESUMO}

PINA, JC. Abordagem hierarquizada para a identificação de dos fatores associados à hospitalização por pneumonia, em menores de cinco anos de idade: estudo caso-controle. 2013. 181 p. Tese (Doutorado) - Escola de Enfermagem de Ribeirão Preto, Universidade de São Paulo, Ribeirão Preto, 2013.

Objetivos: Investigar os fatores associados à hospitalização por pneumonia, em crianças menores de cinco anos de idade, no município de Ribeirão Preto - SP. Métodos: Estudo epidemiológico com delineamento do tipo caso-controle de base hospitalar, com alocação de 345 casos e 345 controles. Fatores socioeconômicos, reprodutivos, ambientais, perinatais, nutricionais, relativos ao cuidado à criança e à morbidade prévia foram considerados variáveis explanatórias. Os dados foram coletados por meio da aplicação de um questionário pré-codificado que contemplou o elenco de variáveis do estudo, incluindo-se o Instrumento de Avaliação da APS PCATool. Odds ratios (OR) brutos e ajustados, com respectivos intervalos de confiança (95\%) foram calculados, aplicando-se a regressão logística multivariada e seguindo-se os pressupostos da abordagem hierarquizada, buscando-se um modelo explicativo que contemplasse as relações hierárquicas existentes entre as exposições e o desfecho, sendo as análises desenvolvidas no software STATA, versão 12.0. Resultados: Renda familiar superior a $\mathrm{R} \$ 700,00$ foi responsável por uma redução de $32 \%$ na chance de hospitalização das crianças por pneumonia $(\mathrm{OR}=0,68$; IC95\%=0,47-0,98). Paridade $\geq 2$ representou um expressivo aumento na chance de hospitalização (categoria 2 partos: OR=4,60, IC95\%=2,18-9,72; categoria $\geq 3$ partos: $\mathrm{OR}=3,25$, IC95\%=1,55-6,81), enquanto $\circ$ intervalo interpartal $\geq 48$ meses e $\circ$ ganho de peso na gestação de $10 \mathrm{Kg}$ ou mais apresentaram efeito protetor para o desfecho (OR=0,28, IC95\%=0,14-0,56 e OR=0,68, IC95\%=0,47-0,97, respectivamente). Frequência à creche foi responsável por um aumento de $67 \%$ na chance de hospitalização por pneumonia $(\mathrm{OR}=1,67, \mathrm{IC} 95 \%=1,16-2,41)$. As crianças desnutridas apresentam uma chance duas vezes maior de serem hospitalizadas pela doença $(\mathrm{OR}=2,53 ; \mathrm{IC}=1,06-6,05)$ enquanto aquelas com excesso de peso apresentam uma redução de $63 \%$ nessa chance $(\mathrm{OR}=0,37$; IC=0,14-0,99); no entanto, questiona-se a plausibilidade biológica desse efeito protetor. A situação vacinal não atualizada foi responsável por um aumento de quase 3 vezes na chance de hospitalização por pneumonia $(\mathrm{OR}=2,81 ; \mathrm{IC}=1,76-4,49)$. As crianças que fizeram uso pregresso de 
medicamentos apresentaram uma chance $67 \%$ maior de serem hospitalizadas por pneumonia $(\mathrm{OR}=1,67 ; \mathrm{IC}=1,00-2,78 ; p=0,049)$. Crianças com sibilância prévia apresentaram o dobro de chance de serem hospitalizadas pela doença (OR categoria 1 episódio = 2,13; IC95\%=1,31-3,47; OR categoria $\geq 3$ episódios = 2,37; IC95\%=1,354,15). A exclusão de pneumonias aspirativas dentre os casos pode ter contribuído para uma maior proporção de crianças com refluxo referido entre os controles, levando a uma associação inversa à esperada (efeito de proteção) entre refluxo gastroesofágico e hospitalização por pneumonia ( $O R=0,55 ; \mathrm{IC}=0,31-0,99)$. Escores Essenciais da APS acima de 3,17 foram responsáveis por um efeito protetor em relação à hospitalização por pneumonia, reduzindo as chances de hospitalização em $43 \%$ (OR para a categoria $>3,41=0,57$; IC $=0,32-0,99$ ) a $50 \%$ (OR para a categoria $>3,17$ e $\leq 3,41=0,50 ; \mathrm{IC}=0,28-0,88)$. Conclusões: $\mathrm{O}$ modelo explicativo obtido pelo presente estudo é composto, em grande parte, por variáveis relacionadas ao cuidado à criança ou às características da mãe e da família. Considerando-se os procedimentos referentes ao planejamento do estudo, à execução da coleta de dados e às análises estatísticas empregadas, reitera-se a consecução de validade interna para o estudo, sendo possível afirmar que o modelo obtido é explicativo do fenômeno da hospitalização por pneumonia, na população estudada.

Descritores: criança; pneumonia; hospitalização; atenção primária à saúde; epidemiologia; estudos caso-controle. 


\begin{abstract}
PINA, JC. A hierarchized approach to the identification of the factors associated with hospitalization due to pneumonia in children under five years of age: a casecontrol study. 2013. 181 p. Doctoral dissertation - University of São Paulo at Ribeirão Preto College of Nursing, Ribeirão Preto, 2013.
\end{abstract}

Objectives: To investigate the factors associated with hospitalization due to pneumonia in children under five years of age in the city of Ribeirão Preto - SP, Brazil.

Methods: Epidemiological study with a hospital-based case-control design, including 345 cases and 345 controls. Socioeconomic, reproductive, environmental, perinatal, nutritional, childcare and previous morbidity factors were considered as explanatory variables. The data were collected through the application of a pre-coded questionnaire that addressed the study variables and included the Primary Care Assessment Tool - PCATool. Gross and adjusted odds ratios (OR) were calculated with their respective confidence intervals (95\%), applying multivariate logistic regression in accordance with the premises of the hierarchized approach, looking for an explanatory model that considered the existing hierarchical relations between the exposures and the outcome. The analyses were developed in STATA software, version 12.0. Results: A family income superior to $R \$ 700$ was responsible for a $32 \%$ reduction in children's chance of hospitalization due to pneumonia $(O R=0.68$; $95 \% \mathrm{Cl}=0.47-0.98)$. Parity $\geq 2$ represented a considerable increase in the chance of hospitalization (category 2 births: $\mathrm{OR}=4.60,95 \% \mathrm{Cl}=2.18-9.72$; category $\geq 3$ births: $\mathrm{OR}=3.25,95 \% \mathrm{Cl}=1.55-6.81$ ), while the inter-birth interval $\geq 48$ months and the weight gain of $10 \mathrm{Kg}$ or more during pregnancy represented a protective effect against the outcome $(\mathrm{OR}=0.28,95 \% \mathrm{Cl}=0.14-0.56$ and $\mathrm{OR}=0.68,95 \% \mathrm{Cl}=0.47-0.97$, respectively). Attending kindergarten was responsible for a $67 \%$ increase in the chance of hospitalization due to pneumonia $(\mathrm{OR}=1.67,95 \% \mathrm{Cl}=1.16-2.41)$. Malnourished children present twice as many chances of being hospitalized due to the disease $(\mathrm{OR}=2.53 ; \mathrm{Cl}=1.06-6.05)$, while children with overweight present a $63 \%$ reduction in that chance $(\mathrm{OR}=0.37 ; \mathrm{Cl}=0.14-0.99)$; the biological plausibility of this protective effect is questioned though. An outdated vaccine situation was responsible for almost three times as many chances of hospitalization due to pneumonia $(\mathrm{OR}=2.81 ; \mathrm{Cl}=1.76-4.49)$. Children with earlier medication use revealed a $67 \%$ higher chance of being hospitalized due to pneumonia $(\mathrm{OR}=1.67 ; \mathrm{Cl}=1.00-2.78 ; p=0.049)$. Children with 
earlier wheezing presented twice as many chances of being hospitalized due to the disease (OR category 1 episode $=2.13 ; 95 \% \mathrm{Cl}=1.31-3.47$; OR category $\geq 3$ episodes $=2.37 ; 95 \% \mathrm{Cl}=1.35-4.15)$. The exclusion of aspiration pneumonias from the cases may have contributed to a greater proportion of children with reflux among the control, leading to an inverse association (protective effect) between gastroesophageal reflux and hospitalization due to pneumonia ( $\mathrm{OR}=0.55 ; \mathrm{Cl}=0.31-0.99$ ). Essencial Scores of PHC superior to 3.17 were responsible for a protective effect with regard to hospitalization due to pneumonia, reducing the chances of hospitalization by $43 \%$ (OR for the category $>3.41=0.57 ; \mathrm{Cl}=0.32-0.99$ ) to $50 \%$ (OR for the category $>3.17$ and $\leq 3.41=0.50 ; \mathrm{Cl}=0.28-0.88)$. Conclusions: The explanatory model obtained in this study largely includes variables related to childcare or the mother's and family's characteristics. In view of the study planning and data collection procedures and the statistical analyses applied, the internal validity of the study is highlighted, based on which it can be affirmed that the obtained model explains the phenomenon of hospitalization due to pneumonia in the study population.

Descriptors: child; pneumonia; hospitalization; primary health care; epidemiology; case-control studies. 


\section{RESUMEN}

PINA, JC. Aproximación jerarquizada a la identificación de los factores asociados a la hospitalización por neumonía en menores de cinco años de edad: estudio caso-control. 2013. 181 p. Tesis (Doctorado) - Escuela de Enfermería de Ribeirão Preto, Universidad de São Paulo, Ribeirão Preto, 2013.

Objetivos: Investigar los factores asociados a la hospitalización por neumonía, en niños con edad inferior a cinco años, en la ciudad de Ribeirão Preto - SP, Brasil. Métodos: Estudio epidemiológico con diseño caso-control y base hospitalaria, con asignación de 345 casos y 345 controles. Factores socioeconómicos, reproductivos, ambientales, perinatales, nutricionales, relativos al cuidado del niño y a la morbilidad previa fueron considerados variables explicativas. Los datos fueron recolectados mediante la aplicación de un cuestionario pre-codificado que contempló el rol de variables del estudio, incluyendo el Instrumento de Evaluación de la APS - PCATool. Odds ratios (OR) brutos y ajustados con respectivos intervalos de confianza (95\%) fueron calculados, aplicándose la regresión logística multivariada y siguiéndose los presupuestos de la aproximación jerarquizada, buscándose un modelo explicativo que contemplara las relaciones jerárquicas existentes entre las exposiciones y el desfecho, siendo los análisis desarrollados en el software STATA, versión 12.0. Resultados: Renta familiar superior a $\mathrm{R} \$ 700,00$ fue responsable por una reducción del $32 \%$ en la chance de hospitalización de los niños por neumonía (OR=0,68; IC95\%=0,47-0,98). Paridad $\geq 2$ representó un aumento expresivo en la chance de hospitalización (categoría 2 partos: $\mathrm{OR}=4,60$, IC95\%=2,18-9,72; categoría $\geq 3$ partos: $\mathrm{OR}=3,25$, IC95\%=1,55-6,81), mientras el intervalo entre partos $\geq 48$ meses y el gaño de peso durante el embarazo de $10 \mathrm{Kg}$ o más presentaron efecto protector para el desfecho (OR=0,28, IC95\%=0,14-0,56 y OR=0,68, IC95\%=0,47-0,97, respectivamente). Frecuentar la guardería fue responsable por un aumento del $67 \%$ en la chance de hospitalización por neumonía $(\mathrm{OR}=1,67$, IC95\%=1,16-2,41). Los niños desnutridos presentan una chance dos veces mayor de ser hospitalizados por la enfermedad $(\mathrm{OR}=2,53 ; \mathrm{IC}=1,06-6,05)$, mientras aquellos con exceso de peso revelan una reducción del $63 \%$ en esa chance $(\mathrm{OR}=0,37 ; \mathrm{IC}=0,14-0,99) ;$ sin embargo, se cuestiona la plausibilidad biológica de ese efecto protector. La situación de vacunas no actualizada fue responsable por un aumento de casi 3 veces en la chance de hospitalización por neumonía $(\mathrm{OR}=2,81 ; \mathrm{IC}=1,76-4,49)$. Los niños que hicieron uso 
anterior de medicamentos revelaron una chance $67 \%$ mayor de ser hospitalizados por neumonía $(\mathrm{OR}=1,67 ; \mathrm{IC}=1,00-2,78 ; p=0,049)$. Niños con sibilancia previa presentaron el doble de chance de ser hospitalizadas debido a la enfermedad (OR categoría 1 episodio = 2,13; IC95\%=1,31-3,47; OR categoría $\geq 3$ episodios = 2,37; IC95\%=1,354,15). La exclusión de neumonías por aspiración entre los casos puede haber contribuido a una mayor proporción de niños con reflujo entre los controles, llevando a una asociación inversa (efecto de protección) entre reflujo gastroesofágico y hospitalización por neumonía $(\mathrm{OR}=0,55 ; \mathrm{IC}=0,31-0,99)$. Escores Essenciales de la APS superiores a 3,17 fueron responsables por un efecto protector con relación a la hospitalización por neumonía, reduciendo las chances de hospitalización en 43\% (OR para la categoría $>3,41=0,57 ; \mathrm{IC}=0,32-0,99$ ) a $50 \%$ (OR para la categoría $>3,17$ y $\leq 3,41=0,50 ; \mathrm{IC}=0,28-0,88)$. Conclusiones: El modelo explicativo alcanzado por el presente estudio abarca principalmente variables relacionadas al cuidado del niño o a las características de la madre y de la familia. Considerándose los procedimientos referentes a la planificación del estudio, a la recolecta de datos y a los análisis estadísticos empleados, se subraya la consecución de validez interna para el estudio, siendo posible afirmar que el modelo alcanzado explica el fenómeno de la hospitalización por neumonía en la población estudiada.

Descriptores: niño; neumonía; hospitalización; atención primaria de salud; epidemiología; estudios caso-control. 


\section{LISTA DE TABELAS}

Tabela 1 - Caracterização de casos e controles participantes do estudo, segundo variáveis sociodemográficas. Ribeirão Preto/SP, 2013

Tabela 2 - Caracterização de casos e controles participantes do estudo, segundo variáveis reprodutivas maternas. Ribeirão Preto/SP, 2013 .68

Tabela 3 - Caracterização de casos e controles participantes do estudo, segundo variáveis ambientais. Ribeirão Preto/SP, 2013.

Tabela 4 - Caracterização de casos e controles participantes do estudo, segundo variáveis perinatais. Ribeirão Preto/SP, 2013. 70

Tabela 5 - Caracterização de casos e controles participantes do estudo, segundo variáveis nutricionais. Ribeirão Preto/SP, 2013

Tabela 6 - Caracterização de casos e controles participantes do estudo, segundo variáveis relativas ao cuidado à criança. Ribeirão Preto/SP, 2013.

Tabela 7 - Caracterização de casos e controles participantes do estudo, segundo variáveis relativas à morbidade. Ribeirão Preto/SP, 2013.

Tabela 8 - Odds ratios com intervalos de confiança (95\%) e valores p para os testes de Wald, segundo variáveis sociodemográficas. Modelos univariados. Ribeirão Preto/SP, 2013 .74

Tabela 9 - Odds ratios com intervalos de confiança (95\%) e valores p para os testes de Wald, segundo variáveis reprodutivas maternas. Modelos univariados. Ribeirão Preto/SP, 2013

Tabela 10 - Odds ratios com intervalos de confiança (95\%) e valores p para os testes de Wald, segundo variáveis ambientais. Modelos univariados. Ribeirão Preto/SP, 
Tabela 11 - Odds ratios com intervalos de confiança (95\%) e valores p para os testes de Wald, segundo variáveis perinatais. Modelos univariados. Ribeirão Preto/SP, 2013

Tabela 12 - Odds ratios com intervalos de confiança $(95 \%)$ e valores p para os testes de Wald, segundo variáveis nutricionais. Modelos univariados. Ribeirão Preto/SP, 2013 .78

Tabela 13 - Odds ratios com intervalos de confiança (95\%) e valores p para os testes de Wald, segundo variáveis relativas ao cuidado à criança. Modelos univariados. Ribeirão Preto/SP, 2013. 79

Tabela 14 - Odds ratios com intervalos de confiança (95\%) e valores p para os testes de Wald, segundo variáveis relativas à morbidade. Modelos univariados. Ribeirão Preto/SP, 2013 80

Tabela 15 - Odds ratios com intervalos de confiança (95\%) e valores p para os testes de Wald. Modelos intermediários. Ribeirão Preto/SP, 2013

Tabela 16 - Odds ratios com intervalos de confiança (95\%) e valores p para os testes de Wald. Modelo final. Ribeirão Preto/SP, 2013. .85 


\section{LISTA DE ABREVIATURAS E SIGLAS}

AIDPI Atenção Integrada às Doenças Prevalentes na Infância

APS Atenção Primária à Saúde

CAHPS Consumer Assesment of Healthcare Providers and Systems

CAPS Centro de Atenção Psicossocial

CDC Center for Disease Control and Prevention

CEREST Centro de Referência em Saúde do Trabalhador

CHERG Child Health Epidemiology Reference Group

$\mathrm{CPDH} \quad$ Centro de Processamento de Dados Hospitalares

CSAP Condições sensíveis à atenção primária

DRA Doença respiratória aguda

DRGE Doença do refluxo gastroesofágico

DRS Departamento Regional de Saúde

ESF Estratégia Saúde da Família

EUA Estados Unidos da América

FMRP Faculdade de Medicina de Ribeirão Preto

Hib Haemophilus influenzae tipo B

HIV Vírus da imunodeficiência humana

HR Hazard ratio

IC95\% Intervalos com 95\% de confiança

IMC Índice de Massa Corporal

IPRS Índice Paulista de Responsabilidade Social

IRA Infecção respiratória aguda

ITRI Infecção do trato respiratório inferior

IVAS Infecções das vias aéreas superiores

MS Ministério da Saúde

NADEF Núcleo de Atenção à Pessoa Deficiente

NCHS National Center for Health Statistics

NGA-59 Núcleo de Gestão Ambulatorial

OPAS Organização Pan-Americana da Saúde

OR Odds ratio

P3C Parents' Perceptions of Primary Care

PA Pronto-atendimento 
PAC Pneumonia adquirida na comunidade

PACS Programa de Agentes Comunitários de Saúde

PAM II Posto de Atendimento Médico

PCATool Primary Care Assesment Tool

PERCH Pneumonia Etiology Research for Child Health

RP Razão de prevalência

RR Risco relativo

SEADE Fundação Sistema Estadual de Análise de Dados

SUS Sistema Único de Saúde

TCLE Termo de Consentimento Livre e Esclarecido

TRO Terapia de reidratação oral

UBDS Unidade Básica e Distrital de Saúde

UBS Unidade Básica de Saúde

UPA Unidade de Pronto-Atendimento

USF Unidade de Saúde da Família

USP Universidade de São Paulo

VSR Vírus sincicial respiratório 
1. INTRODUÇÃO

1.1. A problemática das doenças respiratórias na infância - importância da

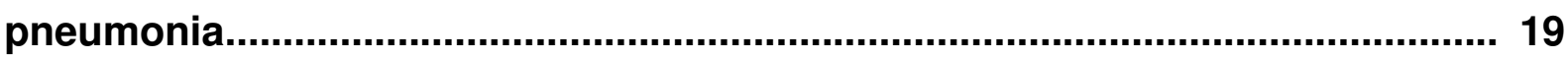

1.2. Pneumonia: epidemiologia, etiologia, clínica e controle.............................. 19

1.3. Fatores envolvidos na ocorrência e agravamento da pneumonia e outras IRA, em crianças menores de cinco anos de idade......................................... 22

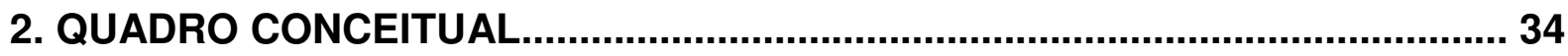

2.1. Fatores relacionados à hospitalização por pneumonia, em crianças menores

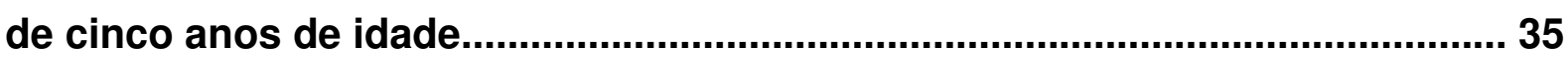

2.2. Papel da APS no controle da pneumonia............................................... 40

2.2.1. APS: conceito, características e avaliação............................................... 42

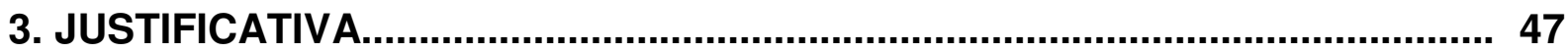

4. OBJETIVOS

5. MATERIAL E MÉTODOS....................................................................... 52

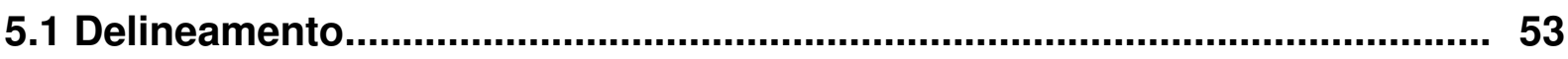

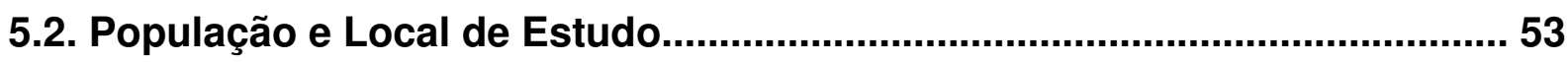

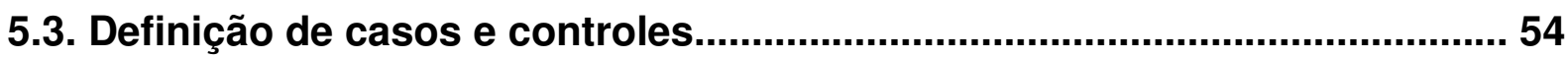

5.4. Estratégias para recrutamento e seleção de casos e controles.................. 55

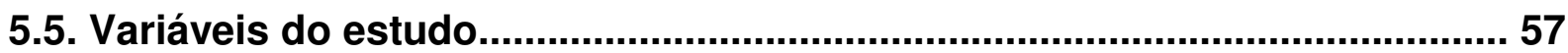

5.5.1. Variável dependente (Resposta ou Desfecho)...................................... 57

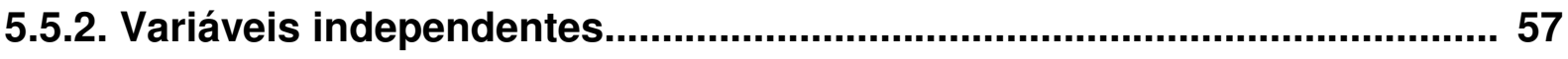

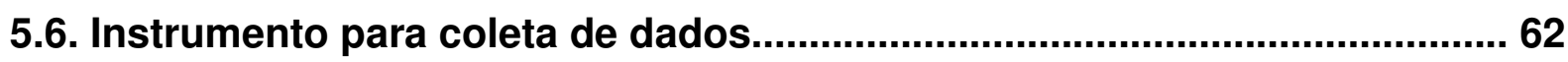

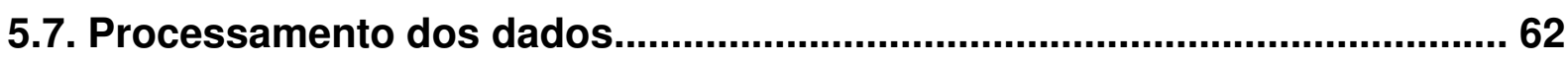

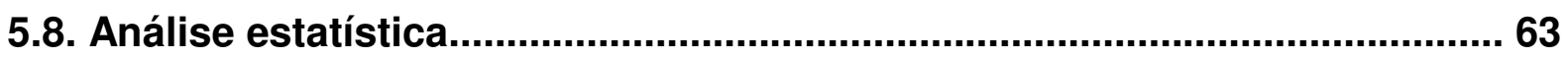

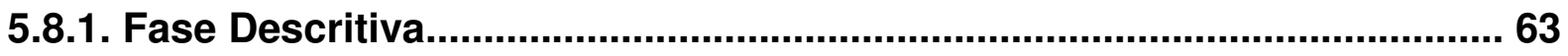

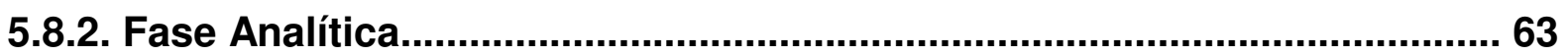

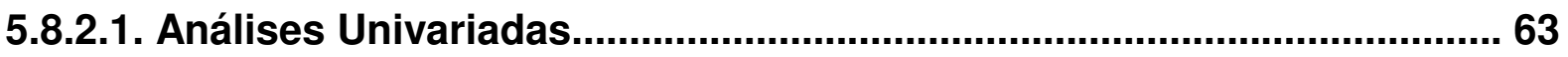

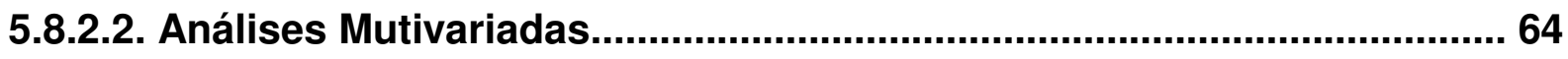

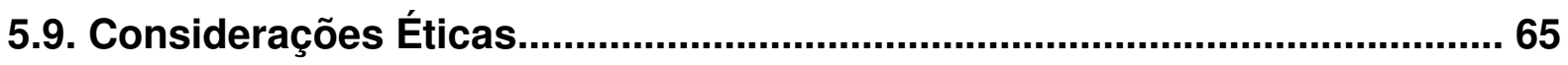

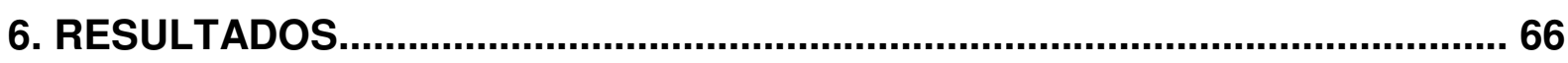

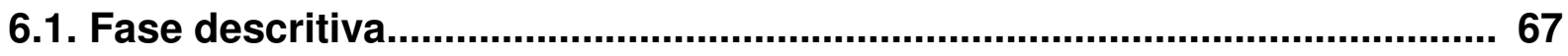

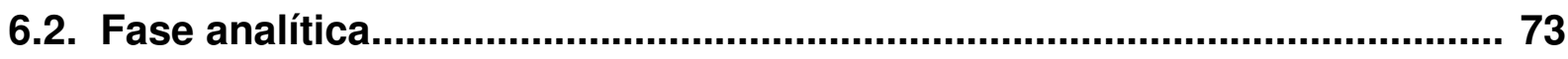




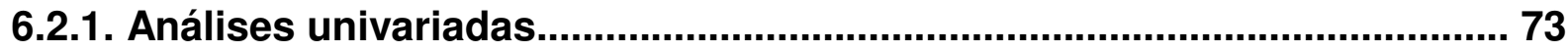

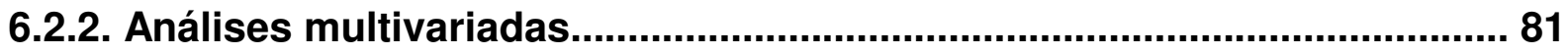

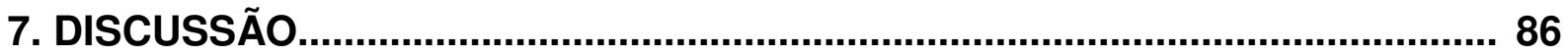

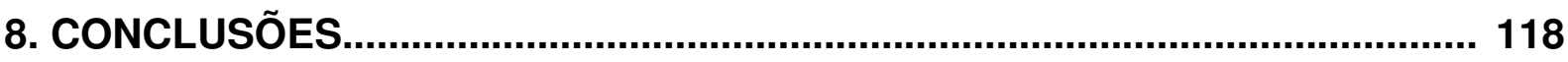

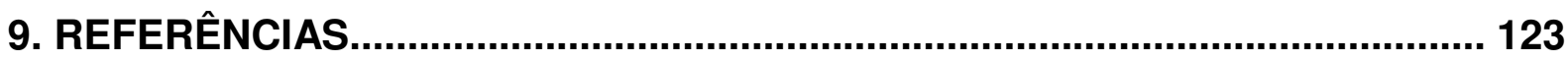

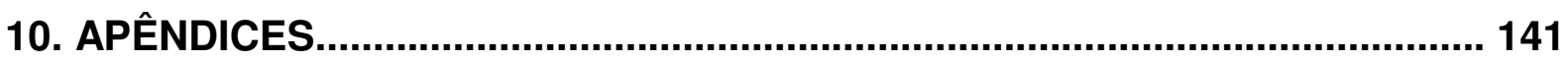


1. INTRODUÇÃO 


\subsection{A problemática das doenças respiratórias na infância - importância da pneumonia}

As infecções respiratórias agudas (IRA) representam a principal causa de mortes em crianças menores de cinco anos de idade, especialmente nos países em desenvolvimento, sendo responsáveis por cerca de $20 \%$ a $50 \%$ do total de mortes nessa faixa etária (BENGUIGUI, 1997a; RUDAN, 2004; TEEPE, 2010).

A problemática das IRA envolve, além da mortalidade, a sua importância como causa de adoecimento e suas consequências, das quais se destacam as hospitalizações, as sequelas, as consultas aos serviços de saúde, o uso inadequado de antibióticos e medicamentos para tosse e resfriado (BENGUIGUI, 1997a). No Brasil, as infecções em crianças ainda persistem como causas importantes de mortalidade pós-neonatal no país e particularmente nas regiões Norte e Nordeste, com cerca de um terço dos casos devidos às pneumonias, diarreias/desidratação e septicemias, causas consideradas evitáveis (MARANHÃO, et al., 2012).

O grupo de doenças do aparelho respiratório representa a terceira causa de morte para essa faixa de idade, no país (as primeiras são afecções perinatais e malformações congênitas), sendo a pneumonia responsável por $66 \%$ das mortes por doenças respiratórias (BRASIL, 2011a). Em relação à hospitalização, em nosso país, as doenças do aparelho respiratório são a principal causa de internação na faixa etária, com grande predomínio da pneumonia (BRASIL, 2012; OLIVEIRA et al., 2010).

\subsection{Pneumonia: epidemiologia, etiologia, clínica e controle}

Segundo a estimativa mais recente disponível, a incidência mundial é de 120 milhões de episódios de pneumonia, ao ano, em menores de cinco anos - sendo 14 milhões de casos com agravamento do quadro (WALKER et al., 2013). Ao ano, aproximadamente 1,2 milhões de crianças menores de cinco anos de idade morrem devido à pneumonia, representando $18 \%$ do total de mortes na faixa etária (UNICEF, 2012). 
Uma maior morbimortalidade é observada nos países em desenvolvimento, nos quais se estima que ocorram cerca de 0,29 episódios de pneumonia por criança menor de cinco anos de idade ao ano, dos quais cerca de 10\% serão graves e necessitarão de hospitalização (RUDAN et al., 2004, 2008).

Nas Américas, a estimativa mais recente para menores de cinco anos é de 7,84 milhões de novos casos de pneumonia clínica ao ano. O Brasil integra o grupo dos quinze países, no mundo todo, com maior número de casos, sendo 1,8 milhões de casos novos ao ano e uma incidência estimada de 0,11 episódios por criança menor de cinco anos de idade ao ano (RUDAN et al., 2008).

A pneumonia é uma infecção do trato respiratório inferior, caracterizada como um processo inflamatório pulmonar, em resposta a um agente agressor. Tal processo inflamatório manifesta-se por infiltrado alveolar, que interfere na absorção de oxigênio e dificulta a respiração (SOCIEDADE BRASILEIRA DE PNEUMOLOGIA E TISIOLOGIA, 2007; UNICEF / WHO, 2006).

A pneumonia que acomete uma pessoa previamente saudável, não relacionada a uma hospitalização prévia ou atual, é denominada pneumonia adquirida na comunidade (PAC) (OSTAPCHUK et al., 2004).

Existem vários agentes etiológicos identificados como causadores da PAC, por meio de estudos epidemiológicos. No entanto, na prática clínica, o agente etiológico não é identificado em até $60 \%$ dos casos de pneumonia, pois a determinação da causa da PAC é frequentemente difícil, especialmente em crianças. A dificuldade para a obtenção de amostras fidedignas e resultados em tempo hábil, portanto, inviabiliza a coleta de exames específicos, como prática rotineira. Além disso, alguns patógenos causadores de pneumonia estão frequentemente presentes no trato respiratório de crianças sem a doença, dificultando o estabelecimento de uma relação causal (OSTAPCHUK et al., 2004; PERCH, 2012; SOCIEDADE BRASILEIRA DE PNEUMOLOGIA E TISIOLOGIA, 2007).

De acordo com o boletim da Organização Mundial da Saúde (OMS) (RUDAN et al., 2008) que revisou os estudos epidemiológicos realizados ao redor do mundo, o conhecimento sobre a etiologia da PAC em menores de cinco anos, nos países em desenvolvimento, é proveniente de duas fontes - estudos prospectivos de base hospitalar e ensaios sobre vacinas. Consultando tais estudos, os autores do boletim identificaram o Streptococcus pneumoniae (pneumococo, responsável por 30 a 50\% dos casos) como o principal agente causador da PAC, seguido do Haemophilus 
influenzae tipo B (Hib) (responsável por 10 a 30\% dos casos), Staphylococcus aureus e Klebsiella pneumoniae. Em relação aos vírus, o principal causador da PAC é o vírus sincicial respiratório (VSR), seguido pelo influenza $A$ e $B$, parainfluenza, metapneumovírus humano e adenovírus, segundo o mesmo boletim.

Geralmente, um quadro de infecção viral alta precede a PAC. Essas infecções elevam o risco de infecção bacteriana secundária e mesmo de co-infecção. A etiologia da PAC, portanto, pode ser mista, o que ocorre em até $25 \%$ dos casos (PERCH, 2012; RUDAN et al., 2008; SOCIEDADE BRASILEIRA DE PNEUMOLOGIA E TISIOLOGIA, 2007).

Considerando a multiplicidade das exposições potencialmente envolvidas na patogênese da pneumonia em crianças, está sendo desenvolvido um rigoroso projeto multicêntrico - Pneumonia Etiology Research for Child Health (PERCH) (PERCH, 2012) - com o objetivo de determinar os fatores de risco e a etiologia da doença, mundialmente. O estudo está previsto para ser finalizado até 2015 , quando serão divulgados novos dados relativos à incidência e etiologia da pneumonia infantil.

Independente do agente etiológico, as principais manifestações que configuram o quadro clínico da pneumonia são: tosse, febre e dificuldade respiratória. O sinal mais importante é a taquipneia, com ou sem dispneia (SOCIEDADE BRASILEIRA DE PNEUMOLOGIA E TISIOLOGIA, 2007). Dadas as dificuldades, já apontadas, de uma prática rotineira de exames laboratoriais e radiológicos para o diagnóstico dos casos suspeitos de pneumonia, o tratamento ambulatorial é empírico e padronizado, realizado a partir do quadro clínico, associado à anamnese (BENGUIGUI, 1997a; SOCIEDADE BRASILEIRA DE PNEUMOLOGIA E TISIOLOGIA, 2007; UNICEF / WHO, 2006).

O tratamento padrão de casos, uma estratégia que integrava o Programa de Controle das IRA, consiste em uma série de decisões que sistematizam as etapas do manejo de casos, quais sejam: avaliação, classificação e tratamento (BENGUIGUI, 1997b). A estratégia Atenção Integrada às Doenças Prevalentes na Infância (AIDPI), uma iniciativa global em saúde da criança, traz aspectos de programas de controle específicos, existentes anteriormente - como o Programa de Controle das IRA - porém que propunham atuações isoladas (BRASIL, 2002). A AIDPI configura uma metodologia de atenção à saúde da criança em consonância com a Atenção Primária à Saúde (APS). Propõe uma avaliação sistemática dos principais fatores que afetam a saúde infantil, integrando ações curativas com medidas de promoção e prevenção, 
conjugando ações de menor complexidade com a qualidade do atendimento (FELISBERTO et al., 2002; OPAS, 1999).

De acordo com recente revisão das recomendações da OMS em relação à abordagem de crianças com queixas respiratórias, no contexto da AIDPI (WHO, 2012), ocorreram algumas mudanças relativas à classificação e tratamento. As novas categorias para classificação são Pneumonia e Pneumonia Grave e considera-se a co-infecção com o vírus da imunodeficiência humana (HIV) para a definição de conduta. Em relação ao tratamento, a nova recomendação é o uso da amoxicilina como tratamento de primeira-linha, devido ao problema da resistência bacteriana ao cotrimoxazol (sulfametoxazol-trimetoprima).

A resistência bacteriana, inclusive, tem sido apontada como um dos principais desafios para o controle da pneumonia, atualmente. Outros desafios incluem o tratamento de crianças co-infectadas com HIV e daquelas afetadas com outros patógenos além do pneumococo, escassez de antibióticos recomendados em apresentação própria para crianças (como amoxicilina em suspensão) e barreiras ao acesso a serviços de saúde (IZADNEGAHDAR et al., 2013).

\subsection{Fatores envolvidos na ocorrência e agravamento da pneumonia e outras IRA, em crianças menores de cinco anos de idade ${ }^{a}$}

Com o objetivo de identificar e priorizar os fatores de risco para a pneumonia a serem investigados pelo projeto multicêntrico PERCH, Wonodi et al. (2012) utilizaramse de uma lista elaborada pelo Child Health Epidemiology Reference Group (CHERG), um grupo de revisão acadêmica constituído pela OMS. Expandindo essa lista por meio de nova revisão de literatura e de consulta a especialistas, os autores obtiveram a seguinte relação de fatores a serem investigados: sexo, idade, tipo de parto, peso ao nascer, idade gestacional, ordem de nascimento, aleitamento materno, desnutrição, suplementação de zinco e vitamina A, morbidades pregressas e atuais, imunização, uso de medicamentos, características maternas e paternas, características

\footnotetext{
${ }^{\text {a }} \mathrm{O}$ presente estudo tem como objeto a pneumonia adquirida na comunidade (PAC). Portanto, em todos os momentos que constar o termo pneumonia no texto, estaremos nos referindo à PAC.
} 
socioeconômicas, saneamento básico, cuidado à criança fora do domicílio e acesso aos serviços de saúde.

Por meio de uma revisão de literatura envolvendo somente estudos que avaliaram o papel de múltiplos fatores de risco, ao mesmo tempo, e que utilizaram a análise multivariada, Rudan et al. (2008) definiram os fatores de risco para a ocorrência da pneumonia e os classificaram, conforme a evidência científica disponível. Os fatores de risco definitivos - para os quais a evidência é consistente englobam a desnutrição, o baixo peso ao nascer, o aleitamento materno não exclusivo durante os primeiros 4 meses de vida, a falta de imunização contra o sarampo no primeiro ano de vida, a poluição intradomiciliar e a aglomeração. Os fatores de risco prováveis são aqueles com alguns achados contraditórios ou com evidências escassas: tabagismo dos pais, deficiência de zinco, experiência da mãe como cuidadora e presença de comorbidades. Fatores de risco possíveis foram identificados esporadicamente por estudos inconsistentes que tratavam de determinados contextos: escolaridade da mãe, frequência à creche, umidade do ar, temperaturas baixas, deficiência de vitamina $A$, ordem de nascimento e poluição extradomiciliar.

Em um estudo caso-controle desenvolvido em Porto Alegre, no sul do Brasil, que buscou investigar os fatores de risco para a pneumonia em crianças menores de dois anos de idade hospitalizadas por essa doença, Victora et al. (1994) elucidaram o papel dos fatores demográficos, socioeconômicos, ambientais, reprodutivos, nutricionais e de morbidade para o desfecho, por meio da análise multivariada hierarquizada. O principal fator de risco identificado foi a frequência à creche [odds ratio $(O R)=11,75]$, provavelmente devido à aglomeração de crianças nesses locais que, segundo os autores, promoveria a transmissão de patógenos por meio de partículas respiratórias. Pelo mesmo motivo, a aglomeração no domicílio representada pelo número de pessoas - foi outro fator de risco ambiental associado ao desfecho (categoria 4 a 5 pessoas: $\mathrm{OR}=1,54$, categoria 6 ou mais pessoas: $\mathrm{OR}=1,84)$. Em relação aos fatores sócio-demográficos, a escolaridade paterna de 8 ou mais anos de estudo apresentou um efeito de proteção $(O R=0,55)$ e a idade materna de 20 ou mais anos permaneceu limítrofe ao nível de significância estatística $(\mathrm{OR}=0,67 ; \mathrm{IC} 95 \%=0,45-1,00 ; p=0,05)$. Dentre os fatores relacionados à criança, os autores destacam o papel dos aspectos nutricionais. O peso de nascimento de $3500 \mathrm{~g}$ ou mais representou um fator de proteção para a hospitalização por pneumonia $(\mathrm{OR}=0,61)$. $\mathrm{O}$ efeito do baixo peso ao nascer no risco de desenvolver a doença estaria 
associado ao comprometimento da resposta imune e da função respiratória. Segundo os autores, pelos mesmos mecanismos o baixo peso para a idade seria responsável pelo incremento no risco, na população estudada (escore-z de peso para idade $\leq-1$ a $\geq-1,9$ : $O R=1,60$; escore $-z$ de peso para idade $\leq-2$ : $O R=4,77$ ). Ainda em relação aos fatores nutricionais, o aleitamento artificial $(\mathrm{OR}=2,61)$ e a falta de alimentação complementar $(\mathrm{OR}=2,83)$ apresentaram expressiva associação com o desfecho. Além das propriedades nutricionais, crianças em aleitamento artificial estariam privadas da proteção passiva contra patógenos que o leite materno oferece. A falta de alimentação complementar, à idade recomendada, poderia levar a uma deficiência de micronutrientes importantes no combate às infecções, mesmo em crianças com peso adequado para a idade. Também englobando os aspectos relativos à criança, a história prévia de pneumonia e sibilância incrementaram o risco de hospitalização por pneumonia, especialmente quando houve necessidade de hospitalização $(O R=2,50$ para pneumonia e $\mathrm{OR}=2,99$ para sibilância), constituindo-se como marcadores para crianças com necessidade de acompanhamento especial.

Outro estudo caso-controle de base hospitalar foi conduzido em Taubaté, na região sudeste brasileira, para estimar os fatores de risco para internação por pneumonia, em menores de cinco anos de idade (NASCIMENTO et al., 2004). Após análise hierarquizada, fatores sócio-demográficos, ambientais e nutricionais permaneceram associados ao desfecho. O modelo final foi composto pelas variáveis escolaridade paterna até 4 anos $(O R=2,81)$, idade materna de 35 anos ou mais $(\mathrm{OR}=0,47)$, 4 ou menos pessoas no domicílio $(\mathrm{OR}=0,45)$ e escore $\mathrm{z}$ de peso para $\leq 0$ idade menor ou igual a zero $(\mathrm{OR}=1,98)$. A variável pessoas no domicílio, categoria 4 ou menos, que não havia se apresentado como fator de proteção à análise univariada, demonstrou tal padrão após ajuste para as demais variáveis.

Por meio de um estudo transversal, a pneumonia foi identificada como responsável por $20 \%$ das internações de crianças menores de cinco anos residentes em São Paulo, Brasil (CAETANO et al., 2002). Os fatores associados à hospitalização foram: maior nível de escolaridade materna (OR variando de 0,43 a 0,30, conforme aumenta a escolaridade); elevada densidade domiciliar ( $O R=1,14)$; avó como cuidadora $(\mathrm{OR}=4,56)$; óbito de irmãos menores de cinco anos $(\mathrm{OR}=2,27)$; baixo peso ao nascer $(\mathrm{OR}=2,71)$; e presença de doença crônica $(\mathrm{OR}=3,32)$.

Macedo et al. (2007) avaliaram os fatores de risco para hospitalização de crianças até um ano de idade, por doença respiratória aguda (DRA), por meio de um 
estudo caso-controle, em Pelotas, sul do Brasil. A principal causa de internação foi a pneumonia (43,7\%). Meninos e crianças com até 6 meses de idade apresentaram maior risco de internação ( $O R=1,5$ e $O R=1,7$, respectivamente), possivelmente devido à imaturidade imunológica e calibre reduzido das vias aéreas (esse último mais frequente em meninos) - favorecendo agravamento do quadro. O maior risco de agravamento da DRA em crianças pequenas estaria relacionado principalmente às infecções virais, especialmente à bronquiolite - responsável por $31 \%$ das internações estudadas. A escolaridade materna apresentou associação mais forte com o desfecho que a renda familiar (OR variando de 3,3 até 12,5, conforme categorias de escolaridade, versus $\mathrm{OR}=3,0$ para renda familiar até 1 salário mínimo), sugerindo que o nível educacional desempenhe um papel independente de outras características socioeconômicas. De acordo com os autores, uma maior escolaridade propiciaria o conhecimento de medidas preventivas e um cuidado mais adequado à criança. Em relação às variáveis ambientais, o tabagismo materno incrementou o risco de internação por DRA $(\mathrm{OR}=1,7)$, possivelmente pelo efeito da exposição à fumaça intradomiciliar nas doenças acompanhadas de broncoespasmos. O número de pessoas dormindo com a criança superior a 3 apresentou significância estatística limítrofe $(\mathrm{OR}=1,7 ; \mathrm{IC} 95 \%=1,0-2,7 ; p=0,05)$. No que tange às questões nutricionais, identificou-se que o aleitamento materno interrompido até 3 meses configura-se como importante fator de risco $(\mathrm{OR}=2,3)$, inclusive apresentando tendência linear $(p<0,001)$ entre as categorias de idade do desmame. O uso de bico permaneceu associado ao desfecho $(\mathrm{OR}=1,9)$ mesmo após a análise multivariada hierarquizada, em que o efeito da amamentação foi controlado. Desse modo, os autores consideram que o risco do uso do bico extrapola a sua interferência na amamentação (pelo fenômeno da confusão de bicos) e inferem que seu papel como fator de risco para hospitalização por DRA englobaria a facilidade de respiração oral em detrimento da nasal e a contaminação do objeto por patógenos. Episódios de sibilância prévia configuraram, nesse estudo, o segundo fator de risco mais importante $(\mathrm{OR}=7,7)$. Os autores também sugerem o acompanhamento dessas crianças, que provavelmente seriam asmáticas sem diagnóstico.

Um estudo foi realizado no sul do Brasil, também em Pelotas, para investigar a associação entre estado nutricional e admissões hospitalares por pneumonia e diarréia, em uma coorte de nascidos vivos (VICTORA et al., 1990). A avaliação do estado nutricional ocorreu ao nascimento (peso ao nascer), em 1984 e 1986, quando 
as crianças estariam com 12 a 28 meses e 36 a 52 meses. Na primeira avaliação (primeiros dois anos de vida), baixo peso ao nascer $(p<0.005)$, ganho de peso insuficiente $(p<0.01)$ e nanismo $(p<0.001)$ estiveram associados à hospitalização por pneumonia. $\mathrm{Na}$ avaliação que remete às crianças entre 2 e 5 anos, apenas o estado nutricional atual esteve associado à hospitalização por pneumonia $(p<0.05)$. Ainda em relação à essa avaliação das crianças entre 2 e 5 anos, as medidas de associação apresentadas para estado nutricional em 1984 e hospitalização por pneumonia em 1985, ajustadas para renda familiar, foram: escore-z de peso para idade menor que 2 [Risco relativo $(R R)=1,75$ ], de -2 a $-1,01 \quad(R R=2,31)$, e de -1 a $-0,01 \quad(R R=1,96)$; escore-z de altura para idade menor que $-2(R R=1,76)$, de -2 a $-1,01(R R=2,49)$, e de -1 a $-0,01(R R=1,44)$.

A partir de outra coorte de nascidos vivos em Pelotas, César et al. (1997) investigaram a influência de fatores socioeconômicos e gestacionais sobre a hospitalização por pneumonia em menores de um ano de idade. Os resultados, a partir da análise hierárquica, apontaram como fatores socioeconômicos de risco a classe social (categoria proletariado típico: $\mathrm{OR}=1,78$, categoria subproletariado: $\mathrm{OR}=3,50$ ), que apresentou tendência linear $(p<0,001)$; e a escolaridade da mãe (categoria 1 a 4 anos de estudo: $\mathrm{OR}=3,24$, categoria 5 a 8 anos de estudo: $\mathrm{OR}=1,97)$, que também apresentou tendência linear $(p<0,001)$. Em relação aos fatores maternos/gestacionais, a idade materna menor que 20 anos $(O R=1,98)$ e a paridade de 3 ou mais filhos $(\mathrm{OR}=2,86)$ permaneceram associadas ao desfecho após análise hierarquizada. A tenra idade materna acarretaria menor experiência na identificação e manejo dos casos graves de pneumonia. Apesar do número de filhos propiciar uma maior experiência no cuidado à criança, um número elevado poderia dificultar esse cuidado. O ganho de peso de $10 \mathrm{Kg}$ ou mais na gestação apresentou-se no limite da significância estatística $(\mathrm{OR}=1,38 ; \mathrm{IC} 95 \%=1,00-1,92 ; p=0,05)$. O ganho de peso na gestação é considerado como principal determinante do peso ao nascer. Contudo, os autores levantam a hipótese de que o efeito do ganho de peso materno nas hospitalizações por pneumonia não seja mediado apenas pelo crescimento fetal, inferindo outros mecanismos como desenvolvimento mais rápido do sistema imune.

César et al. (1999) realizaram um estudo caso-controle aninhado à coorte acima descrita, para avaliar se o aleitamento materno oferece proteção contra pneumonia, no primeiro ano de vida, e se essa proteção varia com a idade. Ressaltamos que, como os casos foram crianças internadas por pneumonia, a 
investigação centra-se no desfecho hospitalização por pneumonia, entre essas crianças. Encontrou-se uma chance de hospitalização por pneumonia quase 4 vezes maior entre crianças em aleitamento misto $(O R=3,8)$, quase 17 vezes maior entre crianças não amamentadas $(O R=16,7)$ e mais de 8 vezes maior em crianças que recebiam alimentação complementar $(\mathrm{OR}=8,5)$. Ao estratificar a amostra por faixas etárias, demonstrou-se uma maior chance entre as crianças desmamadas mais precocemente (categoria 1 a 2 meses: OR=61,1; categoria 3 a 5 meses: $O R=10,1$; categoria 6 a 11 meses: $O R=9,2)$. Para as crianças em aleitamento misto, a associação perdeu significância estatística após a estratificação por idade.

Os fatores associados à hospitalização por pneumonia também foram objeto de investigação em uma coorte de nascidos vivos em Passo Fundo, na região sul do Brasil (GEIB et al., 2007). Estudando as crianças da coorte que foram hospitalizadas por pneumonia, nos seis primeiros meses de vida, encontrou-se associação estatística em relação aos estratos $C / D / E$ da classe econômica $(R R=4.58)$ e ao número de filhos vivos maior que $2(R R=0,54)$, que apresentou efeito protetor. Os demais fatores socioeconômicos, maternos e relativos à criança que demonstraram associação à análise univariada perderam significância estatística à análise ajustada. Os autores discutem as hospitalizações por pneumonia como resultado das desigualdades sociais, na população estudada, assinalando a necessidade de ações intersetoriais direcionadas às classes econômicas mais desfavorecidas.

Dentre os fatores para complicação da pneumonia, Pinto, Maggi e Alves (2004) destacam o papel do risco socioambiental no desenvolvimento de comprometimento pleural em crianças de 3 a 59 meses com pneumonia, no nordeste brasileiro. Por meio de um estudo transversal, encontraram um risco duas vezes maior de comprometimento pleural entre as crianças moradoras de área rural [Razão de Prevalência $(R P)=2,09]$, em casas com até 2 cômodos $(R P=2,03)$ e com baixa renda $(R P=1,99)$, sendo encontrada também associação significativa em relação ao peso de nascimento inferior a $2500 \mathrm{~g}(\mathrm{RP}=1,85)$.

A etiologia e a severidade da pneumonia, em crianças uruguaianas menores de cinco anos de idade, foram estudadas por Hortal et al. (1994). A partir de casos recrutados no hospital e controles ambulatoriais pareados, os autores encontraram associação significativa entre severidade dos casos e: falta de aleitamento materno $(\mathrm{OR}=4,97)$, estado nutricional (chegando a $\mathrm{OR}=2,76$ para o percentil menor que 5), baixo peso de nascimento $(O R=1,64)$, situação vacinal incompleta $(O R=2,73)$, 
número de irmãos (categoria entre 2 e 5: $\mathrm{OR}=1,50$, categoria mais que 5: $\mathrm{OR}=1,75$ ), idade materna (categoria menor que 20 anos: $\mathrm{OR}=1,68$, categoria maior que 44 anos: $\mathrm{OR}=5,38)$, falta de pré-natal $(\mathrm{OR}=4,63)$ e mãe solteira $(\mathrm{OR}=2,34)$.

Um estudo caso-controle de base hospitalar, desenvolvido na Índia (BROOR et al., 2001), identificou fatores de risco associados à infecção do trato respiratório inferior (ITRI) grave, em crianças menores de cinco anos de idade. O uso de combustíveis de biomossa ou querosene para cozinhar contribuem para poluição intradomiciliar e estão associados ao desfecho $(O R=2,51)$. Crianças não amamentadas ou amamentadas até 4 meses apresentaram um incremento de $64 \%$ no risco de hospitalização por ITRI $(\mathrm{OR}=1,64)$, em comparação às amamentadas além dos 4 meses. Desnutrição grave também esteve associada ao desfecho $(O R=1,85)$. O atraso vacinal foi outro fator de risco para hospitalização por ITRI, na população estudada $(\mathrm{OR}=2,85)$, independente da idade e educação materna. De acordo com os autores, as mães que utilizam os serviços de saúde para imunização de seus filhos corretamente estariam também mais propensas a procurar o serviço precocemente em caso de doença. Como a pneumonia é a responsável por grande parte das internações por infecção do trato respiratório, julgamos que os fatores identificados nesse estudo podem estar associados à hospitalização por pneumonia.

Johnson et al. (2008) investigaram os fatores associados à pneumonia com desfecho fatal em menores de cinco anos, na Nigéria, por meio de um estudo transversal com duração de 30 meses. Os autores concluíram que a baixa escolaridade materna ( $p=0,045)$, a exposição à fumaça intradomiciliar $(p=0,006)$, a falta de prescrição de antibióticos previamente à internação $(p=0,04)$, e a desnutrição $(p=0,003)$ estão associadas às complicações que podem resultar em morte por pneumonia. Os autores explanam sobre a vulnerabilidade de crianças malnutridas a infecções bacterianas graves, devido ao comprometimento da integridade da mucosa respiratória, ao baixo nível de fibronectina celular orofaríngea e à pobre regeneração celular. Também discutem sobre o efeito da fumaça intradomiciliar devido à combustão de biomassa, que libera conteúdos tóxicos como hidrocarbonetos, benzeno, monóxido de carbono e dióxido de nitrogênio, que aumentam a susceptibilidade a lesões respiratórias. Associam, inclusive, a baixa escolaridade materna à busca tardia do serviço de saúde, acarretando impossibilidade de tratamento ambulatorial com antibióticos preconizados e necessidade de referência ao hospital. 
Uma metanálise de 36 estudos - provenientes de países desenvolvidos e em desenvolvimento - que tratavam dos fatores de risco para a pneumonia grave, em menores de cinco anos de idade, revelou evidências de associação do desfecho com o baixo peso ao nascer $(\mathrm{OR}=3,18)$, falta de aleitamento materno $(\mathrm{OR}=2,34)$, aglomeração (mais que 7 pessoas na casa) $(\mathrm{OR}=1,96)$, exposição à poluição intradomiciliar $(O R=1,57)$, imunização incompleta $(O R=1,83)$, baixo peso (escore-z de peso para idade <-2) $(\mathrm{OR}=4,47)$ e infecção pelo HIV $(\mathrm{OR}=4,15)$ (JACKSON et al., 2013).

Para avaliar os fatores associados à pneumonia severa entre crianças menores de dois anos internadas em Moçambique, na África, Sigaúque et al. (2009) conduziram um estudo transversal que identificou a anemia $(O R=10,13)$, a desnutrição $(\mathrm{OR}=2,42)$ e a co-infecção com HIV $(\mathrm{OR}=17,21)$ como fatores de risco para a morte pela doença. A desnutrição e a anemia severas, associadas com a pneumonia grave, também estariam associadas à infecção pelo HIV. Crianças com imunossupressão devido ao HIV seriam mais susceptíveis a infecções bacterianas, como a pneumonia bacteriana.

Os aspectos nutricionais e as comorbidades também foram relatados enquanto fatores envolvidos na hospitalização por pneumonia, em um estudo transversal desenvolvido na Bahia, Brasil (NASCIMENTO-CARVALHO et al., 2002), que identificou uma chance 2 vezes maior de internação entre crianças mal nutridas $(\mathrm{OR}=2,0)$ e um risco $40 \%$ maior de internação entre as portadoras de doenças crônicas $(\mathrm{OR}=1,4)$, incluindo cardiopatia, neuropatia, asma, refluxo gastroesofágico, infecção congênita e hipotireoidismo.

Além de contribuírem para a hospitalização, os fatores nutricionais e as comorbidades também podem contribuir para a mortalidade por pneumonia, de acordo com um estudo transversal indiano, no qual a análise multivariada revelou associação do escore-z de peso para idade <-2 $(\mathrm{OR}=1,12)$ e da doença cardíaca congênita $(\mathrm{OR}=1,39)$ com o desfecho (RAMACHANDRAN, et al., 2012).

Ding et al. (2012) também descreveram o papel das doenças de base na severidade da pneumonia entre crianças chinesas, sendo responsáveis por um expressivo incremento na chance de desenvolver um quadro grave $(\mathrm{OR}=6,62)$.

A associação entre distúrbios da respiração durante o sono e pneumonia, em crianças menores de cinco anos de idade, foi objeto de investigação de um estudo caso-controle de base populacional, em Israel (GOLDBART et al., 2012). A apneia do 
sono, diagnosticada por polissonografia, demonstrou forte associação com a pneumonia $(\mathrm{OR}=3,7)$. Além disso, mais crianças com pneumonia apresentavam ronco frequente, em comparação com os controles (18,6\% versus $2,9 \%, p<0,001)$. A plausibilidade biológica dos achados seria explicada, pelo menos em parte, pela possibilidade de hipertrofia da adenoide e da tonsila, associadas ao relaxamento da língua durante o sono, causarem recorrentes microaspirações para o pulmão.

Os fatores de risco perinatais para hospitalização por doença pneumocócica infantil (dentre as quais está a pneumonia pneumocócica) foram objeto de investigação em um estudo de coorte, na Dinamarca (MAHON et al., 2007). À análise estratificada por idade, estiveram significativamente associadas ao desfecho: a multiparidade $(R R=3,87)$ e a prematuridade $(R R=2,89)$, para a faixa etária de 0 a 6 meses; o sexo masculino ( $R R=1,42)$ e o baixo peso ao nascer $(R R=1,80)$, para a faixa etária dos 7 aos 24 meses; e as malformações, para crianças de 0 a 60 meses $(0$ - 6 meses: $\mathrm{RR}=3,35,7-24$ meses: $\mathrm{RR}=1$,93, 25 - 60 meses: $\mathrm{RR}=2,16)$.

Dherani et al. (2008), por meio de uma metanálise realizada a partir de bases de dados da América Latina, África e China, investigaram a redução da poluição intradomiciliar pela queima de combustíveis sólidos como potencial intervenção para prevenir a pneumonia, em menores de cinco anos. Vinte e quatro estudos foram submetidos à metanálise, obtendo-se um OR Geral de 1,79, após ajustes para a variabilidade nos delineamentos, métodos e qualidade dos estudos. Um dos objetivos específicos era investigar se o risco está associado com a severidade do quadro (complicações e morte), o que foi comprovado, segundo os autores, com medidas de associação mais robustas nos estudos com desfechos severos, em comparação aos demais estudos.

A fumaça intradomiciliar foi citada como fator de risco para a hospitalização por pneumonia em estudo caso-controle desenvolvido na Nova Zelândia (GRANT et al., 2012). Nesse estudo, foi a fumaça proveniente do tabagismo que mostrou associação com o desfecho $(\mathrm{OR}=1,99)$, à análise multivariada. Outro fator ambiental associado foi a aglomeração, responsável por quase o triplo de chance de hospitalização por pneumonia (OR=2,87).

A aglomeração também esteve associada à hospitalização por pneumonia em estudo conduzido por Shoham et al. (2005). Ao investigar o impacto da pneumonia na rotina e qualidade de vida das crianças israelenses menores de três anos, por meio de um estudo caso-controle, os autores identificaram que, em comparação aos 
controles, as crianças hospitalizadas possuíam um maior número médio de pessoas na casa $(5,1 \pm 1,9$ vs $4,2 \pm 1,2, p<0.001)$ e um maior número médio de pessoas que dividiam o quarto com elas $(2,4 \pm 0,8$ vs 1,8 $\pm 0,9, p<0,001)$.

Outro estudo caso-controle desenvolvido em Israel avaliou a influência dos fatores nutricionais e história de diarreia na ocorrência de pneumonia alveolar, entre crianças menores de cinco anos hospitalizadas por essa doença (COLES et al., 2005). Anemia $(O R=3,32)$, baixo peso ao nascer $(O R=2,16)$, déficit de estatura $(O R=2,22)$ e episódio de diarreia nos últimos 31 dias $(O R=2,30)$ foram identificados como fatores de risco independentes. Os autores esclarecem que o sinergismo entre a diarreia e a déficit nutricional espolia o organismo em relação a micronutrientes importantes para o combate às infecções.

Um estudo experimental indiano, desenvolvido em comunidades rurais, (BHANDARI et al., 2008) comprovou que a suplementação de zinco a crianças com diarreia, combinada à Terapia de Reidratação Oral (TRO), previne sua posterior hospitalização por pneumonia $(O R=0,29)$, em comparação às crianças que receberam apenas TRO. Os autores destacam, no entanto, que a prescrição do tratamento deve ser associada à orientação do cuidador.

Diante de achados discrepantes na literatura relativos à prevenção da ITRI pela suplementação de zinco, em países em desenvolvimento, foi conduzida uma revisão sistemática da literatura (ROTH; RICHARD; BLACK, 2010). Foi realizada a metanálise de estudos clínicos randomizados controlados da África do Sul, Bangladesh, Índia, México, Peru e Nepal, que revelou um efeito protetor do zinco (na dosagem de pelo menos 70mg / semana, durante um período maior que 3 meses), com razão de incidência de 0,65 (IC95\%=0,52-0,82). Esse achado foi estatisticamente significativo apenas considerando-se os estudos com definição de casos mais específica que o critério respiração rápida. Justifica-se esse achado pelo fato de erros de classificação do desfecho potencialmente conduzirem a medida de associação ao efeito nulo, devido ao grande número de falsos positivos. Ressalta-se que o efeito protetor foi comprovado apenas para as infecções respiratórias do trato inferior, sendo que os mecanismos pelos quais o zinco alteraria a susceptibilidade a essas infecções provavelmente incluiriam: regulação da secreção de citocinas pró-inflamatórias, proliferação de linfócitos, melhora da função de linfócitos T e proteção da integridade do epitélio respiratório nas injúrias pulmonares devido a processos inflamatórios secundários a infecções. 
O efeito do manejo de casos de pneumonia (conforme abordagem proposta pela OMS) na mortalidade de crianças menores de cinco anos foi estimado por meio de uma metanálise, realizada a partir de nove estudos provenientes da Índia, Tanzânia, Paquistão, Filipinas, Nepal, Bangladesh e Indonésia (SAZAWAL; BLACK, 2003). Encontrou-se uma redução na mortalidade geral de $27 \%$ entre neonatos $(\mathrm{OR}=0,73), 20 \%$ entre lactentes $(\mathrm{OR}=0,80)$ e $24 \%$ entre crianças de 1 a 4 anos $(\mathrm{OR}=0,76)$. Quanto à mortalidade específica por pneumonia, evidenciou-se uma redução de $42 \%$ entre neonatos (OR=0,58), 36\% entre lactentes $(O R=0,64)$ e $36 \%$ entre crianças de 1 a 4 anos $(\mathrm{OR}=0,64)$. Os autores recomendam, portanto, que 0 adequado manejo de casos de pneumonia adquirida na comunidade seja realizado na atenção primária à saúde.

A prescrição de antibióticos recomendados, uma das ações do manejo de casos nas infecções respiratórias, foi objeto de um estudo transversal no Reino Unido (WINCHESTER et al., 2009). Os autores buscaram investigar o papel da antibioticoterapia no manejo da pneumonia e de outras ITRI, realizado na APS. O momento da prescrição de antibióticos demonstrou ser um importante fator para o desfecho. Após ajustamento, a prescrição de antibiótico ao ser diagnosticada a infecção esteve associada a uma redução na taxa de hospitalizações [Hazard ratio $(H R)=0,73]$, ao contrário da prescrição ao referir a criança para o hospital $(H R=1,48)$ e 7 dias antes da hospitalização $(H R=1,92)$, que incrementaram o risco de hospitalização.

Por um lado, antibióticos recomendados prescritos em tempo oportuno protegem a criança de complicações, por outro o uso abusivo de antibióticos não recomendados predispõe a criança ao agravamento da pneumonia. Pagaiya e Garner (2005), por meio de um estudo quase-experimental desenvolvido na Tailândia, analisaram os efeitos da capacitação de enfermeiros da APS em protocolos de atendimentos para algumas condições. Os autores encontraram uma redução na prescrição de antibióticos desnecessários para as crianças com IRA, por parte dos enfermeiros capacitados (grupo de intervenção: $42 \%$ antes e $27 \%$ após capacitação; grupo controle: $27-30 \%, p=0,022)$.

Um estudo caso-controle de base populacional, conduzido no México (REYES et al., 1997), analisou a influência das características individuais das crianças e das suas mães, do acesso aos serviços de saúde, do processo de APS e de variáveis socioeconômicas na mortalidade infantil por IRA. Compuseram o modelo final: falta 
de aleitamento materno $(\mathrm{OR}=4,32)$, situação vacinal incompleta $(\mathrm{OR}=3,54)$, prematuridade $(O R=3,54)$, atraso da mãe na busca por serviços de saúde $(O R=19.5)$, trabalho materno extra-domiciliar $(\mathrm{OR}=3,30)$, escolaridade materna menor que 6 anos $(O R=2,21)$, falta de rede de esgotos $(O R=2,10)$, barreiras institucionais $(O R=2,25)$ e não-institucionais ao acesso $(\mathrm{OR}=3,96)$, falta de confiança nos serviços públicos de saúde $(O R=2,58)$, falta de referência da criança ao hospital $(O R=6,83)$, atendimento realizado por dois médicos diferentes $(\mathrm{OR}=5,23)$ e atendimento médico exclusivamente privado $(\mathrm{OR}=4,16)$. Foram construídos indicadores para o elenco de variáveis agrupadas nas categorias mencionadas (características individuais das crianças e das suas mães, acesso aos serviços de saúde, processo de APS e variáveis socioeconômicas), das quais a mais fortemente associada ao desfecho foi a categoria processo de APS (OR=9,68).

A qualidade do atendimento na APS foi apontada por Tanaka e Santo (2008) como fator significativo para a evolução da doença respiratória na infância, em São Paulo, Brasil. Em seu estudo avaliativo, a qualidade do atendimento na APS foi obtida por meio de relato da mãe da criança, com base no nível de acolhimento proporcionado pelas pessoas que integraram a cadeia de atendimento e no tempo de espera para realização da consulta. Comparando-se a evolução do quadro da doença respiratória, encontrou-se um maior percentual de melhora $(78,9 \%, p=0,004)$ entre aquelas crianças cujas mães relataram uma boa qualidade no atendimento. 
A construção do quadro conceitual de uma doença requer o conhecimento dos determinantes biossociais de sua ocorrência e gravidade, bem como das relações entre eles (VICTORA et al., 1997).

Conforme já exposto, aproximadamente 10\% dos episódios de pneumonias em crianças menores de cinco anos de idade, em países em desenvolvimento, serão graves e necessitarão de hospitalização (RUDAN et al., 2004, 2008).

A Sociedade Brasileira de Pneumologia e Tisiologia (2007) recomenda o uso dos sinais clínicos de gravidade da pneumonia preconizados pela OMS para crianças entre 2 meses e 5 anos, os quais são: retração subcostal, incapacidade de ingerir líquidos, dificuldade respiratória grave e cianose central. Acrescenta a esse conjunto os sinais de hipoxemia que precedem a cianose (como sudorese, palidez e a alternância entre sonolência e agitação) e recomenda a oximetria de pulso para mensurar a hipoxemia adequadamente, sendo indicada a internação se $\mathrm{SpO} 2<92 \%$. Além dos sinais clínicos, aponta como critérios de gravidade e necessidade de internação: sinais radiológicos de gravidade (derrame pleural, pneumatoceles, abscesso), doença grave concomitante, falha da terapêutica ambulatorial e incapacidade da família em tratar a criança no domicílio. Em menores de 2 meses de idade, qualquer pneumonia é considerada grave, devido ao risco de agentes Gram negativos, estreptococos $\beta$ hemolíticos e Staphylococcus aureus como causadores de pneumonia, sendo indicada a hospitalização.

Os fatores de risco para internação por pneumonia são aqueles que contribuem para o agravamento ou complicação da doença e, portanto, consequente necessidade de tratamento hospitalar.

\subsection{Fatores relacionados à hospitalização por pneumonia, em crianças menores de cinco anos de idade}

A partir dos estudos apresentados, selecionamos os fatores envolvidos no agravamento da doença, com vistas à construção de um quadro conceitual da hospitalização de crianças menores de cinco anos de idade, por pneumonia.

Crianças do sexo masculino possuem uma chance / risco $40 \%$ a 50\% maior de serem internadas por pneumonia [OR=1,5 (MACEDO et al., 2007) e $R R=1,42$ 
(MAHON et al., 2007)]. Para as menores de 6 meses de idade, a chance é $70 \%$ maior $(\mathrm{OR}=1,7)$ (MACEDO et al., 2007).

Identifica-se uma chance 3 vezes maior $(O R=3,0)$ de hospitalização por pneumonia entre crianças cuja renda familiar é até 1 salário mínimo (MACEDO et al., 2007). Encontra-se, também, associação relativa às classes sociais proletariado típico $(\mathrm{OR}=1,78)$ e subproletariado ( $\mathrm{OR}=3,50)$ (CESAR et al., 1997) e em relação aos estratos $C / D / E$ da classe econômica ( $R R=4,58)$ ( $G E I B$ et al., 2007). A baixa escolaridade materna está associada $(p=0,045)$ à complicação da pneumonia (JOHNSON et al., 2008), com uma chance 2 vezes maior de desfecho fatal $(O R=2,21)$ (REYES et al., 1997). Mães sem escolaridade formal apresentaram a maior chance de terem seus filhos internados (OR=12,5) (MACEDO et al., 2007), seguidas pelas mães com escolaridade de 1 a 4 anos de estudo [OR =3,2 (CESAR et al., 1997) e OR=7,6 (MACEDO et al., 2007)] e de 5 a 8 anos de estudo [OR de 1,97(CESAR et al., 1997) e 3,30 (MACEDO et al., 2007)]. A escolaridade paterna de 8 ou mais anos é responsável por uma redução de $45 \%$ na chance de internação $(O R=0,55)$, enquanto a de até 4 anos foi responsável por um incremento de quase 3 vezes $(O R=2,81)$ nessa chance (NASCIMENTO et al., 2004; VICTORA et al., 1994).

A idade materna de 20 ou mais anos pode reduzir entre $33 \%(\mathrm{OR}=0,67)$ a $53 \%$ $(\mathrm{OR}=0,47)$ a chance de internação (NASCIMENTO et al., 2004; VICTORA et al., 1994), enquanto a idade de menos de 20 anos pode aumentar em $68 \%(\mathrm{OR}=1,68)$ a $98 \%(\mathrm{OR}=1,98)$ essa chance, bem como a idade acima de 44 anos $(\mathrm{OR}=5,38)$ (CESAR et al., 1997; HORTAL et al., 1994).

A multiparidade é descrita como fator de risco para hospitalização, em crianças com pneumonia [RR=3,87 (MAHON et al., 2007); OR=2,86 (CESAR et al., 1997)]. Além das questões reprodutivas, um maior número de filhos aumenta a demanda por cuidados e representa um maior número de crianças no domicílio, contribuindo para a aglomeração e transmissão de patógenos. A falta de adesão ao pré-natal representa um expressivo incremento na chance de desenvolver pneumonia grave $(\mathrm{OR}=4,63)$ (HORTAL et al., 1994).

A prematuridade acresce em 3 vezes o risco de hospitalização $(R R=2,89)$ (MAHON et al, 2007) e morte (OR=3,54) (REYES et al., 1997). Evidências apontam para um risco 69 a $80 \%$ maior de hospitalização por pneumonia entre crianças que nasceram com baixo peso [RR=1,69 (VICTORA et al., 1990); $R R=1,80$ (MAHON et al., 2007)]. A prevalência de hospitalização por pneumonia é 1,85 vezes maior 
$(R P=1,85)$ entre crianças com baixo peso ao nascer (PINTO; MAGGl; ALVES, 2004). Tais crianças têm, aproximadamente, uma chance duas vezes maior de serem internadas por esse diagnóstico [OR=1,64 (HORTAL et al., 2004), OR= 2,16 (COLES et al., 2005) e OR=2,71 (CAETANO et al., 2002)]. Além disso, o peso de nascimento de $3500 \mathrm{~g}$ ou mais foi identificado como um fator protetor para esse desfecho $(\mathrm{OR}=0,61)$ (VICTORA et al., 1994). O ganho de peso na gestação é considerado como principal determinante do peso ao nascer. Contudo, sua influência na chance de hospitalização por pneumonia pode ocorrer também de forma independente, representando um acréscimo de 38\% (OR=1,38) no risco (CÉSAR et al., 1997).

Intervalo interpartal, ordem nascimento e tipo de parto são descritos enquanto fatores possivelmente associados à ocorrência e gravidade da pneumonia (RUDAN et al., 2008; WONODI et al., 2012). Contudo, nos estudos consultados, a associação identificada às análises univariadas não persistiu após ajustamentos nas análises multivariadas (VICTORA et al., 1994; FONSECA et al., 1996; CESAR et al., 1997; CESAR et al., 1999; NASCIMENTO et al., 2004; GEIB et al., 2007).

$O$ escore- $z$ de peso para idade $\leq 0$ está relacionado a um aumento de $98 \%$ na chance de internação por pneumonia (OR=1,98) (NASCIMENTO et al., 2004). Referese, ainda, uma modificação do risco/chance, de acordo com as categorias de escore$\mathrm{z}$ abaixo de zero: de $-0,01$ a -1 [RR=1,96 (VICTORA et al., 1990)], de -1 a $-1,9$ [OR=1,60 (VICTORA et al., 1994) e $R R=2,31$ (VICTORA et al., 1990)] e $\leq-2$ [OR=4,77(VICTORA et al., 1994) e RR=1,75 (VICTORA et al., 1990)]. Da mesma forma, observa-se uma modificação no risco, de acordo com as categorias de escore$z$ de altura para idade: de $-0,01$ a -1 [RR=1,44 (VICTORA et al., 1994)], de -1 a $-1,9$ [RR=2,49(VICTORA et al., 1994)] e $\leq-2$ [RR=1,76 (VICTORA et al., 1990) e OR=2,22 (COLES et al., 2005)]. A falta de aleitamento materno é responsável por uma chance quase cinco vezes maior de internação e morte por pneumonia [OR=4,97 (HORTAL et al., 1994) e OR=4,32 (REYES et al., 1997)]. O desmame precoce surge como importante fator de risco, com um incremento de $64 \%$ na chance de hospitalização entre as crianças não amamentadas exclusivamente até 4 meses $(O R=1,64)$. Quanto mais cedo o desmame, maior é a chance de hospitalização ( $O R=2,30$ para crianças desmamadas até 3 meses) (MACEDO et al., 2007). A maior estimativa de risco é obtida entre as crianças que não recebem qualquer tipo de leite $(\mathrm{OR}=16,7)$ (CESAR et al., 1999), seguidas pelas crianças em aleitamento misto (OR=3,80) (VICTORA et al., 1994) e artificial $(\mathrm{OR}=2,61)$ (VICTORA et al., 1994). A falta de alimentação 
complementar é apontada como fator de risco para a hospitalização por pneumonia $(\mathrm{OR}=2,83)$ (VICTORA et al., 1994), enquanto a introdução de alimentos complementares antes do recomendado é responsável por um expressivo aumento na chance de hospitalização (OR=8,50) (CESAR et al., 1999).

$A$ aglomeração é um dos fatores relacionados às doenças respiratórias mais amplamente estudados. A quantidade de cômodos no domicílio apresenta associação com o desfecho (até 2 cômodos: $\mathrm{RP}=2,03$ ), bem como a densidade domiciliar, que sendo elevada é responsável por uma chance $14 \%$ maior de internação $(O R=1,14)$ (CAETANO et. al., 2002; PINTO; MAGGI; ALVES, 2004). Estima-se um aumento de 54 a $84 \%$ no risco com um maior número de moradores no domicílio (4 a 5 pessoas: $\mathrm{OR}=1,54$; 6 ou mais pessoas: $\mathrm{OR}=1,84$ ) (VICTORA et al., 1994) e uma diminuição de $55 \%$ no risco, com um número menor de moradores (menos de 4 pessoas: $\mathrm{OR}=0,45$ ) (NASCIMENTO et al., 2004). Além disso, é identificada uma maior média de pessoas na casa entre as crianças hospitalizadas $(5,1 \pm 1,9$ vs $4,2 \pm 1,2)$, que também dividem o quarto com mais pessoas (2,4 $\pm 0,8$ vs $1,8 \pm 0,9)$ (SHOHAM et al., 2005). O número de pessoas dormindo com a criança também é apontado como fator de risco (OR=1,7), por outro estudo (MACEDO et al., 2007).

Estima-se um incremento de quase 12 vezes no risco de hospitalização por pneumonia com a frequência à creche $(O R=11,75)$ (VICTORA et al., 1994). A presença de fumaça intradomiciliar é outro fator ambiental estreitamente relacionado à ocorrência e gravidade da doença respiratória. Essa associação foi descrita em relação ao tabagismo - capaz de acrescer em $70 \%$ a chance de hospitalização $(\mathrm{OR}=1,70)$ (MACEDO et al., 2007) - e ao uso de combustíveis de biomassa responsável por uma chance duas a quase três vezes maior de agravamento do caso [OR=2,92 (JOHNSON et al., 2008); OR=2,51 (BROOR et al., 2001); OR=1,79 (DHERANI et al., 2008)]. Morar em área sem saneamento básico contribui para uma chance 2 vezes maior de complicações e morte, em decorrência da pneumonia e outras IRA (OR=2,10) (REYES et al., 1997).

Crianças cujas mães são solteiras possuem o dobro de chance de desenvolver pneumonia severa $(\mathrm{OR}=2,34)$ (HORTAL et al., 1994) e cujas mães trabalham fora possuem o triplo de chance (OR=3,30) (REYES et al., 1997). Ter um cuidador que não seja a mãe pode representar um incremento de quase cinco vezes na chance de hospitalização $(\mathrm{OR}=4,56)$ (CAETANO et al, 2002). O hábito de usar bico pode aumentar em $90 \%$ a chance de ser hospitalizada por DRA (OR=1,90) (MACEDO et 
al., 2007). Crianças com situação vacinal incompleta apresentam uma chance 3 vezes maior de desenvolverem um quadro de pneumonia severa, com o desfecho de hospitalização [OR=2,73 (HORTAL et al., 1994); OR=2,85 (BROOR et al., 2001)] ou morte [OR=3,54 (REYES et al., 1997)]. Morte de irmãos menores de cinco anos duplicam as chances da criança ser hospitalizada ( $O R=2,27)$ (CAETANO et al., 2002).

A presença de comorbidades representa um acréscimo variável no risco de hospitalização por pneumonia, de acordo com a patologia. Dentre elas, destacam-se as doenças crônicas - como cardiopatia, neuropatia, asma, refluxo gastroesofágico, infecção congênita e hipotireoidismo [OR=1,4 (NASCIMENTO-CARVALHO et al., 2002) e $\mathrm{OR}=3,32$ (CAETANO et al., 2002)] - a infecção pelo HIV (OR=17,21) (SIGAÚQUE et al., 2009), os distúrbios respiratórios durante o sono (OR=3,7) (GOLDBART et al., 2012) e as malformações (com riscos variáveis de acordo com a faixa etária: 0 a 6 meses - $R R=3,35 ; 7$ a 24 meses - $R R=1,93$; 25 a 60 meses: $R R=2,16$ ) (MAHON et al., 2007).

Antecedentes de pneumonia e sibilância, principalmente com necessidade de hospitalização, podem aumentar em até 7 vezes a chance de internação [pneumonia tratada em casa $O R=2,46$ ou hospitalizada $O R=2,50$; sibilância tratada em casa $\mathrm{OR}=1,75$ ou hospitalizada OR=2,99 (VICTORA et al., 1994); sibilância prévia, independente do tratamento: $\mathrm{OR}=7,7$ (MACEDO et al., 2007)]. Episódios de diarréia nos últimos 30 dias espoliam o organismo e também estão associados ao desfecho $(O R=2,30)$ (COLES et al., 2005); a suplementação de zinco a crianças com diarréia previne sua posterior hospitalização por pneumonia $(\mathrm{OR}=0,29)$ (BHANDARI et al., 2008).

A qualidade do atendimento na APS é um fator importante para a prevenção de hospitalizações desnecessárias e morte por pneumonia e outras doenças respiratórias. Comparando-se a evolução do quadro da doença respiratória com a qualidade do acolhimento proporcionado e com o tempo de espera para consulta, encontrou-se um maior percentual de melhora $(78,9 \%, p=0,004)$ entre aquelas crianças cujas mães relataram uma boa qualidade no atendimento (TANAKA; SANTO, 2008). Inadequações no processo de trabalho do médico da APS podem contribuir com um aumento de quase 10 vezes na chance de desfecho fatal, em decorrência de IRA $(O R=9,68)$. A falta de acesso ao sistema de saúde público aumenta a estimativa desse risco em mais de 5 vezes (OR=5,27) (REYES et al., 1997). $O$ efeito do manejo de casos de pneumonia na redução de desfecho grave foi estimado em $42 \%$ entre 
neonatos (OR geral=0,58) e 36\% entre lactentes e crianças de 1 a 4 anos (OR geral=0,64). É recomendado que o adequado manejo de casos de pneumonia seja realizado na APS (SAZAWAL; BLACK, 2003). Ele inclui a prescrição de antibióticos ao ser diagnosticada a pneumonia, intervenção associada à redução na taxa de hospitalizações por essa doença (HR=0,73) (WINCHESTER et al., 2009). Ao contrário, uma prescrição tardia de antibióticos recomendados está associada a uma maior chance de hospitalização (HR=1,92) (WINCHESTER et al., 2009). Não obstante, outra situação comum é a de prescrição desnecessária de antibióticos a crianças com IRA, resultando em um manejo inadequado de casos e possibilidade de complicações. Tal situação pode ser prevenida pela adequada capacitação de pessoal de saúde, capaz de reduzir em 15\% $(p=0,022)$ a prescrição desnecessária de antibióticos (PAGAIYA; GARNER, 2005).

\subsection{Papel da APS no controle da pneumonia}

A pneumonia integra um conjunto de problemas de saúde para os quais a efetiva APS diminuiria o risco de complicações - as condições sensíveis à atenção primária (CSAP). Esse termo é a tradução livre do indicador norte-americano ambulatory care sensitive conditions, desenvolvido na década de 1990 como medida da efetividade da APS, que possibilita identificar problemas de acesso e desempenho do sistema de saúde (ALFRADIQUE et al., 2009).

O papel da APS em prevenir complicações por essas condições está centrado em três atividades principais: prevenção primária; diagnóstico e tratamento precoces de condições agudas; acompanhamento, controle e manejo de condições crônicas (ALFRADIQUE et al., 2009; CAMINAL et al., 2004). Considerando essas ações, a APS oportuna e de boa qualidade poderia evitar grande parte das complicações pelas CSAP (dentre elas a pneumonia) reduzindo sua frequência a um nível basal (CAMINAL; CASANOVA, 2003), ao prestar um cuidado resolutivo, abrangente e se responsabilizar pela coordenação do cuidado (ALFRADIQUE et al., 2009; CAMINAL et al., 2004; CAMINAL; CASANOVA, 2003; MACEDO et al., 2007). Além dessas questões, estratégias promotoras de saúde e preventivas, desenvolvidas por esses serviços, podem reduzir a incidência e a severidade da pneumonia, diminuindo, assim, 
a demanda por assistência curativa-hospitalar. Tais estratégias englobam a imunização, ações e orientações que visem uma adequada nutrição, redução da transmissão de patógenos, redução da poluição ambiental e boas práticas de cuidado à criança (incluindo a adesão à puericultura) (KIRKWOOD, 1995).

O Plano de Ação Global para a Prevenção e Controle da Pneumonia (WHO, 2009), com o objetivo de reduzir a severidade dos casos de pneumonia e a mortalidade, em menores de cinco anos, indica intervenções com potencial de diminuir a morbimortalidade pela doença, classificando-as em:

- Intervenções que visam proteger a criança:

- Promoção do aleitamento materno exclusivo até os 6 meses: responsável por 15-23\% de redução na incidência e 13\% na mortalidade geral;

- Adequada nutrição (com macro e micronutrientes): impacto de $6 \%$ na mortalidade geral;

- Redução da incidência de baixo peso ao nascer: sem evidências de impacto disponíveis;

- Redução da poluição intradomiciliar: $75 \%$ de redução na incidência, em contextos específicos;

○ Lavagem das mãos: 3\% de redução na mortalidade geral (combinada à melhoria da qualidade da água e intervenções sanitárias).

- Intervenções para prevenir o adoecimento:

- Vacinação contra pneumonia pneumocócica, Hib, sarampo, coqueluche: 22-34\% de redução na incidência de pneumonia por Hib, 23-35\% de redução na incidência de pneumonia pneumocócica, 4\% de redução na mortalidade geral com a vacinação contra Hib e 1\% com a vacinação contra o sarampo;

- Prevenção da infecção pelo HIV em crianças: $2 \%$ de redução na mortalidade geral;

- Profilaxia das crianças infectadas com HIV com cotrimoxazol: sem evidências de impacto disponíveis;

- Suplementação de zinco em crianças com diarreia: 14-15\% de redução na incidência e 4-5\% de redução na mortalidade geral;

- Intervenções para tratar a criança doente: 
- Promoção da busca por cuidados nos serviços de saúde e geração de demandas nas comunidades: sem evidências de impacto disponíveis;

- Manejo de casos nos serviços de saúde para os casos graves e grupos vulneráveis, como recém-nascidos, crianças desnutridas e infectadas com HIV: $29-45 \%$ de redução na ocorrência de casos fatais, $6 \%$ de redução na mortalidade geral;

- Incremento do acesso ao cuidado apropriado, por meio do manejo de casos na comunidade: $34-50 \%$ de redução na fatalidade dos casos em neonatos; redução na mortalidade geral de $27 \%$ entre neonatos, $20 \%$ entre infantes e $24 \%$ entre crianças; redução de mortalidade específica por pneumonia nos mesmos grupos de $42 \%, 36 \%$ e $36 \%$, respectivamente.

Observamos que várias dessas intervenções são de competência dos profissionais da APS e devem ser realizadas em um contexto de vínculo com a comunidade e de longitudinalidade do cuidado, por meio de ações em nível individual e coletivo.

Para clarear o papel da APS no controle da pneumonia é pertinente uma apropriação do conceito da APS e sua caracterização.

\subsubsection{APS: conceito, características e avaliação}

A APS foi primeiramente definida em Alma-Ata, em 1978, na ocasião da I Conferência Internacional de Saúde sobre Cuidados Primários. Ficou definido que:

[...] os cuidados primários de saúde são cuidados essenciais de saúde baseados em métodos e tecnologias práticas, cientificamente bem fundamentadas e socialmente aceitáveis, colocadas ao alcance universal de indivíduos e famílias da comunidade, mediante sua plena participação e a um custo que a comunidade e o país pode manter em cada fase de seu desenvolvimento, no espírito de auto-confiança e auto-determinação. Fazem parte integrante tanto do sistema de saúde do país, do qual constituem a função central e o foco principal, quanto do desenvolvimento social e econômico global da comunidade. Representam o primeiro nível de contato dos indivíduos, da família e da comunidade com o sistema nacional de saúde 
pelo qual os cuidados de saúde são levados o mais próximo possível aos lugares onde pessoas vivem e trabalham, e constituem o primeiro elemento de um continuado processo de assistência à saúde. (OMS, 1979, p.03)

Após Alma-Ata, nos anos que se seguiram, vários países realizaram mudanças em seus sistemas de saúde, a fim de incorporar os preceitos da APS, que eram passíveis de personalização segundo o contexto de cada país. Desse modo, ocorreu uma multiplicidade em seus processos de implementação, refletida na ambiguidade de algumas de suas definições formais (AGUIAR, 2007). Tal fato conduziu a diferentes linhas de interpretação do conceito de APS, sendo as principais descritas por Mendes (2002) como:

- Atenção Primária Seletiva: entende a APS como Programa, composto por tecnologias simples e de baixo custo, bem como de pessoal de baixa qualificação profissional, destinado a populações desfavorecidas;

- Nível Primário do Sistema de Serviços de Saúde: a APS é concebida como modo de organizar a porta de entrada do sistema, restringindo suas ações de atenção ao primeiro nível;

- $\quad$ Estratégia de Organização do Sistema de Serviços de Saúde: compreende a APS como organizadora do sistema, articulada dentro de uma rede integrada, reordenando recursos para satisfazer as necessidades da população. Essa é a interpretação mais coerente com os princípios filosóficos de Alma-Ata.

Atualmente, em especial após a publicação do documento de posicionamento da Organização Pan-Americana da Saúde (OPAS) e da OMS em relação à renovação da APS nas Américas (OPAS, 2007), a definição de Alma-Ata sofreu ampliação e incorporou a interpretação da APS enquanto estratégia de organização do sistema de saúde. O novo conceito de APS, portanto, enfoca o sistema de saúde como um todo - setores público, privado e sem fins lucrativos. Aplica-se a todos os países e descarta a noção de APS como um conjunto de serviços ligados a tipos específicos de pessoal de saúde.

Segundo tal concepção ampliada, a APS seria definida como um conjunto de valores, princípios e elementos estruturantes (ou atributos) do sistema de saúde. No Brasil, o Ministério da Saúde (MS) tem utilizado a definição da APS proposta por Starfield (2002, p. 61), segundo a qual os atributos essenciais da APS são: 
- $\quad$ Acesso de primeiro contato: "[...] implica acessibilidade e uso do serviço a cada novo problema ou novo episódio de um problema pelo qual as pessoas buscam atenção à saúde". "A medição da atenção ao primeiro contato envolve a avaliação da acessibilidade (elemento estrutural) e da utilização (elemento processual)".

- Longitudinalidade: "[...] pressupõe a existência de uma fonte regular de atenção e seu uso ao longo do tempo".

- Integralidade: "[...] leque de serviços disponíveis e prestados pelos serviços de APS". Implica arranjos das unidades "[...] para que o paciente receba todos os tipos de serviços de atenção à saúde, mesmo que alguns possam não ser oferecidos eficientemente dentro delas".

- Coordenação da atenção: "[...] requer alguma forma de continuidade, seja por parte dos profissionais, seja por meio de prontuários médicos, ou ambos, além de reconhecimento de problemas abordados em outros serviços".

Também são postulados os atributos derivados, que são outras três características da APS: Atenção à saúde centrada na família, Orientação comunitária e Competência cultural (STARFIELD, 2002).

Tal estrutura teórica, proposta pela autora, foi idealizada sob uma perspectiva que possibilita o estabelecimento de padrões para a avaliação de sistemas de saúde embasados na APS. $\mathrm{Na}$ avaliação dos sistemas de atenção primária, deve-se considerar a presença dos aspectos que caracterizam a APS - seus atributos. Há de se levar em consideração a capacidade do recurso (estrutura), a prestação de serviços (processo) e o estado de saúde da população (resultados). Dentre as fontes de dados a serem utilizadas, a autora destaca a entrevista com usuários, profissionais de saúde e gestores dos serviços de saúde, com participação dos atores envolvidos, em um esforço coletivo. No entanto, devido à sua amplitude, a avaliação da APS costuma se restringir a uma das diferentes perspectivas (STARFIELD, 2002).

No cenário mundial, a avaliação da APS tem sido realizada por meio de indicadores - de mortalidade, de morbidade, de hospitalizações por condições sensíveis à atenção ambulatorial / primária, de estrutura dos serviços de saúde, de cobertura de programas e ações de saúde - e por meio de estudos que buscam a percepção de usuários, profissionais e gestores das diferentes instâncias de poder (BRASIL, 2003, 2005). 
Conforme exposto, o arcabouço teórico da APS foi construído de modo a possibilitar o estabelecimento de padrões para a avaliação de sistemas de saúde nela embasados (STARFIELD, 2002). A partir dessa concepção, portanto, vários instrumentos foram desenvolvidos com o propósito de mensurar a qualidade da APS, com a experiência dos atores envolvidos.

Um estudo conduzido nos Estados Unidos da América (EUA) utilizou-se de um desses instrumentos, o Consumer Assesment of Healthcare Providers and Systems (CAHPS), que aborda certos aspectos da efetividade do cuidado primário à saúde atenção centrada na família, acessibilidade e alguns aspectos da coordenação. Tal pesquisa analisou retrospectivamente dados de uma coorte de crianças menores de 17 anos de idade, a fim de determinar a associação entre a qualidade do cuidado relatada pelos pais e posterior utilização de serviços de pronto-atendimento (PA). A qualidade relatada pelos pais foi obtida por meio da aplicação do CAHPS. Os autores identificaram, após ajustamento para fatores de confusão, uma associação entre os aspectos da APS avaliados e subsequente utilização não emergencial do PA. A atenção altamente qualificada, centrada na família, esteve associada a uma redução de $49 \%$ entre crianças menores de dois anos (IRR=0.51) e de $42 \%$ entre usuárias do sistema público de saúde (IRR=0.58). Maiores escores relativos à obtenção de um cuidado oportuno estiveram associados a uma queda na utilização não emergencial do PA de $44 \%$ a $56 \%$, entre crianças maiores (faixa etária de 3 a 11 anos: IRR $=0.56$; 12 anos ou mais: IRR=0.44), de $35 \%$ entre aquelas com seguro de saúde privado (IRR=0.65) e de $37 \%$ entre usuárias do sistema público (IRR=0.63) (BROUSSEAU et al., 2007).

Um estudo de coorte, também desenvolvido nos EUA, utilizou-se de um instrumento para associar o tipo de acesso à experiência prévia de crianças com a APS, de acordo com o relato dos pais (SEID; STEVENS, 2005). O instrumento utilizado foi o Parents' Perceptions of Primary Care (P3C), por meio do qual se identificou que os escores no P3C estão associados ao acesso financeiro (6,2 pontos a menos no escore de crianças sem seguro saúde, $p<0,001$ ), ao acesso potencial (10 pontos a mais no escore de crianças com uma fonte regular de cuidados, $p<0,001) \mathrm{e}$ ao acesso percebido $(10,7$ pontos a menos no escore de crianças cujos pais relatam oportunidades de cuidado perdidas, $p<0,001)$.

Malouin, Starfield e Sepulveda (2009) identificaram, a partir de revisão da literatura, nove instrumentos que se propunham a essa tarefa e os analisaram, para 
determinar se mensuravam os quatro atributos essenciais da APS, se foram testados para confiabilidade e validade e se apresentavam múltiplos formatos (para usuários, profissionais, etc.). Dentre esses instrumentos estavam o CAHPS e o P3C, utilizados nos estudos citados nos dois parágrafos anteriores. Apenas um instrumento atendeu a todos os requisitos - o Primary Care Assesment Tool (PCATool) - sendo então recomendado para avaliar estrutura e processo da APS.

O PCATool foi desenvolvido com base no modelo de avaliação da qualidade de serviços de saúde (DONABEDIAN, 2005), que propõe a mensuração de aspectos de estrutura, processo e resultados dos serviços de saúde. Nesse sentido, para cada atributo da APS a ser avaliado pelo instrumento existe um componente relativo à estrutura e outro relativo ao processo de atenção, possibilitando a avaliação das características organizacionais e de desempenho dos serviços de APS (MACINKO; ALMEIDA; OLIVEIRA, 2003).

A versão adaptada e validada do PCATool para o Brasil é o instrumento recomendado pelo Ministério da Saúde para mensurar a presença e a extensão dos atributos da APS nos serviços de saúde nacionais, tanto para fins de pesquisas acadêmicas como também para a avaliação e monitoramento da qualidade da APS nos serviços e nos diferentes níveis de gestão (BRASIL, 2010a). A avaliação da APS na perspectiva do usuário, portanto, é um dos elementos importantes na avaliação da qualidade em saúde (DONABEDIAN, 1984). Como um dos resultados desejados no processo de atenção à saúde é ofertar serviços que satisfaçam os usuários, o conhecimento da percepção do usuário sobre os serviços prestados é destacado como uma das formas de se mensurar qualidade da atenção à saúde (DONABEDIAN, 1990).

A partir do acesso e utilização dos serviços de saúde, o usuário poderá avaliar o cuidado prestado, segundo a percepção de suas expectativas e satisfação de suas necessidades. 
Em Ribeirão Preto - SP, local do presente estudo, a pneumonia foi responsável por aproximadamente $8 \%$ das hospitalizações em crianças menores de cinco anos de idade, entre os anos de 2009 e 2012, sendo a principal causa de hospitalização entre as doenças do aparelho respiratório (BRASIL, 2012). Embora tenha havido uma diminuição progressiva no número de hospitalizações por pneumonia desde o planejamento deste estudo, em 2009 ( $n=424)$ e 2012 ( $n=354)$, observou-se também diminuição no total de hospitalizações, em 2009 ( $n=5043)$ e $2012(n=4543)$. A pneumonia, portanto, manteve sua importância como causa de internação na população de interesse.

A pneumonia, conforme exposto, é uma das doenças de maior prevalência na infância, responsável por hospitalizações e mortes, especialmente entre as crianças menores de cinco anos de idade. Tais desfechos poderiam ser, em parte, evitados por meio da modificação de fatores que expõem a criança a um risco aumentado de adoecimento, complicação e morte. O atual conhecimento científico versa sobre os fatores envolvidos na ocorrência e agravamento da pneumonia e as intervenções potencialmente efetivas para preveni-los, muitas das quais devem ser realizadas pelos profissionais da APS. Conforme exposto, diversos estudiosos dedicaram-se a analisar os fatores envolvidos no agravamento da pneumonia. Poucos, no entanto, consideraram as relações hierárquicas existentes entre tais fatores.

Os fatores envolvidos na ocorrência e severidade das doenças infecciosas, nos países em desenvolvimento, estão imbricados em um quadro conceitual hierárquico, no qual os fatores mais distais ao desfecho podem influenciar todos os demais fatores proximais, direta ou indiretamente (VICTORA et al., 1997). Tal quadro conceitual deve ser concebido na fase de delineamento do estudo, a partir do conhecimento dos determinantes biológicos e sociais do desfecho, pois influenciará decisões sobre o desenho da pesquisa e coleta dos dados. Além disso, desconsiderar tais relações hierárquicas no momento da análise pode ocasionar o ajustamento simultâneo de variáveis que estão em níveis distintos, o que enfraqueceria associações importantes em relação às variáveis mais distais (VICTORA et al., 1997).

A presente investigação trata do estudo dos fatores relacionados à hospitalização por pneumonia, a partir do estabelecimento de um modelo conceitual hierárquico, envolvendo as variáveis explanatórias e o desfecho. Além disso, entre tais fatores, considera a qualidade da APS. Embora a qualidade da APS venha sendo indicada como potencialmente eficaz para a redução da morbimortalidade relacionada 
à pneumonia, poucos autores têm considerado sua inclusão como variável explanatória, em relação à hospitalização por essa doença. Entende-se que a APS deve ser considerada como um dos fatores potencialmente relacionados à hospitalização por pneumonia. Questões como nível educacional dos pais, peso ao nascer e estado nutricional da criança, por exemplo, podem influenciar o cuidado à criança no contexto desses serviços, que, por sua vez, representam um nível de assistência onde várias intervenções podem ser desenvolvidas para modificar fatores de risco (como o déficit nutricional) e potencializar fatores protetores (como o aleitamento materno), relacionados ao surgimento ou agravamento da pneumonia em crianças. Também é na APS que deve ser realizado o diagnóstico e o tratamento precoces da pneumonia, com vistas a evitar complicações no quadro.

Além da importância epidemiológica da pneumonia na população de menores de cinco anos de idade, em Ribeirão Preto, a escolha do município para essa investigação justifica-se pelo fato de que é um pólo regional em saúde, habilitado na gestão Plena do Sistema de Saúde, possui tradição histórica no desenvolvimento da APS, com ampliação da rede básica desde 1984, Estratégia Saúde da Família (ESF) e Programa de Agentes Comunitários de Saúde (PACS) funcionando há 15 anos e em processo de expansão (PEREIRA, 2008; RIBEIRÃO PRETO, 2012). Considerase pertinente, portanto, a investigação de fatores associados à hospitalização por pneumonia em crianças desse município, em busca de subsídios às políticas de promoção e prevenção em saúde. 
4. OBJETIVOS 
A presente investigação tem por objetivo geral identificar os fatores associados à hospitalização por pneumonia, em crianças menores de cinco anos de idade, no município de Ribeirão Preto - SP.

Objetivos Específicos:

- Identificar os fatores de risco para a hospitalização por pneumonia, em menores de cinco anos;

- Identificar os fatores de proteção para a hospitalização por pneumonia, em menores de cinco anos;

- Avaliar a magnitude da contribuição destes fatores sobre o desfecho, a partir de um modelo explicativo que contemple as relações hierárquicas existentes entre potenciais preditores e o desfecho em questão. 


\subsection{Delineamento}

Estudo epidemiológico analítico, com delineamento caso-controle de base hospitalar, desenvolvido em três hospitais situados no município de Ribeirão Preto SP. O delineamento caso-controle foi escolhido por ser eficiente em termos de custo/tempo e por possibilitar a investigação de fatores de risco e de proteção para diferentes desfechos (HENNEKENS; BURING, 1987; SCHLESSELMAN, 1982).

\subsection{População e Local de Estudo}

Ribeirão Preto está situado na região nordeste do estado de São Paulo. Sua área geográfica é de $642 \mathrm{Km}^{2}$, na qual se distribuem 619.746 habitantes, predominantemente na zona urbana (RIBEIRÃO PRETO, 2012). O município sedia o Departamento Regional de Saúde XIII (DRS XIII) e está organizado em 05 Distritos de Saúde, nos quais se distribuem: 1 Unidade Básica e Distrital de Saúde (UBDS) com serviços de Atenção Básica e Especialidades; 2 UBDS com serviços de Pronto Atendimento, Atenção Básica e Especialidades; 2 UBDS com serviços de Pronto Atendimento e Especialidades; 1 Unidade de Pronto-Atendimento (UPA) porte III; 1 Posto de Atendimento Médico (PAM II) com de atendimento básico de pediatria e especialidades pediátricas; 4 Centros de Atenção Psicossocial (CAPS) (1 CAPS II, 1 CAPS III, 1 CAPS ad e 1 CAPS infantil); 03 Ambulatórios de Saúde Mental; 01 Núcleo de Gestão Ambulatorial (NGA-59); 1 Centro de Referência em Saúde do Trabalhador (CEREST); 1 NADEF (Núcleo de Atenção à Pessoa Deficiente), 02 Centros de Referência em Moléstias Infecciosas; 27 Unidades Básicas de Saúde (UBS) e 14 Unidades de Saúde da Família (USF) - com 30 equipes cadastradas. Vinte e três unidades de saúde possuem o PACS. A rede hospitalar é composta por 09 instituições conveniadas com o Sistema Único de Saúde (SUS). Conta ainda com o componente pré-hospitalar móvel e um Complexo Regulador Municipal (RIBEIRÃO PRETO, 2012).

Em 2012, a população pertencente à faixa etária de 0 a menos de 5 anos totalizou 35.806 habitantes, representando $6 \%$ da população total do município (RIBEIRÃO PRETO, 2012). A escolha de crianças dessa faixa etária justifica-se pela 
relevância epidemiológica da pneumonia nessa população (SOCIEDADE BRASILEIRA DE PNEUMOLOGIA E TISIOLOGIA, 2007).

\subsection{Definição de casos e controles}

Foram considerados casos crianças menores de cinco anos de idade, residentes em municípios pertencentes à DRS XIII, admitidas para internação em três hospitais do município de Ribeirão Preto - SP conveniados com o SUS, no período de estudo, com diagnóstico de pneumonia comunitária estabelecido pelo médico assistente, sendo a pneumonia definida por história clínica de febre, acompanhada de sinais e sintomas respiratórios e comprovada por exame radiológico (OSTAPCHUK, 2004; SOCIEDADE BRASILEIRA DE PNEUMOLOGIA E TISIOLOGIA, 2007). A coleta de dados ocorreu entre março de 2012 e agosto de 2013.

A escolha dos hospitais foi direcionada por um levantamento préviob ${ }^{\mathrm{b}}$, referente ao ano de 2008, por meio do qual se identificou que esses hospitais atenderam cerca de $75 \%$, das 375 internações por pneumonia, em crianças menores de cinco anos.

No presente estudo, foram adotados os seguintes critérios de exclusão para casos e controles: tempo de residência no município menor que 06 meses; história recente de aspiração de líquido ou corpo estranho; e crianças menores de 02 meses de idade. Este último critério visou garantir que não fossem incluídas no estudo crianças com condições que determinariam sua hospitalização obrigatória, como recomendado para menores de 02 meses de idade, com diagnóstico de pneumonia e independentemente da presença de outros fatores (SOCIEDADE BRASILEIRA DE PNEUMOLOGIA E TISIOLOGIA, 2007). Além disso, a exclusão de crianças com pneumonia aspirativa justifica-se pelo fato de que sua diferente etiologia dificultaria a seleção de casos homogêneos.

Cada caso selecionado para o estudo foi emparelhado, por sexo e faixa etária, com um controle hospitalar. As faixas etárias para o emparelhamento foram: $\geq 2$ e $\leq 6$ meses, $>6$ e $\leq 12$ meses, $>12$ e $\leq 24$ meses, $>24$ e $<60$ meses. Além dos critérios de

\footnotetext{
b Realizado a partir do sistema de informações de altas hospitalares do Centro de Processamento de Dados Hospitalares (CPDH) do Departamento de Medicina Social da Faculdade de Medicina de Ribeirão Preto Universidade de São Paulo (FMRP-USP), em 2010.
} 
exclusão já citados excluíram-se, dentre os controles, crianças com suspeita ou diagnóstico atual de pneumonia. Devido à possível semelhança com os casos, em relação às exposições, excluiu-se do grupo de controles crianças com algum grau de parentesco com os casos ou que residiam na mesma casa. Não foram incluídos casos curados de pneumonia como controles ou controles como posteriores casos, se viessem a ser hospitalizados por pneumonia. Para facilitar a seleção de casos e controles, foi confeccionado um fluxograma para orientar os entrevistadores nesse processo (APÊNDICE A).

\subsection{Estratégias para recrutamento e seleção de casos e controles}

Foram selecionados, para o presente estudo, 345 casos e 345 controles, de acordo com cálculo de tamanho amostral efetuado no programa STATA versão 12 (STATA CORP, 2010), com vistas à detecção, em testes bicaudais, de OR $\geq 2.0$, poder estatístico de $80 \%$ e $\alpha=0,05$, considerando-se $10 \%$ como a menor probabilidade de exposição entre os controles.

Para a coleta dos dados, foi formada uma equipe para o trabalho de campo, composta por coordenador/supervisor e entrevistadores, com formação superior e técnica na área de saúde e afins, além de entrevistadores com ensino médio. Os membros da equipe não foram informados sobre os objetivos da pesquisa. A equipe foi submetida a treinamento para a coleta de dados, que englobou: a) procedimentos para recrutamento e seleção de casos e controles; b) treinamento para aplicação de entrevista estruturada e c) treinamento e calibração para a tomada de medidas antropométricas da criança, aplicando-se os indicadores de precisão e exatidão de Habicht (HABICHT, 1974). Após o pré-teste do instrumento de coleta de dados (entrevista estruturada), foi conduzido um estudo piloto com 70 crianças $(10 \%$ da amostra) nos hospitais selecionados para o estudo, com o propósito de identificação de problemas logísticos relacionados à circulação dos entrevistadores nos centros de coleta de dados, ajustes finais do instrumento de coleta de dados, bem como definição da duração da entrevista. O controle de qualidade das entrevistas, no decorrer do trabalho de campo, foi efetuado mediante a replicação de $10 \%$ destas, procedendose a ajustes sempre que necessário. 
As entrevistas de casos e controles foram realizadas nos hospitais selecionados, de segunda-feira a sábado, em horário comercial. Para cada caso selecionado, a equipe buscava um controle de mesmo sexo e faixa etária, no mesmo hospital, recrutado na Enfermaria Pediátrica, no Ambulatório de Pediatria, ou no Pronto Atendimento Pediátrico. A data do diagnóstico do caso foi a data de referência para a coleta de informações pregressas em casos e controles, servindo também essa data como referência para a entrevista do controle.

O recrutamento e a seleção de casos e controles ocorreram de acordo com 0 seguinte fluxograma: a) o entrevistador consultava o registro de internação diário em busca de casos elegíveis; b) ao identificar um caso potencialmente elegível, abordava o responsável pela criança, convidando-os a participar do estudo; c) após os devidos esclarecimentos sobre o estudo e sobre a dinâmica da coleta de dados, e, desde que o responsável assinasse o Termo de Consentimento, o entrevistador aplicava a entrevista ao responsável e tomava as medidas antropométricas da criança, em sala apropriada; d) no mesmo dia, ou durante a internação do caso, o entrevistador iniciava a busca por um controle para ser com ele emparelhado - por sexo e faixa etária recrutado no próprio hospital, primeiramente no setor de Internação Pediátrica, seguindo-se o Ambulatório de Pediatria e, por último, o Pronto-Atendimento Pediátrico. Para garantir que os controles selecionados não estivessem sob suspeita de pneumonia, o recrutamento ocorria somente após o atendimento, quando o médico responsável confirmava ao entrevistador que a criança não estava sob suspeita ou tinha o diagnóstico de pneumonia.

O cuidado em realizar visitas diárias ao hospital e recrutar casos a partir do registro de internação visou garantir a seleção de casos incidentes. A coleta de dados no hospital, durante a internação, ao invés de no domicílio, após a alta, justifica-se em virtude de que tal procedimento pode minimizar o viés de memória em casos e controles, além de contribuir para comparabilidade destes dois grupos, visto que assim a coleta de dados do controle foi contemporânea à do caso (SCHLESSELMAN, 1982).

O recrutamento foi realizado a partir da ordem de internação ou chegada dos casos e controles potenciais, sendo que, em caso de recusa ou exclusão, identificavase outra criança elegível, obedecendo-se à ordem de internação ou chegada. Para checar a confiabilidade do diagnóstico dos casos e minimizar erros de classificação do desfecho, uma amostra de $20 \%$ das radiografias de tórax dos casos, no decorrer 
da coleta, foi submetida à análise por dois radiologistas independentes. Os "desacordos" no diagnóstico foram submetidos ao julgamento de um $3^{0}$ radiologista, que utilizou os critérios da OMS na interpretação de radiografias de tórax para o diagnóstico de pneumonia em crianças (WHO, 2001).

\subsection{Variáveis do estudo}

\subsubsection{Variável dependente (Resposta ou Desfecho)}

A variável dependente ou variável resposta é a hospitalização por pneumonia, classificada como dicotômica ou binária (0-1).

\subsubsection{Variáveis independentes}

Foram incluídas crianças menores de cinco anos, de ambos os sexos. Sexo e idade compõem apenas a fase descritiva, tendo em vista que o emparelhamento de casos e controles por essas variáveis, na fase de desenho, impede sua inclusão no estudo de associação. Casos e controles foram emparelhados segundo intervalos de idade: $\geq 2$ e $\leq 6$ meses, $>6$ e $\leq 12$ meses, $>12$ e $\leq 24$ meses, $>24$ e $<60$ meses.

A partir do conhecimento advindo da literatura sobre as relações entre potenciais fatores de risco e proteção, em relação à hospitalização por pneumonia em menores de cinco anos de idade, foi composto um modelo hierárquico conceitual (Figura 1), com base na proposta de Victora e colaboradores (VICTORA et al., 1997). 


\section{NÍVEL 1}

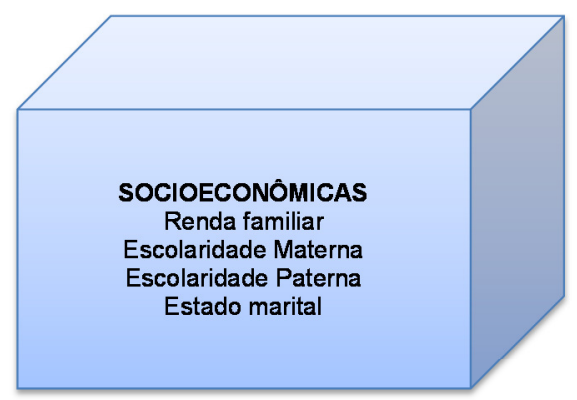

\section{NÍVEL 2}
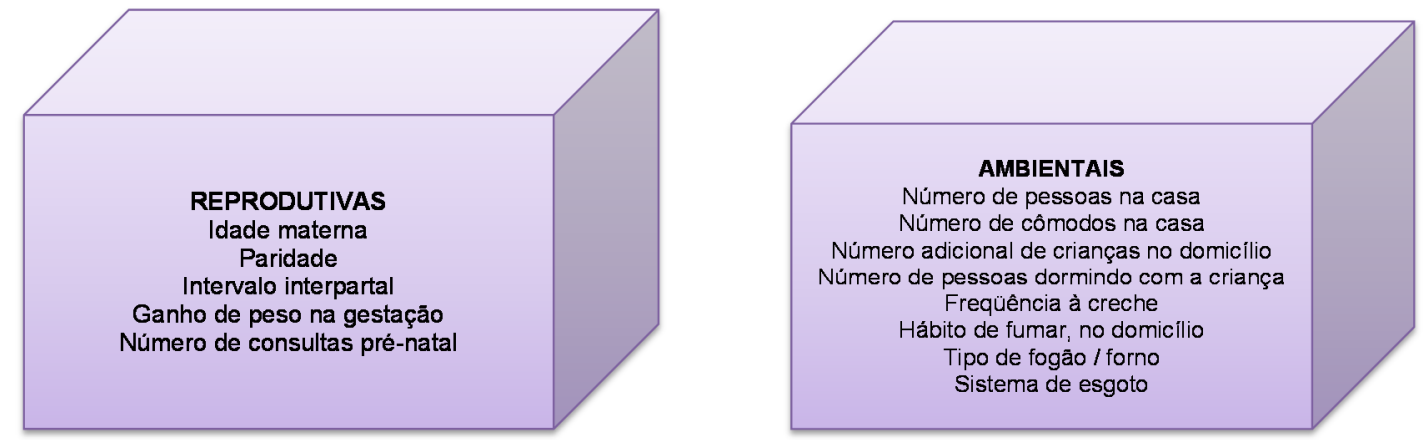

\section{NIIVIE 3}

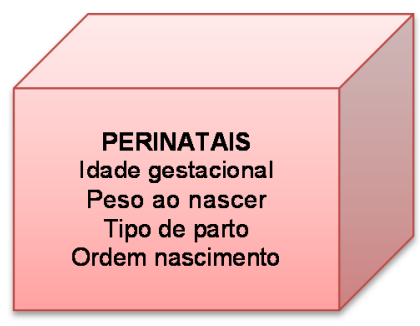

\section{Nines}
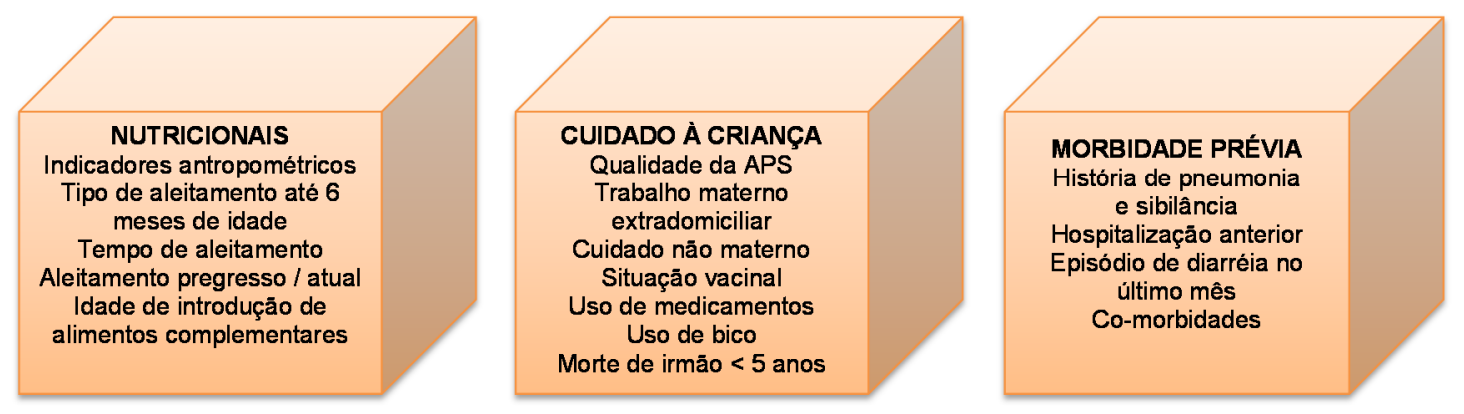

\section{HOSPITALIZAÇÃO POR PNEUMONIA}

Figura 1- Modelo hierárquico conceitual de potenciais fatores associados à hospitalização por pneumonia, em crianças menores de cinco anos de idade. 
As variáveis socioeconômicas estão no $1^{ํ}$ nível hierárquico. As variáveis reprodutivas e ambientais no $2^{\circ}$ nível. As variáveis perinatais compõem o 3ํํível, enquanto as variáveis nutricionais, as relativas ao cuidado à criança e à morbidade prévia compõem o 4ํㅡível hierárquico. O intervalo interpartal, o tipo de parto, a ordem de nascimento e o número adicional de crianças no domicílio não estiveram associados ao desfecho nas análises multivariadas de alguns estudos consultados. Entretanto, como vários autores encontraram associação estatisticamente significativa (análises univariadas) dessas variáveis com o desfecho de interesse (CESAR et al., 1997, 1999; FONSECA et al., 1996; GEIB et al., 2007; NASCIMENTO et al., 2004; VICTORA et al., 1994;), decidiu-se por incluí-las no quadro conceitual.

Quanto às variáveis socioeconômicas, renda familiar mensal foi obtida pela somatória das rendas mensais dos moradores da casa. A escolaridade materna e paterna é equivalente ao número de anos completos de escolaridade formal, com aprovação, de cada um dos pais. O estado marital é considerado de acordo com a presença ou ausência de companheiro(a), na mesma moradia. Renda e escolaridade foram categorizadas, sendo que para a categorização da renda utilizaram-se os pontos de corte equivalentes aos tercis de suas distribuições; a variável estado marital foi tratada como dicotômica (0-1).

Em relação às variáveis reprodutivas, a idade materna foi contabilizada em anos completos. A paridade considerada como o número de partos, ao longo do período reprodutivo da mãe. O intervalo interpartal foi equivalente ao número de meses transcorridos entre o nascimento da criança participante do estudo e o do filho anterior. O ganho de peso na gestação foi obtido pela diferença entre o peso da mãe no momento do parto e antes de engravidar da criança. Para a obtenção de tais dados, foi considerada a informação referida pelo entrevistado. Em relação à variável número de consultas de pré-natal, a informação foi coletada preferencialmente no cartão de gestante, quando disponível e, caso não estivesse, foi considerada a informação referida. As variáveis deste conjunto foram inicialmente tratadas como contínuas e discretas e, posteriormente, categorizadas.

Em relação às variáveis ambientais, o número de pessoas na casa, o número de cômodos, o número adicional de crianças residentes no domicílio e o número de pessoas que dormem com a criança são variáveis discretas que foram categorizadas para a análise dos dados. A frequência à creche foi tratada como binária $(0-1)$. 0 hábito de fumar no domicílio foi considerado como a presença ou ausência de 
fumantes - variável binária (0-1) - considerando-se, também, entre os fumantes do domicílio, o número de cigarros consumidos/dia. Tabagismo materno foi tratada como variável categórica e tabagismo durante a gestação como dicotômica (0-1). A variável tipo de fogão/forno utilizado pela família foi classificada conforme o tipo de combustível. Sistema de esgoto foi definido como a presença/ausência de esgoto ligado à rede pública, no domicílio.

Para as variáveis perinatais, foram consideradas as informações constantes na caderneta de saúde da criança ou, na ausência dessa, as informações fornecidas pelo responsável pela criança. A idade gestacional, variável contínua, foi posteriormente classificada segundo o número de semanas de gestação, em duas categorias. O peso ao nascer (em gramas), coletado como uma variável contínua, também foi posteriormente categorizado. As variável tipo de parto foi tratada como categórica e ordem de nascimento como ordinal.

Em relação às variáveis nutricionais, o estado nutricional foi determinado pelos valores do escore-z, correspondentes ao peso para idade, à altura para idade, ao peso para altura e ao Índice de Massa Corporal (IMC) para idade. O cálculo do escore-z foi obtido a partir das medidas antropométricas, coletadas na ocasião da entrevista. Esses escores foram classificados, seguindo-se as recomendações da OMS para crianças menores de cinco anos de idade (WHO, 2006) em $\geq-2.0$ e <-2.0. Tais normas são atualmente recomendadas em substituição ao referencial do Center for Disease Control and Prevention / National Center for Health Statistics (CDC/NCHS), de 2000 (KUCZMARSKI et al., 2000). Para o cálculo dos indicadores antropométricos foi utilizado o software WHO Anthro, versão 3.2.2 (WHO, 2011). Quanto ao tipo de aleitamento até os seis meses de idade, as crianças foram classificadas em 04 categorias: "aleitamento materno exclusivo" (categoria de referência), "aleitamento materno predominante", "aleitamento misto", e "aleitamento artificial". O aleitamento pregresso / atual também foi categorizado em "nunca mamou", "mamou" e "mama". Para a categorização da variável contínua tempo de aleitamento, utilizaram-se os pontos de corte equivalentes aos tercis de sua distribuição. A idade de introdução de alimentos complementares (em meses) foi também posteriormente classificada em 04 categorias: "não introduzida", "antes de 6 meses", "aos 6 meses", e "depois dos 6 meses".

As variáveis relacionadas ao cuidado da criança foram coletadas conforme explicitado a seguir: 
A situação vacinal foi avaliada por meio da carteira de vacinação da criança ou, na ausência dessa, pela informação do responsável, considerando-se o total de doses recebidas em relação à idade, sendo tal variável classificada em duas categorias: situação vacinal atualizada e não atualizada. Trabalho materno extra-domiciliar, uso de medicamentos e uso de bico foram classificadas em duas categorias (sim/não), conforme informações constantes da entrevista. A informação referida pelo entrevistado foi também utilizada para compor as variáveis cuidado não materno e morte de irmão menor de cinco anos de idade, ambas categóricas.

A qualidade da APS foi obtida por meio de um instrumento específico incorporado à entrevista, aplicado ao responsável pela criança, denominado Instrumento de Avaliação da APS - PCATool Versão Criança, adaptado e validado para o Brasil por Harzheim e colaboradores (BRASIL, 2010a). Criado por Cassady et al. (2000), este instrumento foi desenvolvido em forma de questionário codificado. A qualidade da APS é aferida sob a perspectiva do usuário, em função da presença e extensão de 04 atributos essenciais e de 03 atributos derivados. Cada atributo do instrumento é composto por 01 ou mais componentes, cada um dos quais com 03 ou mais itens. Pode-se calcular o escore para cada componente (média de valores dos itens), o Escore Essencial da APS (média de valores dos componentes dos atributos essenciais) e o Escore Geral da APS (média dos valores de todos os componentes) (BRASIL, 2010a). No presente estudo, a qualidade da APS foi definida pelo Escore Essencial da APS e pelo Escore Geral da APS, variáveis contínuas que foram posteriormente categorizadas segundo os pontos de corte equivalentes aos quartis de sua distribuição.

A morbidade prévia (morbidade referida) foi informada pelo responsável e definida segundo a presença ou ausência (variável binária) das seguintes condições: imunodeficiência, doença do refluxo gastroesofágico, doenças cardiovasculares, outras doenças pulmonares, apneia do sono / ronco, hospitalização prévia, hospitalização prévia por pneumonia e episódio de diarreia no último mês. Em relação ao histórico de pneumonia e histórico de sibilância, considerou-se o número referido de episódios, desde o nascimento da criança até o episódio atual, quando existente, portanto uma variável discreta que foi posteriormente categorizada. 


\subsection{Instrumentos para coleta de dados}

A coleta de dados ocorreu mediante a aplicação de um questionário précodificado (APÊNDICE B) junto ao responsável pela criança. O questionário contempla todas as variáveis de interesse do estudo, incluindo as questões referentes ao PCATool.

Por ocasião da entrevista, também foram obtidas as medidas antropométricas das crianças. Para aferir o peso de menores de dois anos de idade utilizou-se balança infantil digital, com precisão de $5 \mathrm{~g}$. Para as crianças maiores, foi utilizada balança digital portátil, com precisão de $100 \mathrm{~g}$. Para aferição do comprimento, utilizou-se o estadiômetro horizontal (para crianças menores de dois anos), e para estatura, o estadiômetro vertical (para crianças a partir de dois anos), ambos com graduação milimétrica. As medidas antropométricas foram aferidas conforme as recomendações da OMS (WHO, 2008).

Antes da coleta de dados, o questionário foi submetido a um pré-teste, realizado em uma unidade de saúde (não hospitalar) e aplicado junto a quatro mães ou responsáveis por crianças. Posteriormente ao pré-teste, foi conduzido um estudo piloto nas instituições que fizeram parte da pesquisa, que incluiu 70 participantes (10\% da amostra), sendo 35 casos e 35 controles, conforme mencionado no item 5.4.

\subsection{Processamento dos dados}

Diariamente, após a conclusão das entrevistas, os questionários foram submetidos à revisão e, em caso de detecção de erros de preenchimento, os entrevistadores retornavam aos centros de coleta para as devidas correções. Após a revisão, as entrevistas completas foram digitadas em um banco de dados formatado no software Epidata versão 3.1 (LAURITSEN; BRUUS 2004). A construção do banco de dados contemplou amplitudes específicas para os dígitos, com o propósito de minimizar erros de digitação nos campos de entradas dos dados.

Os dados foram digitados por 02 digitadores treinados, mediante dupla digitação, conduzida de modo independente. Após a dupla digitação e finalizada a 
coleta, os bancos de dados foram submetidos à avaliação de consistência externa. Nesta fase, diante de discordância entre as duas digitações, efetuaram-se correções da digitação, retomando-se, sempre que necessário, o questionário original. Após esta fase, procedeu-se à análise de consistência interna dos dados.

\subsection{Análise estatística}

\subsubsection{Fase Descritiva}

$\mathrm{Na}$ fase descritiva, casos e controles foram caracterizados segundo sua distribuição em relação às variáveis do estudo. As proporções de casos e controles foram comparadas em relação às exposições dos diferentes níveis, utilizando-se como medida de associação global os valores obtidos para o qui-quadrado de verossimilhança, adotando-se nível de significância $\alpha=0,05$.

\subsubsection{Fase Analítica}

$\mathrm{Na}$ fase analítica, foram construídos modelos hierarquizados utilizando-se a regressão logística uni e multivariada. As medidas de associação utilizadas foram os odds ratios (OR), calculados por pontos e por intervalos com 95\% de confiança (IC95\%) (HOSMER; LEMESHOW, 1989). Todas as estimativas foram calculadas no software STATA, versão 12 (STATA CORP, 2010).

\subsubsection{Análises Univariadas}

Inicialmente, efetuaram-se análises univariadas, entre cada uma das variáveis independentes e a variável dependente. A partir da análise univariada, utilizou-se 
como critério de inclusão de variáveis para os modelos subsequentes valores $p<0,25$ para a estatística de Wald (HOSMER; LEMESHOW, 1989).

\subsubsection{Análises Mutivariadas}

As análises multivariadas foram realizadas por meio da abordagem hierarquizada, de modo que a ordem de entrada das variáveis selecionadas a partir da análise univariada foi definida pelo modelo conceitual apresentado no item $\mathbf{5 . 5}$ (Figura 1), iniciando-se pelo primeiro nível hierárquico e procedendo-se à inclusão simultânea de variáveis de mesmo nível. Desse modo, as variáveis de um determinado nível foram ajustadas para aquelas do mesmo nível e para as de níveis precedentes pois, nesses modelos, de acordo com Victora et al. (1997), os efeitos de variáveis de um determinado nível sobre o desfecho podem ser influenciados, direta ou indiretamente, por variáveis situadas no mesmo nível hierárquico e/ou nos níveis superiores.

A análise multivariada ocorreu em duas etapas, discriminadas a seguir:

\section{- Modelos Intermediários:}

Inicialmente, compuseram os modelos intermediários as variáveis que atenderam ao critério de valor $p<0,25$ na análise univariada. As variáveis que apresentaram valores $p<0,10$ para o teste de Wald nos modelos intermediários foram selecionadas para a etapa de modelagem seguinte.

\section{- Modelos Finais:}

As variáveis candidatas aos modelos finais (aquelas que alcançaram valores $p<0,10$ nos modelos intermediários) foram mantidas nesta fase de modelagem. No modelo final propriamente dito, entretanto, foram retidas apenas as variáveis que apresentaram valores $p<0,05$ para o teste de Wald. 
Ressalta-se que variáveis com mais de 02 categorias foram transformadas em variáveis indicadoras (dummy).

\subsection{Considerações Éticas}

O presente estudo foi aprovado pelo Comitê de Ética em Pesquisa da Escola de Enfermagem de Ribeirão Preto - USP (ANEXO A). De acordo com as recomendações da Resolução 196/96 do Conselho Nacional de Saúde, os participantes da pesquisa foram esclarecidos a respeito das características do estudo e de seus objetivos, solicitando-se sua participação e consentimento e garantindo-se o sigilo absoluto das informações por eles prestadas. Foram também informados sobre sua liberdade de recusa para participar do estudo, podendo se retirar, caso assim o desejassem, em qualquer momento e sem qualquer tipo de penalidade. Após tomarem ciência do acima exposto, aqueles que aceitaram participar formalizaram sua participação por meio da assinatura do Termo de Consentimento Livre e Esclarecido (TCLE) (APÊNDICE C). Para o pré-teste, foi utilizado um TCLE próprio (APÊNDICE D). Foram solicitadas autorizações das instituições hospitalares selecionadas para a pesquisa, conforme o Termo especificamente desenvolvido para esse fim (APÊNDIDE E). Os resultados da pesquisa serão divulgados em meios científicos. 
6. RESULTADOS 


\subsection{Fase descritiva}

$\mathrm{Na}$ Tabela 1 são apresentadas as características sociodemográficas da população do estudo. Sexo e faixa etária, conforme já exposto, são variáveis de emparelhamento de casos e controles. Observa-se uma maior proporção de controles com renda familiar e escolaridade parental superiores; contudo, essa diferença não foi estatisticamente significativa.

Tabela 1 - Caracterização de casos e controles participantes do estudo, segundo variáveis sociodemográficas. Ribeirão Preto/SP, 2013.

\begin{tabular}{|c|c|c|c|c|c|}
\hline & & & $\mathrm{CO}$ & LES & \\
\hline & $\mathrm{N}$ & $\%$ & $\mathrm{~N}$ & $\%$ & $x^{2^{*}}$ \\
\hline Sexo & & & & & 0,939 \\
\hline Masculino & 179 & 51,88 & 179 & 51,88 & \\
\hline Feminino & 166 & 48,12 & 166 & 48,12 & \\
\hline Faixa etária (meses) & & & & & 0,990 \\
\hline $02-05,9$ & 77 & 22,32 & 76 & 22,03 & \\
\hline $06-11,9$ & 82 & 23,77 & 85 & 24,64 & \\
\hline $12-23,9$ & 98 & 28,41 & 95 & 27,54 & \\
\hline $24-59,9$ & 88 & 25,51 & 89 & 25,80 & \\
\hline Renda familiar em terços $(R \$)$ & & & & & 0,113 \\
\hline $1^{\circ}$ terço $(\leq 400)$ & 133 & 38,55 & 109 & 31,59 & \\
\hline $2^{\circ}$ terço $>400$ e $\leq 700$ & 108 & 31,30 & 111 & 32,17 & \\
\hline $3^{\circ}$ terço $>700$ & 104 & 30,14 & 125 & 36,23 & \\
\hline Escolaridade materna (anos) & & & & & 0,321 \\
\hline $0-4$ & 31 & 8,99 & 30 & 8,70 & \\
\hline $5-8$ & 133 & 38,55 & 115 & 33,33 & \\
\hline$\geq 9$ & 181 & 52,46 & 200 & 57,97 & \\
\hline Escolaridade paterna (anos) & & & & & 0,705 \\
\hline $0-4$ & 43 & 14,05 & 42 & 13,82 & \\
\hline $5-8$ & 132 & 43,14 & 122 & 40,13 & \\
\hline$\geq 9$ & 131 & 42,81 & 140 & 46,05 & \\
\hline Estado marital & & & & & 0,731 \\
\hline Com companheiro & 254 & 73,62 & 250 & 72,46 & \\
\hline Sem companheiro & 91 & 26,38 & 95 & 27,54 & \\
\hline
\end{tabular}

* $x^{2}$ de verossimilhança, respeitando-se os respectivos graus de liberdade. 
A Tabela 2 apresenta a distribuição de casos e controles em relação às variáveis reprodutivas maternas. A faixa etária materna predominante para todas as crianças foi $\geq 20$ a $<35$ anos. As mães dos casos apresentaram maior paridade, menor intervalo interpartal e ganho de peso na gestação. Não houve diferenças significativas em relação à adesão ao pré-natal, que foi adequada para mais de $80 \%$ dos casos e controles.

Tabela 2 - Caracterização de casos e controles participantes do estudo, segundo variáveis reprodutivas maternas. Ribeirão Preto/SP, 2013.

\begin{tabular}{|c|c|c|c|c|c|}
\hline & & & $\mathrm{CO}$ & LES & \\
\hline & $\mathrm{N}$ & $\%$ & $\mathrm{~N}$ & $\%$ & $x^{2^{*}}$ \\
\hline Idade materna (anos) & & & & & 0,771 \\
\hline$<20$ & 27 & 7,83 & 30 & 8,72 & \\
\hline $20-34,9$ & 259 & 75,07 & 250 & 72,67 & \\
\hline$\geq 35$ & 59 & 17,10 & 64 & 18,60 & \\
\hline Paridade (n de partos) & & & & & 0,041 \\
\hline 1 & 105 & 30,43 & 135 & 39,24 & \\
\hline 2 & 124 & 35,94 & 101 & 29,36 & \\
\hline$\geq 3$ & 116 & 33,62 & 108 & 31,40 & \\
\hline Intervalo interpartal (meses) & & & & & 0,028 \\
\hline$<24$ & 154 & 44,77 & 156 & 45,88 & \\
\hline $24-47$ & 74 & 21,51 & 48 & 14,12 & \\
\hline$\geq 48$ & 116 & 33,72 & 136 & 40,00 & \\
\hline Ganho de peso na gestação (Kg) & & & & & 0,035 \\
\hline$<10$ & 102 & 36,17 & 85 & 28,05 & \\
\hline$\geq 10$ & 180 & 63,83 & 218 & 71,95 & \\
\hline № de consultas de pré-natal & & & & & 0,132 \\
\hline$<6$ & 46 & 14,11 & 33 & 10,25 & \\
\hline$\geq 6$ & 280 & 85,89 & 289 & 89,75 & \\
\hline
\end{tabular}

* $x^{2}$ de verossimilhança, respeitando-se os respectivos graus de liberdade.

Na Tabela 3 encontra-se a caracterização de casos e controles quanto às variáveis ambientais. Evidenciou-se maior proporção entre os casos em relação ao número de pessoas na casa, número adicional de crianças no domicílio, número de pessoas no quarto com a criança e frequência à creche. 
Tabela 3 - Caracterização de casos e controles participantes do estudo, segundo variáveis ambientais. Ribeirão Preto/SP, 2013.

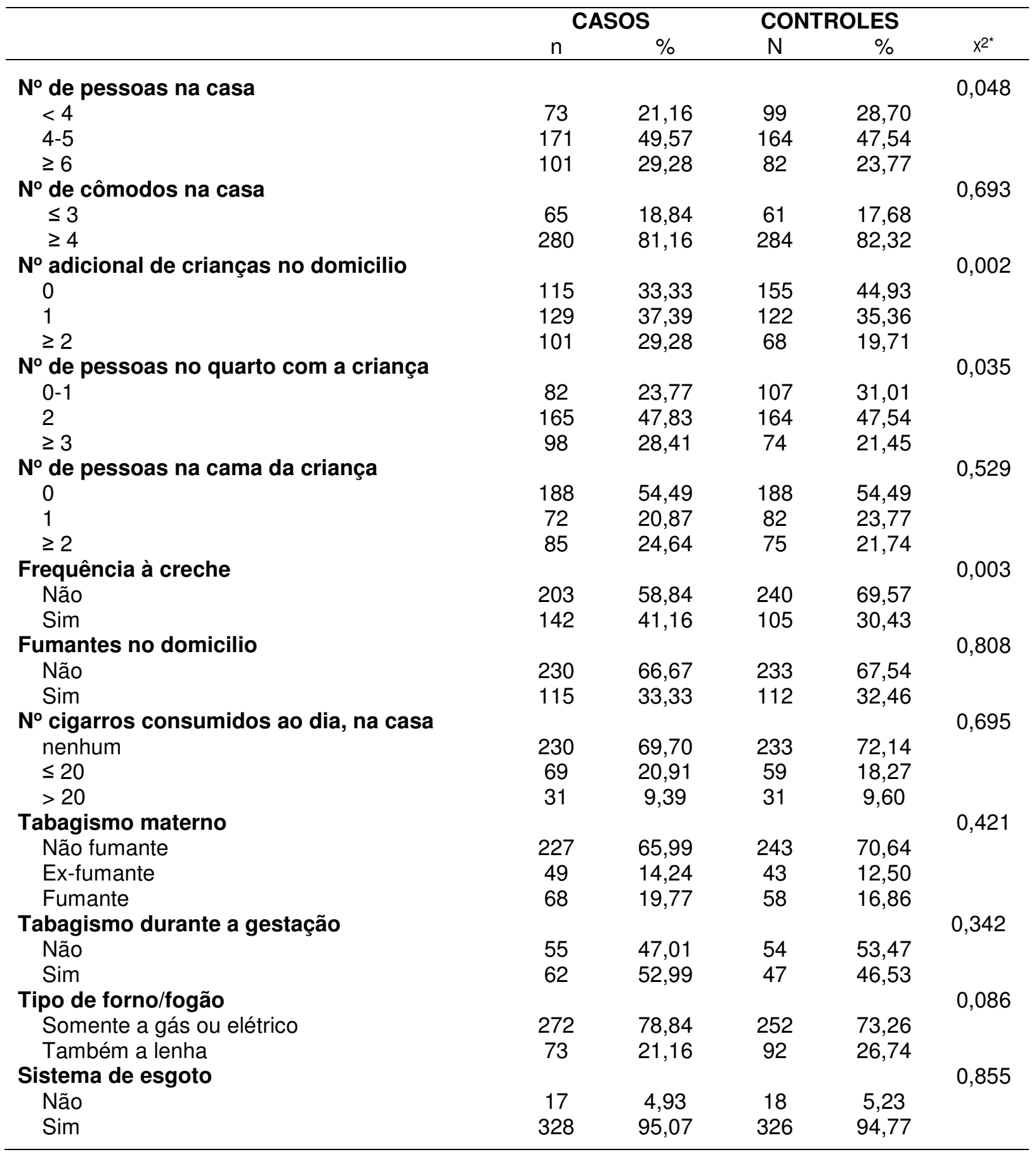

${ }^{*} x^{2}$ de verossimilhança, respeitando-se os respectivos graus de liberdade. 
Conforme se observa na Tabela 4, há uma maior proporção de casos prematuros (Idade gestacional < 37 semanas). Não houve diferenças estatisticamente significativas quanto às demais variáveis perinatais.

Tabela 4 - Caracterização de casos e controles participantes do estudo, segundo variáveis perinatais. Ribeirão Preto/SP, 2013.

\begin{tabular}{|c|c|c|c|c|c|}
\hline & \multicolumn{2}{|c|}{ CASOS } & \multicolumn{2}{|c|}{ CONTROLES } & \multirow[b]{2}{*}{$x^{2^{*}}$} \\
\hline & $\mathrm{N}$ & $\%$ & $\mathrm{~N}$ & $\%$ & \\
\hline Idade gestacional (semanas) & & & & & 0,037 \\
\hline$<37$ & 74 & 21,70 & 53 & 15,50 & \\
\hline$\geq 37$ & 267 & 78,30 & 289 & 84,50 & \\
\hline Peso ao nascer (gramas) & & & & & 0,072 \\
\hline$<2500$ & 72 & 21,18 & 49 & 14,45 & \\
\hline $2500-3499$ & 183 & 53,82 & 199 & 58,70 & \\
\hline$\geq 3500$ & 85 & 25,00 & 91 & 26,84 & \\
\hline Tipo de parto & & & & & 0,512 \\
\hline Vaginal & 195 & 56,69 & 187 & 54,20 & \\
\hline Cesariana & 149 & 43,31 & 158 & 45,80 & \\
\hline Ordem de nascimento & & & & & 0,137 \\
\hline 10 & 114 & 33,04 & 140 & 40,70 & \\
\hline $2^{\circ}$ & 120 & 34,78 & 103 & 29,94 & \\
\hline $3^{\circ}$ & 58 & 16,81 & 60 & 17,44 & \\
\hline $4^{\circ}$ ou posterior & 53 & 15,36 & 41 & 11,92 & \\
\hline
\end{tabular}

${ }^{*} x^{2}$ de verossimilhança, respeitando-se os respectivos graus de liberdade.

Quanto às variáveis nutricionais (Tabela 5), houve diferenças significativas entre casos e controles em relação ao escore-z de peso para idade, escore-z de peso para altura e escore-z de IMC para idade. Tais indicadores evidenciam uma maior ocorrência de baixo peso / desnutrição entre os casos. Observa-se maior tempo de aleitamento materno entre os controles, não havendo diferenças significativas na distribuição de casos e controles em relação às demais variáveis. 
Tabela 5- Caracterização de casos e controles participantes do estudo, segundo variáveis nutricionais. Ribeirão Preto/SP, 2013.

\begin{tabular}{|c|c|c|c|c|c|}
\hline & & & $\mathrm{COI}$ & OLES & \\
\hline & $\mathrm{N}$ & $\%$ & $\mathrm{~N}$ & $\%$ & $x^{2^{*}}$ \\
\hline Escore-z de peso para idade & & & & & 0,049 \\
\hline$\geq-2$ & 309 & 89,83 & 324 & 93,91 & \\
\hline$<-2$ & 35 & 10,17 & 21 & 6,09 & \\
\hline Escore-z de altura para idade & & & & & 0,245 \\
\hline$\geq-2$ & 306 & 89,21 & 314 & 91,81 & \\
\hline$<-2$ & 37 & 10,79 & 28 & 8,19 & \\
\hline Escore-z de peso para altura & & & & & 0,026 \\
\hline$\geq-2$ & 317 & 92,69 & 330 & 96,49 & \\
\hline$<-2$ & 25 & 7,31 & 12 & 3,51 & \\
\hline Escore-z de IMC para idade & & & & & 0,002 \\
\hline Eutrófico & 299 & 87,94 & 297 & 86,84 & \\
\hline Desnutrido & 28 & 8,24 & 14 & 4,09 & \\
\hline Excesso & 13 & 3,82 & 31 & 9,06 & \\
\hline Aleitamento pregresso/atual & & & & & 0,650 \\
\hline Nunca mamou & 24 & 6,96 & 19 & 5,51 & \\
\hline Mamou & 200 & 57,97 & 197 & 57,10 & \\
\hline Mama & 121 & 35,07 & 129 & 37,39 & \\
\hline Tipo de aleitamento até 6 meses & & & & & 0,301 \\
\hline Exclusivo & 34 & 9,88 & 47 & 13,62 & \\
\hline Predominante & 68 & 19,77 & 76 & 22,03 & \\
\hline Misto & 218 & 63,37 & 203 & 58,84 & \\
\hline Artificial & 24 & 6,98 & 19 & 5,51 & \\
\hline Tempo de Aleitamento (meses) & & & & & 0,007 \\
\hline Nunca mamou $(0)$ & 24 & 6,98 & 19 & 5,51 & \\
\hline $1^{\circ}$ terço $(0,1-3,3)$ & 127 & 36,92 & 89 & 25,80 & \\
\hline 2o terço $(3,31-8,6)$ & 94 & 27,33 & 120 & 34,78 & \\
\hline $3^{\circ}$ terço $(>8,6)$ & 99 & 28,78 & 117 & 33,91 & \\
\hline Alimentação complementar ${ }^{\dagger}$ & & & & & 0,895 \\
\hline Não introduzida & 43 & 13,27 & 44 & 13,62 & \\
\hline Introduzida antes dos 6 meses & 156 & 48,15 & 147 & 45,51 & \\
\hline Introduzida aos 6 meses & 99 & 30,56 & 107 & 33,13 & \\
\hline Introduzida depois dos 6 meses & 26 & 8,02 & 25 & 7,74 & \\
\hline
\end{tabular}

* $x^{2}$ de verossimilhança, respeitando-se os respectivos graus de liberdade.

† Introdução de alimentos sólidos (como papas e frutas).

De acordo com a Tabela 6, que apresenta a caracterização dos participantes quanto às variáveis relativas ao cuidado à criança, os casos apresentaram escores mais baixos na avaliação da qualidade da APS e entre eles houve maior proporção de atraso vacinal e uso pregresso de medicamentos. 
Tabela 6 - Caracterização de casos e controles participantes do estudo, segundo variáveis relativas ao cuidado à criança. Ribeirão Preto/SP, 2013.

\begin{tabular}{|c|c|c|c|c|c|}
\hline & & & $\mathrm{COI}$ & DLES & \\
\hline & $\mathrm{n}$ & $\%$ & $\mathrm{~N}$ & $\%$ & $x^{2^{*}}$ \\
\hline Escore Essencial da APS & & & & & 0,004 \\
\hline $1^{\circ}$ quarto $(\leq 2,79)$ & 121 & 35,07 & 86 & 25,00 & \\
\hline 20 quarto $(>2,79$ e $\leq 3,17)$ & 96 & 27,83 & 86 & 25,00 & \\
\hline $3 \circ$ quarto $(>3,17$ e $\leq 3,41)$ & 60 & 17,39 & 86 & 25,00 & \\
\hline $4^{\circ}$ quarto $(>3,41)$ & 68 & 19,71 & 86 & 25,00 & \\
\hline Escore Geral da APS & & & & & 0,016 \\
\hline $1^{\circ}$ quarto $(\leq 2,64)$ & 116 & 33,72 & 86 & 24,93 & \\
\hline $2^{\circ}$ quarto $(>2,64$ e $\leq 3,04)$ & 90 & 26,16 & 86 & 24,93 & \\
\hline $3^{\circ}$ quarto $(>3,04$ e $\leq 3,39)$ & 80 & 23,26 & 87 & 25,22 & \\
\hline $4^{\circ}$ quarto $(>3,39)$ & 58 & 16,86 & 86 & 24,93 & \\
\hline Trabalho materno extradomiciliar & & & & & 0,445 \\
\hline Não & 190 & 55,07 & 180 & 52,17 & \\
\hline Sim & 155 & 44,93 & 165 & 47,83 & \\
\hline Cuidado não-materno & & & & & 0,804 \\
\hline Não necessário (mãe em casa) & 83 & 24,13 & 90 & 26,09 & \\
\hline Avó / avô & 98 & 28,49 & 102 & 29,57 & \\
\hline Creche/escola & 85 & 24,71 & 75 & 21,74 & \\
\hline Outro & 78 & 22,67 & 78 & 22,61 & \\
\hline Situação vacinal & & & & & $<0,001$ \\
\hline Atualizada & 226 & 65,89 & 277 & 80,29 & \\
\hline Não atualizada & 117 & 34,11 & 68 & 19,71 & \\
\hline Uso pregresso de medicamentos & & & & & 0,013 \\
\hline Não & 58 & 16,81 & 84 & 24,42 & \\
\hline Sim & 287 & 83,19 & 260 & 75,58 & \\
\hline Uso de bico & & & & & 0,324 \\
\hline Não & 44 & 12,75 & 53 & 15,36 & \\
\hline Sim & 301 & 87,25 & 292 & 84,64 & \\
\hline Morte de irmão $<5$ anos & & & & & 0,067 \\
\hline Sem irmãos & 107 & 31,01 & 136 & 39,42 & \\
\hline Não & 222 & 64,35 & 196 & 56,81 & \\
\hline Sim & 16 & 4,64 & 13 & 3,77 & \\
\hline
\end{tabular}

${ }^{*} x^{2}$ de verossimilhança, respeitando-se os respectivos graus de liberdade.

Em relação às variáveis relativas à morbidade, apresentadas na Tabela 7, destaca-se a maior ocorrência de problemas respiratórios entre os casos, grupo no qual a hospitalização prévia também ocorreu com maior frequência, especialmente por pneumonia. 
Tabela 7 - Caracterização de casos e controles participantes do estudo, segundo variáveis relativas à morbidade. Ribeirão Preto/SP, 2013.

\begin{tabular}{|c|c|c|c|c|c|}
\hline & \multicolumn{2}{|c|}{ CASOS } & \multicolumn{2}{|c|}{ CONTROLES } & \multirow[b]{2}{*}{$x^{2^{*}}$} \\
\hline & $\mathrm{n}$ & $\%$ & $\mathrm{~N}$ & $\%$ & \\
\hline № de episódios de pneumonia ${ }^{\dagger}$ & & & & & $<0,001$ \\
\hline 0 & 0 & 0,00 & 286 & 83,14 & \\
\hline 1 & 262 & 75,95 & 43 & 12,50 & \\
\hline 2 & 45 & 13,04 & 9 & 2,62 & \\
\hline$\geq 3$ & 38 & 11,01 & 6 & 1,74 & \\
\hline № de episódios de sibilância & & & & & $<0,001$ \\
\hline 0 & 104 & 34,67 & 164 & 52,23 & \\
\hline 1 & 89 & 29,67 & 71 & 22,61 & \\
\hline 2 & 31 & 10,33 & 36 & 11,46 & \\
\hline$\geq 3$ & 76 & 25,33 & 43 & 13,69 & \\
\hline Hospitalização prévia & & & & & 0,075 \\
\hline Não & 238 & 68,99 & 259 & 75,07 & \\
\hline Sim & 107 & 31,01 & 86 & 24,93 & \\
\hline Hospitalização prévia por pneumonia & & & & & $<0,001$ \\
\hline Não & 305 & 88,66 & 331 & 95,94 & \\
\hline Sim & 39 & 11,34 & 14 & 4,06 & \\
\hline Episódio de diarreia & & & & & 0,374 \\
\hline Não & 246 & 71,51 & 236 & 68,41 & \\
\hline Sim & 98 & 28,49 & 109 & 31,59 & \\
\hline Apneia do sono / ronco & & & & & 0,819 \\
\hline Não & 291 & 84,59 & 294 & 85,22 & \\
\hline Sim & 53 & 15,41 & 51 & 14,78 & \\
\hline Imunodeficiência & & & & & 0,304 \\
\hline Não & 340 & 99,13 & 343 & 99,71 & \\
\hline Sim & 3 & 0,87 & 1 & 0,29 & \\
\hline Outras doenças pulmonares $\ddagger$ & & & & & $<0,001$ \\
\hline Não & 297 & 86,84 & 326 & 94,77 & \\
\hline Sim & 45 & 13,16 & 18 & 5,23 & \\
\hline Refluxo & & & & & 0,150 \\
\hline Não & 298 & 88,17 & 280 & 84,34 & \\
\hline Sim & 40 & 11,83 & 52 & 15,66 & \\
\hline Doenças cardiovasculares & & & & & 0,172 \\
\hline Não & 322 & 93,60 & 329 & 95,92 & \\
\hline Sim & 22 & 6,40 & 14 & 4,08 & \\
\hline
\end{tabular}

${ }^{*} x^{2}$ de verossimilhança, respeitando-se os respectivos graus de liberdade.

$\dagger$ Incluindo o episódio atual.

‡Excluindo-se pneumonia.

\subsection{Fase analítica}

\subsubsection{Análises univariadas}


As Tabelas 8 a 14 apresentam os resultados das análises univariadas. Destacam-se, em negrito, os valores $p<0,25$ para o teste de Wald - critério de seleção das variáveis para os modelos multivariados.

Dentre as variáveis sociodemográficas (nível 1), apenas renda familiar passou pelo critério de seleção para os modelos subsequentes. Ressalta-se que sexo e faixa etária são variáveis de emparelhamento entre casos e controles (Tabela 8).

Tabela 8 - Odds ratios com intervalos de confiança (95\%) e valores $p$ para os testes de Wald, segundo variáveis sociodemográficas. Modelos univariados.

Ribeirão Preto/SP, 2013.

\begin{tabular}{|c|c|c|}
\hline & OR (IC95\%) & $\begin{array}{c}\text { Valor de } p \\
\text { (teste de Wald) }\end{array}$ \\
\hline \multicolumn{3}{|l|}{ Sexo } \\
\hline Masculino & 1,00 & \\
\hline Feminino & $1,00(0,74-1,35)$ & 1,000 \\
\hline \multicolumn{3}{|l|}{ Faixa etária (meses) } \\
\hline $02-05,9$ & 1,00 & \\
\hline $06-11,9$ & $0,95(0,61-1,48)$ & 0,827 \\
\hline $12-23,9$ & $1,02(0,67-1,56)$ & 0,934 \\
\hline $24-59,9$ & $0,98(0,63-1,50)$ & 0,912 \\
\hline \multicolumn{3}{|c|}{ Renda familiar em terços $(R \$)$} \\
\hline $1^{\circ}$ terço $(\leq 400)$ & 1,00 & \\
\hline $2^{\circ}$ terço $>400$ e $\leq 700$ & $0,80(0,55-1,15)$ & 0,226 \\
\hline $3^{\circ}$ terço $>700$ & $0,68(0,47-0,98)$ & 0,039 \\
\hline \multicolumn{3}{|c|}{ Escolaridade materna (anos) } \\
\hline $0-4$ & 1,00 & \\
\hline $5-8$ & $1,12(0,64-1,96)$ & 0,694 \\
\hline$\geq 9$ & $0,88(0,51-1,50)$ & 0,631 \\
\hline \multicolumn{3}{|c|}{ Escolaridade paterna (anos) } \\
\hline $0-4$ & 1,00 & \\
\hline $5-8$ & $1,06(0,65-1,73)$ & 0,826 \\
\hline$\geq 9$ & $0,91(0,56-1,49)$ & 0,717 \\
\hline \multicolumn{3}{|l|}{ Estado marital } \\
\hline Com companheiro & 1,00 & \\
\hline Sem companheiro & $0,94(0,67-1,32)$ & 0,731 \\
\hline
\end{tabular}

Do conjunto de variáveis reprodutivas maternas (nível 2), somente idade materna não atingiu o critério de seleção para a abordagem hierarquizada. Assim, paridade, intervalo interpartal, ganho de peso na gestação e número de consultas de pré-natal representaram esse conjunto nas análises multivariadas (Tabela 9). 
Tabela 9 - Odds ratios com intervalos de confiança (95\%) e valores $p$ para os testes de Wald, segundo variáveis reprodutivas maternas. Modelos univariados. Ribeirão Preto/SP, 2013.

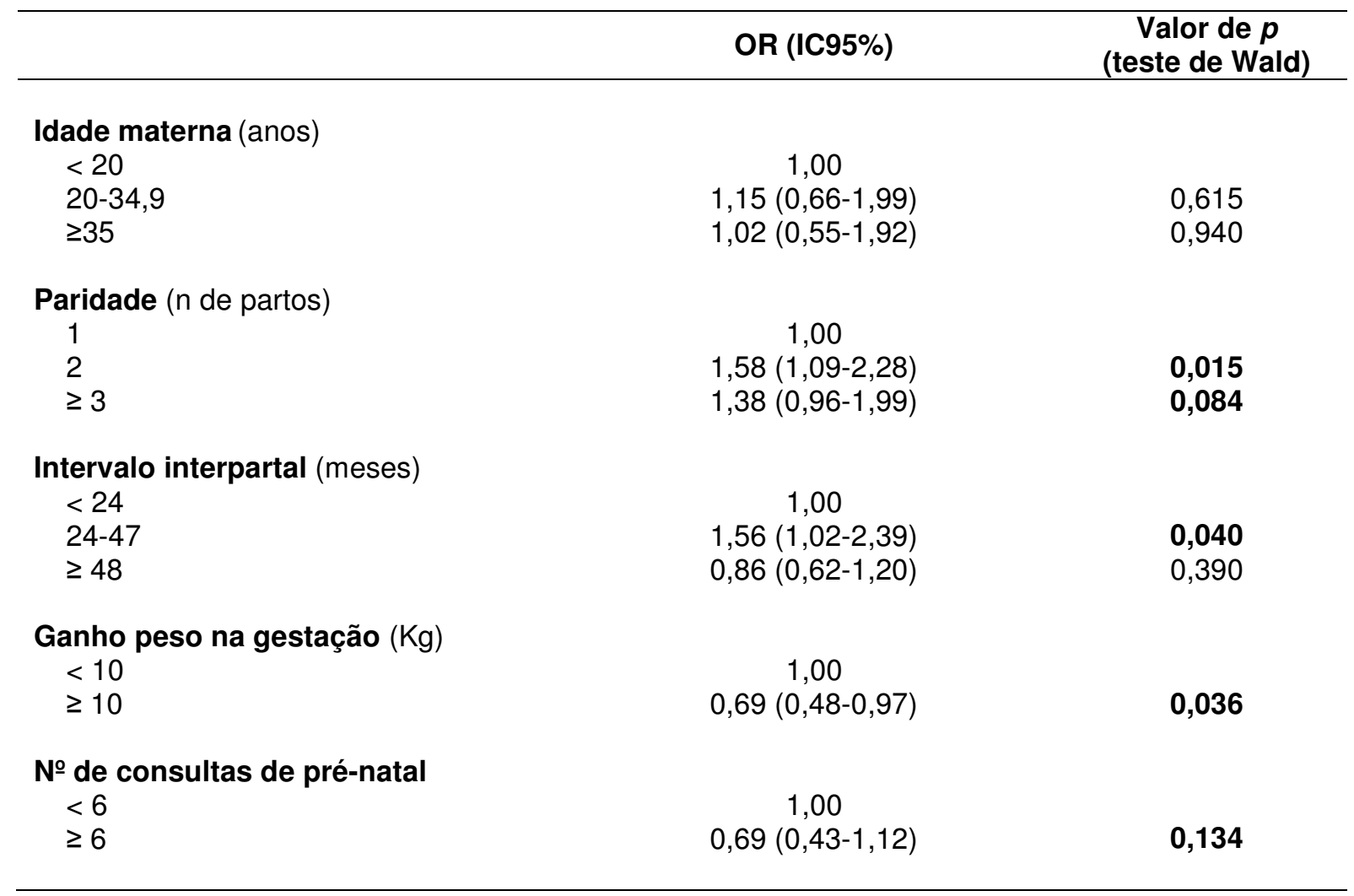

Conforme se observa na Tabela 10, as variáveis ambientais (nível 2) que alcançaram valor $p<0,25$ foram: número de pessoas na casa, número adicional de crianças no domicílio, número de pessoas que dividem o quarto com a criança, frequência à creche e tipo de forno / fogão. 
Tabela 10 - Odds ratios com intervalos de confiança (95\%) e valores $p$ para os testes de Wald, segundo variáveis ambientais. Modelos univariados. Ribeirão Preto/SP, 2013.

\begin{tabular}{|c|c|c|}
\hline & OR (IC95\%) & $\begin{array}{c}\text { Valor de } p \\
\text { (teste de Wald) }\end{array}$ \\
\hline \multicolumn{3}{|l|}{$N^{\circ}$ de pessoas na casa } \\
\hline$<4$ & 1,00 & \\
\hline $4-5$ & $1,41(0,98-2,05)$ & 0,067 \\
\hline$\geq 6$ & $1,67(1,10-2,54)$ & 0,017 \\
\hline \multicolumn{3}{|l|}{$N^{\circ}$ de cômodos na casa } \\
\hline$\leq 3$ & 1,00 & \\
\hline & $0,92(0,63-1,36)$ & 0,694 \\
\hline \multicolumn{3}{|c|}{$\mathrm{N}^{\circ}$ adicional de crianças no domicilio } \\
\hline 0 & 1,00 & \\
\hline 1 & $1,42(1,01-2,01)$ & 0,045 \\
\hline$\geq 2$ & $2,00(1,35-2,96)$ & $<0,001$ \\
\hline \multicolumn{3}{|c|}{$N^{\circ}$ de pessoas no quarto com a criança } \\
\hline $0-1$ & 1,00 & \\
\hline 2 & $1,31(0,92-1,88)$ & 0,138 \\
\hline$\geq 3$ & $1,73(1,14-2,62)$ & 0,010 \\
\hline \multicolumn{3}{|c|}{$\mathrm{N}^{\circ}$ de pessoas na cama da criança } \\
\hline 0 & 1,00 & \\
\hline 1 & $0,88(0,60-1,28)$ & 0,497 \\
\hline$\geq 2$ & $1,13(0,78-1,64)$ & 0,508 \\
\hline \multicolumn{3}{|l|}{ Frequência à creche } \\
\hline Não & 1,00 & \\
\hline Sim & $1,60(1,17-2,19)$ & 0,003 \\
\hline \multicolumn{3}{|l|}{ Fumantes no domicilio } \\
\hline Não & 1,00 & \\
\hline Sim & $1,04(0,76-1,43)$ & 0,808 \\
\hline \multicolumn{3}{|c|}{$\mathrm{N}^{\circ}$ cigarros consumidos ao dia, no domicílio } \\
\hline Nenhum & 1,00 & \\
\hline$\leq 20$ & $1,18(0,80-1,75)$ & 0,397 \\
\hline$>20$ & $1,01(0,60-1,72)$ & 0,962 \\
\hline \multicolumn{3}{|l|}{ Tabagismo materno } \\
\hline Não fumante & 1,00 & \\
\hline Ex-fumante & $1,22(0,78-1,91)$ & 0,384 \\
\hline Fumante & $1,25(0,85-1,86)$ & 0,259 \\
\hline \multicolumn{3}{|l|}{ Tabagismo durante gestação } \\
\hline Não & 1,00 & \\
\hline Sim & $1,29(0,76-2,21)$ & 0,342 \\
\hline \multicolumn{3}{|l|}{ Tipo de forno/fogão } \\
\hline Somente a gás ou elétrico & 1,00 & \\
\hline Também a lenha & $0,73(0,52-1,04)$ & 0,086 \\
\hline \multicolumn{3}{|l|}{ Sistema de esgoto } \\
\hline Não & 1,00 & \\
\hline Sim & $1,06(0,54-2,10)$ & 0,855 \\
\hline
\end{tabular}


Em relação às variáveis perinatais (nível 3), idade gestacional, peso ao nascer e ordem de nascimento enquadraram-se no critério de seleção para as etapas subsequentes de modelagem. A única variável não selecionada foi tipo de parto (Tabela 11). Na análise univariada, ressalta-se que a variável peso ao nascer foi recodificada e tratada em duas categorias $(<2500$ e $\geq 2500)$.

Tabela 11 - Odds ratios com intervalos de confiança (95\%) e valores $p$ para os testes de Wald, segundo variáveis perinatais. Modelos univariados. Ribeirão Preto/SP, 2013.

\begin{tabular}{|c|c|c|}
\hline & OR (IC95\%) & $\begin{array}{c}\text { Valor de } p \\
\text { (teste de Wald) }\end{array}$ \\
\hline \multicolumn{3}{|c|}{ Idade gestacional (semanas) } \\
\hline$<37$ & 1,00 & \\
\hline$\geq 37$ & $0,66(0,45-0,98)$ & 0,038 \\
\hline \multicolumn{3}{|c|}{ Peso ao nascer (gramas) } \\
\hline$<2500$ & 1,00 & \\
\hline$\geq 2500$ & $1,59(1,07-2,37)$ & 0,023 \\
\hline \multicolumn{3}{|l|}{ Tipo de parto } \\
\hline Vaginal & 1,00 & \\
\hline Cesariana & $0,90(0,67-1,22)$ & 0,512 \\
\hline \multicolumn{3}{|c|}{ Ordem de nascimento } \\
\hline 10 & 1,00 & \\
\hline $2^{\circ}$ & $1,43(1,00-2,05)$ & 0,052 \\
\hline $3^{0}$ & $1,19(0,77-1,84)$ & 0,442 \\
\hline $4^{\circ}$ ou posterior & $1,59(0,98-2,56)$ & 0,057 \\
\hline
\end{tabular}

Em relação às variáveis nutricionais (nível 4), expostas na Tabela 12, atingiram valor $p<0,25$ : escore- $z$ de peso para idade, escore-z de altura para idade, escore-z de peso para altura, escore-z de IMC para idade, aleitamento até 6 meses e tempo de aleitamento. As variáveis aleitamento pregresso/atual e alimentação complementar não se enquadraram no critério de seleção para os modelos multivariados. 
Tabela 12 - Odds ratios com intervalos de confiança (95\%) e valores $p$ para os testes de Wald, segundo variáveis nutricionais. Modelos univariados. Ribeirão Preto/SP, 2013.

\begin{tabular}{|c|c|c|}
\hline & OR (IC95\%) & $\begin{array}{c}\text { Valor de } p \\
\text { (teste de Wald) }\end{array}$ \\
\hline \multicolumn{3}{|l|}{ Escore-z de peso para idade } \\
\hline$\geq-2$ & 1,00 & \\
\hline$<-2$ & $1,75(0,99-3,07)$ & 0,052 \\
\hline \multicolumn{3}{|l|}{ Escore-z de altura para idade } \\
\hline$\geq-2$ & 1,00 & \\
\hline$<-2$ & $1,36(0,81-2,27)$ & 0,247 \\
\hline \multicolumn{3}{|l|}{ Escore-z de peso para altura } \\
\hline$\geq-2$ & 1,00 & \\
\hline$<-2$ & $2,17(1,07-4,39)$ & 0,031 \\
\hline \multicolumn{3}{|l|}{ Escore-z de IMC para idade } \\
\hline Eutrófico & 1,00 & \\
\hline Desnutrido & $1,99(1,02-3,85)$ & 0,042 \\
\hline Excesso & $0,42(0,21-0,81)$ & 0,010 \\
\hline \multicolumn{3}{|l|}{ Aleitamento pregresso/atual } \\
\hline Nunca mamou & 1,00 & \\
\hline Mamou & $0,80(0,43-1,51)$ & 0,499 \\
\hline Mama & $0,74(0,39-1,42)$ & 0,370 \\
\hline \multicolumn{3}{|l|}{ Aleitamento até 6 meses } \\
\hline Exclusivo & 1,00 & \\
\hline Predominante & $1,24(0,71-2,14)$ & 0,448 \\
\hline Misto & $1,48(0,92-2,40)$ & 0,107 \\
\hline Artificial & $1,75(0,83-3,68)$ & 0,143 \\
\hline \multicolumn{3}{|l|}{ Tempo de Aleitamento (meses) } \\
\hline Nunca mamou $(0)$ & 1,00 & \\
\hline $1^{\circ}$ terço $(0,1-3,3)$ & $1,13(0,58-2,19)$ & 0,717 \\
\hline $2^{\circ}$ terço $(3,31-8,6)$ & $0,62(0,32-1,20)$ & 0,156 \\
\hline 3ำ terço $(>8,6)$ & $0,67(0,35-1,29)$ & 0,233 \\
\hline \multicolumn{3}{|l|}{ Alimentação complementar ${ }^{*}$} \\
\hline Não introduzida & 1,00 & \\
\hline Introduzida antes dos 6 meses & $1,09(0,67-1,75)$ & 0,735 \\
\hline Introduzida aos 6 meses & $0,95(0,57-1,56)$ & 0,831 \\
\hline Introduzida após os 6 meses & $1,06(0,53-2,12)$ & 0,860 \\
\hline
\end{tabular}

*Introdução de alimentos sólidos (como papas e frutas).

Conforme se observa na Tabela 13, que apresenta as variáveis relativas ao cuidado à criança (nível 4), escore essencial da APS, escore geral da APS, situação vacinal, uso de medicamentos e morte de irmão $<5$ anos alcançaram o critério de seleção para as etapas subsequentes de modelagem. 
Tabela 13 - Odds ratios com intervalos de confiança $(95 \%)$ e valores $p$ para os testes de Wald, segundo variáveis relativas ao cuidado à criança. Modelos univariados. Ribeirão Preto/SP, 2013.

\begin{tabular}{|c|c|c|}
\hline & OR (IC95\%) & $\begin{array}{c}\text { Valor de } p \\
\text { (teste de Wald) }\end{array}$ \\
\hline \multicolumn{3}{|l|}{ Escore Essencial da APS } \\
\hline $1^{\circ}$ quarto $(\leq 2,79)$ & 1,00 & \\
\hline 2 quarto $(>2,79$ e $\leq 3,17)$ & $0,79(0,53-1,18)$ & 0,258 \\
\hline 3o quarto $(>3,17$ e $\leq 3,41)$ & $0,50(0,32-0,76)$ & 0,001 \\
\hline $4^{\circ}$ quarto $(>3,41)$ & $0,56(0,37-0,86)$ & 0,007 \\
\hline \multicolumn{3}{|l|}{ Escore Geral da APS } \\
\hline $1^{\circ}$ quarto $(\leq 2,64)$ & 1,00 & \\
\hline $2^{\circ}$ quarto $(>2,64$ e $\leq 3,04)$ & $0,78(0,52-1,16)$ & 0,221 \\
\hline 3 quarto $(>3,04$ e $\leq 3,39)$ & $0,68(0,45-1,03)$ & 0,069 \\
\hline 40 quarto $(>3,39)$ & $0,50(0,32-0,77)$ & 0,002 \\
\hline \multicolumn{3}{|l|}{ Mãe trabalha fora de casa } \\
\hline Não & 1,00 & \\
\hline Sim & $0,89(0,66-1,20)$ & 0,445 \\
\hline \multicolumn{3}{|l|}{ Cuidado não-materno } \\
\hline Não necessário & 1,00 & \\
\hline Avó / avô & $1,04(0,69-1,56)$ & 0,844 \\
\hline Creche/escola & $1,23(0,80-1,89)$ & 0,348 \\
\hline Outro & $1,08(0,70-1,67)$ & 0,714 \\
\hline \multicolumn{3}{|l|}{ Situacão vacinal } \\
\hline Atualizada & 1,00 & \\
\hline Não atualizada & $2,11(1,49-2,98)$ & $<0,001$ \\
\hline \multicolumn{3}{|l|}{ Uso de medicamentos } \\
\hline Não & 1,00 & \\
\hline Sim & $1,60(1,10-2,32)$ & 0,014 \\
\hline \multicolumn{3}{|l|}{ Uso de bico } \\
\hline Não & 1,00 & \\
\hline Sim & $1,24(0,81-1,91)$ & 0,325 \\
\hline \multicolumn{3}{|l|}{ Morte de irmão $<5$ anos } \\
\hline Sem irmãos & 1,00 & \\
\hline Não & $1,44(1,05-1,98)$ & 0,025 \\
\hline Sim & $1,56(0,72-3,39)$ & 0,257 \\
\hline
\end{tabular}

Dentre as variáveis relativas à morbidade (nível 4), enquadraram-se no critério de seleção para permanecer nos modelos subsequentes de modelagem: número de episódios de pneumonia, número de episódios de sibilância, hospitalização prévia, hospitalização prévia por pneumonia, outras doenças pulmonares, refluxo e doenças cardiovasculares (Tabela 14). 
Tabela 14 - Odds ratios com intervalos de confiança (95\%) e valores $p$ para os testes de Wald, segundo variáveis relativas à morbidade. Modelos univariados.

Ribeirão Preto/SP, 2013.

\begin{tabular}{|c|c|c|}
\hline & OR (IC95\%) & $\begin{array}{c}\text { Valor de } p \\
\text { (teste de Wald) }\end{array}$ \\
\hline \multicolumn{3}{|c|}{ № de episódios de pneumonia ${ }^{*}$} \\
\hline 0 & 1,00 & \\
\hline 1 & $167,61(82,52-340,45)$ & $<0,001$ \\
\hline 2 & $143,00(55,09-371-17)$ & $<0,001$ \\
\hline$\geq 3$ & $181,13(62,30-526,59)$ & $<0,001$ \\
\hline \multicolumn{3}{|c|}{ № de episódios de sibilância } \\
\hline 0 & 1,00 & \\
\hline 1 & $1,98(1,33-2,94)$ & 0,001 \\
\hline 2 & $1,36(0,79-2,33)$ & 0,266 \\
\hline$\geq 3$ & $2,79(1,78-4,36)$ & $<0,001$ \\
\hline \multicolumn{3}{|c|}{ Hospitalização prévia } \\
\hline Não & 1,00 & \\
\hline Sim & $1,35(0,97-1,89)$ & 0,075 \\
\hline \multicolumn{3}{|c|}{ Hospitalização prévia por pneumonia } \\
\hline Não & 1,00 & \\
\hline Sim & $3,02(1,61-5,68)$ & 0,001 \\
\hline \multicolumn{3}{|c|}{ Episódio de diarreia } \\
\hline Não & 1,00 & \\
\hline Sim & $0,86(0,62-1,19)$ & 0,374 \\
\hline \multicolumn{3}{|c|}{ Apneia do sono / ronco } \\
\hline Não & 1,00 & \\
\hline Sim & $1,05(0,69-1,59)$ & 0,819 \\
\hline \multicolumn{3}{|c|}{ Imunodeficiência } \\
\hline Não & 1,00 & \\
\hline Sim & $3,03(0,31-29,24)$ & 0,339 \\
\hline \multicolumn{3}{|c|}{ Outras doenças pulmonares ${ }^{\dagger}$} \\
\hline Não & 1,00 & \\
\hline Sim & $2,74(1,55-4,85)$ & 0,001 \\
\hline \multicolumn{3}{|l|}{ Refluxo } \\
\hline Não & 1,00 & \\
\hline Sim & $0,72(0,46-1,13)$ & 0,151 \\
\hline \multicolumn{3}{|c|}{ Doenças cardiovasculares } \\
\hline Não & 1,00 & \\
\hline Sim & $1,61(0,81-3,19)$ & 0,177 \\
\hline
\end{tabular}

* Incluindo o episódio atual.

${ }^{\dagger}$ Excluindo-se pneumonia. 


\subsubsection{Análises multivariadas}

Os modelos intermediários, a partir dos quais foi iniciada a abordagem hierarquizada, são apresentados na Tabela 15. Destacam-se, em negrito, as variáveis que apresentaram valores $p<0,10$ para o teste de Wald. Tais variáveis foram então selecionadas para a fase de modelagem seguinte.

Tabela 15 - Odds ratios com intervalos de confiança (95\%) e valores $p$ para os testes de Wald. Modelos intermediários. Ribeirão Preto/SP, 2013.

\begin{tabular}{|c|c|c|}
\hline Níveis hierárquicos & OR (IC95\%) & $\begin{array}{c}\text { Valor de } p \\
\text { (teste de Wald) }\end{array}$ \\
\hline 1 - Variáveis Socioeconômicas & & \\
\hline $\begin{array}{l}\text { Renda familiar em terços }(\mathrm{R} \$) \\
1^{\circ} \text { terço }(\leq 400) \\
2^{\circ} \text { terço }>400 \text { e } \leq 700 \\
3^{\circ} \text { terço }>700\end{array}$ & $\begin{array}{c}1,00 \\
0,80(0,55-1,15) \\
0,68(0,47-0,98)\end{array}$ & $\begin{array}{l}0,226 \\
\mathbf{0 , 0 3 9}\end{array}$ \\
\hline 2o - Variáveis Reprodutivas e Ambien & & \\
\hline $\begin{array}{l}\text { Paridade (n de partos) } \\
\quad 1 \\
2 \\
\geq 3\end{array}$ & $\begin{array}{c}1,00 \\
3,80(1,56-9,27) \\
2,22(0,91-5,41)\end{array}$ & $\begin{array}{l}0,003 \\
0,080\end{array}$ \\
\hline $\begin{array}{l}\text { Intervalo interpartal (meses) } \\
\quad<24 \\
24-47 \\
\geq 48\end{array}$ & $\begin{array}{c}1,00 \\
0,54(0,25-1,16) \\
0,29(0,14-0,61)\end{array}$ & $\begin{array}{l}0,116 \\
\mathbf{0 , 0 0 1}\end{array}$ \\
\hline $\begin{array}{l}\text { Ganho peso na gestação }(\mathrm{Kg}) \\
\quad<10 \\
\geq 10\end{array}$ & $\begin{array}{c}1,00 \\
0,71(0,49-1,05)\end{array}$ & 0,084 \\
\hline $\begin{array}{l}\text { № de consultas de pré-natal } \\
\quad<6 \\
\geq 6\end{array}$ & $\begin{array}{c}1,00 \\
0,94(0,53-1,67)\end{array}$ & 0,826 \\
\hline $\begin{array}{l}N^{\circ} \text { de pessoas na casa } \\
<4 \\
4-5 \\
\geq 6\end{array}$ & $\begin{array}{c}1,00 \\
1,53(0,88-2,68) \\
1,31(0,69-2,52)\end{array}$ & $\begin{array}{l}0,132 \\
0,408\end{array}$ \\
\hline
\end{tabular}


... continuação da Tabela 15

\begin{tabular}{|c|c|c|}
\hline Níveis hierárquicos & OR (IC95\%) & $\begin{array}{c}\text { Valor de } p \\
\text { (teste de Wald) }\end{array}$ \\
\hline \multicolumn{3}{|l|}{$\mathrm{N}^{\circ}$ adicional de crianças no domicilio } \\
\hline 0 & 1,00 & \\
\hline 1 & $0,99(0,54-1,81)$ & 0,980 \\
\hline$\geq 2$ & $1,54(0,78-3,06)$ & 0,214 \\
\hline \multicolumn{3}{|l|}{$N^{\circ}$ de pessoas no quarto com a criança } \\
\hline $0-1$ & 1,00 & \\
\hline 2 & $1,62(1,04-2,51)$ & 0,031 \\
\hline$\geq 3$ & $1,35(0,78-2,34)$ & 0,277 \\
\hline \multicolumn{3}{|l|}{ Frequência à creche } \\
\hline Não & 1,00 & \\
\hline Sim & $1,97(1,34-2,89)$ & 0,001 \\
\hline \multicolumn{3}{|l|}{ Tipo de forno/fogão } \\
\hline Somente a gás ou elétrico & 1,00 & \\
\hline Também a lenha & $0,71(0,47-1,08)$ & 0,108 \\
\hline \multicolumn{3}{|l|}{ 3ㅇ - Variáveis Perinatais ${ }^{\dagger}$} \\
\hline \multicolumn{3}{|l|}{ Idade gestacional (semanas) } \\
\hline$<37$ & 1,00 & \\
\hline$\geq 37$ & $0,85(0,49-1,46)$ & 0,559 \\
\hline \multicolumn{3}{|l|}{ Peso ao nascer (gramas) } \\
\hline$<2500$ & 1,00 & \\
\hline$\geq 2500$ & $1,04(0,60-1,79)$ & 0,891 \\
\hline \multicolumn{3}{|l|}{ Ordem de nascimento } \\
\hline $1^{\circ}$ & 1,00 & \\
\hline $2^{\circ}$ & $0,34(0,04-3,17)$ & 0,346 \\
\hline $3^{\circ}$ & $0,59(0,05-6,87)$ & 0,676 \\
\hline $4^{\circ}$ ou posterior & $0,62(0,05-7,50)$ & 0,709 \\
\hline \multicolumn{3}{|c|}{$\begin{array}{l}\text { 4 - Variáveis nutricionais, relativas ao cuidado à } \\
\text { criança e à morbidade }\end{array}$} \\
\hline \multicolumn{3}{|l|}{ Escore-z de peso para idade } \\
\hline$\geq-2$ & 1,00 & \\
\hline$<-2$ & $0,78(0,25-2,47)$ & 0,674 \\
\hline \multicolumn{3}{|l|}{ Escore-z de altura para idade } \\
\hline$\geq-2$ & 1,00 & \\
\hline$<-2$ & $1,08(0,41-2,88)$ & 0,876 \\
\hline Escore-z de peso para altura & 1,00 & \\
\hline$\geq-2$ & $1,25(0,07-21,99)$ & 0,878 \\
\hline$<-2$ & & \\
\hline
\end{tabular}


... conclusão da Tabela 15

\begin{tabular}{|c|c|c|}
\hline Níveis hierárquicos & OR (IC95\%) & $\begin{array}{c}\text { Valor de } p \\
\text { (teste de Wald) }\end{array}$ \\
\hline \multicolumn{3}{|l|}{ Escore-z de IMC para idade } \\
\hline Eutrófico & 1,00 & \\
\hline Desnutrido & $2,07(0,13-33,36)$ & 0,607 \\
\hline Excesso & $0,32(0,11-0,93)$ & 0,036 \\
\hline \multicolumn{3}{|l|}{ Tempo de Aleitamento (meses) } \\
\hline Nunca mamou (0) & 1,00 & \\
\hline $1^{\circ}$ terço $(0,1-3,3)$ & $1,92(0,54-6,84)$ & 0,313 \\
\hline $2^{\circ}$ terço $(3,31-8,6)$ & $1,07(0,30-3,83)$ & 0,914 \\
\hline $3^{\circ}$ terço $(>8,6)$ & $0,80(0,22-2,90)$ & 0,738 \\
\hline \multicolumn{3}{|l|}{ Escore Essencial da APS } \\
\hline 10 quarto $(\leq 2,79)$ & 1,00 & \\
\hline $2^{\circ}$ quarto $(>2,79$ e $\leq 3,17)$ & $0,87(0,49-1,56)$ & 0,645 \\
\hline 3o quarto $(>3,17$ e $\leq 3,41)$ & $0,49(0,27-0,91)$ & 0,024 \\
\hline $4^{\circ}$ quarto $(>3,41)$ & $0,58(0,31-1,09)$ & 0,090 \\
\hline \multicolumn{3}{|l|}{ Situação vacinal } \\
\hline Atualizada & 1,00 & \\
\hline Não atualizada & $2,88(1,74-4,76)$ & $<0,001$ \\
\hline \multicolumn{3}{|l|}{ Uso de medicamentos } \\
\hline Não & 1,00 & \\
\hline Sim & $1,74(1,00-3,03)$ & 0,051 \\
\hline \multicolumn{3}{|l|}{ № de episódios de sibilância } \\
\hline 0 & 1,00 & \\
\hline 1 & $2,40(1,42-4,07)$ & 0,001 \\
\hline 2 & $1,29(0,61-2,72)$ & 0,509 \\
\hline$\geq 3$ & $2,24(1,20-4,19)$ & 0,011 \\
\hline Hospitalização prévia & 1,00 & \\
\hline Não & $0,79(0,45-1,40)$ & 0,419 \\
\hline Sim & & \\
\hline \multicolumn{3}{|l|}{ Hospitalização prévia por pneumonia } \\
\hline Não & 1,00 & \\
\hline Sim & $2,16(0,78-5,98)$ & 0,138 \\
\hline \multicolumn{3}{|l|}{ Outras doenças pulmonares§ } \\
\hline Não & 1,00 & \\
\hline Sim & $2,03(0,82-5,02)$ & 0,125 \\
\hline \multicolumn{3}{|l|}{ Refluxo } \\
\hline Não & 1,00 & \\
\hline Sim & $0,44(0,22-0,87)$ & 0,019 \\
\hline \multicolumn{3}{|l|}{ Doenças cardiovasculares } \\
\hline Não & 1,00 & \\
\hline Sim & $0,76(0,25-2,31)$ & 0,624 \\
\hline
\end{tabular}

$\S$ Excluindo-se pneumonia. 
Detectou-se colinearidade entre os pares de variáveis independentes especificados a seguir:

- paridade e morte de irmão menor de cinco anos de idade;

- tipo de aleitamento até 6 meses e tempo de aleitamento materno; e

- escore essencial da APS e escore geral da APS.

Com o propósito de direcionar os procedimentos de modelagem, optou-se por comparar os modelos intermediários contendo cada variável do par correlacionado; foram, então, selecionadas para permanecer aquelas variáveis que conferiram maior estabilidade ao modelo, quais sejam: paridade, tempo de aleitamento materno e escore essencial da APS.

Em relação à variável número de episódios de pneumonia, obtiveram-se medidas de associação aberrantes e intervalos de confiança amplos. Como para a definição do desfecho (variável dependente ou resposta) considerou-se o episódio atual de pneumonia - que determinou a hospitalização da criança - as associações aberrantes observadas deveram-se a uma forte correlação entre número de episódios de pneumonia e o desfecho em questão. Desse modo, não seria possível mensurar com precisão a magnitude da associação entre os episódios anteriores de pneumonia e o desfecho. Optou-se, portanto, por excluir esta variável dos modelos intermediários.

Os modelos finais, construídos a partir da análise multivariada por abordagem hierarquizada, são apresentados na Tabela 16. Na última fase de modelagem, permaneceram no modelo apenas as variáveis que apresentaram valores $p<0,05$ para o teste de Wald (em negrito).

Considerando, pois, os critérios adotados para a abordagem hierarquizada, o elenco de variáveis que permaneceu no modelo final foi composto por: "02 ou mais partos", "frequência à creche", "desnutrição, "situação vacinal não-atualizada", "uso de medicamentos nos últimos 30 dias", "histórico de sibilância (1 ou $\geq 3$ episódios)" (fatores de risco) e " $3^{\circ}$ terço da renda familiar", "intervalo interpartal de 48 meses ou mais", "ganho de peso de 10 kg ou mais na gestação", "excesso de peso", "escore essencial da APS maior que 3,17" e "refluxo gastroesofágico" (fatores de proteção). 


\section{Tabela 16 - Odds ratios com intervalos de confiança (95\%) e valores $p$ para os testes de Wald. Modelo final. Ribeirão Preto/SP, 2013.}

\begin{tabular}{|c|c|c|}
\hline Níveis hierárquicos & OR (IC95\%) & $\begin{array}{c}\text { Valor de } p \\
\text { (teste de Wald) }\end{array}$ \\
\hline \multicolumn{3}{|l|}{ 1․ - Variáveis Socioeconômicas } \\
\hline 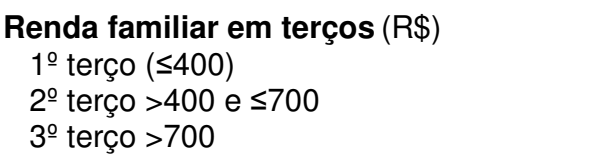 & $\begin{array}{c}1,00 \\
0,80(0,55-1,15) \\
0,68(0,47-0,98)\end{array}$ & $\begin{array}{l}0,226 \\
\mathbf{0 , 0 3 9}\end{array}$ \\
\hline \multicolumn{3}{|l|}{$2^{\circ}$ - Variáveis Reprodutivas e Ambientais ${ }^{\star}$} \\
\hline $\begin{array}{l}\text { Paridade ( } \mathrm{n} \text { de partos) } \\
\quad 1 \\
2 \\
\geq 3\end{array}$ & $\begin{array}{c}1,00 \\
4,60(2,18-9,72) \\
3,25(1,55-6,81)\end{array}$ & $\begin{array}{l}<0,001 \\
0,002\end{array}$ \\
\hline $\begin{array}{l}\text { Intervalo interpartal (meses) } \\
\quad<24 \\
24-47 \\
\geq 48\end{array}$ & $\begin{array}{c}1,00 \\
0,51(0,25-1,05) \\
0,28(0,14-0,56)\end{array}$ & $\begin{array}{c}0,067 \\
<0,001\end{array}$ \\
\hline $\begin{array}{l}\text { Ganho peso na gestação }(\mathrm{Kg}) \\
\quad<10 \\
\geq 10\end{array}$ & $\begin{array}{c}1,00 \\
0,68(0,47-0,97)\end{array}$ & 0,036 \\
\hline $\begin{array}{l}N^{\circ} \text { de pessoas no quarto com a criança } \\
0-1 \\
2 \\
\geq 3\end{array}$ & $\begin{array}{c}1,00 \\
1,48(0,97-2,25) \\
1,35(0,80-2,28)\end{array}$ & $\begin{array}{l}0,066 \\
0,261\end{array}$ \\
\hline $\begin{array}{l}\text { Frequência à creche } \\
\text { Não } \\
\text { Sim }\end{array}$ & $\begin{array}{c}1,00 \\
1,67(1,16-2,41)\end{array}$ & 0,006 \\
\hline $\begin{array}{l}\text { 3o- Variáveis nutricionais, relativas ao c } \\
\text { à morbidade }{ }^{\dagger}\end{array}$ & & \\
\hline $\begin{array}{l}\text { Escore-z de IMC para idade } \\
\text { Eutrófico } \\
\text { Desnutrido } \\
\text { Excesso }\end{array}$ & $\begin{array}{c}1,00 \\
2,53(1,06-6,05) \\
0,37(0,14-0,99)\end{array}$ & $\begin{array}{l}0,037 \\
0,049\end{array}$ \\
\hline $\begin{array}{l}\text { Escore Essencial da APS } \\
1^{\circ} \text { quarto }(\leq 2,79) \\
2^{\circ} \text { quarto }(>2,79 \text { e } \leq 3,17) \\
3^{\circ} \text { quarto }(>3,17 \text { e } \leq 3,41) \\
4^{\circ} \text { quarto }(>3,41)\end{array}$ & $\begin{array}{c}1,00 \\
0,98(0,57-1,68) \\
0,50(0,28-0,88) \\
0,57(0,32-0,99)\end{array}$ & $\begin{array}{l}0,951 \\
0,017 \\
\mathbf{0 , 0 4 9}\end{array}$ \\
\hline $\begin{array}{l}\text { Situação vacinal } \\
\text { Atualizada } \\
\text { Não atualizada }\end{array}$ & $\begin{array}{c}1,00 \\
2,81(1,76-4,49)\end{array}$ & $<0,001$ \\
\hline $\begin{array}{l}\text { Uso de medicamentos } \\
\text { Não } \\
\text { Sim }\end{array}$ & $\begin{array}{c}1,00 \\
1,67(1,00-2,78)\end{array}$ & 0,049 \\
\hline $\begin{array}{l}\text { № de episódios de sibilância } \\
0 \\
1 \\
2 \\
\geq 3\end{array}$ & $\begin{array}{c}1,00 \\
2,13(1,31-3,47) \\
1,04(0,53-2,06) \\
2,37(1,35-4,15)\end{array}$ & $\begin{array}{l}\mathbf{0 , 0 0 2} \\
0,903 \\
\mathbf{0 , 0 0 3}\end{array}$ \\
\hline $\begin{array}{l}\text { Refluxo } \\
\text { Não } \\
\text { Sim }\end{array}$ & $\begin{array}{c}1,00 \\
0,55(0,31-0,99)\end{array}$ & 0,048 \\
\hline
\end{tabular}

Ajustadas para renda familiar.

${ }^{\dagger}$ Ajustadas para as variáveis dos níveis 1 e 2 . 


\section{DISCUSSÃO}


O presente estudo identificou os fatores de risco e proteção para a hospitalização de crianças menores de cinco anos de idade por pneumonia, no município de Ribeirão Preto - SP. Obteve-se um modelo explicativo para o desfecho, o qual contemplou as relações hierárquicas existentes. Nesse modelo, o nível socioeconômico, as características reprodutivas maternas, o ambiente, o estado nutricional, a situação vacinal, o uso de medicamentos, a qualidade de APS e o histórico de morbidade configuraram-se como preditores da hospitalização por pneumonia, na população estudada.

Tal modelo explicativo foi obtido por meio da abordagem hierarquizada, que considera as relações hierárquicas existentes entre as exposições e o desfecho, durante as análises. Segundo Victora et al. (1997), desconsiderar tais relações no momento das análises poderia enfraquecer a associação entre as variáveis distais e o desfecho, à medida que as mesmas poderiam ser ajustadas por variáveis intervenientes, pertencentes a níveis mais proximais. De acordo com as recomendações dos referidos autores, durante o planejamento deste estudo construiu-se um modelo conceitual da hospitalização por pneumonia em menores de cinco anos de idade, considerando-se os determinantes biológicos e sociais envolvidos. Esse modelo conceitual foi utilizado para estruturar a modelagem estatística. Seguindo tal proposta, os modelos de cada etapa das análises multivariadas (modelos intermediários e modelos finais) foram construídos adicionando-se as variáveis de cada nível hierárquico simultaneamente, iniciando-se pelo primeiro nível. As estimativas de efeito foram obtidas no momento em que as variáveis de cada nível compuseram o modelo. Desse modo, os OR das variáveis do nível 1 foram aqueles obtidos no modelo que continha apenas as variáveis deste nível. Ao compor o modelo nível 1 + nível 2, obteve-se o efeito de cada variável do nível 2 , ajustado para as variáveis no mesmo nível e do nível 1, e assim, sucessivamente, até o último nível (variáveis mais proximais ao desfecho) cujas medidas de associação foram ajustadas para as variáveis do mesmo nível e também para aquelas pertencentes aos níveis precedentes.

Entende-se que a evolução dos conceitos saúde e doença demanda a utilização de métodos estatísticos condizentes, que considerem a história natural dos agravos e permitam o entendimento de saúde e doença como produção social (BRASIL, 2010b). A abordagem hierarquizada atende essa necessidade, na medida que permite incluir adequadamente no modelo explicativo variáveis como as 
socioeconômicas e ambientais, importantes na história natural das doenças infecciosas infantis (especialmente em países em desenvolvimento), que raramente causam a doença diretamente, mas que contribuem para a ocorrência de uma série de condições que, em conjunto, contribuem para a gênese da doença ou agravo à saúde (VICTORA et al., 1997). Ademais, tal abordagem pressupõe uma base conceitual de inter-relação entre as variáveis explanatórias para a compreensão do fenômeno, ao invés de centrar-se apenas em associações estatísticas.

Os casos e controles do presente estudo foram emparelhados por sexo e faixas etárias, tendo em vista a necessidade do emparelhamento de frequência. Não se tratando de emparelhamento fino, como seria, por exemplo, o emparelhamento por vizinhança, utilizou-se a análise de regressão logística não condicional. (HOSMER; LEMESHOW, 1989). Ressalta-se, ainda, que não houve indício de linearidade no efeito de variáveis com mais de duas categorias, não havendo, portanto, indicação para a utilização de testes estatísticos de tendência linear.

A literatura tem descrito o papel dos fatores socioeconômicos na ocorrência e, especialmente, na complicação da pneumonia infantil (CAETANO et al., 2002; CÉSAR et al., 1997; MACEDO et al., 2007; NASCIMENTO et al., 2004; VICTORA et al., 1994). No presente estudo, identificou-se que a renda familiar superior a $R \$ 700,00$ foi responsável por uma redução de $32 \%$ na chance de hospitalização $(O R=0,68$; IC95\%=0,47-0,98).

Pinto, Maggi e Alves (2004), por meio de um estudo transversal conduzido no nordeste brasileiro, identificaram um risco quase duas vezes maior $(R P=1,99)$ de comprometimento pleural entre as crianças de 3 a 59 meses hospitalizadas por pneumonia grave que possuíam baixa renda familiar. Há que se considerar, contudo, que estes autores investigaram apenas fatores socioambientais, por meio de análises univariadas. Desse modo, as estimativas não foram depuradas para o efeito de confusão e as inter-relações entre fatores biológicos e sociais não foram consideradas.

Utilizando análise multivariada por abordagem hierarquizada, Geib et al. (2007) encontraram associação estatística entre os estratos C/D/E da classe econômica $(R R=4,58)$ e a hospitalização por pneumonia nos primeiros seis meses de vida, em crianças pertencentes a uma coorte de nascidos vivos em Passo Fundo, na região sul do Brasil. 
Também por meio da abordagem hierarquizada, outro estudo (César et al.,1997) realizado em uma coorte de nascidos vivos em Pelotas, Sul do Brasil, identificou a influência da classe social na hospitalização por pneumonia em menores de um ano de idade, com OR de 1,78 para a categoria proletariado típico e de 3,50 para a categoria subproletariado.

O efeito da renda familiar ou da classe socioeconômica na hospitalização de crianças pequenas por pneumonia é sabidamente mediado por questões como escolaridade parental, qualidade do domicílio e acesso a recursos. No entanto, é possível que uma parte dessa contribuição esteja diretamente associada ao desfecho, visto que em algumas situações ocorre a chamada internação social, também considerada um viés de admissão (GARBINATO et al., 2007). Ou seja, em casos de crianças doentes cujas famílias não dispõem de condições adequadas ao tratamento domiciliar é realizada a hospitalização da mesma, ainda que o quadro clínico não indique tal conduta (VICTORA et al., 1999).

O Índice Paulista de Responsabilidade Social (IPRS) - desenvolvido pela Fundação Sistema Estadual de Análise de Dados (SEADE) - tem sido utilizado para análise dos aspectos sociais dos municípios paulistas, com a finalidade de caracterizá-los quanto ao desenvolvimento humano a partir das dimensões renda, escolaridade e longevidade. A região administrativa de Ribeirão Preto ocupa a segunda posição no estado em termos de longevidade, a quinta posição em termos de riqueza e a $13^{\underline{a}}$ posição em termos de escolaridade - sua principal fragilidade. A dimensão com maior contribuição para a melhora do índice da região foi a riqueza com exceção de um município, todos os demais evoluíram em relação às avaliações anteriores (GOVERNO DO ESTADO DE SÃO PAULO, 2012). A importância do poder aquisitivo na região reflete-se na associação encontrada em nosso estudo, em relação à renda familiar e o desfecho. Os municípios da referida região que referenciaram as crianças para os hospitais participantes deste estudo vem experimentando uma evolução do nível econômico da população, com potencial impacto nas condições de vida e no acesso a recursos, ocasionando, desse modo, um efeito protetor para a hospitalização das crianças por pneumonia.

A referida evolução, contudo, não tem sido acompanhada de uma melhoria na escolaridade da população, como seria esperado. Nas questões relacionadas à saúde infantil, a escolaridade dos pais desempenha importante papel no cuidado da criança (CAETANO et al., 2002; CÉSAR et al., 1997; MACEDO et al., 2007; NASCIMENTO et 
al., 2004; VICTORA et al., 1994), pelo conhecimento de medidas preventivas e reconhecimento da necessidade de busca do serviço de saúde, dentre outros aspectos. O grau de escolaridade pode influir na determinação do crescimento da criança, por estar diretamente relacionado com uma melhor compreensão das práticas de cuidados infantis (ROMANI; LIRA, 2004), estando associado à mortalidade infantil, às internações hospitalares e aos indicadores antropométricos de crianças com até 20 meses de idade (VICTORA, 1992). Estudo de Barros et al. (2010) aponta que crianças de famílias com dificuldades socioeconômicas e baixa escolaridade, quando ficam doentes, têm menor acesso aos serviços de saúde e, como consequência, podem apresentar maiores taxas de mortalidade e maior risco de terem problemas nutricionais.

No entanto, Rudan et al. (2008), em boletim da OMS que trata da epidemiologia e etiologia da pneumonia, apontam que a baixa escolaridade parental seria um possível fator de risco para a doença, porém a evidência disponível é inconsistente e pode variar de acordo com o contexto. Buscando caracterizar o contexto da população estudada, na fase descritiva do presente estudo foi possível identificar que quase $92 \%$ das mães entrevistadas tinham mais de 20 anos de idade, porém 35\% possuíam entre 5 e 8 anos de escolaridade - portanto, não concluíram ou sequer iniciaram o ensino médio. Entretanto, no que pesem estas informações provenientes da fase descritiva, no presente estudo não foram encontradas associações entre a escolaridade parental e a hospitalização por pneumonia. Embora não se disponham de informações sobre a idade paterna, a proporção de pais com 5 a 8 anos de escolaridade é ainda maior, ultrapassando 41\%. Essas proporções, contudo, não diferiram entre casos e controles. Assim, a escolaridade parental, embora não condizente com a prosperidade econômica da região, não foi determinante da hospitalização por pneumonia, no contexto da população estudada.

Dentre as características reprodutivas maternas investigadas no presente estudo, o número de partos $\geq 2$ representou um expressivo aumento no risco de hospitalização das crianças por pneumonia (categoria 2 partos: OR=4,60, $\mathrm{IC} 95 \%=2,18-9,72$; categoria $\geq 3$ partos: OR=3,25, IC95\%=1,55-6,81), enquanto 0 intervalo interpartal $\geq 48$ meses e o ganho de peso na gestação de $10 \mathrm{Kg}$ ou mais apresentaram efeito protetor para o desfecho (OR=0,28, IC95\%=0,14-0,56 e $\mathrm{OR}=0,68, \mathrm{IC} 95 \%=0,47-0,97$, respectivamente). 
A partir de uma coorte de nascidos vivos em Pelotas, César et al. (1997) investigaram a influência de fatores socioeconômicos e gestacionais na hospitalização por pneumonia em menores de um ano de idade. Os autores identificaram, na análise hierarquizada, associação de elevada magnitude entre a paridade de 3 ou mais filhos $(\mathrm{OR}=2,86)$ e o desfecho. Quanto ao intervalo interpartal, a associação identificada à análise univariada, relativa à categoria $<24$ meses $(O R=2,02)$, perdeu significância estatística durante a modelagem final.

O papel das variáveis reprodutivas maternas sobre o desfecho em questão tem sido descrito como sendo, em grande parte, mediado pelas variáveis perinatais (DEWEY; COHEN, 2007; GIRMA; BERHANE, 2011; GRIBBLE; MURRAY; MENOTTI, 2009; VICTORA et al., 1999). Ressalta-se, no entanto, que no presente estudo as associações identificadas em relação às variáveis perinatais e o desfecho perderam significância estatística à análise multivariada (modelos intermediários), ao serem ajustadas para as variáveis dos níveis 1 e 2 (variáveis sociodemográficas, reprodutivas maternas e ambientais).

Apesar de que o número de filhos pode contribuir para uma maior experiência materna no cuidado da criança, um número elevado poderia dificultar esse cuidado, especialmente em relação às crianças menores, que demandam maior dedicação. Um estudo de coorte (MAHON et al., 2007), realizado na Dinamarca, encontrou associação entre a multiparidade (2 ou mais partos) e a hospitalização por doença pneumocócica infantil $(R R=3,87)$, significativa apenas para a faixa etária de 0 a 6 meses. Além das dificuldades maternas e familiares em cuidar de mais de uma criança, outra hipótese aventada pelos autores seria o contato com irmãos mais velhos, que frequentam ambientes extradomiciliares e, consequentemente, possuem uma maior exposição a patógenos. Como na Dinamarca é comum as crianças não frequentarem escolas e creches nos primeiros 6 meses de vida, as crianças dessa faixa etária que possuem irmãos estariam em maior risco de exposição ao $S$. pneumoniae do que aquelas que não possuem. Após os 6 meses de idade, além de apresentar uma maior maturidade imunológica, a maioria das crianças terá contato com outras crianças, então o fato de possuir irmãos deixaria de exercer efeito sobre o desfecho. Embora o estudo tenha sido realizado em um país com características diferentes e o desfecho seja hospitalização por doença pneumocócica, é possível uma comparação dos resultados, visto que a população do estudo dinamarquês também era atendida por um sistema de saúde universal e a pneumonia fora responsável por 
$81,9 \%$ das hospitalizações por doença pneumocócica entre os participantes do estudo. Na região que integra o presente estudo também é comum o ingresso na creche ou escola após os 4 a 6 primeiros meses de vida, período em que se encerra a licença-maternidade.

Apesar do exposto, os resultados do presente estudo sugerem que o papel da multiparidade sobre o desfecho não se deve apenas a uma dificuldade no cuidado (pelo maior número de filhos) ou mesmo por uma maior exposição a patógenos (pelo contato com outras crianças), visto que, nos modelos multivariados, não se encontraram associações em relação às variáveis ordem de nascimento e número adicional de crianças no domicílio. Se o efeito da multiparidade ocorresse prioritariamente em decorrência desses fatores, seria provável que ser primeiro filho ou a única criança na casa fosse fator de proteção para o desfecho. As associações identificadas durante a etapa de análises univariadas perderam significância quando tais variáveis foram ajustadas para renda familiar, variáveis reprodutivas e ambientais.

Em relação a outros mecanismos que podem elucidar o efeito da multiparidade sobre o desfecho, tem sido destacado, na literatura, que as multíparas buscam menos os serviços de saúde na APS e possuem menor acesso a suporte social do que as primíparas (LAGERBERG; MAGNUSSON, 2013; MELO et al., 2013), o que poderia retardar o acesso da criança com pneumonia ao tratamento precoce adequado, resultando em maior risco de hospitalização.

Os achados do presente estudo, referentes ao intervalo interpartal, diferem de outros estudos brasileiros, nos quais a variável perdeu significância estatística nas análises multivariadas ou sequer foi significativa nas análises univariadas. Dois desses estudos têm como desfecho a hospitalização por pneumonia (CÉSAR et al., 1997; VICTORA et al., 1994) e um tem como desfecho a ocorrência da pneumonia, porém a seleção dos casos foi realizada em um ambulatório hospitalar (FONSECA et al., 1996). Tais estudos também utilizaram a abordagem hierarquizada para a análise multivariada, sendo que a variável em questão foi ajustada para variáveis muito semelhantes às do presente estudo. É pouco provável, portanto, que as divergências observadas em relação ao intervalo interpartal tenham ocorrido mediante diferenças metodológicas dos estudos, sendo plausível que o efeito dessa variável sobre o desfecho possa estar relacionado a características específicas da população estudada. 
No presente estudo, a informação do peso adquirido durante a gestação foi referida pelas mães, pois as mesmas não estavam de posse do cartão da gestante com registro dos pesos. Tal informação é passível, portanto, do viés de recordação. Entretanto, é improvável que as mães dos casos tenham recordado o peso de forma diferente das mães dos controles.

O ganho de peso na gestação tem sido considerado como determinante do peso ao nascer, à medida que é um marcador do crescimento fetal (KRAMER, 1987, 2002; NEUFELD et al., 2004; THAME et al., 2004; ZADIK, 2003). Seu efeito sobre a hospitalização de crianças por pneumonia, portanto, seria mediado pelo peso ao nascer que, por sua vez, predisporia as crianças a um maior risco, por meio do comprometimento da resposta imune e da função respiratória (no caso de crianças com baixo peso ao nascer). Além disso, bebês que nasceram com baixo peso tendem a ser amamentados por menor tempo e possuir déficit nutricional (VICTORA et al., 1999).

Nos indicadores de saúde infantil, o peso da criança ao nascer é abordado como o maior determinante das chances de um recém-nascido sobreviver e de ter um crescimento e desenvolvimento adequados (ROMANI; LIRA, 2004). No Brasil, a prevalência de baixo peso ao nascer tem permanecido no patamar de $8 \%$, desde o ano 2000 (VICTORA et al., 2011) . Na população do presente estudo, todavia, a variável peso ao nascer perdeu seu efeito sobre o desfecho, à análise multivariada. Questiona-se, portanto, o mecanismo de ação do ganho de peso na gestação sobre a hospitalização por pneumonia, na população estudada.

Uma hipótese seria que o crescimento fetal fora garantido à custa do estado nutricional materno, conforme sugerido por Merchant, Martorell e Haas (1990) e Millman e Cooksey (1987), em estudos desenvolvidos na Guatemala e na Malásia, respectivamente. Desse modo, a criança poderia nascer com peso adequado, mesmo que a mãe tivesse um ganho de peso insuficiente durante a gestação. No entanto, os fatores que teriam ocasionado o baixo ganho de peso materno durante a gestação como a alimentação inadequada - continuariam a operar no binômio, impactando nas condições de saúde da criança e possível hospitalização por pneumonia.

Cesar et al. (1997) encontraram resultados semelhantes aos do presente estudo - associação relativa ao ganho de peso na gestação, porém ausência de associação em relação ao peso ao nascer - e aventaram a possibilidade de outros mecanismos que pudessem explicar o efeito do ganho de peso na gestação sobre a 
hospitalização de crianças por pneumonia, como o desenvolvimento mais adequado do sistema imunológico nas crianças cujas mães apresentam melhor estado nutricional - que estariam mais propensas a realizar escolhas alimentares adequadas para seu filho, contribuindo para uma melhor resistência a patógenos.

Não obstante, é ainda possível que a variável peso ao nascer não tenha permanecido nos modelos hierarquizados devido à qualidade da informação, obtida em parte pela carteira de vacinação e em parte por referência da mãe ou entrevistado. Tal fato pode ter ocasionado vício de aferição ou erros de classificação da exposição, que potencialmente poderiam contribuir para a exclusão da variável dos modelos, devido a um valor $p$ superior ao adotado. Entretanto, novamente ressaltamos que é pouco provável que as mães dos casos tenham recordado o peso ao nascer de forma diferente das mães dos controles.

A relação entre paridade, intervalo interpartal e ganho de peso na gestação é reconhecida e descrita na literatura. A multiparidade e o curto intervalo interpartal espoliam o organismo materno em relação à reserva de nutrientes e influenciam o ganho de peso na gestação, podendo resultar em parto pré-termo e baixo peso ao nascer (DEWEY; COHEN, 2007; GIRMA; BERHANE, 2011; GRIBBLE; MURRAY; MENOTTI, 2009). Na literatura, há evidências de que tais fatores podem também exercer seus efeitos a longo prazo, ao influenciar o estado nutricional durante a infância e, desse modo, predispor as crianças a condições associadas à deficiência nutricional - como as doenças infecciosas.

Um estudo com 3853 crianças menores de cinco anos de idade, em El Salvador, evidenciou a relação entre o intervalo interpartal e a desnutrição infantil. Por meio da regressão logística multivariada, encontrou-se que o intervalo interpartal $\leq 35$ meses foi responsável por um incremento no risco de desnutrição crônica, caracterizada pelo déficit de altura para idade $(<24$ meses: $O R=1,52 ; 25-36$ meses: OR=1,30) (GRIBBLE; MURRAY; MENOTTI, 2009).

Rutstein (2005), por meio de um estudo transversal realizado em 14 países em desenvolvimento, identificou que um curto intervalo interpartal pode comprometer o estado nutricional e contribuir para a mortalidade de crianças ao longo dos cinco primeiros anos de vida. Segundo os achados do estudo, as crianças nascidas após um intervalo interpartal $<18$ meses possuem uma chance $43 \%$ maior de apresentar déficit de altura e $40 \%$ maior de possuir baixo peso para idade. Em relação à 
mortalidade, o intervalo interpartal $\geq 48$ meses diminui em cerca de $20 \%$ o risco de morte nos primeiros cinco anos de vida.

Outro mecanismo possível para explicar a associação entre variáveis reprodutivas maternas e hospitalização do filho por pneumonia seria o manejo do aleitamento materno. Embora haja na literatura referência a uma maior experiência por parte das multíparas, que estariam mais propensas a articular o manejo do aleitamento materno exclusivo com as demais tarefas domésticas (KHANAL; SAUER; ZHAO, 2013), outros autores afirmam que a multiparidade espolia o organismo materno quanto à reserva de nutrientes - especialmente se associada ao curto intervalo interpartal - manifestando-se, muitas vezes, por um ganho de peso inadequado durante a gestação (DEWEY; COHEN, 2007; GIRMA; BERHANE, 2011; GRIBBLE; MURRAY; MENOTTI, 2009). Ainda que seja improvável que a má nutrição materna afete diretamente a produção láctea, em termos de quantidade, é questionado se a deficiência de certos micronutrientes poderia afetar a qualidade nutricional do leite materno. De qualquer modo, é também possível que a percepção materna relativa às questões nutricionais poderia afetar as escolhas alimentares que a mãe faz para seu filho. Ou seja, se a mãe ganhou pouco peso na gestação por escolhas alimentares inadequadas, é possível que ela reproduza esse padrão em relação ao filho; ou ainda, percebendo-se desnutrida e julgando-se incapaz de produzir leite suficiente, a mãe pode iniciar precocemente a alimentação complementar da criança ou introduzir o leite artificial, ocasionando o desmame precoce. Tais condutas podem contribuir para uma deficiência nutricional e imunológica da criança, especialmente em relação à capacidade de defesa contra patógenos causadores da diarreia e das infecções respiratórias que, por sua vez, espoliam ainda mais o organismo (DEWEY; COHEN, 2007; GRIBBLE; MURRAY; MENOTTI, 2009).

Os achados do presente estudo sugerem que os fatores reprodutivos maternos operem, em parte, de modo independente dos fatores perinatais, no risco de hospitalização por pneumonia. Mesmo diante de condições de nascimento adversas, tais como parto pré-termo e baixo peso ao nascer, a capacidade de autocuidado materno teria o potencial de impactar na capacidade de cuidar da criança, conforme sugerido por Boerma e Bicego (1992). Os pais, especialmente as mães, representam figuras de referência na infância para segurança, adaptação aos eventos da vida e 
suprimento das necessidades das crianças, tais como a alimentação (BRITTO; ULKUER, 2012).

Boerma e Bicego (1992), a partir de dados demográficos e de saúde de 17 países, desenvolveram um estudo transversal que identificou que os fatores pré-natais desempenhavam um papel preponderante em relação aos fatores pós-natais, na mortalidade de crianças menores de cinco anos de idade. Uma mulher com baixa paridade, adequado intervalo interpartal e ganho de peso na gestação provavelmente teria o perfil de aderir às boas práticas de saúde e realizar acompanhamento nos serviços de saúde. Estaria, portanto, mais propensa a aderir às recomendações relativas ao cuidado da criança e à puericultura.

Em relação às variáveis ambientais, a frequência à creche foi a única variável do bloco que permaneceu no modelo final do presente estudo, sendo responsável por um aumento de $67 \%$ na chance de hospitalização por pneumonia $(O R=1,67$, IC95\%=1,16-2,41).

Em um estudo caso-controle que utilizou a abordagem hierarquizada (VICTORA et al.,1994), realizado em Porto Alegre, no Sul do Brasil, a frequência à creche foi o principal fator de risco para a hospitalização de crianças menores de dois anos de idade por pneumonia. $O$ fato de frequentar a creche contribuiu para uma chance quase doze vezes maior $(\mathrm{OR}=11,75)$ de hospitalização.

Outro estudo caso-controle (PATRIA et al., 2013), desenvolvido na Itália, cujo objetivo foi analisar as características de crianças com pneumonia de repetição, em comparação às crianças que nunca tiveram pneumonia, encontrou diferenças altamente significativas $(p<0,001)$ em relação à idade de ingresso na creche, sendo maior a proporção de casos naquelas que ingressaram antes de 24 meses de idade.

Um estudo de coorte com 2809 crianças alemãs com até 6 anos de idade também identificou que aquelas que ingressaram na creche com até dois anos de idade eram mais propensas a desenvolver pneumonia e outras doenças infecciosas durante os primeiros dois a três anos de vida, sendo o efeito ainda mais pronunciado entre as crianças que ingressaram na creche no primeiro ano de vida e entre as crianças sem irmãos (ZUTAVERN et al., 2007).

A partir de uma revisão sistemática da literatura envolvendo estudos de coorte e ensaios clínicos, Sangrador, Sánchez e Martín (2007) encontraram uma evidência consistente no tempo e em diferentes contextos de que a frequência à creche está relacionada a um maior risco de desenvolver pneumonia $(R R=1,70)$. 
O papel da frequência à creche no incremento da chance de ser hospitalizado por pneumonia pode estar relacionado à aglomeração de crianças nessas instituições e consequente transmissão de patógenos, por meio de partículas respiratórias ou de compartilhamento de objetos que são levados à boca (DENNY et al., 1986; FLEMING et at., 1987; VICTORA et al,1994). As crianças mais novas estariam mais propensas a contrair a doença, devido à imaturidade imunológica. Além disso, a permanente exposição aos patógenos poderia causar episódios de repetição, contribuindo para o agravamento e necessidade de hospitalização (PATRIA et al, 2013). No presente estudo não se considerou a idade de ingresso na creche, apenas a frequência atual. Por conseguinte, considerações sobre o efeito desta variável sobre o desfecho carecem de complementação.

Cabe, ainda, considerar a hipótese de que a frequência à creche seja um marcador de famílias com baixo nível socioeconômico ou de famílias nas quais a mãe trabalha fora (LU et al., 2004). Entretanto, é demonstrado que o perfil das crianças que frequentam a creche e suas famílias pode ser diversificado em função do tempo e do contexto socioeconômico e geográfico (RUDAN et al., 2008; ZUTAVERN et al., 2007). Em alguns locais, a frequência à creche está associada a um maior nível de escolaridade paterna (ZUTAVERN et al., 2007). As diretrizes brasileiras enfatizam que o atendimento às crianças de 0 a 6 anos em instituições de educação infantil é gratuito e dever do Estado, um direito da criança e opção da família (BRASIL, 2006). Tal proposta se coloca como universal, isto é, para todas as crianças, independente de sua origem social.

Embora haja evidência da associação entre frequência à creche e ocorrência de doenças infecciosas, em crianças pequenas, cabe ressaltar os benefícios em termos de estimulação cognitiva e socialização que essas instituições oferecem às crianças. Além disso, segundo a perspectiva higienista, é possível que a exposição precoce a agentes infecciosos forneça certa proteção contra algumas doenças de base (como as doenças atópicas, por exemplo) ao longo da vida, por intermédio da resposta imunológica desencadeada (HAMILTON, 1998; LU et al., 2004; ZUTAVERN et al., 2007).

Amorim, Yazlle e Rossetti-Ferreira (2001) destacam uma preocupação com a disseminação de uma visão depreciativa da creche, a partir de estudos que identificam associações entre frequência à creche e doenças infecciosas. Segundo os autores, o processo saúde-doença é complexo e deve ser compreendido dentro do decurso do 
desenvolvimento da criança, que é estimulado nesses espaços. Problematiza-se, inclusive, a questão da maturidade imunológica: enquanto a imaturidade do sistema imune seria responsável pela maior vulnerabilidade da criança pequena à transmissão de doenças infecciosas, o processo de amadurecimento do mesmo sistema estaria intimamente relacionado às interações que a criança estabelece com as pessoas e o ambiente. No cenário da creche, são destacados que os campos interativos estabelecidos representam não apenas um maior risco de contaminação, mas propiciam o desenvolvimento da criança em termos cognitivos, sociais e imunológicos. Os autores ressaltam que esse novo olhar sobre outros elementos do processo saúdedoença nas creches possibilita a atuação nas ações interativas que ocorrem nesses cenários, com vistas a potencializar o efeito da frequência à creche como um preditor de saúde, ao invés de doença.

Os resultados do presente estudo sugerem a importância de se diminuir o nível de exposição das crianças à contaminação nesses espaços, por meio da redução do número de alunos por sala, do incremento das medidas de higiene e da conscientização dos educadores quanto à prevenção de doenças transmissíveis. Ainda, que todos os processos de transição (início de nova turma, mudança de educadora, entre outros) sejam planejados de modo a evitar o estresse da criança e consequente imunossupressão (EVANS; CLOW; HUCKLEBRIDGE, 1997). É de extrema relevância o estabelecimento de uma relação próxima entre famílias e creches, não somente para a inserção da criança no ambiente de educação infantil, mas também pela possibilidade de garantir a continuidade do aleitamento materno, mesmo na creche, contribuindo para a redução da incidência e gravidade das doenças infecciosas e adequada nutrição do lactente (AMORIM, YAZLLE E ROSSETTIFERREIRA, 2001). Cabe destacar, também, a importância da capacitação dos educadores na identificação precoce dos sinais das doenças infecciosas e da necessidade de busca do serviço de saúde. É desejável, inclusive, que a instituição possua uma sistemática de encaminhamento da criança à unidade de saúde, quando necessário.

No presente estudo, esperava-se que a densidade domiciliar também fosse significativa para a hospitalização por pneumonia, já que a aglomeração é um dos principais mecanismos do efeito da frequência à creche sobre o desfecho. Contudo, as variáveis número de pessoas na casa, número adicional de crianças no domicílio e número de pessoas no quarto com a criança perderam significância estatística ao 
comporem os modelos multivariados. É plausível que o efeito da aglomeração sobre o desfecho seja diferente quando se trata de aglomeração domiciliar ou institucional. Elevada densidade domiciliar está associada com condições sócio-sanitárias ruins, baixo nível educacional e baixa renda que, por sua vez, estão associados com infecções na infância (VICTORA et al., 1997). Contudo, estas variáveis (exceto renda familiar) não permaneceram nos modelos, talvez porque outras variáveis possuíam maior força de associação com o desfecho.

As variáveis ambientais relativas ao hábito de fumar no domicílio e ao tipo de forno/fogão - determinantes da presença de fumaça intradomiciliar - não apresentaram associações significativas em nenhuma das etapas de análises. Tais resultados corroboram com os achados de Victora et al. (1994) que justificam que a maioria dos estudos que encontraram associação entre fumaça intradomiciliar e hospitalização por pneumonia são provenientes de áreas mais frias, nas quais a ventilação da casa estaria prejudicada e onde seria comum a queima de combustíveis de biomassa dentro do domicílio. De fato, Ribeirão Preto é um município com temperaturas elevadas a maior parte do ano, o que poderia contribuir para a manutenção de portas e janelas das casas abertas, além de um maior tempo dispendido fora do domicílio, com atividades ao ar livre. Ainda, o uso de forno ou fogão com queima de combustível foi limitado na população do estudo e, nos poucos casos em que foi utilizado, deveria estar localizado na parte externa da casa.

Outra hipótese é que a poluição intradomiciliar estaria mais associada a outras ITRI, como bronquite e bronquiolite (VICTORA et al ,1994). Com efeito, os estudos cujo desfecho foi IRA, e não especificamente pneumonia, identificaram mais frequentemente a fumaça intradomiciliar (proveniente do tabaco e da queima de combustíveis de biomassa) como fator de risco (BROOR et al., 2001; JONES et al., 2011; LEMKE et al., 2013; MACEDO et al., 2007). Diante da proposta de investigação de fatores associados às internações por pneumonias (desfecho), estas últimas classificadas segundo rigoroso critério diagnóstico de casos - pneumonia confirmada por radiografia de tórax - outras afecções do trato respiratório não foram incluídas no presente estudo.

Em relação às variáveis nutricionais, o escore-z de IMC para idade permaneceu no modelo final do presente estudo. De acordo com a classificação do estado nutricional, a partir desse indicador (eutróficos, desnutridos e com excesso de peso), as crianças desnutridas apresentaram uma chance duas vezes maior de serem 
hospitalizadas por pneumonia $(\mathrm{OR}=2,53$; $I C=1,06-6,05)$ enquanto aquelas com excesso de peso apresentam uma redução de $63 \%$ nessa chance $(O R=0,37$; IC=0,140,99), quando comparadas com as crianças eutróficas.

A desnutrição é apontada como um dos fatores de risco para os quais existe evidência científica consistente, em relação ao seu papel na ocorrência e gravidade da pneumonia (RUDAN et al., 2008).

A desnutrição infantil é uma das principais causas de mortalidade em menores de cinco anos de idade. No período de 1974 a 2007, o Brasil reduziu o déficit de altura para idade de 37,1\% para 7,1\%; apesar desse decréscimo, o país ainda apresenta déficit de altura três vezes superior ao encontrado em populações bem nutridas (VICTORA et al., 2011). As causas macroestruturais da desnutrição estão bem documentadas na literatura, como o papel da pobreza, privação e fatores socioeconômicos correlacionados (BLACK et al., 2008; MONTEIRO et al., 2009). No nível microestrutural, as investigações apontam sua complexidade, incluindo os comportamentos alimentares do cuidador, a qualidade do ambiente onde a criança vive, as interações cuidador-criança e a alimentação responsiva (WALKER et al., 2011; WORLD HEALTH ORGANIZATION, 2002).

No Brasil, estimativas de efeito da desnutrição com magnitudes semelhantes às do presente estudo foram obtidas por autores de diferentes regiões, utilizando-se de diferentes delineamentos. Outro estudo caso-controle de base hospitalar conduzido em Taubaté, na região sudeste, identificou o escore-z de peso para idade $\leq 0$ como fator de risco $(\mathrm{OR}=1,98)$ para internação por pneumonia, em menores de cinco anos de idade (NASCIMENTO et al., 2004). Um estudo transversal, desenvolvido na Bahia, identificou uma chance 2 vezes maior $(O R=2,0)$ de internação por pneumonia entre crianças mal nutridas (NASCIMENTO-CARVALHO et al., 2002). Um estudo de coorte em Pelotas, na região sul, identificou associações entre hospitalização por pneumonia e escore-z de peso para idade (RR de até 2,31 para a categoria $\geq-2$ e $\leq-1,0$ ) e escore- $z$ de altura para idade (RR de até 2,49 para a categoria $\geq-2$ e $\leq-1,0$ ) (VICTORA et al., 1990).

No Uruguai, Hortal et al. (1994), em estudo caso-controle, encontraram associação significativa entre severidade dos casos de pneumonia em menores de cinco anos de idade e estado nutricional, com magnitude do $\mathrm{OR}=2,76$ para o percentil $<5$. 
Na Índia, um estudo caso-controle desenvolvido por Broor et al. (2001) apontou a desnutrição grave como fator de risco $(\mathrm{OR}=1,85)$ para a ITRI grave, em crianças menores de cinco anos de idade. No mesmo país, Ramachandran e colaboradores (2012), por meio de estudo transversal, identificaram efeito do escore-z de peso para idade <-2 sobre a mortalidade por pneumonia $(\mathrm{OR}=1,12)$.

$\mathrm{Na}$ Nigéria, África, estudo transversal apontou a desnutrição como fator associado à pneumonia com desfecho fatal, em menores de cinco anos $(p=0,003)$ (JOHNSON et al., 2008). Outro estudo transversal, também conduzido na África, identificou associação entre desnutrição e pneumonia severa $(O R=2,42)$ em crianças menores de dois anos, internadas em Moçambique (SIGAÚQUE et al., 2009).

Em Israel, os resultados do estudo caso-controle desenvolvido por Coles et al. (2005) assinalam que a variável nutricional associada à hospitalização por pneumonia, em menores de cinco anos, foi o déficit de estatura $(\mathrm{OR}=2,22)$.

Embora os estudos supracitados sejam provenientes de países em desenvolvimento, há evidências de que o efeito do déficit nutricional sobre a ocorrência e gravidade da pneumonia não se restringe a esses contextos. Metanálise conduzida a partir de estudos provenientes de países desenvolvidos e em desenvolvimento, que investigaram fatores de risco para a pneumonia grave em menores de cinco anos de idade, revelou evidências de associação do desfecho com escore-z de peso para idade <-2 (OR=4,47) (JACKSON et al., 2013).

Grande parte dos estudos apresentados utilizou a variável escore-z de peso para idade como indicador do estado nutricional. Tal indicador é sensível a mudanças recentes, inclusive em função de episódios de doenças agudas. Questiona-se, portanto, seu uso para investigar o efeito do déficit nutricional na ocorrência e agravamento da pneumonia, já que a criança pode perder peso devido à inapetência decorrida da própria doença. Além disso, este indicador não considera a adequação do peso em função da altura da criança. O escore-z de altura para idade reflete o prejuízo no crescimento em função da desnutrição crônica ou de episódios recorrentes de doenças. O escore-z de peso para altura é utilizado para avaliar a desnutrição aguda em função de doença ou privação de alimentos, bem como o sobrepeso e a obesidade. O escore-z de IMC para idade é especialmente utilizado para monitorar a crescente epidemia de sobrepeso e obesidade infantil. Em pré-escolares, os escores$z$ de peso para altura e IMC para idade proporcionam informações semelhantes, porém o escore-z de IMC para idade é um indicador mais completo, visto que relaciona 
peso, estatura/comprimento e idade, sendo recomendado internacionalmente para o diagnóstico individual e coletivo dos distúrbios nutricionais (ONIS et al., 2012; SOCIEDADE BRASIILEIRA DE PEDIATRIA, 2009; WHO, 2008).

As crianças malnutridas são mais susceptíveis a infecções graves devido ao comprometimento da resposta imune, afetando os mecanismos de defesa antígenoespecíficos e não antígeno-específicos (FONSECA, 1996; VICTORA et al., 1999). Pode ocorrer perda da integridade da mucosa respiratória, baixo nível de fibronectina celular orofaríngea e pobre regeneração celular (JOHNSON et al., 2008). A reposta imune celular é particularmente afetada com a desnutrição calórico-proteica, porém também pode ocorrer declínio da concentração de imunoglobulina $A$ em diversos órgãos (incluindo o trato respiratório), comprometimento da fagocitose e do sistema de ativação do complemento (VICTORA et al., 1999).

É importante ressaltar que o baixo peso está comumente associado à deficiência de micronutrientes, embora essa deficiência também ocorra em crianças com peso adequado para idade (CAULFIELD et al., 2004). Ainda que não haja consenso na literatura sobre o impacto da suplementação de micronutrientes na prevenção de infecções, há evidências de que a deficiência de alguns micronutrientes modifica a susceptibilidade a infecções respiratórias. A deficiência de zinco alteraria a secreção de citocinas pró-inflamatórias, a proliferação e função de linfócitos e a proteção da integridade do epitélio respiratório (ROTH; RICHARD; BLACK, 2010). A deficiência de vitamina A prejudicaria a diferenciação celular do epitélio respiratório e sua integridade; a de ferro alteraria componentes da resposta imune celular e a de vitamina $D$ afetaria a síntese endógena de peptídeos antimicrobianos, dentre outras funções imunes (ROTH et al., 2008; WHO, 1995). É possível, portanto, que parte do efeito do estado nutricional sobre a hospitalização por pneumonia seja mediada pela deficiência de micronutrientes.

Cabe destacar, contudo, a possibilidade do viés de causalidade reversa, devido ao sinergismo entre desnutrição e doenças infecciosas (CAULFIELD et al., 2004; FONSECA, 1996; VICTORA et al., 1999). O estado nutricional, portanto, pode ter sido alterado em decorrência da pneumonia. De qualquer modo, consideramos que essa possibilidade não invalida o papel da desnutrição no desfecho do presente estudo, que é a hospitalização por pneumonia e não a ocorrência da mesma. É plausível que a criança com pneumonia, sofrendo de inapetência, tenha uma perda de peso aguda 
e esse seja um fator para o agravamento do quadro e consequente necessidade de hospitalização.

Quanto ao efeito protetor do excesso de peso, evidenciado no presente estudo, algumas considerações parecem pertinentes. Na literatura tem sido descrito que o sobrepeso e a obesidade predispõem os indivíduos a doenças respiratórias, causando inflamação das vias aéreas, hiperresponsividade brônquica e redução da função pulmonar, mecanismos que, por sua vez, aumentam a susceptibilidade à pneumonia (MURUGAN; SHARMA, 2008; SCOTT, 2012). Por outro lado, outros estudos corroboram o achado do efeito protetor do excesso de peso, em relação à gravidade da pneumonia em adultos, denominando tal efeito como paradoxal (CORRALESMEDINA et al., 2011; INOUE et al., 2007; LACROIX et al., 1989). Recomendam-se investigações adicionais para confirmar esse efeito em crianças, visto que os estudos prévios que analisaram a associação entre estado nutricional e ocorrência e gravidade da pneumonia na população infantil não utilizaram o IMC, que é o indicador recomendado para diagnosticar o sobrepeso e a obesidade (WHO, 2008). É possível que o mecanismo do efeito protetor do excesso de peso envolva outros fatores a ele associados e que não puderam ser identificados no presente estudo.

Ao contrário do retratado na literatura (BROOR et al., 2001; CÉSAR et al., 1999; HORTAL et al., 1994; JACKSON et al., 2013; MACEDO et al. 2007; RUDAN et al., 2008; VICTORA et al., 1994), o presente estudo não identificou associações significativas entre nenhuma das variáveis relativas ao aleitamento materno e o desfecho. No geral, identificou-se uma baixa ocorrência de aleitamento materno exclusivo na população de estudo, em comparação aos dados do município de Ribeirão Preto - SP. Segundo dados do Projeto Amamunic, da Secretaria Estadual da Saúde de São Paulo, 32,5\% dos menores de 6 meses estão em aleitamento materno exclusivo e $12 \%$ em aleitamento materno predominante, no município (RIBEIRÃO PRETO, 2013). Já na população do presente estudo, a proporção de menores de 6 meses em aleitamento materno exclusivo é bem menor $(11,7 \%)$ e em aleitamento materno predominante é maior (20,9\%). Portanto, poucas crianças do presente estudo estiveram em aleitamento materno exclusivo nos primeiros seis meses de vida, não havendo diferenças significativas entre casos e controles. Como todos os participantes foram recrutados nos hospitais, é possível que muitas das condições que levaram os controles à hospitalização também sejam condições associadas à falta do aleitamento materno, como a diarreia e os demais processos infecciosos. 
No presente estudo, o conjunto que apresentou maior número de variáveis independentemente associadas ao desfecho (modelos finais) pertencia ao bloco relativo ao cuidado à criança e à morbidade.

A situação vacinal não atualizada foi responsável por um aumento de quase 3 vezes na chance de hospitalização por pneumonia (OR=2,81; IC95\%=1,76-4,49), na população estudada. Achados semelhantes foram obtidos por um estudo casocontrole no Uruguai (HORTAL et al., 1994), com crianças menores de cinco anos de idade, no qual a situação vacinal incompleta esteve associada à severidade da pneumonia $(\mathrm{OR}=2,73)$. Estimativa de efeito com magnitude semelhante também foi obtida por outro estudo caso-controle desenvolvido na Índia (BROOR et al., 2001), em relação ao atraso vacinal $(\mathrm{OR}=2,85)$, porém o desfecho foi a hospitalização por ITRI. Um estudo caso-controle desenvolvido na Etiópia identificou que a vacinação reduziu o risco de morte em 74\% $(\mathrm{OR}=0,26)$ entre crianças menores de cinco anos, sendo que a principal causa de morte na população estudada foi a pneumonia (GIRMA; BERHANE, 2011). Jackson et al. (2013) conduziram uma metanálise que revelou evidências de associação da pneumonia grave com a imunização incompleta $(\mathrm{OR}=1,83)$.

O incremento da cobertura vacinal tem potencial para reduzir a morbimortalidade por pneumonia, entre crianças menores de cinco anos de idade, além de ser uma intervenção custo-efetiva (KIRKWOOD et al., 1995; NIESSEN et al., 2009). Em especial, há evidência de impacto em relação às vacinas contra o pneumococo e Hib - agentes que causam pneumonia - e contra o sarampo e a coqueluche - doenças que podem ter como complicação a pneumonia (JONES et al., 2003).

É possível que a associação identificada pelo presente estudo entre situação vacinal e hospitalização por pneumonia deva-se especificamente à imunização conferida pelas vacinas pneumo 10 valente, pneumo 23 valente, Hib, tetra ou pentavalente (que contêm as vacinas contra coqueluche e Hib) e tríplice viral (que contém a vacina contra o sarampo). Todavia, não foram analisadas, no presente estudo, associações entre as doses específicas de cada vacina e o desfecho, apenas a situação vacinal como um todo. De qualquer forma, esse achado sugere que as mães que utilizam os serviços de saúde para imunização correta e em tempo oportuno de seus filhos estariam também mais aptas a identificar sinais de doença e mais 
propensas a procurar o serviço precocemente, evitando o agravamento do quadro (BROOR et al., 2001).

Os participantes do presente estudo que fizeram uso pregresso de medicamentos apresentaram uma chance 67\% maior de serem hospitalizados por pneumonia $(\mathrm{OR}=1,67 ; \mathrm{IC}=1,00-2,78 ; p=0,049)$.

A prescrição de antibioticoterapia para tratamento das pneumonias bacterianas, realizada em tempo oportuno, é capaz de evitar a hospitalização pela doença $(H R=0,73)$, ao contrário da prescrição tardia, que incrementa o risco de hospitalização em 92\% (HR=1,92), conforme achados de um estudo transversal conduzido no Reino Unido (WINCHESTER et al., 2009). Contudo, é comum o uso abusivo de antibióticos não recomendados para o tratamento das IRA, que predispõe a criança ao desenvolvimento de resistência bacteriana à droga e consequente episódio grave de pneumonia (PAGAIYA; GARNER, 2005).

Os medicamentos antiácidos, incluindo os anti-histamínicos antagonistas do receptor $\mathrm{H} 2$ e os inibidores da bomba de prótons, utilizados no tratamento da doença do refluxo gastroesofágico (DRGE), se utilizados por longos períodos podem comprometer o efeito do suco gástrico na imunidade inata - causando hipocloridria e alterando a flora gástrica - e, desse modo, contribuir para uma maior vulnerabilidade do indivíduo ao desenvolvimento de infecções gastrointestinais e pneumonia (CANANI et al., 2011; LAHEIJ et al., 2004). Essa é uma questão importante quando se considera a prevalência de DRGE entre crianças (CANANI et al., 2011).

A terapia prolongada com glucocorticóides em altas doses é reconhecidamente imunossupressora, aumentando a probabilidade de ocorrência de infecção grave. Tem sido descrito, porém, um efeito imunossupressor com doses mais baixas e em menor período de uso. O emprego desses medicamentos no tratamento das infecções respiratórias virais, mesmo que por 3 a 4 dias, pode deteriorar o quadro do paciente e aumentar o risco de desenvolver pneumonia grave (HAN et al., 2011; MATSUMOTO et al., 2011).

Destaca-se a questão do uso abusivo de medicamentos em pediatria - muitas vezes sem prescrição - que expõe as crianças a um risco aumentado de reações adversas, multidroga-resistência, desenvolvimento e complicação de doenças (CARDOSO et al., 2012).

Ainda que na análise realizada no presente estudo não esteja especificado o medicamento utilizado, é possível que as crianças internadas por pneumonia 
estivessem fazendo uso, no domicílio, de medicamentos para o tratamento comunitário da própria pneumonia ou de alguma infecção respiratória que a antecedeu. Esse fato poderia ser o responsável pela diferença observada entre casos e controles, em relação ao uso pregresso de medicamentos. Portanto, embora haja plausibilidade biológica para a associação encontrada, devemos ressaltar que, nesse momento, não é possível estabelecer uma relação causal entre uso de medicamentos e internação por pneumonia. A criança poderia estar em uso de um medicamento que aumentou sua vulnerabilidade ao desenvolvimento de um quadro grave de pneumonia, ou apenas estar em uso de um medicamento para tratamento sintomático respiratório, o qual não contribuiu para a deteriorização do quadro. Investigações futuras com a especificação dos medicamentos utilizados seriam oportunas para melhor compreensão da associação observada.

No presente estudo, o número de episódios de sibilância esteve associado à hospitalização por pneumonia: as crianças com sibilância prévia apresentaram o dobro de chance de serem hospitalizadas pela doença (OR categoria 1 episódio = 2,13; IC95\%=1,31-3,47; OR categoria $\geq 3$ episódios = 2,37; IC95\%=1,35-4,15).

Em um estudo caso-controle desenvolvido em Porto Alegre, no sul do Brasil, a história de sibilância incrementou a chance de hospitalização de crianças menores de dois anos de idade por pneumonia $(\mathrm{OR}=1,75$ para sibilância tratada em casa e OR=2,99 para sibilância com necessidade de hospitalização).

Episódios de sibilância prévia configuraram o segundo fator de risco mais importante $(\mathrm{OR}=7,7)$ para hospitalização de crianças menores de um ano de idade por doença respiratória aguda (das quais a pneumonia foi a mais frequente), em um estudo caso-controle em Pelotas, sul do Brasil (MACEDO et al., 2007).

Um estudo desenvolvido no Kuwait (QASEMA et al., 2013) identificou que o Mycoplasma pneumoniae é mais comum em pacientes asmáticos (15\%) que em pacientes não-asmáticos $(9 \%)(p<0,05)$, podendo estar relacionado à exacerbação dos sintomas e gravidade do quadro. Relação semelhante foi encontrada a respeito da Chlamydia pneumoniae e da Legionella pneumophila (HAHN, 1999; LIEBERMAN et al., 2002; MARTIN et al., 2001).

É possível que as crianças com sibilância recorrente sejam asmáticas sem diagnóstico (MACEDO et al., 2007). Nesse sentido, a doença pulmonar predisporia a criança a uma maior vulnerabilidade aos patógenos causadores da pneumonia, ao mesmo tempo em que o episódio de pneumonia exacerbaria os sintomas da asma. É 
demonstrada, na literatura, que a interação entre sibilância e pneumonia é deletéria para o organismo acometido, contribuindo para o agravamento do quadro (REED et al., 2012).

Atualmente, contudo, propõe-se que a sibilância recorrente pode ocorrer devido a outras causas, como a bronquite bacteriana, sendo necessária maior acurácia dos critérios diagnósticos da doença. Inclusive, em algumas crianças, as duas condições podem coexistir, compondo um círculo vicioso com pneumonias de repetição. Existe a hipótese de que o prejuízo ao epitélio mucociliar causado pela asma e outras doenças pulmonares de base permitem a colonização bacteriana e a formação de um biolfilme nas vias aéreas, que pode ser responsável pela ocorrência de pneumonia ou broncopneumonia se os microorganismos que o compõem atingirem o pulmão. Da mesma forma, os patógenos causadores da pneumonia podem ascender às vias aéreas e ali se estabelecerem, em uma estrutura que oferece proteção contra as respostas do hospedeiro e até contra a antiboticoterapia, podendo ocasionar uma bronquite bacteriana crônica (EVERARD, 2012).

A associação encontrada no presente estudo entre refluxo gastroesofágico e hospitalização por pneumonia foi inversa ao esperado - o distúrbio foi mais frequente entre os controles, levando a um odds de proteção ( $O R=0,55 ; I C=0,31-0,99)$. A literatura aponta que a DRGE pode ocasionar episódios recorrentes de aspiração ou microaspiração do conteúdo gástrico, com consequente pneumonia aspirativa ou mesmo patologia broncopulmonar crônica, que predispõem o indivíduo à ocorrência de pneumonia (SALCEDO POSADAS et al., 2004).

Existem algumas explicações alternativas para o efeito identificado no presente estudo. O primeiro deles é a exclusão de crianças com pneumonias aspirativas, o que pode ter contribuído para uma menor proporção de crianças com refluxo entre os casos. A segunda é ausência de confirmação diagnóstica da doença, pois embora na entrevista fosse especificamente questionado se a criança possuía refluxo diagnosticado pelo médico, é possível que o entrevistado tenha referido a informação incorreta, por confusão com regurgitação, especialmente nos lactentes. Por último, como um dos locais em que se realizou o recrutamento de controles foi o ambulatório hospitalar, com alguma frequência eram selecionadas crianças que estavam realizando acompanhamento médico por refluxo, o que pode ter contribuído para uma maior proporção de controles com esse distúrbio. Enfatiza-se, contudo, que a relação entre refluxo gastroesofágico e hospitalização por pneumonia deve ser melhor 
explorada, a fim de esclarecer se o efeito de proteção encontrado por este estudo deve-se às particularidades expostas ou a algum mecanismo atualmente desconhecido.

A qualidade da APS, na forma do indicador Escore Essencial da APS, apresentou associação significativa com o desfecho do presente estudo. Escores acima de 3,17 foram responsáveis por um efeito protetor em relação à hospitalização por pneumonia, reduzindo as chances de hospitalização em 43\% (OR para a categoria $>3,41=0,57 ; \mathrm{IC}=0,32-0,99$ ) a $50 \%$ (OR para a categoria $>3,17$ e $\leq 3,41=0,50$; $\mathrm{IC}=0,28-0,88)$.

Por meio de uma metanálise, Sazawal e Black (2003) identificaram que o adequado manejo de casos, realizado na APS, é responsável por reduzir a mortalidade específica por pneumonia em $42 \%$ entre neonatos (OR=0,58), 36\% entre lactentes $(\mathrm{OR}=0,64)$ e $36 \%$ entre crianças de 1 a 4 anos $(\mathrm{OR}=0,64)$.

O conjunto de variáveis relativas ao manejo de casos na APS foi o mais fortemente associado $(\mathrm{OR}=9,68)$ à mortalidade infantil por IRA, no México (REYES et al., 1997), em comparação às variáveis relativas à criança $(O R=7,22)$, à mãe $(\mathrm{OR}=4,03)$ e ao acesso aos serviços de saúde $(\mathrm{OR}=5,27)$. Compuseram esse conjunto de variáveis: número de visitas ao serviço de saúde em virtude do episódio de IRA, tipo de serviço (público/privado), número de médicos que atenderam a criança no mesmo episódio, tipo de tratamento instituído e referência da criança ao hospital (REYES et al., 1997).

A prescrição de antibióticos recomendados, uma das ações do manejo de casos na APS, é capaz de reduzir as chances de hospitalização por pneumonia. Um estudo caso-controle do Reino Unido identificou que havia uma menor propensão à prescrição de antibióticos na primeira consulta na APS (devido à queixa respiratória) para as crianças que posteriormente foram internadas por pneumonia $(O R=0,53)$, em comparação àquelas que foram tratadas em casa (CROCKER, 2012). Winchester et al. (2009) também demonstraram que o momento da prescrição de antibióticos é um importante fator para a hospitalização por pneumonia e outras ITRI. Após ajustamento, a prescrição de antibiótico ao ser diagnosticada a infecção esteve associada a uma redução na taxa de hospitalizações (HR=0,73), ao contrário da prescrição tardia ( $\mathrm{HR}=1,92)$, que incrementou o risco de hospitalização.

Tais estudos prévios que investigaram o papel da APS no controle da pneumonia centraram-se no diagnóstico precoce e no tratamento da doença. $O$ 
manejo de casos é de extrema importância para o adequado tratamento da pneumonia, a fim de evitar complicações e agravamento do quadro. Porém, entendese que o papel da APS não se restringe à atenção recebida no episódio da doença.

As orientações de cuidado à criança com infecções respiratórias agudas são fundamentais, tendo em vista a busca de melhor entendimento das situações de saúde, para não restringir a atenção no episódio da doença. Estudo (CARVALHO, VERISSIMO, 2011) que buscou descrever o processo de comunicação entre profissionais e mães, em consultas de enfermeiros e médicos para crianças com IRA, em unidades básicas de saúde, mostra que as orientações são inconstantes e incompletas, predominantemente prescritivas e centradas na doença, principalmente no tratamento medicamentoso. As autoras apontam, ainda, que a comunicação é centralizada no profissional, dificultando um processo educativo emancipatório.

Conforme já mencionado, a pneumonia integra o conjunto das condições sensíveis à atenção primária, para o qual a APS efetiva diminuiria a incidência e/ou o risco de complicações, por meio da prevenção primária, do diagnóstico e do tratamento precoces de condições agudas e do acompanhamento, controle e manejo de condições crônicas (ALFRADIQUE et al., 2009; CAMINAL et al., 2004).

Um estudo que se propõe a avaliar a contribuição da APS para a prevenção de hospitalizações por pneumonia, portanto, deve necessariamente considerar todas as características ou atributos da APS e não apenas a atenção recebida no episódio de pneumonia.

Nesse sentido, o presente estudo fornece uma importante contribuição à literatura científica: comprova o papel protetor e qualificado da APS na hospitalização por pneumonia em crianças menores de cinco anos de idade, com base em uma abordagem metodológica adequada e em um instrumento estruturado e validado para a avaliação da APS. O PCATool é o instrumento atualmente recomendado para avaliar a estrutura e o processo da APS. Sua conformação permite avaliar os atributos essenciais e derivados dessa modalidade de atenção (BRASIL, 2010a).

A associação identificada, em relação ao Escore Essencial da APS, permitenos afirmar que os serviços de APS da região estudada podem evitar a hospitalização das crianças por pneumonia por meio de uma estrutura e de um desempenho que garantam a afiliação e o acesso ao serviço de saúde, a longitudinalidade, a integralidade e a coordenação da atenção, que são os atributos essenciais da APS (exceto grau de afiliação). Os atributos derivados - orientação familiar e orientação 
comunitária - compõem o Escore Geral da APS que, no presente estudo, não integrou o modelo final.

As crianças que tiveram maior acessibilidade e uso de um serviço de APS de referência apresentaram uma menor chance de serem hospitalizadas por pneumonia, levando em conta a organização da APS como uma fonte regular de atenção, que podem utilizar ao longo do tempo, por meio de uma variedade de serviços e articulações com outras unidades e que, mesmo recebendo atenção por outros profissionais e serviços, têm garantida a continuidade da atenção.

Serão discutidas, a seguir, as ações específicas que devem ser desenvolvidas na APS, visando o cuidado integral, longitudinal e coordenado, que pode impactar na prevenção das hospitalizações de crianças por pneumonia.

Entendendo a promoção da saúde como uma estratégia de articulação transversal, que visa à criação de mecanismos que reduzam as situações de vulnerabilidade da população, é preciso ampliar o escopo das intervenções em saúde, tomando como objeto não apenas os problemas e necessidades de saúde e seus condicionantes e determinantes, mas também incidindo sobre as condições de vida e favorecendo a ampliação das escolhas saudáveis, por parte de sujeitos e coletividades (BRASIL, 2010b).

Nessa direção, é necessário que os profissionais da APS sejam disseminadores de hábitos saudáveis entre as crianças e suas famílias, incluindo a promoção do aleitamento materno e da alimentação saudável, a prática de atividade física e a prevenção e o controle do tabagismo. Contudo, não basta fornecer orientações à população, visto que a questão de mudança de comportamento muitas vezes não envolve apenas escolhas individuais. Tomando-se como exemplo a alimentação saudável - além do aporte calórico e nutricional, há questões como segurança alimentar, higiene, renda e educação familiar, que sinalizam a necessidade de novos tipos de parcerias, a fim atingir a origem dos distúrbios nutricionais (THE WORLD BANK, 2006).

É necessário, portanto, organizar o trabalho em rede, instituindo parcerias, e estimular o exercício da cidadania, favorecendo o protagonismo social de todos os atores envolvidos, inclusive dos próprios profissionais de saúde (BRASIL, 2010b).

A organização dos serviços de saúde em rede está ligada à concepção de aprofundar a estratégia de regionalização, no âmbito do SUS, para a qualificação da atenção, da gestão e do cuidado em saúde. A organização de redes integradas e 
regionalizadas de atenção à saúde visa a oferta de um conjunto de ações e serviços de saúde articulados, de diferentes densidades tecnológicas, com a finalidade de garantir a integralidade da atenção à saúde (BRASIL, 2011b). Os benefícios da integração e da constituição das redes de saúde são: racionalizar gastos, otimizar recursos e promover uma atenção condizente com as necessidades dos usuários, os quais dependem do aperfeiçoamento na gestão intergovernamental das regiões de saúde, para um adequado pacto de responsabilidades entre as esferas de governo e a qualificação da APS para coordenar o cuidado e ordenar a continuidade da atenção à saúde (SILVA, 2011).

Cabe destacar, também, que a promoção do planejamento familiar e da adesão ao pré-natal e à puericultura são igualmente prioritárias. Conforme já exposto, fatores anteriores ao nascimento da criança são importantes quando se trata da morbidade por pneumonia. A possibilidade de organização da família para a chegada da nova criança é essencial para o cuidado da mesma e sua inserção no núcleo familiar. $O$ acompanhamento da saúde do binômio mãe-filho possibilita o estabelecimento de um vínculo com o serviço, além da promoção e vigilância do crescimento, do desenvolvimento e do estado de saúde geral (BRASIL, 2012b).

A adesão ao acompanhamento sistemático do crescimento e do desenvolvimento da criança, comumente denominado de assistência em puericultura, envolve as ações básicas da saúde da criança. No entanto, além do alcance da adesão a essa prática, há necessidade de se preocupar com os valores das mães e famílias e com o estabelecimento de vínculo e co-responsabilidade entre os sujeitos (MELLO et al., 2012), em busca de melhores condições de saúde e vida das crianças.

Embora o presente estudo não tenha identificado associações entre as variáveis relativas ao aleitamento materno e a hospitalização por pneumonia, é reconhecido na literatura o papel protetor da amamentação, em relação às infecções na infância. A proteção, promoção e apoio ao aleitamento materno faz parte de uma agenda global em saúde da criança; contudo, os indicadores de início e de duração do aleitamento materno têm sido baixos em muitos países (MORAN et al., 2005; CWIEK et al., 2010). Os benefícios do aleitamento materno para as crianças têm sido relacionados às menores taxas de diarreia, infecções do trato respiratório, otite média e outras infecções, e menor mortalidade por essas doenças em crianças amamentadas quando comparadas às não amamentadas (LEÓN-CAVA et al., 2002). Evidências de vários locais indicam que melhorias nos indicadores de aleitamento materno são 
possíveis na presença do direcionamento efetivo de ações e, entre as medidas, enfatizam o início precoce da amamentação nas maternidades e a capacitação dos profissionais de saúde para o aconselhamento de mulheres acerca do aleitamento materno (UNICEF, 2009). A provisão de adequado suporte tem sido um fator importante para a questão da duração do aleitamento materno (MORAN et al., 2005; CLIFFORD, MCINTYRE, 2008). O apoio pós-parto às mulheres pode trazer efeitos positivos, com repercussões na amamentação por mais tempo, maior autoestima, menos depressão materna e mães mais aptas a cuidar dos bebês (BRUGGEMANN, PARPINELLI, OSIS, 2005). As ações de proteção, promoção e apoio ao aleitamento materno devem ser planejadas e operacionalizadas na perspectiva de um trabalho articulado entre os diversos serviços de saúde que integram a rede.

A vacinação desempenha papel de indiscutível relevância na proteção específica das crianças, sendo capaz de impactar na prevalência das doenças da infância, dentre elas a pneumonia, conforme já exposto (BRASIL, 2012b). É uma ação rotineira nos serviços de APS, com grande influência nas condições gerais de saúde da criança. Essa prática de saúde pública representa expressivo avanço tecnológico em saúde nas últimas décadas e é considerada procedimento de boa relação custo/eficácia no setor saúde (GUIMARÃES; ALVES; TAVARES, 2009). Para ampliar as metas de qualquer programa de imunização é necessário administrar as vacinas adequadamente, em tempo oportuno e com esforços efetivos dos profissionais de saúde, em relação às mudanças nas atitudes e crenças sobre a imunização (JOYCE, 2007). Se a vacinação estiver integrada ao cuidado da criança, no processo de crescimento e desenvolvimento, mais sucesso a imunização terá como indicador de cobertura vacinal, contribuindo também para ampliar o entendimento das famílias sobre essa ação de saúde (FIGUEIREDO et al., 2011). Os profissionais da APS devem desenvolver estratégias para garantir o acesso das crianças às vacinas do calendário básico, às campanhas de vacinação e aos imunobiológicos especiais, quando indicados.

A suplementação de micronutrientes e a fortificação de alimentos também são ações de proteção específica desenvolvidas na APS com potencial efeito no estado nutricional e na morbidade infantil. Em alguns casos, a suplementação é realizada obedecendo-se indicação específica com base em avaliação individual, como no caso da vitamina $D$, e em outros é realizada seguindo um protocolo mais geral, como a 
suplementação de vitamina A em regiões consideradas de risco e a suplementação de zinco para o tratamento da diarreia (BRASIL, 2012b).

Especificamente quanto ao diagnóstico e tratamento precoces de condições agudas, o manejo de casos estruturado direciona os profissionais da APS quanto às condutas diagnósticas e terapêuticas, de acordo com a melhor evidência científica disponível. A estratégia AIDPI integra várias ações visando à abordagem integrada das doenças de maior prevalência na infância, dentre elas a pneumonia (BRASIL, 2002). Consiste em um conjunto de critérios para avaliar, classificar e tratar as doenças prevalentes que podem evoluir para quadros graves e levar à morte crianças menores de cinco anos (BENGUIGUI, 2001). A proposta da AIDPI é avaliar sistemática e integradamente sinais clínicos preditivos positivos que definem a necessidade de se introduzir tratamento na atenção primária e no domicílio, ou o encaminhamento adequado para uma unidade de maior densidade tecnológica, envolvendo as famílias com enfoque altamente efetivo - que integra ações curativas, de prevenção e promoção da saúde. Desse modo, a estratégia reforça o conceito de integralidade e fortalece a capacidade de planejamento e resolução dos problemas no nível primário de atenção, disponibilizando ferramentas mais apropriadas para lidar com os agravos prevalentes na infância (BENGUIGUI, 2001).

No entanto, para que o manejo de casos seja instituído, faz-se necessário promover o acesso das crianças ao serviço de saúde, no momento em que elas necessitam. Um dos pontos críticos, nesse sentido, é a falta de organização das unidades de APS para o atendimento da demanda espontânea, pois os eventos agudos não têm sido valorizados na agenda de trabalho dessas equipes, parecendo não haver uma real desburocratização do acesso aos serviços de saúde (FRANCO; MERHY, 2003).

No contexto da APS, estudo (OLIVEIRA et al., 2012) analisou o acesso de primeiro contato para crianças menores de cinco anos com problemas respiratórios e mostrou que o primeiro contato está ocorrendo em unidades de emergência, com atenção a episódios agudos de problemas de saúde, em vez de unidades de atenção básica, sem ações programáticas e acolhimento como metodologia de ação cotidiana. Ainda, a demanda espontânea em situação de crise é regulada por um conjunto de normas organizativas que, muitas vezes, impedem o acesso. Assim, a atenção primária vem atuando pouco como reguladora do sistema de saúde, sendo necessário revisar seu papel e a retomada de sua função. 
Os usuários que não encontram acolhidas as suas queixas nas unidades de APS conformam uma demanda reprimida e acabam sendo atendidos em prontosocorros, buscando a satisfação de suas necessidades imediatas e forçando a organização do sistema de saúde em torno dos serviços mais voltados ao prontoatendimento. Desse modo, a APS, destinada a ser organizadora do sistema de serviços de saúde, assume um caráter apenas de porta de entrada desse sistema, ou seja, um local, em geral, com baixa resolutividade, cuja função é apenas recepcionar os usuários e encaminha-los aos demais níveis de atenção, sem uma articulação dentro do sistema de serviços de saúde (MENDES, 2002). Para PAIM et al. (2011), alguns dos desafios do sistema de saúde brasileiro são a reforma de sua estrutura de financiamento, tendo em vista assegurar a universalidade, igualdade e sustentabilidade a longo prazo, a renegociação dos papeis público e privado, a adequação do modelo de atenção para atender as rápidas mudanças demográficas e epidemiológicas do país e a promoção da qualidade do cuidado e da segurança dos usuários.

Por fim, sem a pretensão de esgotar as possibilidades de atenção à criança na APS, destaca-se a importância do acompanhamento, controle e manejo de condições crônicas capazes de predispor a criança a um quadro grave de pneumonia, como as doenças de base pulmonar, as doenças cardiovasculares, as neuropatias graves, as doenças metabólicas e as imunológicas (JACKSON et al., 2013; NASCIMENTOCARVALHO et al., 2002; RAMACHANDRAN, et al., 2012; SIGAÚQUE et al., 2009).

É importante ressaltar que a avaliação da APS no presente estudo considerou apenas a perspectiva do usuário, mais especificamente da mãe ou responsável pela criança. A avaliação da APS sob a ótica do usuário é um dos elementos importantes na avaliação da qualidade em saúde (DONABEDIAN, 1984). Contudo, recomenda-se confirmar os achados do presente estudo por meio da utilização da versão do PCATool para profissionais de saúde.

Faz-se necessário, ainda, discorrer sobre alguns aspectos metodológicos do presente estudo, visando apontar as suas limitações e potencialidades.

Em estudos caso-controle, os pesquisadores buscam investigar, retrospectivamente, fatores associados a uma condição atual. Desse modo, avaliam o efeito da(s) exposição(ões) - fatores de risco ou de proteção - sobre um desfecho de interesse (SCHLESSELMAN, 1982). 
O delineamento caso-controle é frequentemente adotado por sua eficiência, em termos de custo/tempo, e pela possibilidade de investigação simultânea do efeito de fatores de risco/proteção para diferentes desfechos (HENNEKENS; BURING, 1987; SCHLESSELMAN, 1982). É necessário, contudo, que sejam observados princípios para garantir a validade do estudo. Entende-se que a perfeita adesão a um determinado princípio pode ser muito difícil em condições não experimentais, principalmente porque, algumas vezes, pode haver conflito entre os princípios. Nesses casos, são recomendados esforços para obter-se o mínimo de violação (WACHOLDER et al., 1992).

A seguir, são apresentados os aspectos do presente estudo relacionados à aderência aos pressupostos recomendados para delineamentos do tipo caso-controle.

Em relação aos princípios de comparabilidade, casos e controles devem ser representativos da mesma base, a fim de evitar viés de seleção. Entende-se por base um conjunto de pessoas no qual os indivíduos acometidos por um determinado desfecho são identificados como casos (SCHLESSELMAN, 1982; WACHOLDER et al., 1992).

Como se trata de um estudo caso-controle de base hospitalar (base secundária), os controles foram selecionados nos mesmos hospitais em que os casos foram diagnosticados (mesma base populacional), obedecendo-se, de modo geral, aos mesmos critérios de exclusão em ambos os grupos. Entende-se, desse modo, que os controles foram selecionados de uma base composta por indivíduos que seriam hospitalizados no mesmo hospital se fossem diagnosticados com pneumonia comunitária, já que foram aí hospitalizados por outro motivo.

A Central de Regulação do município de Ribeirão Preto - SP, bem como da região, segue a orientação de referenciar os casos mais graves e aqueles com comorbidades para o Hospital $A$, sendo que a referência para os Hospitais $B$ e $C$ segue apenas o critério de disponibilidade de vaga. No caso de crianças com co-morbidades, é fato que a referência sempre será para o Hospital $A$, qual seja a causa da internação. Contudo, nos casos em que a criança não possui co-morbidades, ela pode estar internada no Hospital A por ter um quadro grave de outra doença, mas se futuramente vier a adoecer de pneumonia sem complicações, não necessariamente será referenciada ao mesmo hospital. Essa, todavia, é uma questão inerente a estudos de base-hospitalar, cuja validade reside na suposição, ainda que tênue, de que a distribuição das exposições entre os controles hospitalares selecionados é a mesma 
da base populacional de onde provieram, ou dela difere em razão de fatores mensuráveis (WACHOLDER et al., 1992).

Uma das estratégias recomendadas para confirmar a existência de associações é a seleção de diferentes conjuntos de controles, entre os quais se destacam os controles comunitários (SCHLESSELMAN, 1982). No presente estudo, contudo, tal procedimento não pôde ser realizado, pois selecionar controles comunitários (de vizinhança ou de mesma unidade básica de saúde do caso) inviabilizaria a investigação do papel da qualidade da APS no desfecho, pois casos e controles dessa série estariam emparelhados por acesso ao serviço de saúde.

Ainda, para a garantia de comparabilidade em relação às exposições entre casos e controles, procurou-se selecionar o controle correspondente ao respectivo caso, dentro do menor tempo possível, adotando-se a data do diagnóstico do caso como referência para as exposições pregressas nos dois grupos (WACHIOLDER et al., 1992).

Ainda em termos de comparabilidade, o princípio da acurácia pressupõe que as medidas das exposições de interesse sejam aferidas com a mesma acurácia para casos e controles, com vistas a evitar vieses de informação (WACHOLDER et al., 1992). Buscou-se garantir a adesão a esse princípio por meio do treinamento e calibração da equipe de entrevistadores que, ademais, desconhecia as hipóteses sob investigação (cegamento), conforme recomendado.

Em se tratando de base hospitalar, cabe destacar a possibilidade do viés de Berkson: se uma dada exposição está relacionada com a hospitalização de controles, mas não com a de seus respectivos casos, a distribuição desta exposição, em casos e controles, pode não refletir a verdadeira distribuição na base de referência (WACHOLDER et. al, 1992). Em algumas situações, por exemplo, foram incluídas no estudo crianças internadas ou que passaram por atendimento hospitalar devido à gastroenterocolite aguda, sendo que a diarreia no último mês era uma das exposições de interesse. Por outro lado, como por meio deste estudo buscamos estudar diversas exposições, seria impraticável excluir entre os controles aquelas crianças internadas por condições que poderiam estar associadas a exposições de interesse do estudo. Essa prática também dificultaria ainda mais a seleção de controles, por limitar as possibilidades, tornando maior a diferença de tempo entre a entrevista do caso e a do controle, o que comprometeria a comparabilidade. Assim, a opção foi selecionar controles com diversidade de doenças ou condições, prática recomendada para 
minimizar a possibilidade do viés de Berkson (SCHLESSELMAN, 1982; WACHOLDER et al., 1992).

Torna-se importante mencionar, também, que o controle de confusão estatística foi garantido por meio do emprego de técnicas estatísticas multivariadas, em abordagem hierarquizada que, por pressuposto, impede o ajustamento para variáveis intervenientes que poderiam mascarar associações importantes entre potenciais fatores de risco ou de proteção sobre o desfecho investigado.

No que pesem as dificuldades inerentes aos estudos caso-controle relacionadas, principalmente, ao seguimento estrito de todos os princípios teóricometodológicos (pois atender a alguns deles significaria violar outros), no presente estudo adotaram-se os pressupostos fundamentais para a garantia da validade interna do estudo, de tal modo que os resultados aqui apresentados não parecem decorrentes de vícios sistemáticos. 
8. CONCLUSÕES 
O presente estudo Identificou os fatores de risco e proteção para a hospitalização por pneumonia, em crianças menores de cinco anos de idade e avaliou a magnitude da contribuição destes fatores sobre o desfecho, a partir de um modelo explicativo que contemplou as relações hierárquicas existentes entre potenciais preditores e o desfecho em questão.

Dentre os fatores socioeconômicos, renda familiar superior a $R \$ 700,00$ foi responsável por uma redução de $32 \%$ na chance de hospitalização $(O R=0,68$; IC95\%=0,47-0,98), denotando a importância do poder aquisitivo na região estudada. Porém, a prosperidade econômica da região não é acompanhada de uma melhoria na escolaridade da população, que permanece abaixo da média estadual, mas não foi um fator determinante da hospitalização por pneumonia.

Em relação às características reprodutivas maternas investigadas no presente estudo, o número de partos $\geq 2$ representou um expressivo aumento no risco de hospitalização das crianças por pneumonia (categoria 2 partos: OR=4,60, IC95\%=2,18-9,72; categoria $\geq 3$ partos: OR=3,25, IC95\%=1,55-6,81), enquanto 0 intervalo interpartal $\geq 48$ meses e o ganho de peso na gestação de $10 \mathrm{Kg}$ ou mais apresentaram efeito protetor para o desfecho (OR=0,28, IC95\%=0,14-0,56 e $\mathrm{OR}=0,68$, IC95\%=0,47-0,97, respectivamente). Embora o papel das variáveis reprodutivas maternas sobre o desfecho em questão seja descrito como mediado, em grande parte, pelas variáveis perinatais, estas últimas não permaneceram nos modelos finais. Infere-se a possibilidade de que os fatores reprodutivos maternos operem, em parte, de modo independente dos fatores perinatais no risco de hospitalização por pneumonia. Mesmo diante de condições de nascimento adversas (como parto pré-termo e baixo peso ao nascer), a capacidade de autocuidado materno teria o potencial de impactar na capacidade de cuidar da criança.

Dentre as variáveis ambientais, frequência à creche foi a única variável do bloco que permaneceu no modelo final do presente estudo, sendo responsável por um aumento de $67 \%$ na chance de hospitalização por pneumonia (OR=1,67; IC95\%=1,162,41). Embora haja evidência da associação entre frequência à creche e ocorrência de doenças infecciosas, em crianças pequenas, devem ser ressaltados os benefícios em termos de estimulação cognitiva e socialização que essas instituições oferecem às crianças. Além disso, segundo a hipótese higienista, é possível que a exposição precoce a agentes infecciosos forneça certa proteção contra algumas doenças de 
base ao longo da vida (como as doenças atópicas), por intermédio da reposta imunológica desencadeada.

Em relação às variáveis nutricionais, apenas escore-z de IMC para idade permaneceu no modelo final do presente estudo. De acordo com a classificação construída a partir desse indicador (eutróficos, desnutridos e com excesso de peso), as crianças desnutridas apresentam uma chance duas vezes maior de serem hospitalizadas por pneumonia $(\mathrm{OR}=2,53 ; \mathrm{IC}=1,06-6,05)$ enquanto aquelas com excesso de peso apresentam uma redução de $63 \%$ nessa chance $(\mathrm{OR}=0,37 ; \mathrm{IC}=0,14$ $0,99)$. O efeito protetor do excesso de peso também foi encontrado por outros estudos, sendo considerado paradoxal, visto que o sobrepeso e a obesidade predispõem os indivíduos a doenças respiratórias, causando inflamação das vias aéreas, hiperresponsividade brônquica e redução da função pulmonar, mecanismos que aumentam a susceptibilidade à pneumonia, ao invés de diminui-la.

No presente estudo, o conjunto com maior número de variáveis significativas que foram retidas no modelo final correspondeu ao bloco relacionado ao cuidado à criança e à presença de morbidades.

A situação vacinal não atualizada foi responsável por um aumento de quase 3 vezes na chance de hospitalização por pneumonia ( $O R=2,81$; $I C=1,76-4,49)$, na população estudada. Embora a literatura aponte evidências de impacto em relação às vacinas contra sarampo, coqueluche, pneumococo e Hib, o presente estudo não investigou associação entre cada vacina e o desfecho. A associação investigada e identificada foi em relação ao conjunto das vacinas recomendadas de acordo com a idade da criança, em concordância com o calendário básico estipulado. Esse achado sugere que as mães que utilizam os serviços de saúde para imunização de seus filhos corretamente estariam também mais propensas a aderirem à puericultura, a identificarem sinais de doença e a procurar o serviço precocemente, evitando o agravamento do quadro.

Os participantes do estudo que fizeram uso pregresso de medicamentos apresentaram uma chance $67 \%$ maior de serem hospitalizados por pneumonia $(\mathrm{OR}=1,67 ; \mathrm{IC}=1,00-2,78 ; p=0,049)$. Embora haja plausibilidade biológica para a associação encontrada, devemos ressaltar que não foi possível estabelecer o efeito específico do uso de medicamentos sobre a internação por pneumonia, por não estarem disponíveis para o estudo especificações farmacológicas sobre o medicamento utilizado, sendo pertinentes investigações futuras para este fim. 
No presente estudo, o número de episódios de sibilância esteve associado à hospitalização por pneumonia - crianças com sibilância prévia apresentaram o dobro de chance de serem hospitalizadas pela doença (OR categoria 1 episódio $=2,13$; IC95\%=1,31-3,47; OR categoria $\geq 3$ episódios = 2,37; IC95\%=1,35-4,15). É aventada a possibilidade de um círculo vicioso envolvendo as causas da sibilância, como a asma ou a bronquite bacteriana, e as pneumonias de repetição.

A associação encontrada no presente estudo entre refluxo gastroesofágico e hospitalização por pneumonia foi inversa ao esperado - o distúrbio foi mais frequente entre os controles, levando a um odds de proteção ( $O R=0,55 ; I C=0,31-0,99)$. A exclusão de crianças com pneumonias aspirativas, a ausência de confirmação diagnóstica do refluxo e o recrutamento de controles que realizavam acompanhamento médico por DRGE podem ter contribuído para uma maior proporção de controles com esse distúrbio e consequente efeito protetor. Enfatiza-se, no entanto, que são recomendadas investigações adicionais para elucidar os mecanismos que levaram ao efeito protetor do refluxo gastroesofágico, em relação à hospitalização de crianças por pneumonia.

A qualidade da APS, na forma do indicador Escore Essencial da APS, apresentou associação significativa com o desfecho do presente estudo. Escores acima de 3,17 foram responsáveis por um efeito protetor em relação à hospitalização por pneumonia, reduzindo as chances de hospitalização em 43\% (OR para a categoria $>3,41=0,57 ; \mathrm{IC}=0,32-0,99$ ) a 50\% (OR para a categoria $>3,17$ e $\leq 3,41=0,50$; $\mathrm{IC}=0,28-0,88)$. O presente estudo fornece uma importante contribuição à literatura científica: comprova o papel protetor da APS de qualidade na hospitalização de crianças menores de cinco anos de idade por pneumonia, por meio de uma metodologia adequada e de um instrumento estruturado e validado para a avaliação da APS. As crianças que tiveram maior acessibilidade e uso de um serviço de APS de referência apresentam uma menor chance de serem hospitalizadas por pneumonia, levando em conta a organização da APS como uma fonte regular de atenção, que podem utilizar ao longo do tempo, por meio de uma variedade de serviços e articulações com outras unidades e que, mesmo recebendo atenção por outros profissionais e serviços, têm garantida a continuidade da atenção.

Considerando-se o modelo explicativo para a hospitalização de crianças menores de cinco anos de idade por pneumonia, obtido pelo presente estudo, observa-se que grande parte das variáveis que compõem o modelo final relaciona-se 
ao cuidado à criança - como a qualidade da APS, o uso de medicamentos, a situação vacinal e a frequência à creche - ou à mãe e à família da criança - como a paridade, o intervalo interpartal e a renda familiar. Os mecanismos biológicos por meio dos quais os fatores analisados exercem seu efeito sobre o desfecho parecem estar relacionados à qualidade do cuidado à criança e à família, em especial ao binômio mãe-filho. Depreendemos dessa leitura que as práticas de cuidado à criança seriam capazes de operar sobre as adversidades biológicas e reduzir a chance de hospitalização por pneumonia.

Na saúde infantil, embora avanços venham ocorrendo no tocante à redução da mortalidade infantil e ampliação da cobertura dos serviços de saúde brasileiros, há o desafio de melhorar a qualidade das intervenções de saúde. Assim, ações de prevenção de agravos, promoção, tratamento e recuperação da saúde, oferecidas e organizadas de forma indissociável, devem buscar garantir na APS a vigilância do crescimento e desenvolvimento infantil, a orientação da alimentação adequada da criança, a imunização completa, a prevenção de acidentes e a atenção às doenças prevalentes na infância, bem como ações efetivas no pré-natal e planejamento familiar, como práticas essenciais para proporcionar boas condições de saúde na infância, as quais também contribuem para ampliar o cuidado.

Considerando-se os procedimentos relativos ao planejamento do estudo, à execução da coleta de dados e às análises estatísticas empregadas, reitera-se a consecução de validade interna para o estudo, sendo possível afirmar que o modelo obtido é explicativo do fenômeno da hospitalização por pneumonia, na população estudada. 


\section{REFERÊNCIAS}


AGUIAR, R. A. T. A construção internacional do conceito de atenção primária à saúde (APS) e sua influência na emergência e consolidação do sistema único de saúde no Brasil. 2007. 136f. Dissertação (Mestrado) - Faculdade de Medicina, Universidade Federal de Minas Gerais, Belo Horizonte-MG, 2007.

ALFRADIQUE, M. E. et al. Internações por condições sensíveis à atenção primária: a construção da lista brasileira como ferramenta para medir o desempenho do sistema de saúde (Projeto ICSAP - Brasil). Cadernos de Saúde Pública, v. 25, n. 6, p. 13371349, jun 2009.

AMORIM, K. S.; YAZLLE, C.; ROSSETTI-FERREIRA, M. C. Saúde e doença em ambientes coletivos de educação da criança de 0 a 6 anos. Centro de Investigações sobre Desenvolvimento Humano e Educação Infantil (CINDEDI): 2001. $32 \mathrm{p}$.

BARROS, F. C.; VICTORA, C. G.; SCHERPBIER, R.; GWATKIN, D. Socioeconomic inequities in the health and nutrition of children in low/middle income countries. Revista de Saúde Pública, v. 44, n. 1, p. 1-16, 2010.

BENGUIGUI, Y. (Ed.). Infecções respiratórias agudas: fundamentos técnicos das estratégias de controle. Washington (D.C.): OPS, 1997a. 249p.

(Ed.). Controle das infecções respiratórias agudas: implementação, acompanhamento e avaliação. Washington (D.C.): OPS, 1997b. 226p.

. Integrated Management of Childhood IIIness (IMCI): An innovative vision for child health care. Revista Brasileira de Saúde Materno Infantil, v. 1, n. 3, p. 223236, 2001.

BHANDARI, N. et. al. Effectiveness of Zinc Supplementation Plus Oral Rehydration Salts Compared With Oral Rehydration Salts Alone as a Treatment for Acute Diarrhea in a Primary Care Setting: A Cluster Randomized Trial. Pediatrics, v. 121, p. e1279e1285, 2008.

BLACK, R. E. et al. Maternal and child undernutrition: global and regional exposures and health consequences. Lancet, v. 371, n. 9608, p. 243-260, 2008.

BOERMA, J. T.; BICEGO, G. T. Preceding Birth Intervals and Child Survival: Searching for Pathways of Influence. Studies in Family Planning, v. 23, n. 4, p. 243-256, jul./aug. 1992. 
BRASIL. Ministério da Saúde. Organização Mundial da Saúde. Organização PanAmericana da Saúde. Atenção integrada às doenças prevalentes na infância: curso de capacitação. 2. ed. rev. Brasília, DF: Ministério da Saúde, 2002. (Comunicação e Educação em Saúde, série F.).

. Ministério da Saúde. Secretaria de Atenção à Saúde. Departamento de Atenção Básica. Coordenação de Acompanhamento e Avaliação da Atenção Básica. Documento Final da Comissão de Avaliação da Atenção Básica. Produto do trabalho da Comissão instituída pela Portaria № 676 GM/MS de 03 de junho de 2003, publicada no DOU em 04 de junho de 2003. Brasília, DF: Ministério da Saúde, 2003. $36 \mathrm{p}$.

Ministério da Saúde. Secretaria de Atenção à Saúde. Departamento de Atenção Básica. Coordenação de Acompanhamento e Avaliação. Avaliação na Atenção Básica em Saúde: caminhos da institucionalização. Brasília, DF: Ministério da Saúde, 2005. 36 p.

. Ministério da Educação. Secretaria de Educação Básica. Política Nacional de Educação Infantil: pelo direito das crianças de zero a seis anos à educação. Brasília, DF: Ministério da Educação. Secretaria de Educação Básica, 2006.

. Ministério da Saúde. Secretaria de Atenção em Saúde. Departamento de Atenção Básica. Manual do instrumento de avaliação da atenção primária à saúde: Primary Care Assessment Tool Pcatool. Brasília (DF): Ministério da Saúde, 2010a. 80 p. : il. - (Série A. Normas e Manuais Técnicos).

- Ministério da Saúde. Secretaria de Vigilância em Saúde. Secretaria de Atenção à Saúde. Política Nacional de Promoção da Saúde. 3. ed. Brasília, DF: Ministério da Saúde, 2010b. 60 p.

- Ministério da Saúde. Departamento de Informática do Sistema Único de Saúde (DATASUS). Banco de dados do SUS: Mortalidade geral e específica, Brasil - 2011a. Disponível em: <http://www.datasus.gov.br>. Acesso em: 10 jun. 2013.

. Decreto $\mathrm{n} \times 7508$, de 28 de Junho de 2011. 2011b. Disponível em: <http://www.saude.mt.gov.br/upload/documento/4/decreto-n-7508-de-28062011regulamenta-a-lei-n-8080-[4-250711-SES-MT].pdf>. Acesso em: 22 nov. 2013.

- Ministério da Saúde. Departamento de Informática do Sistema Único de Saúde (DATASUS). Banco de dados do SUS: Morbidade hospitalar SUS, Brasil 2012a. Disponível em: <http://www.datasus.gov.br>. Acesso em: 10 jun. 2013. 
Ministério da Saúde. Secretaria de Atenção à Saúde. Departamento de Atenção Básica. Saúde da criança: crescimento e desenvolvimento. Brasília, DF: Ministério da Saúde, 2012b. 272 p.: il. (Cadernos de Atenção Básica, 33).

BRITTO, P. R; ULKUER, N. Child development in developing countries: child rights and policy implications. Child Development, v. 83, n. 1, p. 92-103, 2012.

BROOR, S. et al. Risk factors for severe acute lower respiratory tract infection in underfive children. Indian pediatrics., v. 38, n. 12, p. 1361-1369, 2001.

BROUSSEAU, D. C. et al. Quality of primary care and subsequent pediatric emergency department utilization. Pediatrics, v. 119, n. 6, p. 1131-1138, jun. 2007.

BRUGGEMANN, O. M.; PARPINELLI, M. A.; OSIS, M. J. D. Evidências sobre o suporte durante o trabalho de parto/parto: uma revisão de literatura. Cadernos de Saúde Pública, v. 21, n. 5, p. 1316-1327, 2005.

CAETANO, J. R. M. et al. Fatores associados à internação hospitalar de crianças menores de cinco anos, São Paulo, SP. Revista de Saúde Pública, v. 36, p. 3, p. 285-291, 2002.

CAMINAL, J.; CASANOVA, C. La evaluación de la atención primaria y las hospitalizaciones por ambulatory care sensitive conditions. Marco conceptual. Atencion Primaria, v. 31, n. 1, p. 61-65, 2003.

CAMINAL, J. et al. The role of primary care in preventing ambulatory care sensitive conditions. European Journal of Public Health, v. 14, n. 3, p. 246-251, 2004.

CANANI, R. B. et al. Therapy with gastric acidity inhibitors increases the risk of acute gastroenteritis and community-acquired pneumonia in children. Pediatrics, v. 117, p. e817-e820, 2006.

CARDOSO, T. et al. Additional risk factors for infection by multidrug-resistant pathogens in healthcare associated infection: a large cohort study. BMC Infectious Diseases, v. 12, n. 375, p. 1-9, 2012.

CARVALHO, A. P. A.; VERISSIMO, M. L. Ó. R. Comunicação e educação nas consultas de crianças com infecções respiratórias agudas. Revista da Escola de Enfermagem da USP, v.45, n.4, p. 847-854, 2011. 
CASSADY, C. E. et al. Measuring consumer experiences with primary care. Pediatrics, v. 105, p. 998-1003, 2000.

CAULFIELD, L. E. et al. Undernutrition as an underlying cause of chuld deaths associated with diarrhea, pneumonia, malaria and measles. American Journal of Clinical Nutrition, v. 80, p. 193-198, 2004.

CESAR, J. A. et. al. Hospitalizações por pneumonia: influência de fatores socioeconômicos e gestacionais em uma coorte de crianças no Sul do Brasil. Revista de Saúde Pública, v. 31, n. 1, p. 53-61, 1997.

. et al. Impact of brestfeeding on admission for pneumonia during post neonatal period in Brazil: nested case-control study. BMJ, v. 318, n. 7194, p. 1316-1320, may 1999.

CLIFFORD J.; MCINTYRE E. Who supports breastfeeding? Breastfeed Review., v. 16, n. 2, p. 9-19, 2008.

COLES, C. L. et. al. Nutritional Status and Diarrheal Illness as Independent Risk Factors for Alveolar Pneumonia. American Journal of Epidemiology, v. 162, n. 10, p. 999-1007, 2005.

CORRALES-MEDINA, V. F. et al. The obesity paradox in community-acquired bacterial pneumonia. International Journal of Infectious Diseases, v. 15, p. e54e57, 2011.

CROCKER, J. C. et al. Paediatric pneumonia or empyema and prior antibiotic use in primary care: a case-control study. Journal of Antimicrobial Chemotherapy, v. 67, n. 2, p. 478-487, feb. 2012.

CWIEK, D. et al. Reasons for giving up breastfeeding and support during problems with lactation in the north-western part of Poland. Annales Academiae Medicae Stetinensis, v. 56, n. 2, p.129-132, 2010.

DENNY, F. W.; COLLIER, A. M.; HENDERSON, F. W. ARI in day care. Revista of Infectious Diseases, v. 8, p. 527-532, 1986. 
DEWEY, K. G.; COHEN, R. J. Does birth spacing affect maternal or child nutritional status? A systematic literature review. Maternal and Child Nutrition, v. 3, p. 151-173, 2007.

DHERANI, M. et al. Indoor air pollution from unprocessed solid fuel use and pneumonia risk in children aged under five years: a systematic review and meta-analysis. Bulletin of the World Health Organization, v. 86, n. 5, p. 390-398, 2008.

DING, X. F. et. al. Viral etiology and risk factors for severe community-acquired pneumonia in children. Zhongguo Dang Dai Er Ke Za Zhi, v. 14, n. 6, p. 449-453, jun. 2012.

DONABEDIAN, A. La capacidade de la atención médica: definición e métodos de evaluacón. México: La prensa Médica Mexicana, 1984.

. The seven pillars of quality. Archives of Pathology and Laboratory Medicine, n.114, p.1115-1118, 1990.

. Evaluating the quality of medical care, 1966. The Milbank Quarterly, v. 83, n. 4, p. 691-729, 2005.

EVANS, P.; CLOW, A.; HUCKLEBRIDGE, F. Stress and Imune system. The Psychologist, p. 303-307, jul. 1997.

EVERARD, M. L. Recurrent lower respiratory tract infections - going around in circles, respiratory medicine style. Paediatric Respiratory Reviews, v. 13, p. 139-143, 2012.

FELISBERTO, E. et al. Avaliação do processo de implantação da estratégia da Atenção Integrada às Doenças Prevalentes da Infância no Programa Saúde da Família, no Estado de Pernambuco, Brasil. Cadernos de Saúde Pública, v. 18, n. 6, p. 1737-1745, nov./dez. 2002.

FIGUEIREDO, G. L. A.; PINA, J. C.; TONETE, V. L. P.; LIMA, R. A. G.; MELLO, D. F. Experiences of families in the immunization of Brazilian children under two years old. Revista Latino-Americana de Enfermagem, v.19, n.3, p. 598-605, 2011.

FLEMING, D. W. et al. Childhood upper respiratory tract infections: to what degree is incidence affected by day-care attendance? Pediatrics, v. 79, p. 55-60, 1987. 
FONSECA, W.; KIRKWOOD, B. R.; VICTORA, C. G.; FUCHS, S. R.; FLORES, J. A.; MISAGO, C. Risk factors for childhood pneumonia among the urban poor in Fortaleza, Brazil: a case-control study. Bulletin of the World Health Organization, v. 74, n. 2, p. 199-208, 1996.

FRANCO, T. B.; MERHY, E. E. Programa de Saúde da Família (PSF): contradições de um programa destinado à mudança do modelo tecnoassistencial. In: MERHY, E. E. et al. $O$ trabalho em saúde: olhando e experienciando o SUS no cotidiano. São Paulo: Hucitec, 2003. p. 55-124.

GARBINATO, L. R. et al. Prevalência de internação hospitalar e fatores associados: um estudo de base populacional em um centro urbano no Sul do Brasil. Cadernos de Saúde Pública, v. 23, n. 1, p. 217-224, 2007.

GEIB, L. T. C. et al. Iniquidade na hospitalização por pneumonia: coorte de nascidos vivos. Online Brazilian Journal of Nursing, v. 6, n. 3, 2007.

GIRMA, B.; BERHANE, Y. Children who were vaccinated, breast fed and from low parity mothers live longer: a community based case-control study in Jimma, Ethiopia. BMC Public Health, v. 11, p. 197-203, 2011.

GOLDBART, A. D. et al. Sleep Disordered Breathing is a Risk Factor for CommunityAcquired Alveolar Pneumonia in Early Childhood. Chest, v. 141, n. 5, p. 1210-1215, 2012.

GOVERNO DO ESTADO DE SÃO PAULO. Secretaria de Planejamento e Desenvolvimento Regional. Caracterização socioeconomica de São Paulo - região administrativa de Ribeirão Preto. Governo do Estado de São Paulo: São Paulo, 2012.

GRANT, C. C. et al. Risk factors for community-acquired pneumonia in pre-schoolaged children. Journal of Paediatrics and Child Health, v. 48, n. 5, p. 402-412, may 2012.

GRIBBLE, J. N. et al. Reconsidering childhood undernutrition: can birth spacing make a difference? An analysis of the 2002-2003 El Salvador National Family Health Survey. Maternal and Child Nutrition, v. 5, p. 49-63, 2009.

GUIMARÃES, T. M. R.; ALVES, J. G. B.; TAVARES, M. M. F. Impacto das ações de imunização pelo Programa Saúde da Família na mortalidade infantil por doenças evitáveis em Olinda, Pernambuco, Brasil. Cadernos de Saúde Pública, v. 25, n. 4, p. 868-876, 2009. 
HABICHT, J. P. Estandarizacion de Métodos Epidemiológicos Cuantitativos sobre el terreno. Boletín de la Oficina Sanitaria Panamericana, p. 375-384, may 1974.

HENNEKENS, C. H.; BURING, J. E. Epidemiology in medicine. Boston: Little Brown, 1987.

HAHN, D. L. C. pneumoniae, asthma and COPD: what is the evidence? Annals of Allergy, Asthma, and Immunology, v. 83, p. 271-288, 1999.

HAMILTON, G. Filthy: is too little dirt causing the allergy epidemic? New Scientist, v. 2143, p. 26-31, 1998.

HAN, K. et al. Early use of glucocorticoids was a risk factor for critical disease and death from pH1N1 infection. Clinical Infectious Diseases, v. 53, n. 4, p. 326-333, 2011.

HORTAL, M. et. al. Etiology and severity of community acquired pneumonia in children from Uruguay: a 4-year study. Revista do Instituto de Medicina Tropical de São Paulo, v. 36, n. 3, p. 255-264, 1994.

HOSMER, D. W.; LEMESHOW, S. Applied logistic regression. New York: John Wiley \& Sons, 1989.

INOUE, Y. et al. Risk and protective factors related to mortality from pneumonia among middle aged and elderly community residents: the JACC Study. Journal of Epidemiology, v. 17, p.194-202, 2007.

IZADNEGAHDAR, R. et al. Childhood pneumonia in developing countries. The Lancet Respiratory Medicine, Early Online Publication, 18 June 2013. Disponível em <http://dx.doi.org/10.1016/S2213-2600(13)70075-4>. Acesso em 20 jun. 2013.

JACKSON, S. et al. Risk factors for severe acute lower respiratory infections in children - a systematic review and meta-analysis. Croatian Medical Journal, v. 54, p.110121, 2013.

JOHNSON, A. W. B. R. et al. Etiologic agents and outcome determinants of community-acquired pneumonia in urban children: a hospital-based study. Journal of the National Medical Association, v. 100, n. 4, p. 370-385, apr. 2008. 
JONES, G. et al. How many child deaths can we prevent this year? Lancet, v. 362, n. 9377, p. 65-71, jul. 2003.

JONES, L. L. et al. Parental and household smoking and the increased risk of bronchitis, bronchiolitis and other lower respiratory infections in infancy: systematic review and meta-analysis. Respiratory Research, v. 12, n. 5, p. 1-11, 2011.

JOYCE, C. Steps to success: getting children vaccinated on time. Pediatric Nursing, v. 33, n. 6, p. 491-496, 2007.

KHANAL, V.; SAUER, K.; ZHAO, Y. Exclusive breastfeeding practices in relation to social and health determinants: a comparison of the 2006 and 2011 Nepal Demographic and Health Surveys. BMC Public Health, v. 13, n. 958, 2013.

KIRKWOOD, B. R. et al. Potencial interventions for the prevention of childhood pneumonia in developing countries: a systematic review. Bulletin of the World Health Organization, v. 73, n. 6, p.793-798. 1995.

KRAMER, M. S. Determinants of low birth weight: methodological assessment and meta-analysis. Bulletin of the World Health Organization, v. 65, p. 666-737, 1987.

Balanced protein/energy supplementation in pregnancy. Cochrane Review. Cochrane Library. Issue 4. Oxford: Update Software, 2002.

KUCZMARSKI, R. J.; OGDEN, C. L.; GUO, S. S. 2000 CDC growths chartsfor the United States: methods and development. Center for Disease Control and Prevention / National Center for Health Statistics, 2000.

LACROIX, A. Z. et al. Prospective study of pneumonia hospitalizations and mortality of U.S. older people: the role of chronic conditions, health behaviors, and nutritional status. Public Health Reports, v. 104, p. 350-360, 1989.

LAGERBERG, D; MAGNUSSON, M. Utilization of child health services, stress, social support and child characteristics in primiparous and multiparous mothers of 18-monthold children. Scandinavian Journal of Public Health, v. 41, n. 4, p. 374-383, 2013.

LAHEIJ, R. J. F. et al. Risk of community-acquired pneumonia and use of gastric acidsuppressive drugs. JAMA, v. 292, n. 16, p. 1955- 1960, oct. 2004. 
LAURITSEN, J. M.; BRUUS, M. EpiData (version 3.1). A comprehensive tool for validated entry and documentation of data. Odense, Denmark: The EpiData Association, 2004.

LEMKE, M. et al. Relationship of secondhand smoke and infant lower respiratory tract infection severity by familial atopy status. Annals of Allergy, Asthma \& Immunology, v. 110 , n. 6 , p. 433-437, jun. 2013.

LEÓN-CAVA, N. et al. Quantifying the benefits of breastfeeding: a summary of the evidence. Washington, DC: PAHO, 2002.

LIEBERMAN, D. et al. Serological evidence of Mycoplasma pneumoniae infection in acute exacerbation of COPD. Diagnostic Microbiology and Infectious Disease, v. 44, n. 1, p. 1-6, sep. 2002.

LU, N. et al. Child day care risks of common infectious diseases revisited. Child Care, Health and Development, v. 30, p. 361-368, 2004.

MACEDO, S. E. C. et al. Fatores de risco para internação por doença respiratória aguda em crianças até um ano de idade. Revista de Saúde Pública, v. 41, n. 3, p. 351-358, 2007.

MACINKO, J.; ALMEIDA, C.; OLIVEIRA, E. Avaliação das características organizacionais dos serviços de atenção básica em Petrópolis: teste de uma metodologia. Saúde em Debate, v. 27, n. 65, p.243-256, 2003.

MAHON, B. E. et al. Perinatal risk factors for hospitalization for pneumococcal disease in chidhood: a population-based cohort study. Pediatrics, v. 119, n. 4, p. e804-e812, 2007.

MALOUIN, R. A.; STARFIELD, B.; SEPULVEDA, M. J. Evaluating the Tools Used To Assess the Medical Home. Managed Care, p. 44-48, jun. 2009.

MARANHÃO, A. G. K. Mortalidade infantil no Brasil: tendências, componentes e causas de mortes no período 2000 a 2010. In: BRASIL. Ministério da Saúde. Secretaria de Vigilância em Saúde. Departamento de Análise de Situação de Saúde. Saúde Brasil 2011: uma análise da situação de saúde e a vigilância da saúde da mulher. Brasília, DF: Ministério da Saúde, 2012. 444 p. 
MARTIN, R. J. et al. A link between chronic asthma and chronic infection. Journal of Allergy and Clinical Immunology, v. 107, p. 595-601, 2001.

MATSUMOTO, Y. et al. Risk factors for infection in patients with remitted rheumatic diseases treated with glucocorticoids. Acta Medica Okayama, v.65, n. 5, p. 329-334, 2011.

MELLO, D. F. et al. Seguimento da saúde da criança e a longitudinalidade do cuidado. Revista Brasileira de Enfermagem, v. 65, n. 4, p. 675-679, 2012.

MELO, A. M. C. et al. Characteristics and factors associated with health care in children younger than 1 year with very low birth weight. Jornal de Pediatria, v. 89, n. 1, p. 75-82, 2013.

MENDES, E.V. A atenção primária à saúde no SUS. Ceará: Escola de Saúde Pública do Ceará, 2002. p. 7-29.

MERCHANT, K.; MARTORELL, R.; HAAS, J. D. Maternal and fetal responses to the stresses of lactation concurrent with pregnancy and of short recuperative intervals. American Journal of Clinical Nutrition, v. 52, p. 280-288, 1990.

MILLMAN, S.R.; COOKSEY, E.C.. Birth weight and the effects of birth spacing and breastfeeding on infant mortality. Studies in Family Planning, v. 18, p. 202-212, 1987.

MONTEIRO, C. A. et al. Causas do declínio da desnutrição infantil no Brasil, 19962007. Revista de Saúde Pública, v. 43, n. 1, p. 35-43, 2009.

MORAN, V. H. et al. An evaluation of the breastfeeding support skills of midwives and voluntary breastfeeding supporters using the breastfeeding support skills tool (BeSST). Maternal \& Child Nutrition, v. 1, n. 4, p. 241-249, 2005.

MURUGAN, A. T.; SHARMA, G. Obesity and respiratory diseases. Chronic Respiratory Disease, v. 5, n. 4, p, 233-242, 2008.

NASCIMENTO-CARVALHO, C. M. C. et al. Childhood pneumonia: clinical aspects associated with hospitalization or death. Brazilian Journal of Infectious Diseases, v. 6 , n. 1, p. 22-28, 2002. 
NASCIMENTO, L. F. C. et al. S. Análise hierarquizada dos fatores de risco para pneumonia em crianças. Jornal Brasileiro de Pneumologia, v. 30, n. 5, p. 445-451, set-out 2004.

NEUFELD, L. M. et al. Changes in maternal weight from the first to second trimester of pregnancy are associated with fetal growth and infant length at birth. American Journal of Clinical Nutrition, v. 79, p. 646-652, 2004.

NIESSEN, L. W. et al. Comparative impact assessment of child pneumonia interventions. Bulletin of the World Health Organization, v. 87, n. 6, p. 472-480, jun. 2009.

OLIVEIRA, B. R. G. et al. Causas de hospitalização no SUS de crianças de zero a quatro anos no Brasil. Revista Brasileira de Epidemiologia, v. 13, n. 2, p. 268-277, 2010.

OLIVEIRA, B. R. G. et al. Acesso de primeiro contato na atenção primária em saúde para crianças. Revista da Rede de Enfermagem do Nordeste, v. 13, n. 2, p. 332342, 2012.

OMS (Organização Mundial da Saúde). UNICEF (Fundo das Nações Unidas para a Infância). Alma-Ata 1978. Cuidados Primários de Saúde. Brasília: UNICEF, 1979.

ONIS, M. et al. Worldwide implementation of the WHO Child Growth Standards. Public Health Nutrition, v. 15, p. 1603-1610, 2012.

OPAS (Organização Pan-Americana de Saúde). Atenção Integrada às Doenças Prevalentes na Infância. Conversando com as mães sobre AIDPI: o processo de comunicação com as mães durante as consultas nos serviços de saúde. Tradução de Maria Helena Valente e Maria De La Ó Ramallo Veríssimo. São Paulo: Ministério da Saúde, 1999. 122 p., il. (Série HCT/AIDPI, 14).

OPAS (Organização Panamericana da Saúde). Renovação da Atenção Primária à Saúde nas Américas. Documento de posicionamento da Organização Panamericana da Saúde / Organização Mundial da Saúde (OPAS/OMS). Washington: OPAS/OMS, 2007.

OSTAPCHUK, M.; ROBERTS, D. M.; HADDY, R. Community-acquired pneumonia in infants and children. American Family Physician, v. 70, n. 5, p. 889-908, 2004. 
PAGAIYA, N.; GARNER, P. Primary care nurses using guidelines in Thailand: a randomized controlled trial. Tropical Medicine and International Health, v. 10, n. 5, p. 471-477, may 2005.

PAIM, J. et al. O sistema de saúde brasileiro: história, avanços e desafios. Lancet, v. 377, n. 9780, p. 11-31, 2011.

PATRIA, F. et al. Clinical profile of recurrent community-acquired pneumonia in children. BMC Pulmonary Medicine, v. 13, n. 60, 2013.

PERCH (Pneumonia Etiology Research for Child Health). Pneumonia Etiology Research for Child Health, 2012. Disponível em <http://www.jhsph.edu/research/centers-and-institutes/ivac/projects/perch/>. Acesso em 10 jun. 2013.

PEREIRA, M. J. B. Avaliação das características organizacionais e de desempenho das unidades de atenção básica em saúde do distrito oeste do município de Ribeirão Preto. 2008. Tese (Livre docência) - Escola de Enfermagem de Ribeirão Preto, Universidade de São Paulo, Ribeirão Preto-SP, 2008.

PINTO, K. D. B. P. C.; MAGGI, R. R. S.; ALVES, J. G. B. Análise de risco sócioambiental para comprometimento pleural na pneumonia grave em crianças menores de 5 anos. Revista Panamericana de Salud Publica, v. 15, n. 2, p. 104-109, 2004.

QASEMA, J. A. et al. Application of three uniplex polymerase chain reaction assays for the detection of atypical bacteria in asthmatic patients in Kuwait. Journal of Infection and Public Health, v. 6, p. 134-141, 2013.

RAMACHANDRAN, P. et al. Risk factors for mortality in community -acquired pneumonia among children aged 1-59 months admitted in a referral hospital. Indian Pediatrics, v. 49, p.889-895, nov. 2012.

REED, C. et al. Development of the Respiratory Index of Severity in Children (RISC) score among young children with respiratory infections in South Africa. PLoS ONE, v. 7, n. 1, p. e27793, jan. 2012.

REYES, $\mathrm{H}$. et al. Infant mortality due to acute respiratory infections: the influence of primary care processes. Health Policy and Planning, v. 12, n. 3, p. 214-223, 1997. 
RIBEIRÃO PRETO. Secretaria Municipal de Saúde. Relatório de Gestão - período de janeiro a dezembro de 2012. Ribeirão Preto (SP): Secretaria Municipal da Saúde, 2012.

RIBEIRÃO PRETO. Secretaria Municipal de Saúde. Rede Amamenta Brasil em Ribeirão Preto 2013. Indicadores de Aleitamento Materno no Município de Ribeirão nos anos de 1999, 2003 e 2008, 2011. Disponível em: $<$ http://www.ribeiraopreto.sp.gov.br/ssaude/programas/aleita/amamenta brasil/rede amamenta rp-2013.pdf>. Acesso em 22 nov. 2013.

ROMANI, S. A. M.; LIRA, P. I. C. Fatores determinantes do crescimento infantil. Revista Brasileira de Saúde Materno Infantil, v. 4, n. 1, p.15-23, 2004.

ROTH, D. E.; RICHARD, S. A.; BLACK, R. E. Zinc supplementation for the prevention of acute lower respiratory infection in children in developing countries: meta-analysis and meta-regression of randomized trials. International Journal of Epidemiology, v. 39, p. 795-808, 2010.

RUDAN, I et al. Global estimate of incidence of clinical pneumonia among children under five years of age. Bulletin of the World Health Organization, v. 82, n. 12, p. 895-903, dec. 2004.

RUDAN, I. et al. Epidemiology and etiology of childhood pneumonia. Bulletin of the World Health Organization, v. 86, n. 5, p. 408-416, may 2008.

RUTSTEIN, S. O. Effects of preceding birth intervals on neonatal, infant and underfive years mortality and nutritional status in developing countries: evidence from the demographic and health surveys. International Journal of Gynecology and Obstetrics, v. 89, p. S7-S24, 2005.

SALCEDO POSADAS, A. et al. Problemática diagnóstica y terapéutica de la patología respiratoria asocial: al síndrome aspirativo recurrente y al reflujo gastroesofágico / Diagnostic and therapeutic problems presented by respiratory disease associated with recurrent aspiration syndrome and gastroesophageal reflux. Acta Pediatrica Española, v. 62, n. 4, p. 135-142, abr. 2004.

SANGRADOR, C. O.; SÁNCHEZ, M. V. B.; MARTÍN, B. M. Relación entre la asistencia a guarderías y enfermedad infecciosa aguda en la infancia. Una revisión sistemática. Revista Española de Salud Pública, v. 81, n. 2, p. 113-129, mar./abr. 2007. 
SAZAWAL, S.; BLACK, R. E. Effect of pneumonia case management on mortality in neonates, infants, and preschool children: a meta-analysis of community-based trials. The Lancet, v. 3, n. 9, p. 547-556, sep. 2003.

SCHLLESSELMAN, J. J. Case-control studies - design conduct and analysis. New York: Oxford University Press, 1982.

SCOTT, H. A. et al. Dietary restriction and exercise improve airway inflammation and clinical outcomes in overweight and obese asthma: a randomized trial. Clinical \& Experimental Allergy, v. 43, p. 36-49, 2012.

SEID, M.; STEVENS, G. D. Access to Care and Children's Primary Care Experiences: Results from a Prospective Cohort Study. Health Services Research, v. 40, n. 6, pt 1, p. 1758-1780, dec. 2005.

SHOHAM, Y. et. al. Community-acquired pneumonia in children: quantifying the burden on patients and their families including decrease in quality of life. Pediatrics, v. 115, p. 1213-1219, 2005.

SIGAÚQUE, B. et. al. Severe pneumonia in mozambican young children: clinical and radiological characteristics and risk factors. Journal of Tropical Pedriatrics, v. 55, n. 6, p. 379-387, 2009.

SILVA, S. F. Organização de redes regionalizadas e integradas de atenção à saúde: desafios do Sistema Único de Saúde (Brasil). Ciência e saúde coletiva, v.16, n.6, p. 2753-2762, 2011.

SOCIEDADE BRASILEIRA DE PEDIATRIA. Avaliação nutricional da criança e do adolescente - Manual de Orientação. São Paulo: Sociedade Brasileira de Pediatria, 2009. $112 \mathrm{p}$.

SOCIEDADE BRASILEIRA DE PNEUMOLOGIA E TISIOLOGIA. Diretrizes brasileiras em pneumonia adquirida na comunidade em pediatria - 2007. Jornal Brasileiro de Pneumologia, v. 33, p. S31-S50, 2007. Suplemento 1.

Bronquiolite Aguda: Tratamento e Prevenção. Diretrizes Clínicas na Saúde Suplementar. Associação Médica Brasileira e Agência Nacional de Saúde Suplementar, 2011. 
STARFIELD, B. Atenção Primária à Saúde: equilíbrio entre as necessidades de saúde, serviços e tecnologias. Brasília: UNESCO, 2002. 726p.

STATA CORP-LP. Stata/MP versão 12 for Windows. Copyright 2010. Stata CorpLP.

TANAKA, O. U.; SANTO, A. C. G. E. Avaliação da qualidade da atenção básica utilizando a doença respiratória da infância como traçador, em um distrito sanitário do município de São Paulo. Revista Brasileira de Saúde Materno Infantil, v. 8, n. 3, p. 325-332, jul./set. 2008.

TEEPE, J.; GRIGORYAN, L.; VERHEIJ T. J. M. Determinants of community-acquire pneumonia in chldren and young adults in primary care. European Respiratory Journal, v. 35, p. 1113-1117, 2010.

THAME, M. et al. Fetal growth is directly related to maternal anthropometry and placental volume. European Journal of Clinical Nutrition, v. 58, p. 894-900, 2004.

THE WORLD BANK. World development report 2006 - Equity and Development. New York: Oxford University Press, 2006.

UNICEF (United Nations Children's Fund) / WHO (World Health Organization). Pneumonia: The forgotten killer of children. UNICEF / WHO, 2006.

UNICEF (United Nations Children's Fund). Tracking progress on child and maternal nutrition: a survival and development priority. UNICEF, 2009.

Levels \& Trends in Child Mortality. Report 2012. New York: UNICEF, 2012.

VICTORA, C. G. et al. Pneumonia, diarrhea and growth in the first y of life: a longitudinal study of 5914 urban brazilian children. American Journal of Clinical Nutrition, v. 52, p. 391-396, 1990.

. The association between wasting and stunting: an international perspective. Jurnal of Nutrition, v. 122, n. 5, p. 1105-1110, 1992.

et al. Risk factors for pneumonia among children in a Brazilian metropolitan area. Pediatrics, v. 93, n. 6, p. 977-985, jun. 1994. 
et al. The role of conceptual frameworks in Epidemiological analysis: a hierarchical approach. International Journal of Epidemiology, v. 26, n. 1, p. 224227, feb. 1997.

et al. Potential interventions for the prevention of chilhood pneumonia in developing countries: improving nutrition. American Journal of Clinical Nutrition, v. 70, p. 309-320, 1999.

et al. Maternal and child health in Brazil: progress and challenges. Lancet, v. 377, n. 9780, p. 1863-1876, 2011.

WALKER, S. P. et al. Inequality in early childhood: risk and protective factors for early child development. Lancet, v. 378, n.9799, p.1325-1338, 2011.

WALKER, C. L. et al. Global burden of childhood pneumonia and diarrhoea. Lancet, v. 381, n. 9875, p. 1405-1416, apr. 2013.

WINCHESTER, C. C. et al. Antibiotic Prescribing and Outcomes of Lower Respiratory Tract Infection in UK Primary Care. Chest, v. 135, n. 5, p. 1163-1172, 2009.

WHO (World Health Organization). The Vitamin A and Pneumonia Working Group. Potential interventions for the prevention of childhood pneumonia in developing countries: a meta-analysis of data from field trials to assess the impact of vitamin A supplementation on pneumonia morbidity and mortality. Bulletin of the World Health Organization, v. 73, n. 5, p. 609-619, 1995.

- Pneumonia Vaccine Trial Investigators Group. Standardization of interpretation of chest radiographs for de diagnoses of pneumonia in children. Geneva: WHO, 2001.

Department of Nutrition for Health and Development. Complementary feeding: report of the global consultation, and summary of guiding principles for complementary feeding of the breastfed child. Geneva: WHO, 2002.

Multicentre Growth Reference Study Group. WHO Child Growth Standards based on length / height, weight and age. Acta Paediatrica, v. 95, s. 450, p. 76-85, 2006. 
WHO child growth standards: training course on child growth assessment. Geneva: WHO, 2008.

Global Action Plan for Prevention and Control of Pneumonia (GAPP). Geneva: WHO, 2009.

Anthro for personal computers. Software for assessing growth and development of the world's children. Version 3.1. Geneva: WHO, 2010.

Recommendations for management of common childhood conditions:

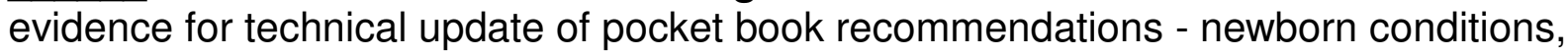
dysentery, pneumonia, oxygen use and delivery, common causes of fever, severe acute malnutrition and supportive care. Geneva: WHO, 2012.

WONODI, C. B. et. al. Evaluation of Risk Factors for Severe Pneumonia in Children: The Pneumonia Etiology Research for Child Health Study. Clinical Infectious Diseases, v. 54, s. 2, p. S124-S131, 2012. Supplement.

ZADIK, Z. Maternal nutrition, fetal weight, body composition and disease in later life. Journal of Endocrinological Investigation, v. 26, p. 941-946, 2003.

ZUTAVERN, A. et al. Day care in relation to respiratory-tract and gastrointestinal infections in a German birth cohort study. Acta Pædiatrica, v. 96, p. 1494-1499, 2007. 


\section{APÊNDICE A \\ FLUXOGRAMA PARA SELEÇ̃̃O DE CASOS}

Entrevistador: seguem critérios para selecionar as crianças que participarão do estudo como CASOS

ATENCẼ̃O: cada criança só participará uma única vez do estudo

Seguir o critério de temporalidade - ORDEM DE ENTRADA É FUNDAMENTAL (começar a busca pelo que chegou primeiro) NÃO INCLUIR CRIANÇAS QUE ESTÃO INTERNADAS DESDE O NASCIMENTO

Primeiramente, buscar crianças com diagnóstico de pneumonia, na Enfermaria Pediátrica, consultando o censo ou livro de internação. Ao identificar uma criança de interesse, pedir que o enfermeiro indique o médico responsável por ela.

$>$ A seguir, checar com a O MÉDICO RESPONSÁVEL PELA CRIANCA as informações abaixo:

a) A criança foi internada com diagnóstico de pneumonia, confirmado por RX e registrado em prontuário?

- Se NÃO=Excluir;

- Se SIM=Ir para item b)

b) A pneumonia atual foi adquirida no hospital (apareceu depois de $48 \mathrm{~h}$ de internação)?

- Se SIM, ou seja, se for uma pneumonia hospitalar=Excluir;

- Se NÃ̃o, ou seja, se for uma pneumonia comunitária (adquirida em casa ou na comunidade)=Checar as demais informações com a MÃE ou responsável pela criança, seguindo o fluxograma abaixo:

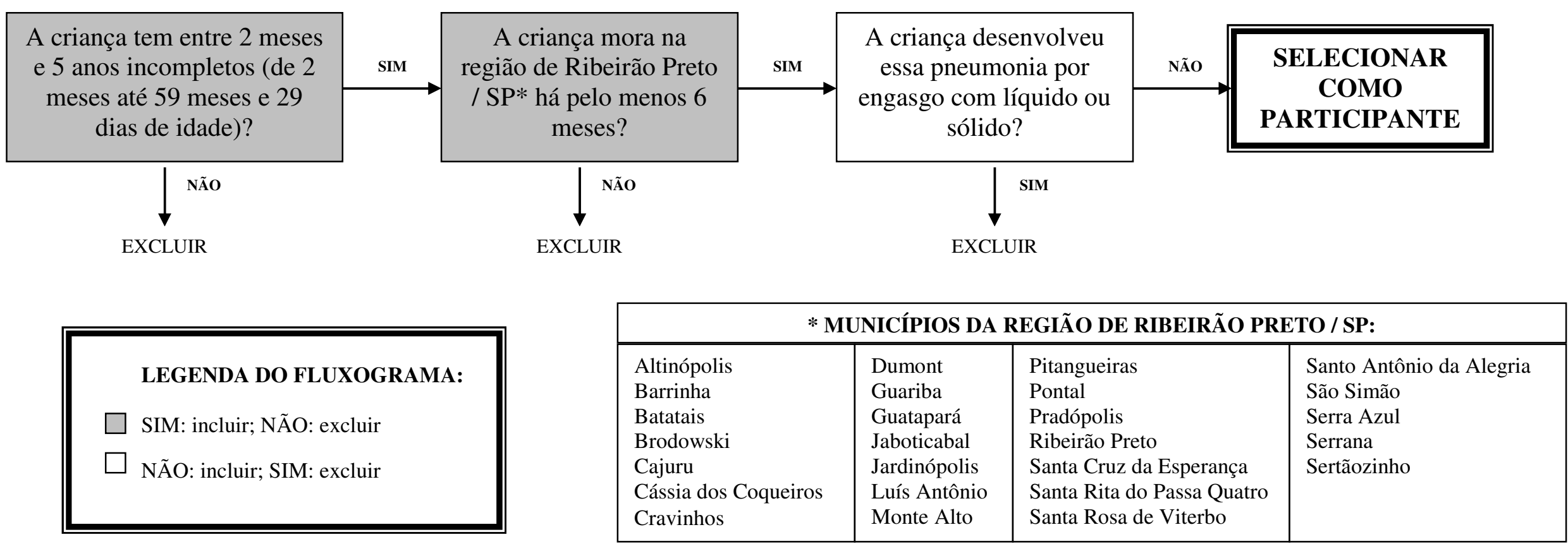




\section{FLUXOGRAMA PARA SELECÃO DE CONTROLES}

Entrevistador: seguem critérios para selecionar as crianças que participarão do estudo como CONTROLES ATENÇÃO: cada criança só participará uma única vez do estudo

Seguir o critério de temporalidade - ORDEM DE ENTRADA É FUNDAMENTAL (começar a busca pelo que chegou primeiro) NÃO INCLUIR CRIANÇAS QUE ESTÃO INTERNADAS DESDE O NASCIMENTO

$>$ Procurar crianças sem doencas respiratórias, de sexo e faixa etária* constantes na lista de controles a serem recrutados, obedecendo a seguinte ordem:

10) ENFERMARIA PEDIÁTRICA - buscar no censo ou no livro de internação

$2^{\circ}$ ) AMBULATÓRIO PEDIÁTRICO - busca na agenda de consultas ou livro de registro de entradas

$3^{\circ}$ ) PRONTO-ATENDIMENTO PEDIÁTRICO (PA) - buscar na lista de pacientes ou livro de registro de entradas \#\# Se não encontrar crianças sem doenças respiratórias, entrar em contato com o coordenador de campo.\#\#

$>$ Após identificação de um controle em potencial, proceder de acordo com o setor:

$\left.1^{\circ}\right)$ ENFERMARIA PEDIÁTRICA - Perguntar ao médico responsável pela criança: A criança está com suspeita ou diagnóstico atual de pneumonia? - Se SIM=Excluir como controle - avaliar se preenche os critérios de seleção de casos;

- Se NÃO=Checar as demais informações com a MÃE ou responsável pela criança, seguindo o fluxograma.

$2^{\circ}$ ) AMBULATÓRIO PEDIÁTRICO / PA - Perguntar ao médico do ambulatório/PA, após a realização da consulta / atendimento: A criança está com suspeita ou diagnóstico atual de pneumonia?

- Se SIM=Excluir;

- Se NÃO=Checar as demais informações com a MÃE ou responsável pela criança, seguindo o fluxograma.

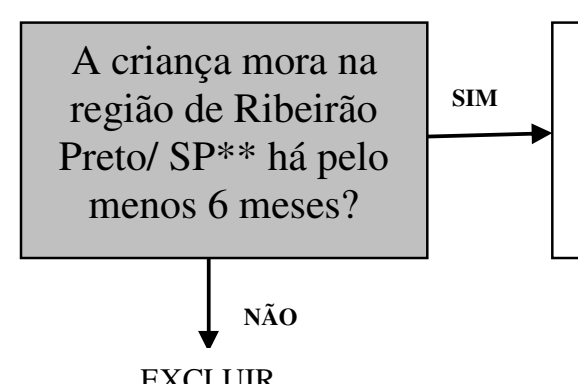

LEGENDA DO FLUXOGRAMA:

$\square$ SIM: incluir; NÃO: excluir

$\square$ NÃO: incluir; SIM: excluir

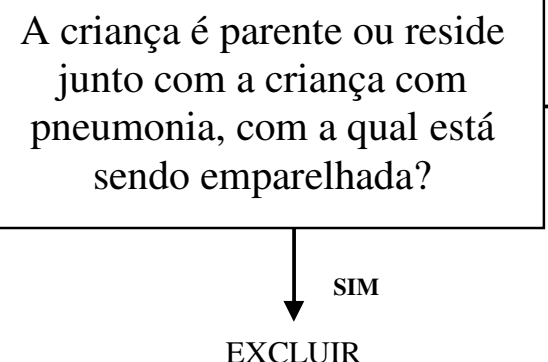

\begin{tabular}{|c|}
\hline $\begin{array}{c}\text { *Faixas etárias para } \\
\text { emparelhamento de casos e } \\
\text { controles: }\end{array}$ \\
2 meses 1 dia a 6 meses \\
6 meses 1 dia a 12 meses \\
12 meses 1 dia a 24 meses \\
24 meses 1 dia a 59 meses 29 dias
\end{tabular}

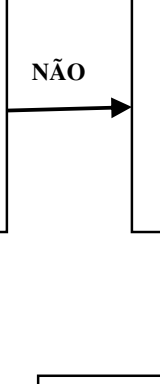

\begin{tabular}{|l|l|l|l|}
\hline \multicolumn{3}{|c|}{$* *$ MUNICÍPIOS DA REGIÃO DE RIBEIRÃO PRETO / SP: } \\
\hline Altinópolis & Dumont & Pitangueiras & Santo Antônio da Alegria \\
Barrinha & Guariba & Pontal & São Simão \\
Batatais & Guatapará & Pradópolis & Serra Azul \\
Brodowski & Jaboticabal & Ribeirão Preto & Serrana \\
Cajuru & Jardinópolis & Santa Cruz da Esperança & Sertãozinho \\
Cássia dos Coqueiros & Luís Antônio & Santa Rita do Passa Quatro & \\
Cravinhos & Monte Alto & Santa Rosa de Viterbo & \\
\hline
\end{tabular}

A criança engasgou com líquido ou sólido, nos últimos 2 meses, e vem apresentando febre, falta de apetite e tosse ou dificuldade para respirar, desde então?
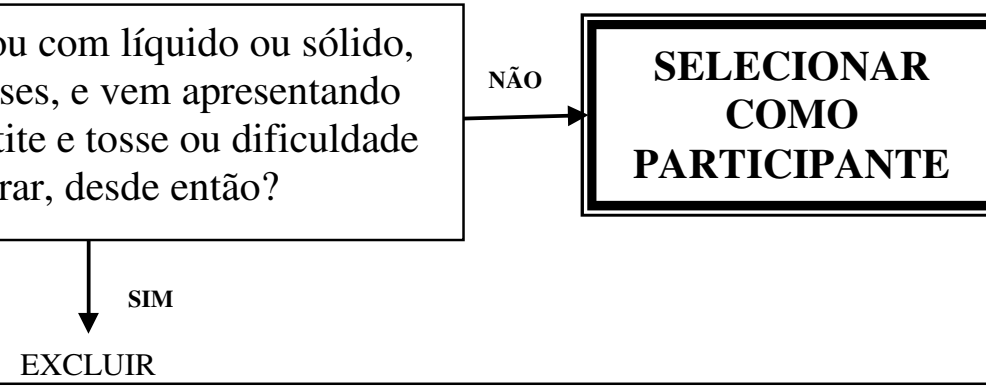

SIM

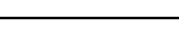




\section{APÊNDICE B - QUESTIONÁRIO SOBRE A SAÚDE DE CRIANÇAS}

Hospital:

Entrevistador 1:

Data da entrevista:

Entrevistador 2:

Coordenador:

Supervisor: data:

1

Digitador 1: Digitador 2:

Número do questionário: I____ I I Registro:

$\mathrm{CA}() \quad \mathrm{CO}()$

\section{INFORMAÇÕES GERAIS}

Entrevistador: Se o entrevistado não souber qualquer uma das informações ou não responder, lançar o código 99 (ou com mais dígitos, se necessário) ou assinalar NS/NR.

1 Nome completo da criança:

\begin{tabular}{|l|l|}
\hline & Local de seleção da criança: \\
\hline
\end{tabular}

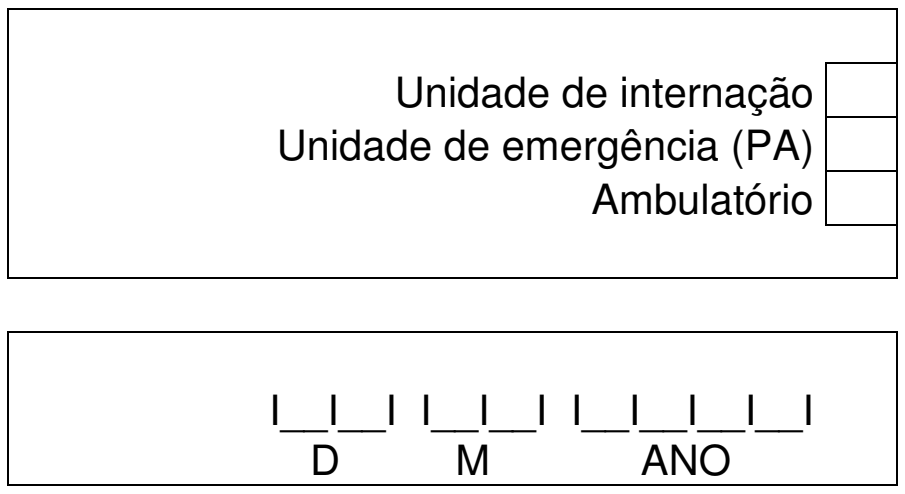

3

Data da hospitalização / entrada / consulta:

D

$\mathrm{M}-\overline{\mathrm{ANO}}$

4 Motivos da hospitalização / entrada / consulta:

\begin{tabular}{|l|l|}
\hline 5 & Sexo da criança: \\
\hline
\end{tabular}

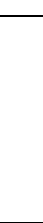

Feminino. .1

Masculino 2

Data de nascimento da criança:

$\frac{I}{D}-1 \frac{1}{M}-1-\frac{1}{A N O}-1$


Idade da criança:

7

Entrevistador - faça o cálculo da idade em meses $E$ anote a faixa etária: idade em meses: I

2 a 6 meses

6 meses e 1 dia a 12 meses

12 meses e 1 dia a 24 meses

24 meses e 1 dia a 59 meses e 29 dias

Nome completo do responsável:

Endereço: Logradouro:

8

$\mathrm{n}: \ldots$, Complemento: , Bairro:

Cidade:

Estado: CEP:

Telefones fixos: $(\quad)$

Telefones celulares: ( )

9 Qual é a sua relação com a criança?

Mãe. 1

Pai. 2

Irmão 3

Outro parente..................................4

Amigo 5

Outro: 6

\section{INFORMAÇÕES SOBRE A CRIANÇA, SUA FAMÍLIA E DOMICÍLIO}

10

Quantas pessoas moram na casa desta criança?

Quantos cômodos existem no domicílio desta

11 criança, contando com o banheiro?

Entrevistador: cômodos = áreas divididas por paredes

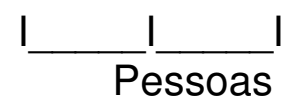

1

Cômodos 
12

Quantos são utilizados como quarto?

Quantas pessoas dividem o quarto com esta criança?

13 criança?

$14 \begin{aligned} & \text { Quantas pessoas dividem a cama com esta } \\ & \text { criança? }\end{aligned}$

15

Quantas crianças (menores de 12 anos), além desta, residem na mesma casa?

No domicílio desta criança, é utilizado algum outro

16 tipo de fogão/forno, além do a gás ou do elétrico?

A casa onde mora esta criança possui esgoto

17 ligado à rede pública?

18

Quantas pessoas que moram na casa desta criança possuem renda (incluindo o entrevistado)?

Qual foi a renda do chefe da família desta criança, no último mês?
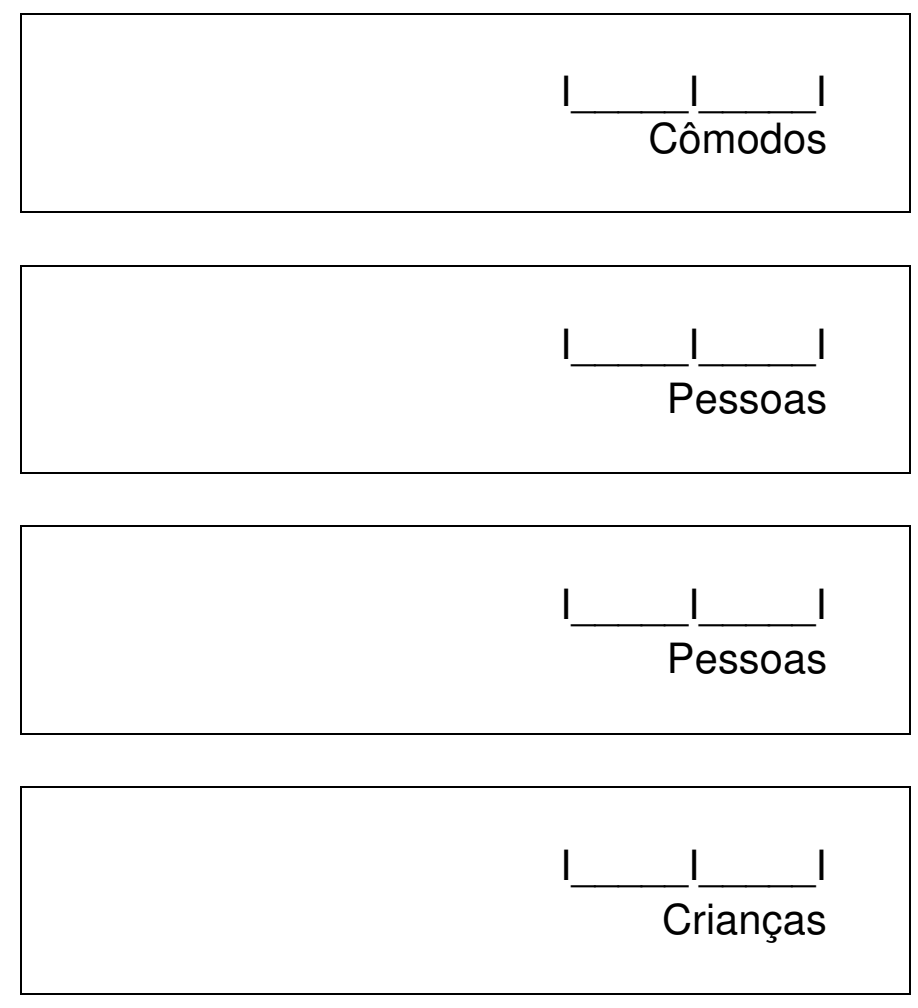

Não.

. .1

Sim, churrasqueira ..............2

Sim, a lenha......................... 3

Sim, a querosene ................. 4

NS/NR. 9

Não. .1

Sim 2

NS/NR.

.9

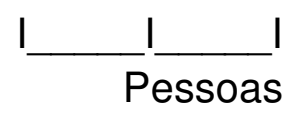

R\$ I_I_I_I_I_I,I_I_I 


\begin{tabular}{|l|l|}
\hline 20 & $\begin{array}{l}\text { O(a) Sr.(a) poderia me dizer qual foi a renda } \\
\text { de cada uma das pessoas da casa, no último } \\
\text { mês? }\end{array}$ \\
\hline
\end{tabular}

Morador 1

\begin{tabular}{|l|l|}
\hline 21 & $\begin{array}{l}\text { Há quantas pessoas, maiores de } 18 \text { anos, sem } \\
\text { renda, na casa desta criança? }\end{array}$ \\
\hline
\end{tabular}

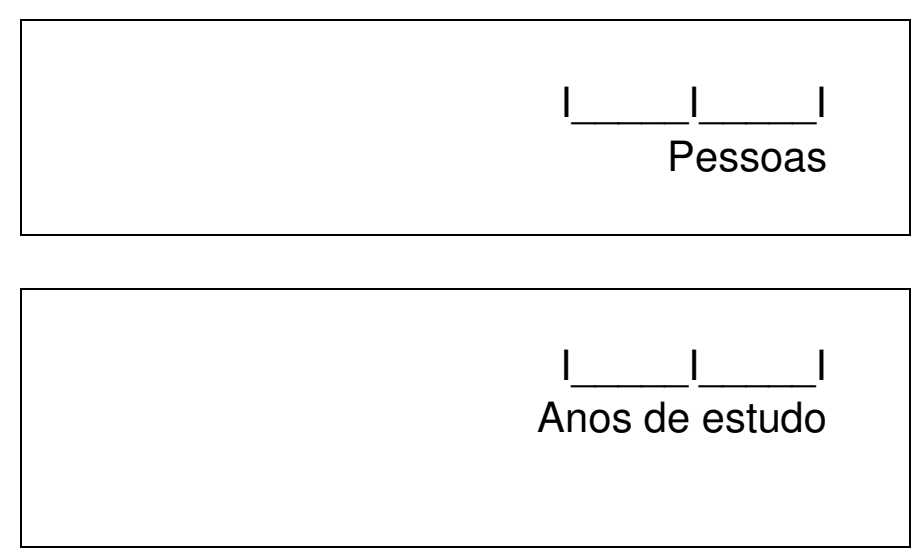

Qual é a escolaridade do pai da criança?

22 Entrevistador: considerar anos de estudo, de escolaridade formal, com aprovação.

Qual é a escolaridade da mãe da criança ou de seu responsável?

Entrevistador: considerar anos de estudo, de escolaridade formal, com aprovação.

Qual foi a data de nascimento da mãe desta criança?

Entrevistador: Em caso de desconhecimento, anotar a idade em anos completos.

Atualmente, a mãe desta criança ou seu

25 responsável vive com um companheiro?

Não.

Sim.

NS/NR. 


\begin{tabular}{|l|l|}
\hline 26 & $\begin{array}{l}\text { Atualmente, a mãe desta criança ou seu } \\
\text { responsável trabalha fora de casa? }\end{array}$ \\
\hline
\end{tabular}

\begin{tabular}{|l|l|}
\hline 27 & $\begin{array}{l}\text { Desde o nascimento desta criança, a mãe dela ou } \\
\text { seu responsável trabalhou, alguma vez, fora de } \\
\text { casa? } \\
\text { Entrevistador: se SIM, perguntar por quanto tempo. }\end{array}$ \\
\hline
\end{tabular}

\begin{tabular}{|l|l|}
\hline 28 & $\begin{array}{l}\text { Atualmente, a mãe desta criança fuma? } \\
\text { Entrevistador: } 1 \text { maço }=20 \text { cigarros }\end{array}$ \\
\hline
\end{tabular}

\begin{tabular}{|l|l|}
\hline 29 & $\begin{array}{l}\text { Há quanto tempo a mãe desta criança fuma? } \\
\text { Entrevistador: considerar anos e meses completos de fumo. } \\
\text { Descontar os períodos de interrupção do hábito. }\end{array}$ \\
\hline
\end{tabular}

\begin{tabular}{|l|l|}
30 & $\begin{array}{l}\text { Quantos cigarros a mãe desta criança fuma, por } \\
\text { dia? } \\
\text { Entrevistador: } 1 \text { maço = } 20 \text { cigarros }\end{array}$ \\
\hline
\end{tabular}

Se não fuma, a mãe desta criança alguma vez já 31 fumou?
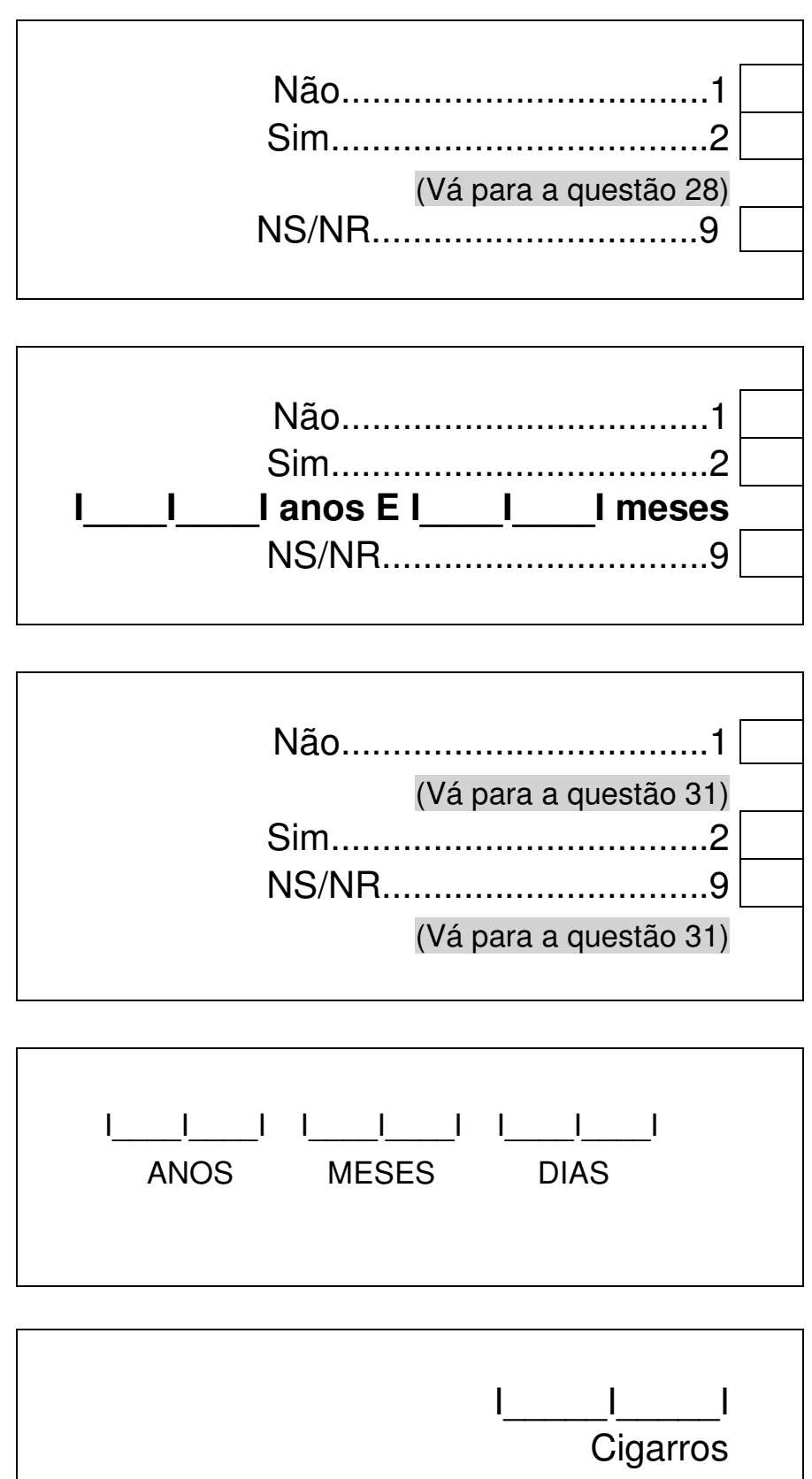

(Vá para a questão 35)

Não. ..1

(Vá para a questão 38)

Sim. 2

NS/NR .............................9

(Vá para a questão 38) 
Por quanto tempo a mãe desta criança fumou?

Entrevistador: considerar anos e meses completos de fumo Descontar os períodos de interrupção do hábito.

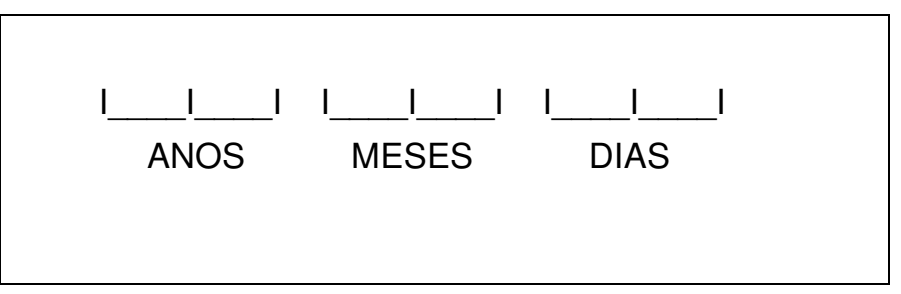

Há quanto tempo a mãe desta criança parou de fumar?

Entrevistador: considerar anos e meses completos de abandono do tabagismo

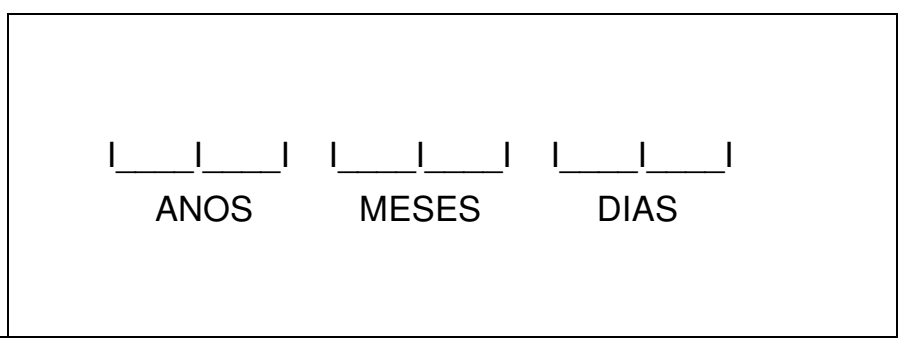

Quantos cigarros a mãe desta criança fumava, por 34 dia?

Entrevistador: 1 maço $=20$ cigarros

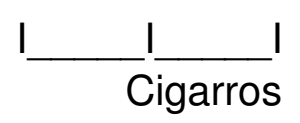

A mãe desta criança fumou durante a gestação dela?

Por quanto tempo a mãe desta criança fumou, durante a gestação dela?

Entrevistador: considerar anos e meses completos de fumo. Descontar os períodos de interrupção do hábito.

Quantos cigarros a mãe desta criança fumava, por dia, durante a gestação dela?

Não .1

(Vá para a questão 38)

Sim 2

NS/NR .9

(Vá para a questão 38)

Entrevistador: 1 maço $=20$ cigarros

$1 \quad \frac{1}{\text { MESES }}$ e $\frac{1}{\text { DIAS }}$

I Cigarros 


\begin{tabular}{|l|l|}
\hline 38 & Há mais alguém na casa desta criança que fuma? \\
\hline 39 & $\begin{array}{l}\text { Quantas pessoas (além da mãe) fumam na casa } \\
\text { em que esta criança mora? }\end{array}$ \\
\hline
\end{tabular}
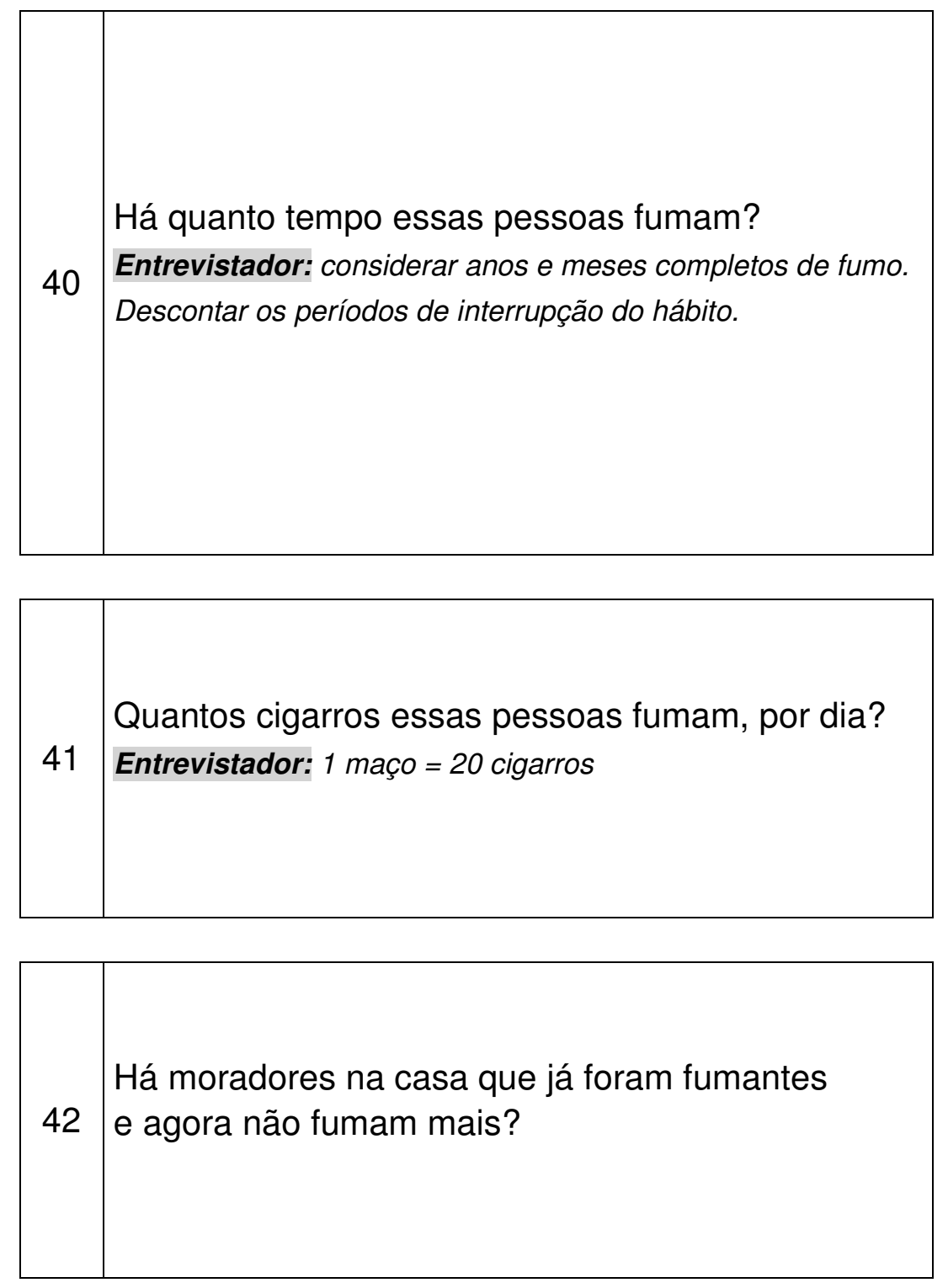

Não .1

(Vá para a questão 42)

Sim. 2 NS/NR 9

(Vá para a questão 42)

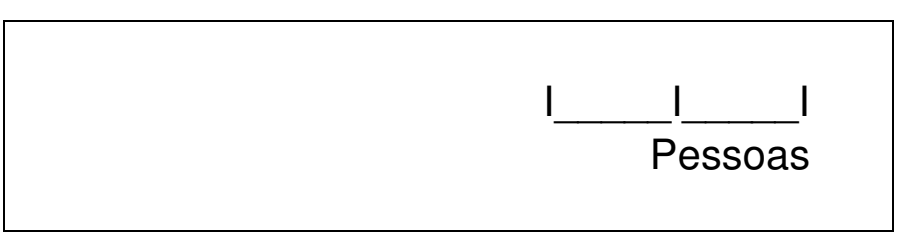

\begin{tabular}{|c|c|c|c|c|c|}
\hline Fumante $1: I$ & I & 11 & 11 & _ & I \\
\hline & ANOS & MESES & & DIAS & \\
\hline \multirow[t]{2}{*}{ Fumante $2: 1$} & _ & 11 & 11 & I & I \\
\hline & ANOS & MESES & & DIAS & \\
\hline \multirow[t]{2}{*}{ Fumante $3: 1$} & - & 1 & 11 & I & I \\
\hline & ANOS & MESES & & DIAS & \\
\hline \multirow[t]{2}{*}{ Fumante $4: 1$} & - & 11 & 11 & - & I \\
\hline & ANOS & MESES & & DIAS & \\
\hline \multirow[t]{2}{*}{ Fumante $5: 1$} & I & 11 & 11 & I & I \\
\hline & ANOS & MESES & & DIAS & \\
\hline
\end{tabular}

Fumante 1: Fumante 2:

Fumante 3: 1

Fumante 4:

Fumante 5: I

Não 1

(Vá para a questão 47)

Sim. 2 NS/NR. 
Quantos moradores na casa já foram fumantes e agora não fumam mais?

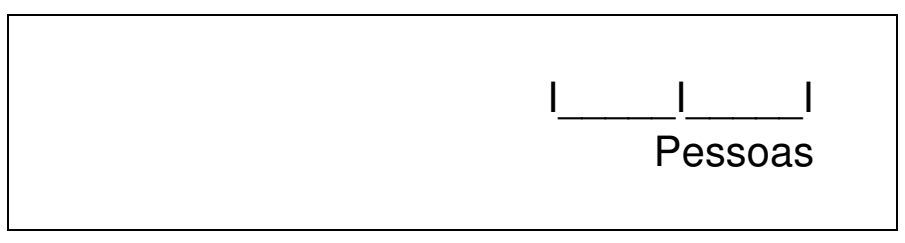

Por quanto tempo fumaram?

Entrevistador: considerar anos e meses completos de fumo.

Descontar os períodos de interrupção do hábito.

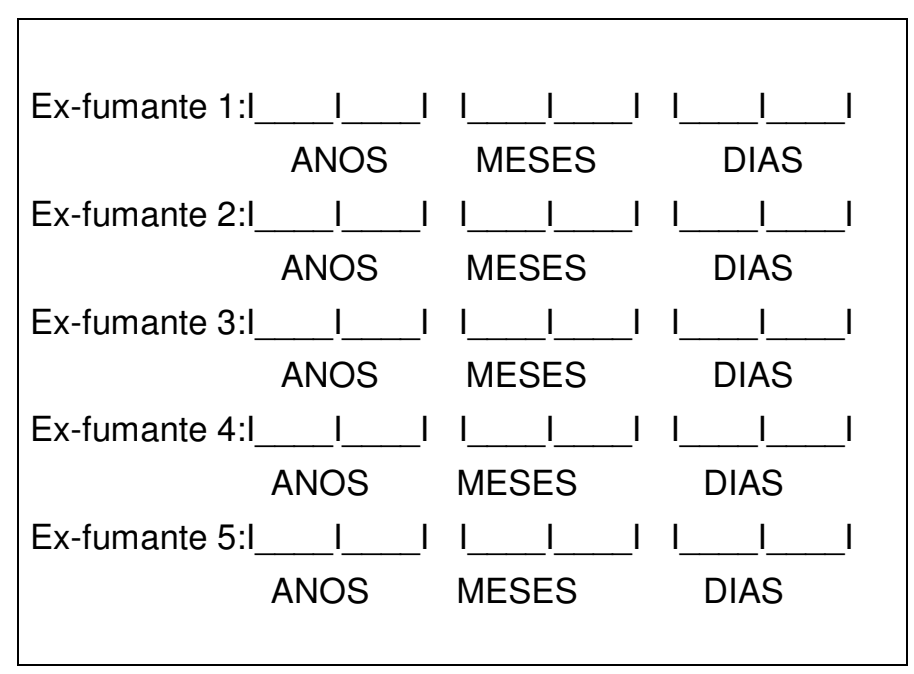

Há quanto tempo pararam de fumar?

Entrevistador: considerar anos e meses completos de abandono do tabagismo.

Quantos cigarros essas pessoas fumavam, ao dia?

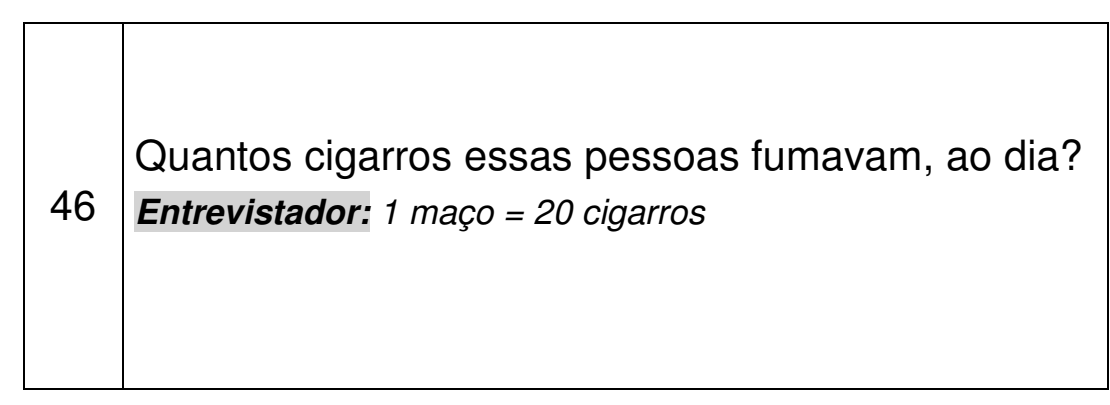

Ex-fumante $1: I_{\text {Ex-fumante } 2: I \text { INOS }}$

Ex-fumante 1: I

Ex-fumante 2:

Ex-fumante 3:

Ex-fumante 4:

Ex-fumante 5: 
$\mathrm{O}$ (a) Sr.(a) saberia me dizer qual era o peso e a altura da mãe dessa criança, antes de engravidar dela?

Entrevistador: É o peso referido no período antes da gravidez. Ex: se a mãe soube que estava grávida em março de 2011, com 03 meses de gestação, pergunte o peso que ela tinha em dezembro de 2010. Registrar o peso em Kg e a altura em metros.

$\mathrm{O}$ (a) Sr.(a) saberia me dizer qual era o peso e a altura da mãe dessa criança, no momento em que essa criança nasceu?

Entrevistador: registrar o peso em $\mathrm{Kg}$ e a altura em metros.

Atualmente qual é o peso e a altura da mãe dessa criança?

Entrevistador: registrar o peso em $\mathrm{Kg}$ e a altura em metros.

\begin{tabular}{|l|l|}
\hline 50 & $\begin{array}{l}\text { Quantas gestações, partos e abortos a mãe desta } \\
\text { criança teve? }\end{array}$ \\
\hline
\end{tabular}

$\mathrm{O}$ (a) Sr.(a) saberia me dizer qual foi o intervalo de tempo entre o parto desta criança e da anterior?

Entrevistador: registrar o intervalo em anos e meses.

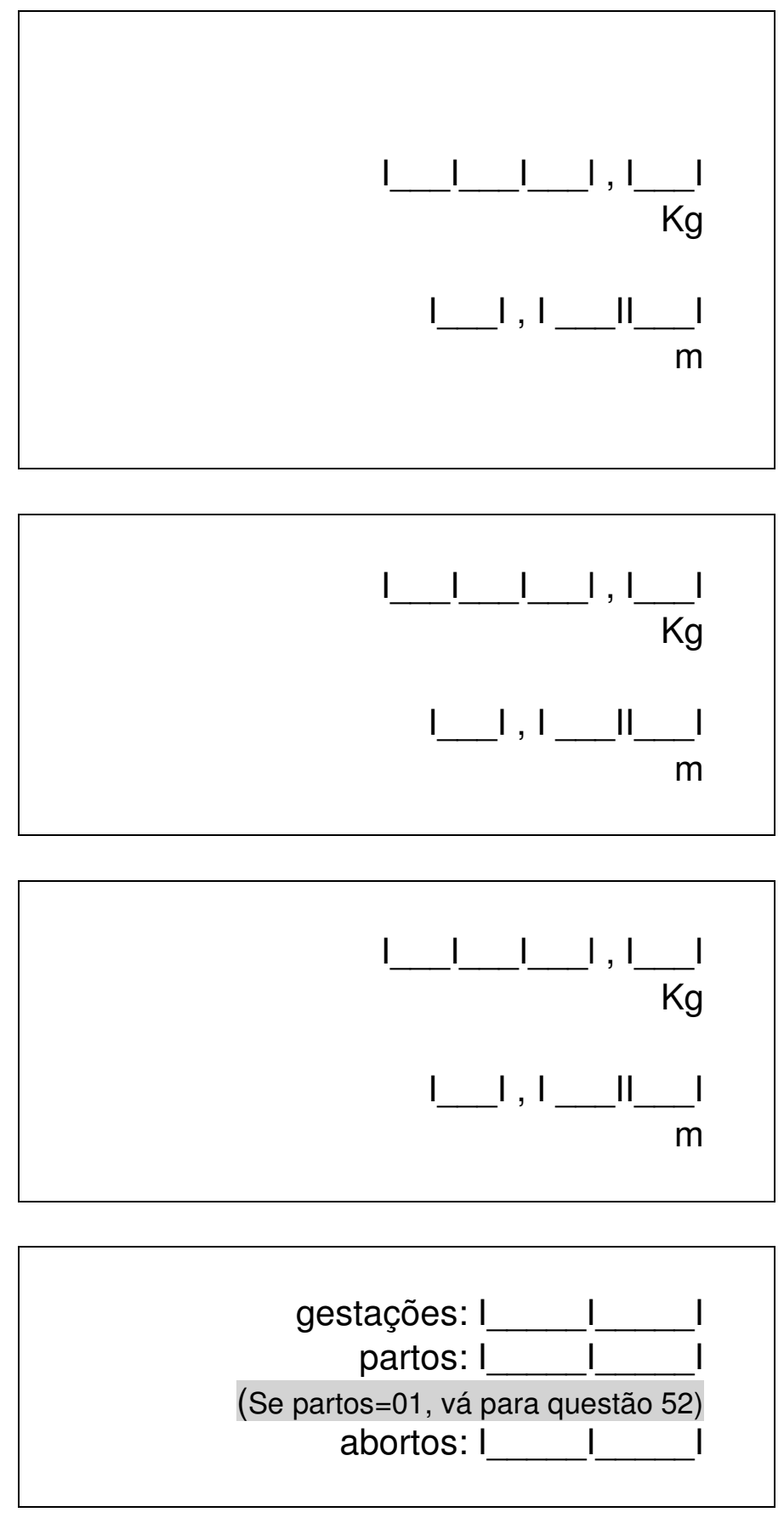


Quantas consultas de pré-natal a mãe desta criança realizou, durante a gestação dela?

52

Entrevistador: consultar cartão da gestante. Se ausente, considerar a informação referida. Em Ribeirão Preto: $1 x /$ mês até 32 sem., 15/15 dias até 36 sem., 1x/semana até o parto.

Quanto tempo durou a gestação desta criança? Entrevistador: se não souber, vá para a questão 54.

53 Anotar o dado preferencialmente em Semanas e Dias. Consultar cartão da gestante. Se ausente, considerar a informação referida.

54 Essa criança nasceu prematura, ou seja, antes do tempo?

$\mathrm{O}$ (a) $\mathrm{Sr}(\mathrm{a})$. saberia me dizer qual foi o tipo de parto

55 desta criança?

Entrevistador: Consultar cartão da criança. Se ausente, considerar a informação referida.

Qual foi o peso de nascimento desta criança?

56 Entrevistador: Consultar a caderneta de saúde da criança. Se ausente, considerar a informação referida. Registrar 0 peso em gramas e anotar a origem da informação.

Qual foi a ordem na nascimento desta criança, em relação aos seus irmãos?

57 Entrevistador: exemplificar - a criança foi o $1^{\circ}$ filho, $2^{\circ}$ filho, etc. Anotar o número 01 para 1 filho, 02 para $2^{\circ}$ filho, etc. Se único filho, anotar 01 e ir para a questão 60.

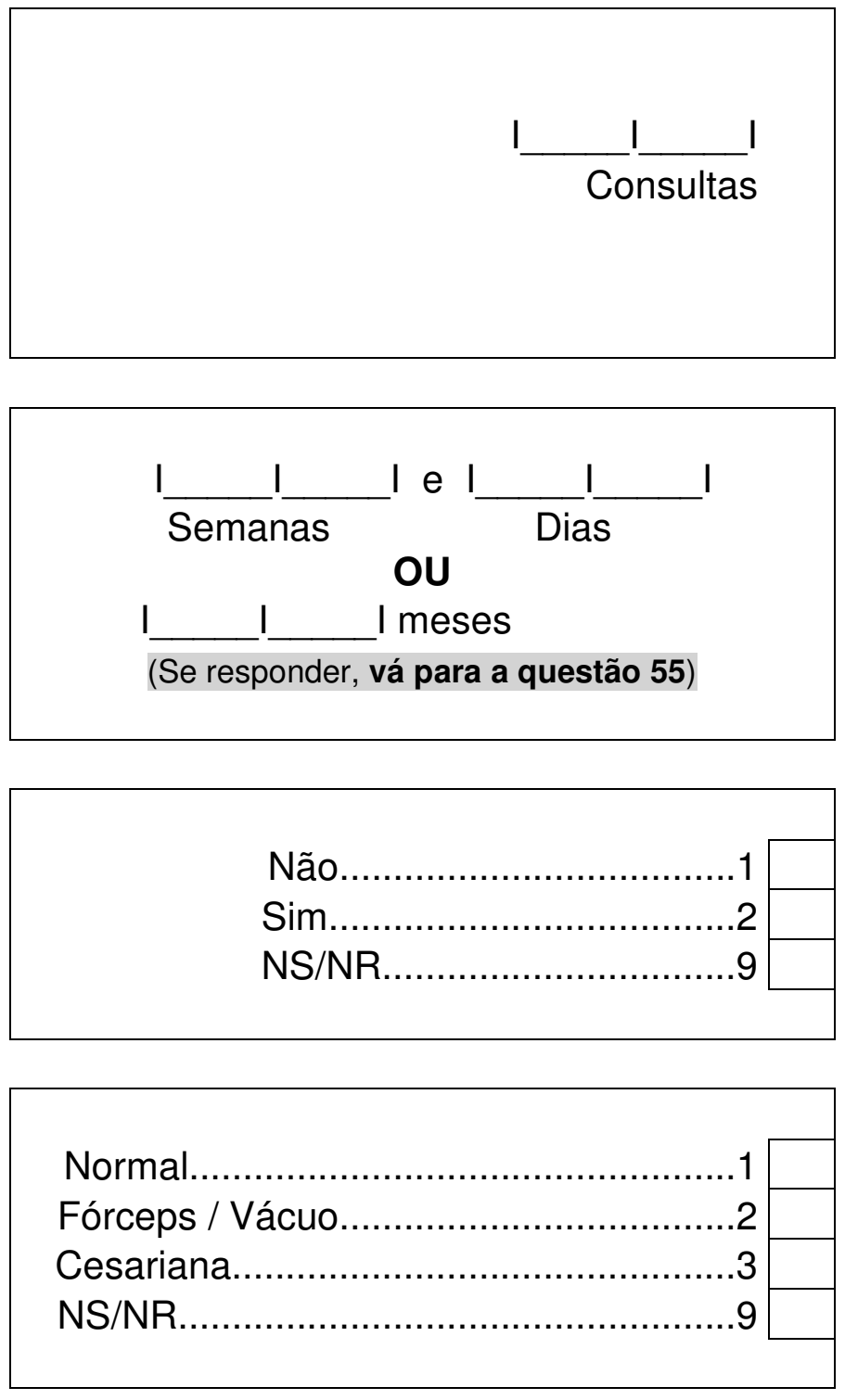

Norma 2

Cesariana..............................................

NS/NR I gramas

Caderneta

Referido NS / NR

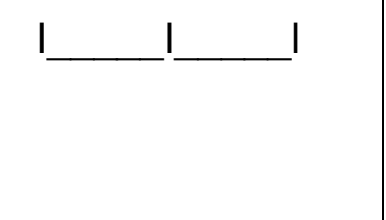




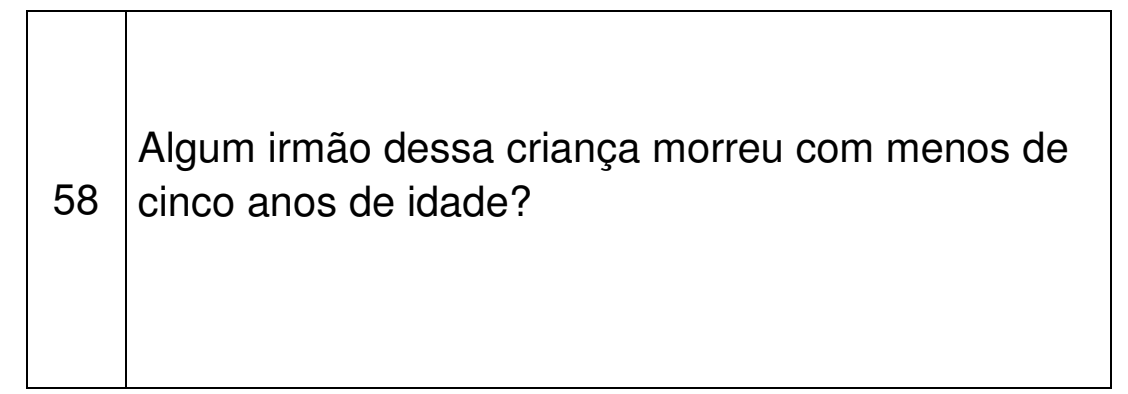

\begin{tabular}{|l|l|}
\hline 59 & $\begin{array}{l}\text { Quantos irmãos desta criança morreram com } \\
\text { menos de cinco anos de idade? }\end{array}$ \\
\hline
\end{tabular}
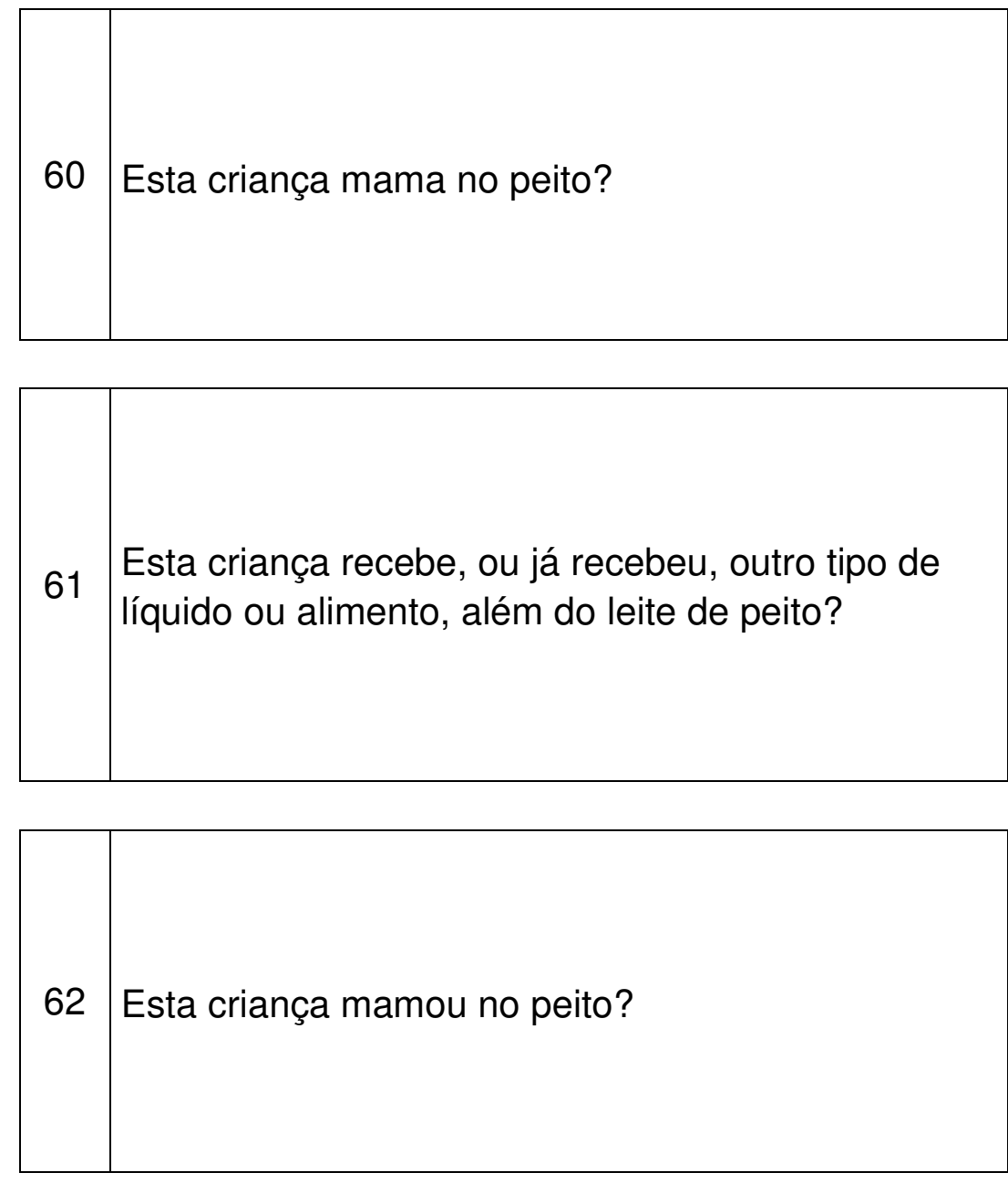

63

Até que idade esta criança mamou no peito?

Entrevistador: anotar a idade em meses e dias.
Não .1

(Vá para a questão 60)

Sim. 2

NS/NR

9

(Vá para a questão 60)

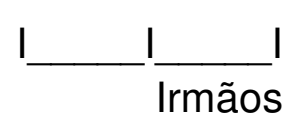

Não.

. .1

(Vá para a questão 62)

Sim. 2

NS/NR. 9

(Vá para a questão 62)

Não.

Sim

(Vá para a questão 70)

NS/NR.

(Vá para a questão 64)

2
$9)$

(Vá para a questão 70)

Não

.1

(Vá para a questão 64)

Sim

2

NS/NR.

.9

(Vá para a questão 64) 


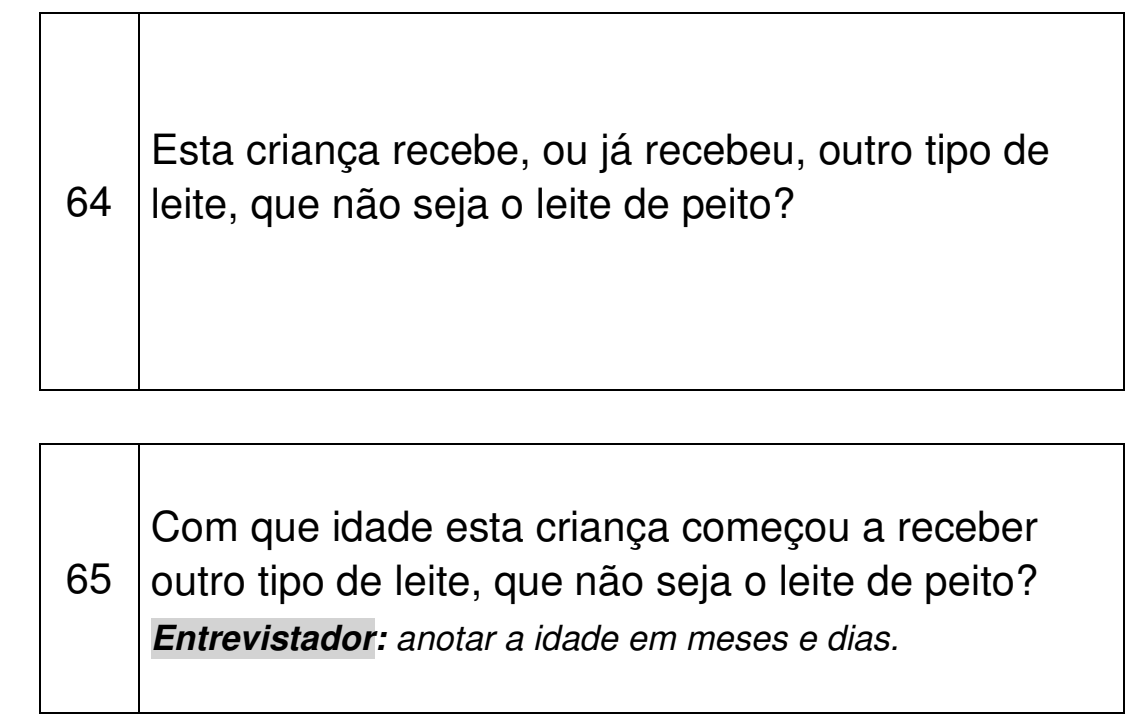

\begin{tabular}{|l|l|}
\hline 66 & $\begin{array}{l}\text { Esta criança recebe, ou já recebeu, outros líquidos, } \\
\text { como água, chás e sucos? }\end{array}$ \\
\hline 67 & $\begin{array}{l}\text { Com que idade esta criança começou a receber } \\
\text { tais líquidos? } \\
\text { Entrevistador: anotar a idade em meses e dias. }\end{array}$ \\
\hline
\end{tabular}

\begin{tabular}{|l|l|}
\hline 68 & $\begin{array}{l}\text { Esta criança recebe, ou já recebeu, alimentos } \\
\text { sólidos (frutas / papas)? }\end{array}$ \\
\hline 69 & $\begin{array}{l}\text { Com que idade esta criança começou a receber } \\
\text { alimentos sólidos? }\end{array}$ \\
\hline
\end{tabular}

Não

.1

(Vá para a questão 66)

Sim 2

NS/NR.

.9

(Vá para a questão 66)

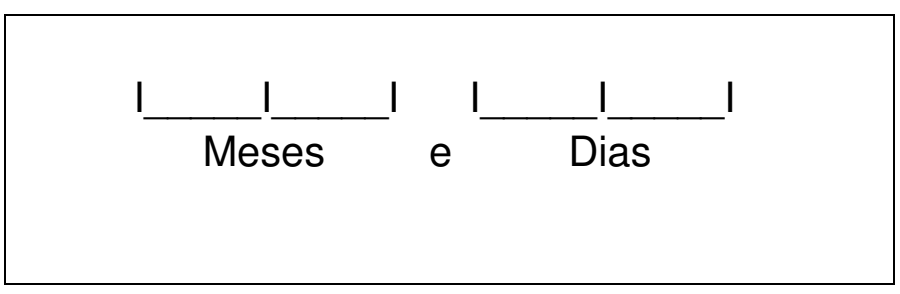

Não

. .1

(Vá para a questão 68)

Sim

2

NS/NR.

.9

(Vá para a questão 68)

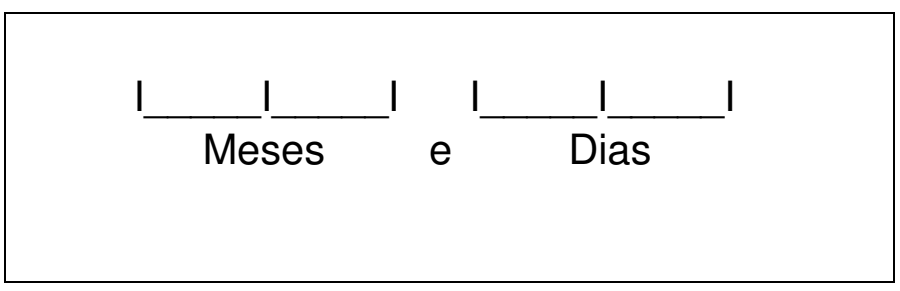

Não

.1

(Vá para a questão 70)

Sim

2

NS/NR

9

(Vá para a questão 70)

I_Lses $e \frac{\mid}{\text { Dias }}$



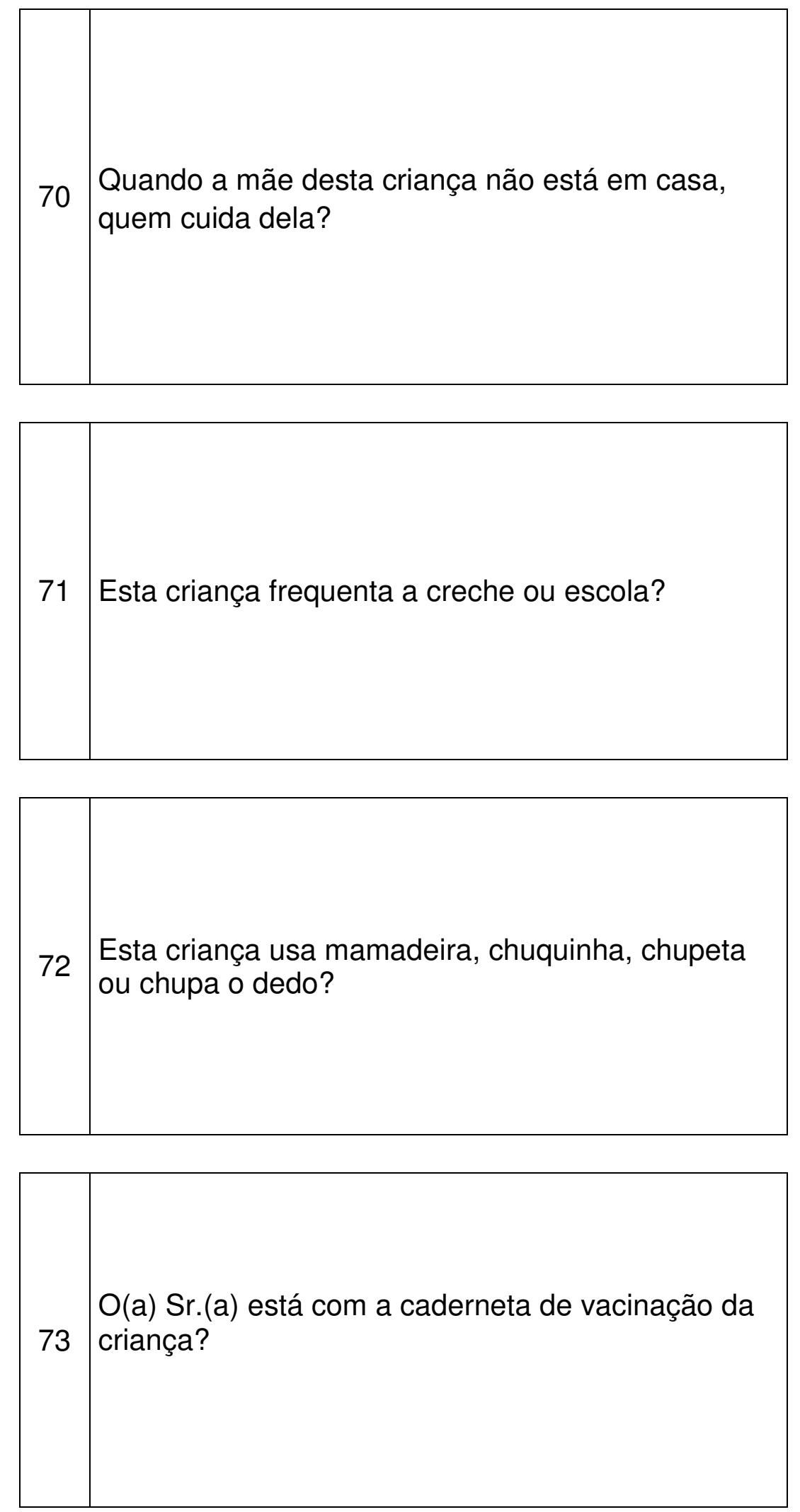

Avó / Avô. 1

Irmão.

Outro pessoa.

2

Quem?

Creche / escola.

4

Mãe sempre em casa..

NS/NR.

9

Não.

1

Sim.

2

NS/NR

9

Não

.1

Sim, mamadeira / chuquinha 2

Sim, chupeta. 3

Sim, chupa o dedo. 4

NS/NR.

Não. 1

Sim.

(Vá para a questão 75)

NS/NR.

9

(Vá para a questão 75) 


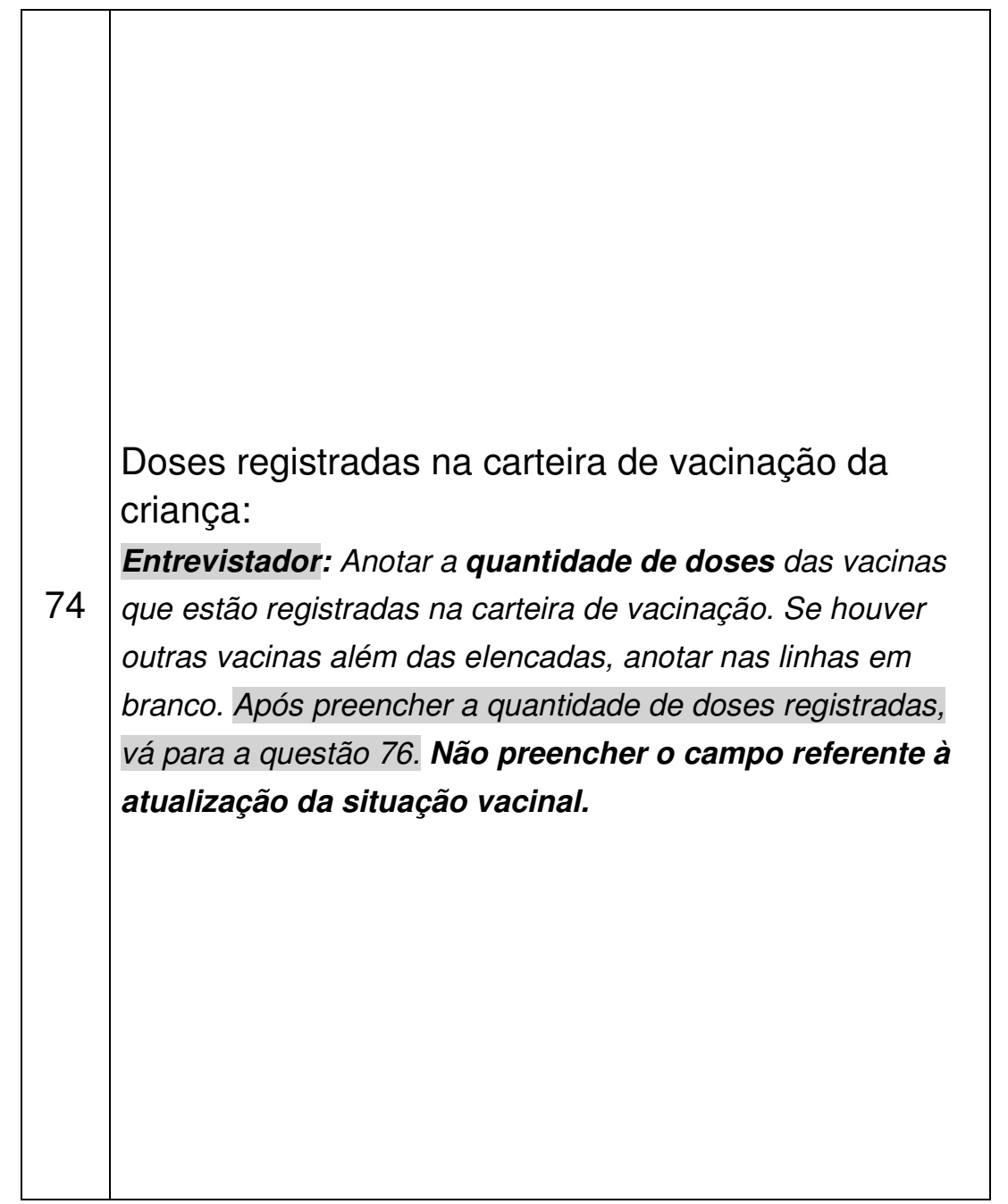

75 Essa criança está com alguma vacina em atraso?

\section{Esta criança usou algum medicamento, nos} últimos 30 dias?

Entrevistador: Caso a resposta for SIM, anotar o nome do medicamento. Se criança internada, considerar período antes da internação. Se não souber o nome, anotar indicação.

\section{BCG}

Hepatite B

Poliomielite (Sabin/Salk)

Poliomielite (Sabin) campanha

Tetravalente (DTP+Hib)

Rotavírus

Meningo-C

Pneumo 10 Valente

Febre Amarela

Tríplice Viral (SCR)

Tríplice Viral (SCR) campanha.

DTP

Entrevistador: o campo abaixo será preenchido pelo avaliador da situação vacinal, portanto $\mathbf{N A ̃ O}$ PREENCHER. Vá para a questão 76.

Situação vacinal atualizada. 1

Situação vacinal não-atualizada. 2

Não 1

Sim. 2

Qual?

NS/NR 9

Não. 1

Sim. 2

Qual?

$$
\text { NS/NR. }
$$


77

Esta criança já teve algum episódio de pneumonia, desde o nascimento?

Entrevistador: se SIM, perguntar quantos episódios. Se a criança estiver com pneumonia, considerar o episódio atual.

Esta criança já teve algum episódio de chiado no peito, desde o nascimento?

Entrevistador: se SIM, perguntar quantos episódios. Se a criança estiver com chiado, considerar o episódio atual.

Esta criança teve diarréia, no último mês?

79

Entrevistador: se SIM, perguntar quantos episódios. Para ser considerado um novo episódio, a criança deve ter voltado a apresentar fezes normais antes de ter diarréia novamente.

Esta criança tem refluxo, diagnosticado pelo

80 médico?

Esta criança tem algum problema como diabetes

81 e problemas na tireóide (doenças endócrinas / hormonais)?

Entrevistador: Caso a resposta for SIM, anotar o nome do problema ou doença.

Esta criança tem algum problema no sistema de defesa do organismo, como lúpus, artrite

82 reumatóide (doenças autoimunes), AIDS, falta do baço ou outro problema nas células de defesa? Entrevistador: Caso a resposta for SIM, anotar o nome do problema ou doença.
Não. 1

Sim 2

Número de episódios: I

NS/NR. 9

Não. 1

Sim 2

Número de episódios: I

NS/NR. 9

Não. 1

Sim. 2

Número de episódios: I

NS/NR.

Não 1

Sim 2

NS/NR 9

Não 1

Sim 2

Qual?

NS/NR 9

Não 1

Sim 2

Qual?

NS/NR 


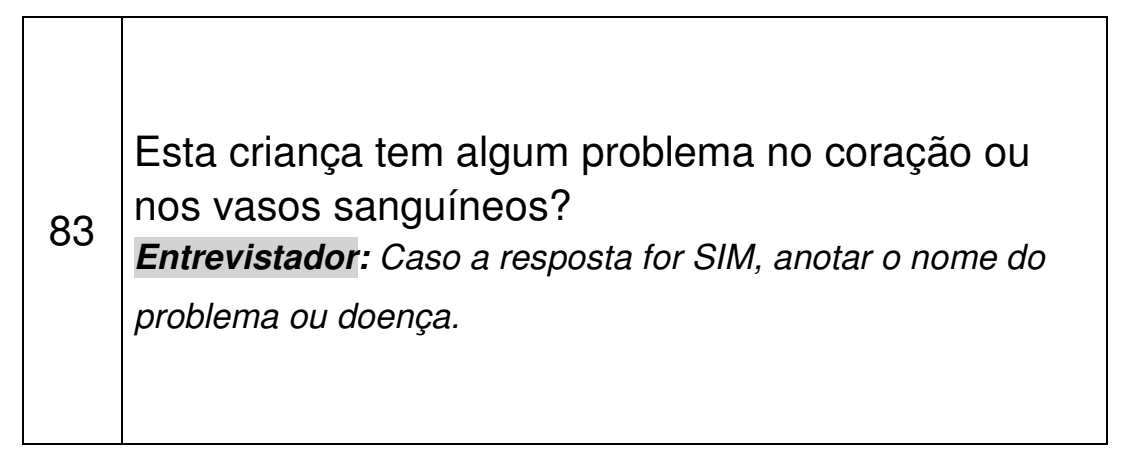

84 \begin{tabular}{l|l|}
\hline Esta criança tem algum problema no pulmão, como \\
asma, fibrose cística ou outra doença pulmonar \\
crônica? \\
Entrevistador: Caso a resposta for SIM, anotar o nome do \\
problema ou doença. Se criança com pneumonia, não \\
considerar aqui.
\end{tabular}

85 \begin{tabular}{l|l|}
\hline Esta criança tem algum problema para respirar \\
enquanto dorme, como ronco e apnéia do sono \\
(pára de respirar enquanto dorme)? \\
Entrevistador: Caso a resposta for SIM, anotar o nome do \\
problema ou doença.
\end{tabular}

86

Esta criança tem algum problema no cérebro, nervos ou músculos, como convulsões e paralisia? Entrevistador: Caso a resposta for SIM, anotar o nome do problema ou doença.

Esta criança tem alguma síndrome (Síndrome de 87 Down e Síndrome de Cushing, por ex.)?

Entrevistador: Caso a resposta for SIM, anotar o nome da Síndrome.
Não 1

Sim. .2

Qual?

NS/NR 9

Não 1

Sim. 2

Qual?

NS/NR. 9

Não . .1

Sim. 2

Qual?

NS/NR. 9

Não 1

Sim 2

Qual?

NS/NR. 9

Não 1

Sim. 2

Qual?

NS/NR .9 


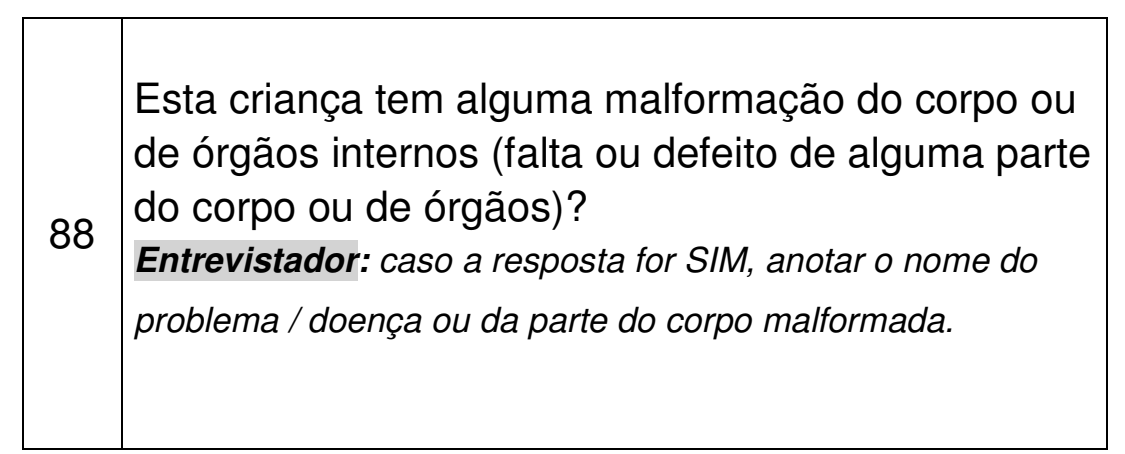

89 \begin{tabular}{l|l|}
\hline & $\begin{array}{l}\text { Entrevistador: Caso a resposta for SIM, anotar o tipo de } \\
\text { câncer. }\end{array}$ \\
\hline
\end{tabular}

\begin{tabular}{|l|l|}
\hline 90 & $\begin{array}{l}\text { Esta criança tem alguma outra doença? } \\
\text { Entrevistador: se SIM, anotar qual doença. Lembrar de } \\
\text { consulta, que não sejam pneumonia e não se enquadrem nas } \\
\text { questões anteriores, além de outra doenças detectadas } \\
\text { nesta internação ou consulta. }\end{array}$ \\
\hline
\end{tabular}
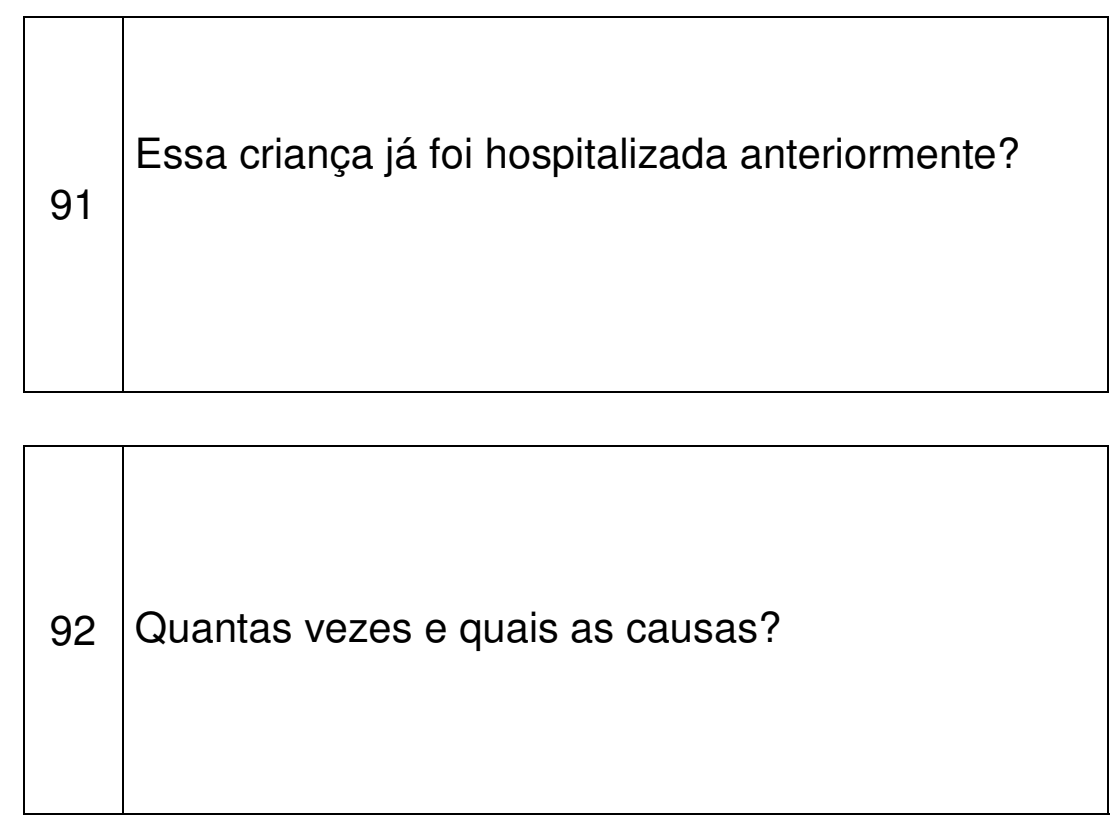

Não. 1

Sim.

Qual?

NS/NR

Não .1

Sim. 2

Qual?

NS/NR. 9

Não 1

Sim. 2

Qual?

NS/NR. .9

Não. . .1

(Vá para a questão 95)

Sim. ..2

NS/NR. .9

(Vá para a questão 95)

número de vezes: I

Causas: 
93

Qual foi a data da última hospitalização?

Entrevistador: anotar a data da alta.

Esta criança foi hospitalizada por pneumonia, no último ano?

Entrevistador: se SIM, perguntar quantas vezes.

Peso atual da criança

95

Entrevistador: anotar duas medidas, em gramas $\mathbf{E}$ em Kq. Se houver diferença > 100g entre os dois valores, anotar a

3a medida. Registrar se está em uso de dispositivos.

Estatura ou comprimento atual da criança Entrevistador: anotar duas medidas, em centímetros.

96 Se houver diferença $>\mathbf{0 , 5} \mathbf{c m}$ entre os dois valores, anotar a 3a medida. Registrar se está em uso de dispositivos.

\section{$\frac{\mathrm{I}-\mathrm{I}}{\mathrm{D}} \mathrm{I}-\mathrm{I}+\frac{\mathrm{I}}{\mathrm{ANO}} \mathrm{I}$}

Não. 1

Sim. 2

Número de vezes: I

NS/NR. 9

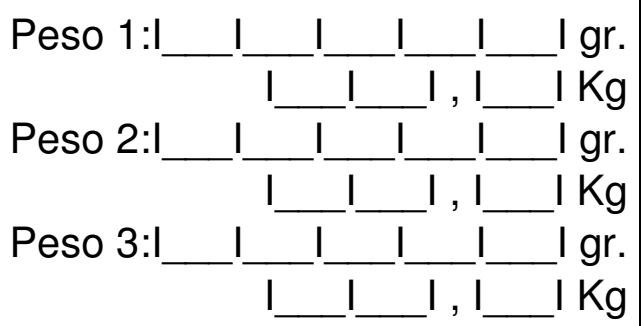

Não está em uso de dispositivos. 1

Está em uso de dispositivos. 2 Qual?

Est./comp. 1:I

Est./comp. 2:I

Est./comp. 3:I

I

1

$\mathrm{Icm}$ I_ I, I $\mathrm{I} \mathrm{cm}$ $\mathrm{Icm}$

Não está em uso de dispositivos.........1

Está em uso de dispositivos. 2 Qual?

\section{INSTRUMENTO DE AVALIAÇÃO DA ATENÇÃO PRIMÁRIA}

\section{A - GRAU DE AFILIAÇÃO}

Há um médico/enfermeiro ou serviço de saúde onde você geralmente leva essa criança quando ela está doente ou quando você precisa de algum conselho sobre a saúde dela?

Entrevistador: em caso de SIM, anotar nome e endereço.
Não. 1

Sim. 2

Nome:

Unidade: 


\begin{tabular}{|l|l|}
\hline A2 & $\begin{array}{l}\text { Há um médico/enfermeiro ou serviço de saúde que } \\
\text { conhece melhor essa criança como pessoa? } \\
\text { Entrevistador: em caso de SIM, DIFERENTE QUE A1, } \\
\text { anotar nome e endereço. }\end{array}$ \\
\hline
\end{tabular}

A3 $\begin{aligned} & \text { Há um médico/enfermeiro ou serviço de saúde que } \\ & \text { é mais responsável pelo atendimento de saúde } \\ & \text { dessa criança? } \\ & \begin{array}{l}\text { Entrevistador: em caso de SIM, DIFERENTE QUE A1 e A2, } \\ \text { anotar nome e endereço. }\end{array}\end{aligned}$

Não. 1

Sim, o mesmo que $A 1$................2

Nome:

Sim, diferente que $A 1$ 3

Unidade:

Não 1

Sim, o mesmo que A1 e A2.............2

Sim, o mesmo que A1 ......................3

Sim, o mesmo que A2 .....................4

Sim, diferente de $A 1$ e A2............... 5 Nome:

Unidade:

\section{PARA O ENTREVISTADOR: SEGUE ESQUEMA PARA A IDENTIFICAÇÃO DO SERVIÇO DE SAÚDE OU MÉDICO/ENFERMEIRO A SER AVALIADO:}

Identifique o serviço de saúde que será avaliado, conforme as orientações abaixo:

- Se o entrevistado indicou o MESMO serviço de saúde nas 3 PERGUNTAS, continue o restante do questionário sobre esse médico/enfermeiro ou serviço de saúde. (Preencha o item A5).

- Se o entrevistado respondeu 2 PERGUNTAS IGUAIS continue o restante do questionário sobre esse médico/enfermeiro ou serviço de saúde. (Preencha o item A5).

- Se TODAS AS RESPOSTAS forem DIFERENTES, continue o restante do questionário sobre o médico/enfermeiro ou serviço de saúde IDENTIFICADO NA PERGUNTA A1. (Preencha o item A5).

- Se o entrevistado respondeu NÃO a 2 PERGUNTAS, continue o restante do questionário sobre o médico/enfermeiro ou serviço de saúde IDENTIFICADO NA PERGUNTA que respondeu SIM. (Preencha o item A5).

-Se o entrevistado respondeu NÃO a pergunta A1 e indicar RESPOSTAS DIFERENTES para A2 e A3, continue o restante do questionário sobre esse médico/enfermeiro ou serviço de saúde IDENTIFICADO NA RESPOSTA A3. (Preencha o item A5).

- Se o entrevistado respondeu NÃO A TODAS 3 PERGUNTAS, por favor, PERGUNTE O NOME DO ÚLTIMO médico/enfermeiro/serviço de saúde ONDE A CRIANÇA CONSULTOU e continue o restante do questionário sobre esse médico/enfermeiro ou serviço de saúde. (Preencha os itens A4 e A5). 
A4 - Nome do médico/enfermeiro ou serviço de saúde procurado pela última vez:

Entrevistador: Esclareça ao entrevistado que, a partir de agora, TODAS AS PERGUNTAS serão sobre o(a):

A5 -

(Nome do médico/enfermeiro e do serviço de saúde). (VÁ PARA A SEÇÃO B)

B - ACESSO DE PRIMEIRO CONTATO - UTILIZAÇÃO (USE O CARTÃO RESPOSTA)
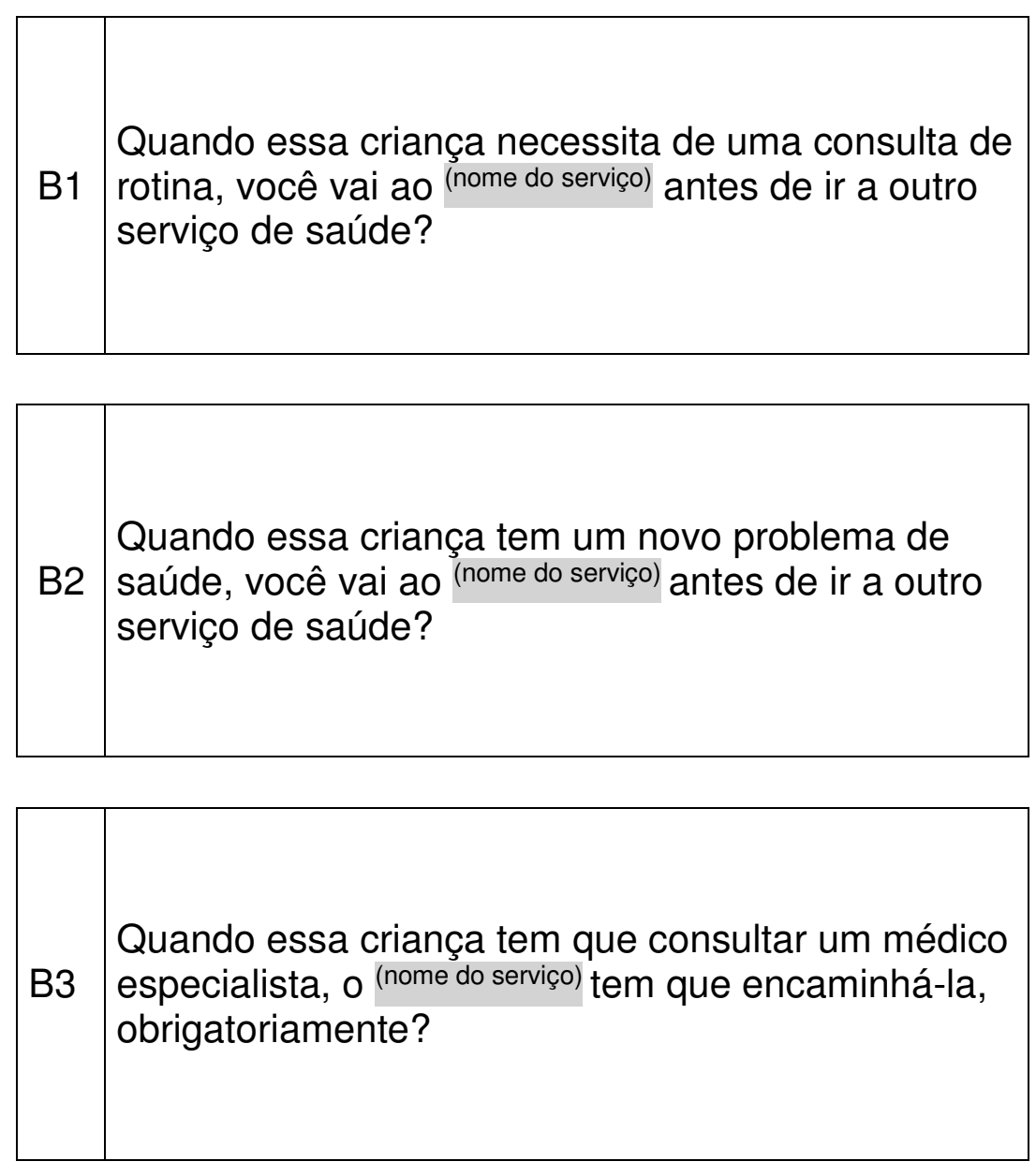

Com certeza, não.

Provavelmente, não

Provavelmente, sim

Com certeza, sim.

$\mathrm{NS} / \mathrm{NR}$

Com certeza, não.

Provavelmente, não

Provavelmente, sim

Com certeza, sim.

NS/NR
1 4 9

Com certeza, não. .1 2 . .3 .4 .9

Provavelmente, não (1)

Provavelmente, sim .2

Com certeza, sim. 3

NS/NR 4 9

\section{C - ACESSO DE PRIMEIRO CONTATO - ACESSIBILIDADE (USE O CARTÃO RESPOSTA)}

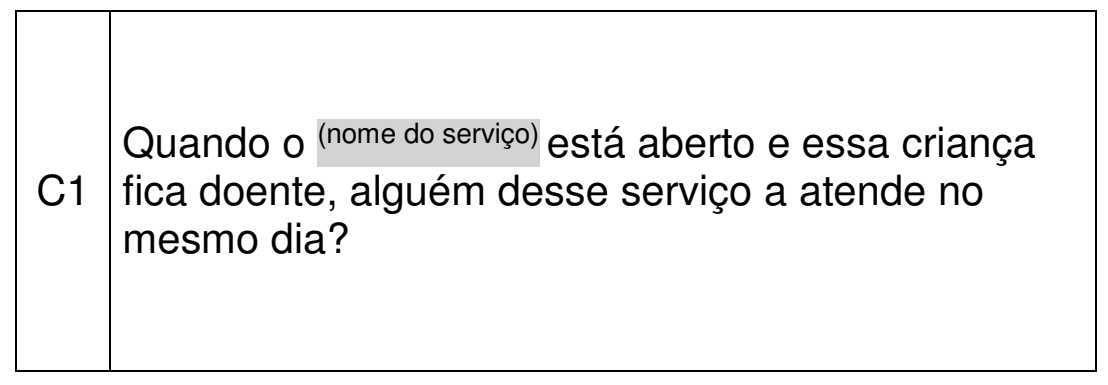

Com certeza, não. 1

Provavelmente, não

Provavelmente, sim .2

Com certeza, sim 3

$\mathrm{NS} / \mathrm{NR}$ 


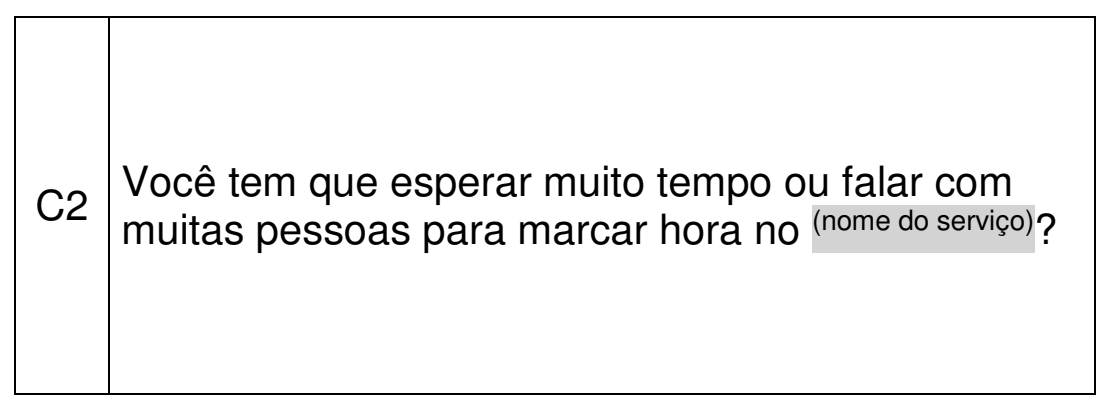

C3 \begin{tabular}{l|l|} 
É fácil marcar uma consulta de rotina no (nome do \\
serviço)?
\end{tabular}

\begin{tabular}{|l|l|} 
C4 & $\begin{array}{l}\text { Quando você chega no (nome do serviço), tem que } \\
\text { esperar mais que } 30 \text { minutos para que a criança } \\
\text { consulte? }\end{array}$ \\
\hline
\end{tabular}

\begin{tabular}{|l|l|}
\hline C5 & $\begin{array}{l}\text { É difícil conseguir atendimento médico para essa } \\
\text { criança no (nome do serviço), quando você acha } \\
\text { necessário? }\end{array}$ \\
\hline
\end{tabular}

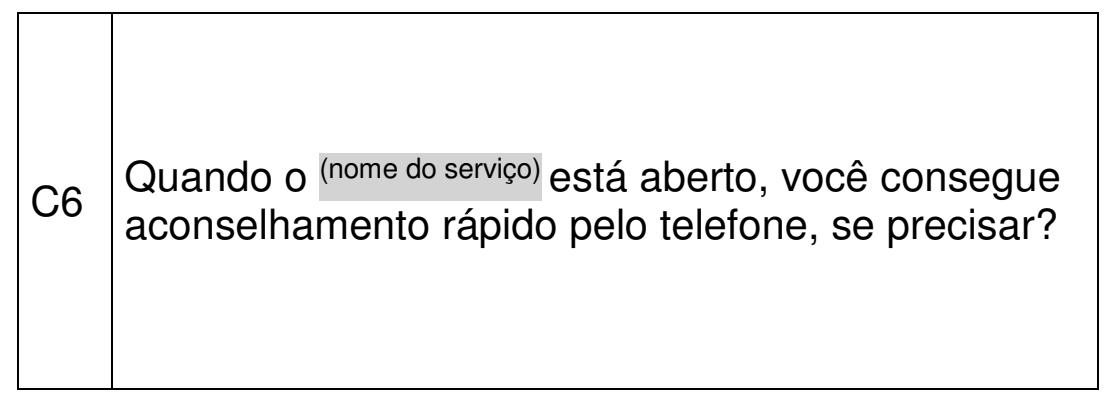

Com certeza, não. 1

Provavelmente, não 2

Provavelmente, sim 3

Com certeza, sim.

NS/NR

Com certeza, não. 1

Provavelmente, não

Provavelmente, sim .2

Com certeza, sim. 3

NS/NR

Com certeza, não. 1

Provavelmente, não

Provavelmente, sim 3

Com certeza, sim.

NS/NR

Com certeza, não. 1

Provavelmente, não 2

Provavelmente, sim .3

Com certeza, sim.

NS/NR

Com certeza, não. . .1

Provavelmente, não 2

Provavelmente, sim

Com certeza, sim. .3

NS/NR 


\section{D - LONGITUDINALIDADE}

(USE O CARTÃO RESPOSTA)
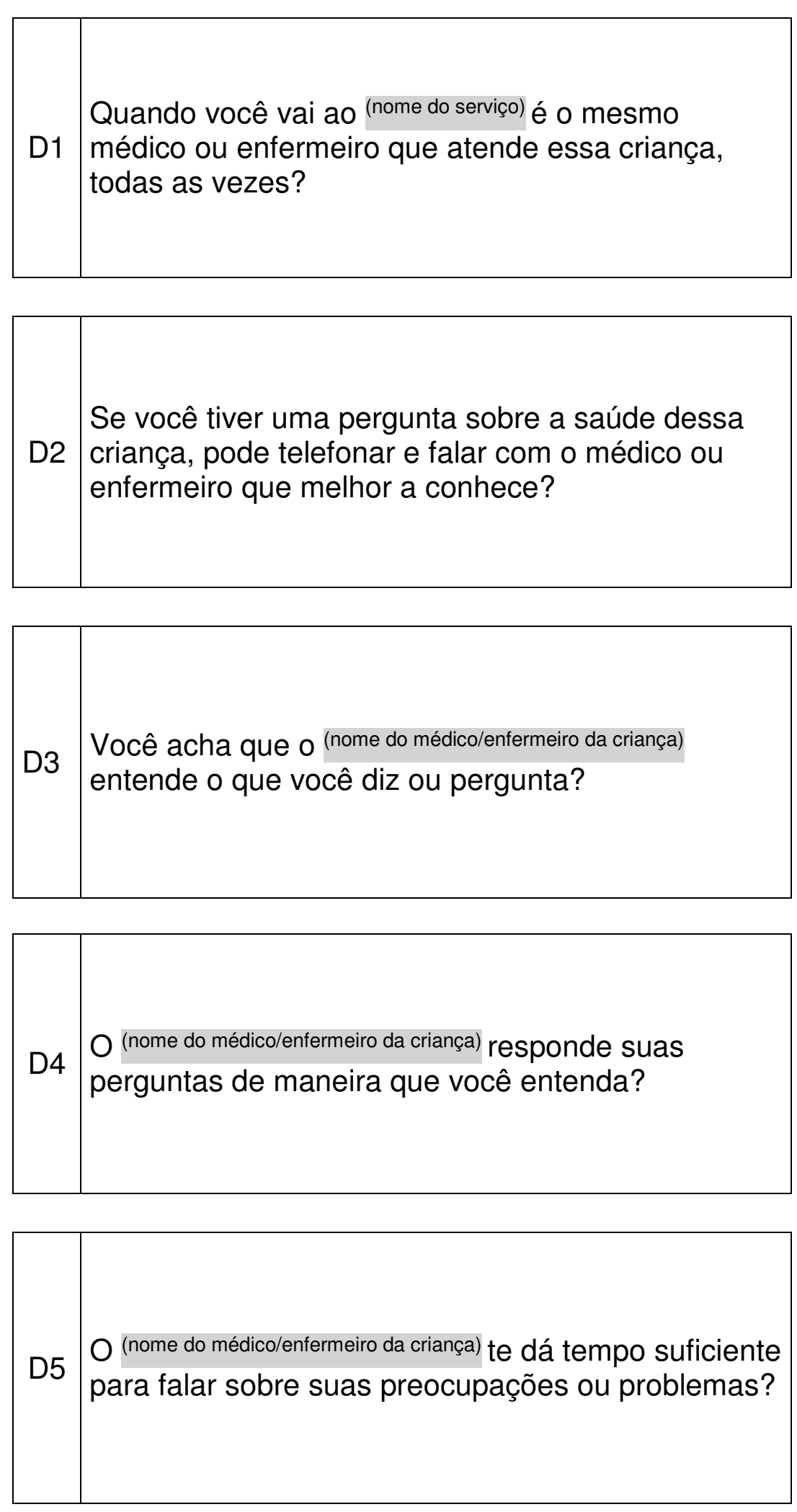

Com certeza, não.

Provavelmente, não 1

Provavelmente, sim 2

Com certeza, sim..

NS/NR. 3 4 9

Com certeza, não.

Provavelmente, não 1

Provavelmente, sim

Com certeza, sim.

$\mathrm{NS} / \mathrm{NR}$

Com certeza, não 1

Provavelmente, não 2

Provavelmente, sim 3

Com certeza, sim 4

NS/NR 9

Com certeza, não. 1

Provavelmente, não

Provavelmente, sim .2

Com certeza, sim. .3

NS/NR

Com certeza, não. . .1

Provavelmente, não 2

Provavelmente, sim 3

Com certeza, sim.

NS/NR 

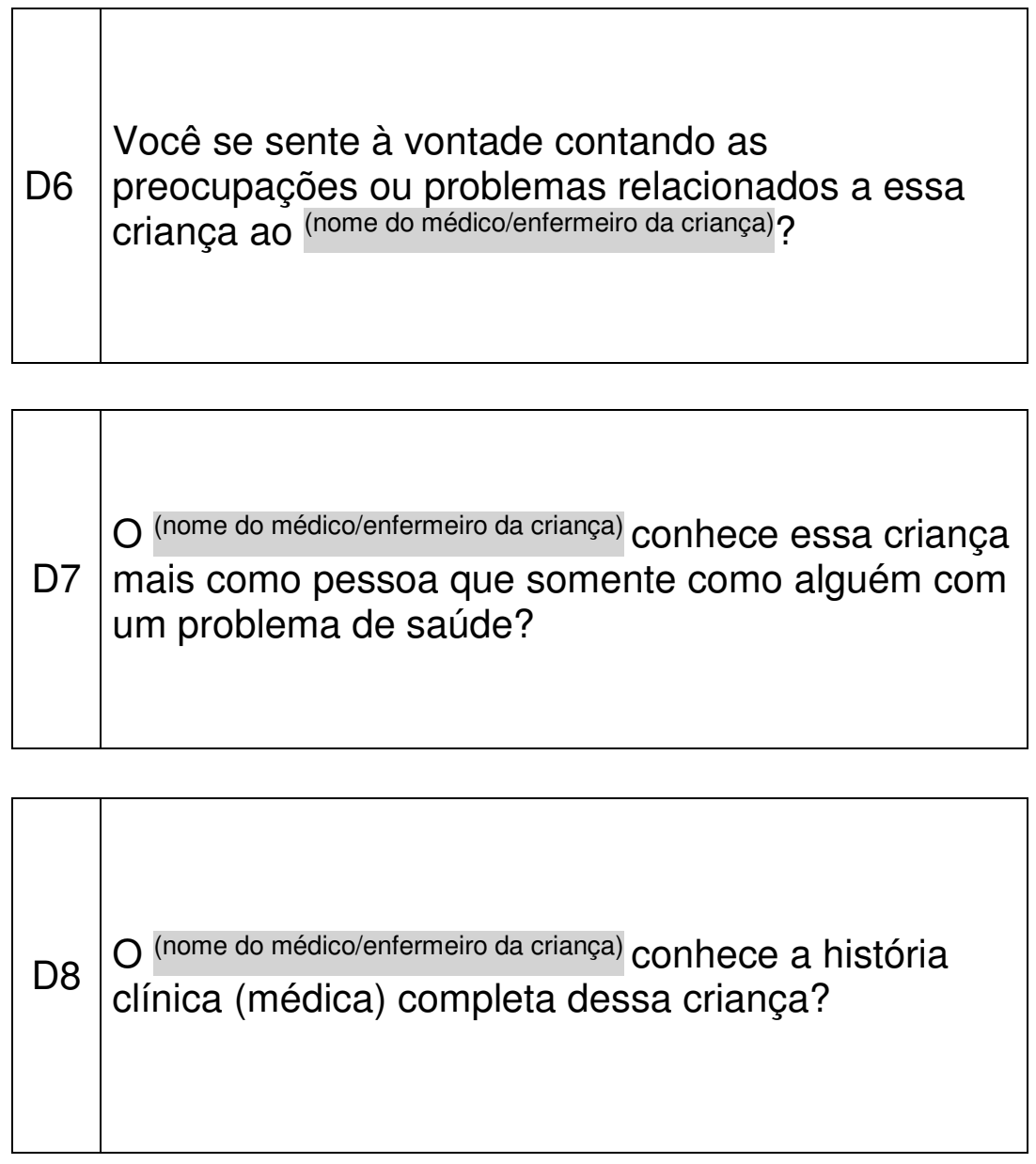

O (nome do médico/enfermeiro da criança) sabe a respeito de todos os medicamentos que essa criança está

D9 tomando?

Entrevistador: desconsiderar medicamentos iniciados nessa internação. Se a criança não toma medicamentos, relacionar a situações passadas ou supostas.

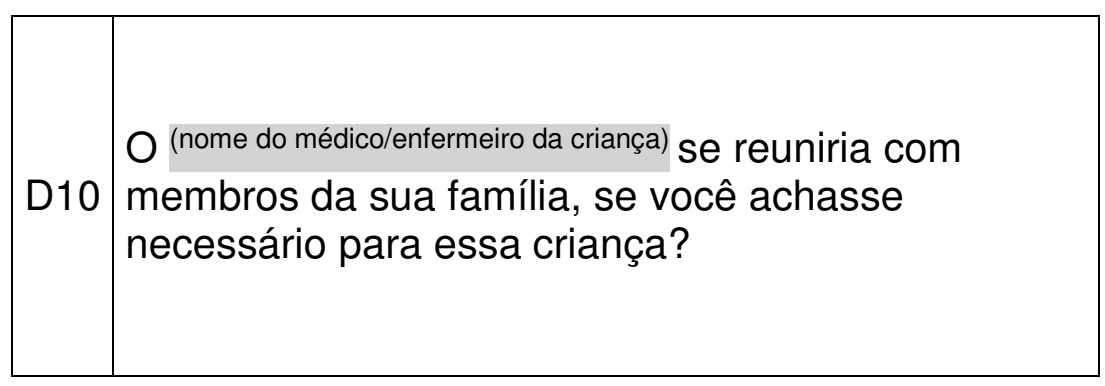

Com certeza, não. 1

Provavelmente, não 2

Provavelmente, sim 3

Com certeza, sim. 4

NS/NR .9

Com certeza, não. 1

Provavelmente, não

Provavelmente, sim .2

Com certeza, sim. 3

NS/NR 9

Com certeza, não .1

Provavelmente, não 2

Provavelmente, sim 3

Com certeza, sim. 4

NS/NR 9

Com certeza, não. 1

Provavelmente, não

Provavelmente, sim 2

Com certeza, sim. 3

NS/NR

Com certeza, não. 1

Provavelmente, não 2

Provavelmente, sim

Com certeza, sim. 3 NS/NR.

\begin{tabular}{l|l|}
\hline \\
\hline \\
\hline \\
\hline \\
\hline \\
\hline \\
\hline
\end{tabular}




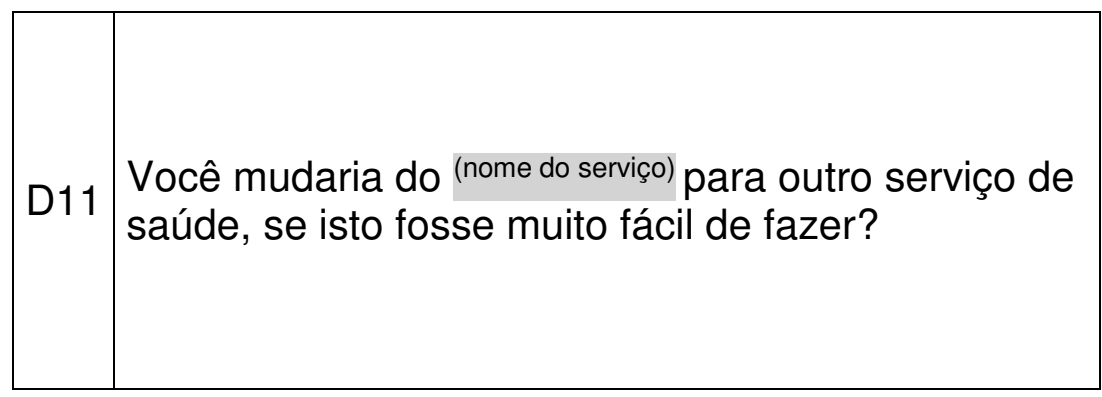

Com certeza, não 1

Provavelmente, não 2

Provavelmente, sim

Com certeza, sim 3

NS/NR

\section{E - COORDENAÇÃO - INTEGRAÇÃO DE CUIDADOS}

\begin{tabular}{|c|c|c|}
\hline \multirow{4}{*}{ E1 } & Essa criança foi consultar qualquer tipo de & $\begin{array}{r}\text { Não......................................... } \\
\text { (Vá para a questão F1) }\end{array}$ \\
\hline & especialista ou serviço especializado no período em & 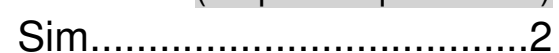 \\
\hline & & NS/NR....................... \\
\hline & & (Vá para a questão F1) \\
\hline
\end{tabular}

\section{(USE O CARTÃO RESPOSTA)}
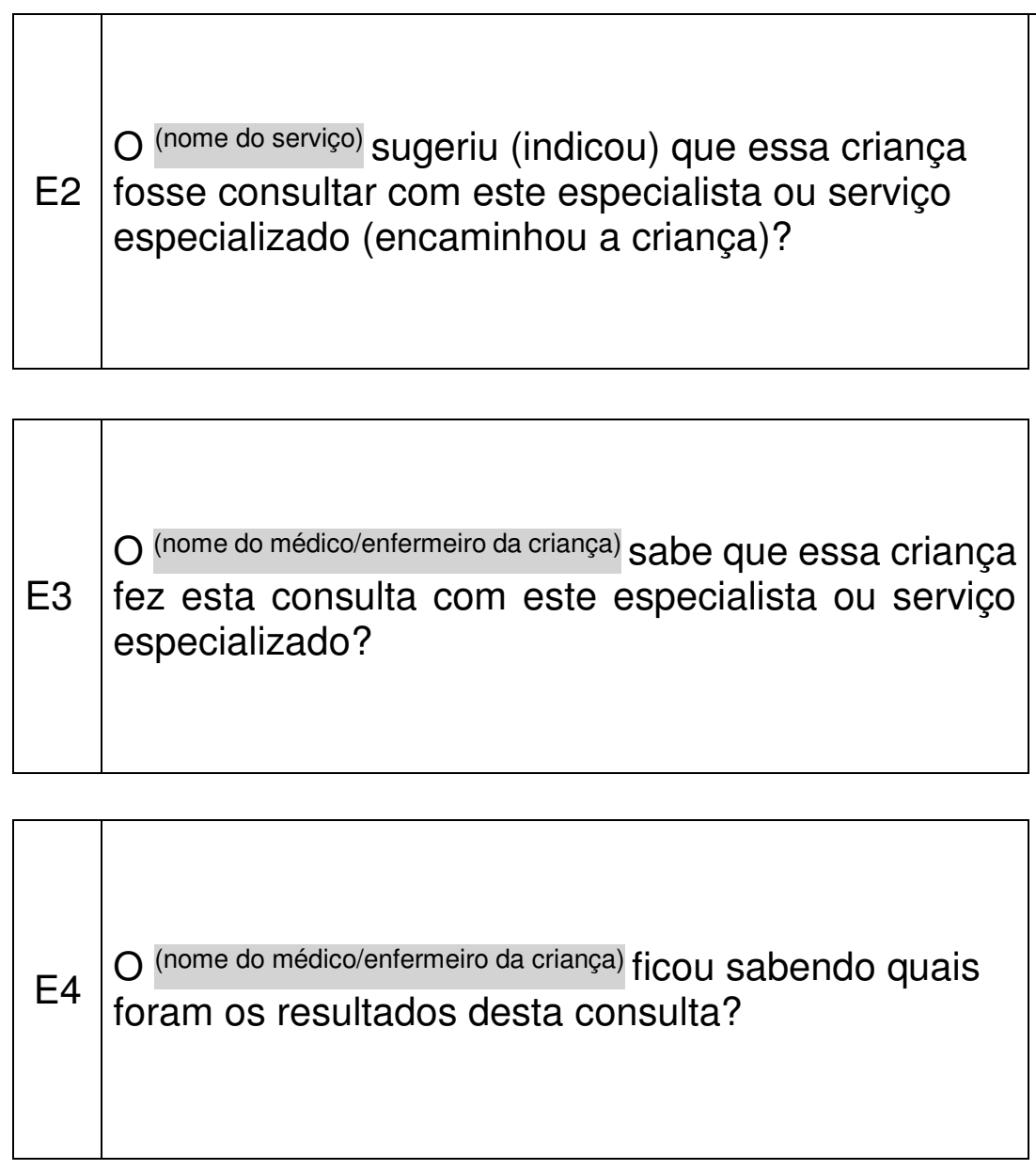

Com certeza, não. 1

Provavelmente, não

Provavelmente, sim

Com certeza, sim.

NS/NR 2 .3 .4 .9

Com certeza, não. .1

Provavelmente, não 2

Provavelmente, sim 3

Com certeza, sim. 4

NS/NR .9

Com certeza, não. 1

Provavelmente, não 2

Provavelmente, sim .3

Com certeza, sim. NS/NR. 
Depois desta consulta com o especialista ou

E5 serviço especializado, o (nome do médico/enfermeiro da criança) conversou com você sobre o que aconteceu durante esta consulta?

O (nome do médico/enfermeiro da criança) pareceu interessado

E6 na qualidade do cuidado que foi dado a ela no especialista ou serviço especializado?

\section{F - COORDENAÇÃO - SISTEMA DE INFORMAÇÕES} (USE O CARTÃO RESPOSTA)

Com certeza, não.

Provavelmente, não

Provavelmente, sim

Com certeza, sim.

NS/NR
.1

2

3 .4 .9

Com certeza, sim

$\mathrm{NS} / \mathrm{NR}$

Quando você leva essa criança no (nome do serviço), você leva algum dos registros de saúde ou boletins de atendimento que ela recebeu no passado? (exemplificar "registro" - fichas de atendimento, carteira de vacinação)

Quando você leva essa criança no (nome do serviço), o

F2 prontuário dela está sempre disponível na consulta?

F3

Você poderia ler, consultar o prontuário / ficha dessa criança, se quisesse, no (nome do serviço)?
Com certeza, não. 1

Provavelmente, não 2

Provavelmente, sim

Com certeza, sim. 3

NS/NR 4 9

Com certeza, não. 1

Provavelmente, não 2

Provavelmente, sim 3

Com certeza, sim 4

$\mathrm{NS} / \mathrm{NR}$ 9

Com certeza, não. .1

Provavelmente, não 2

Provavelmente, sim 3

Com certeza, sim. 4 NS/NR 9

\section{G - INTEGRALIDADE - SERVIÇOS DISPONÍVEIS (USE O CARTÃO RESPOSTA)}


A seguir, apresentamos uma lista de serviços/orientações que você e sua família ou as pessoas que utilizam esse serviço podem necessitar em algum momento. Indique, por favor, se no (nome do serviço) esses serviços / orientações estão disponíveis:

Entrevistador: REPETIR A CADA 3-4 ITENS: "Está disponível no (nome do serviço) ...?"

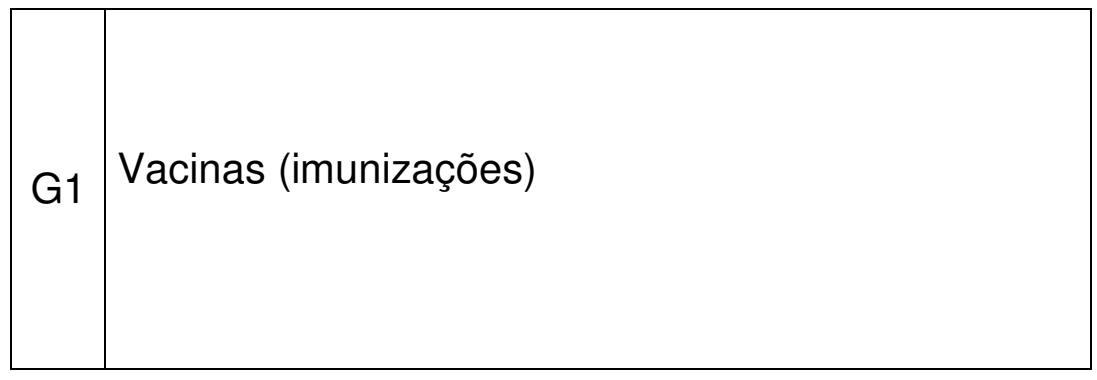

\begin{tabular}{|l|l|} 
G2 & $\begin{array}{l}\text { Verificar se sua família pode participar de algum } \\
\text { programa de assistência social ou benefícios } \\
\text { sociais }\end{array}$ \\
\hline
\end{tabular}

\begin{tabular}{|l|l|}
\hline G3 & Planejamento familiar \\
\hline
\end{tabular}

G4 \begin{tabular}{l|l|} 
Programa de suplementação nutricional (ex: leite e \\
alimentos)
\end{tabular}

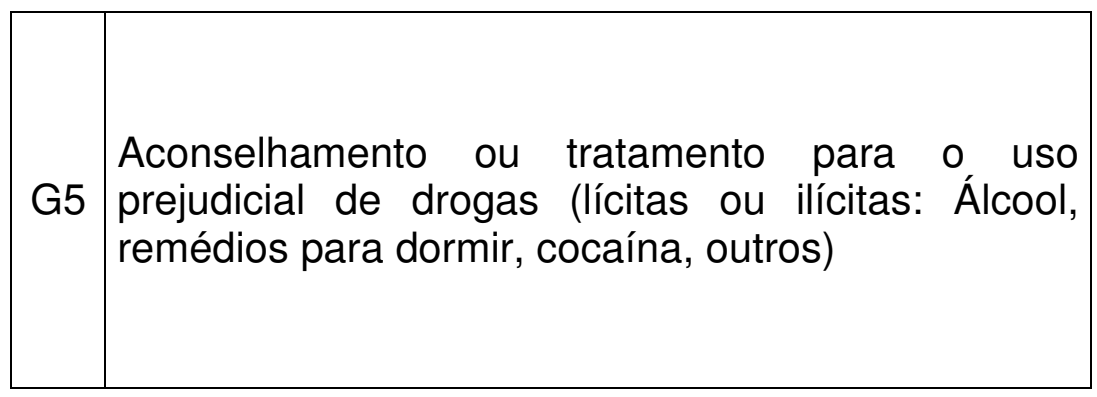

Com certeza, não. 1

Provavelmente, não

Provavelmente, sim 2

Com certeza, sim. 3

NS/NR

Com certeza, não. 1

Provavelmente, não 2

Provavelmente, sim .3

Com certeza, sim. 4

NS/NR 9

Com certeza, não 1

Provavelmente, não 2

Provavelmente, sim

Com certeza, sim. ..3

NS/NR

Com certeza, não. 1

Provavelmente, não 2

Provavelmente, sim

Com certeza, sim. 3

NS/NR 4 9

Com certeza, não. 1

Provavelmente, não 2

Provavelmente, sim .3

Com certeza, sim 4

NS/NR 


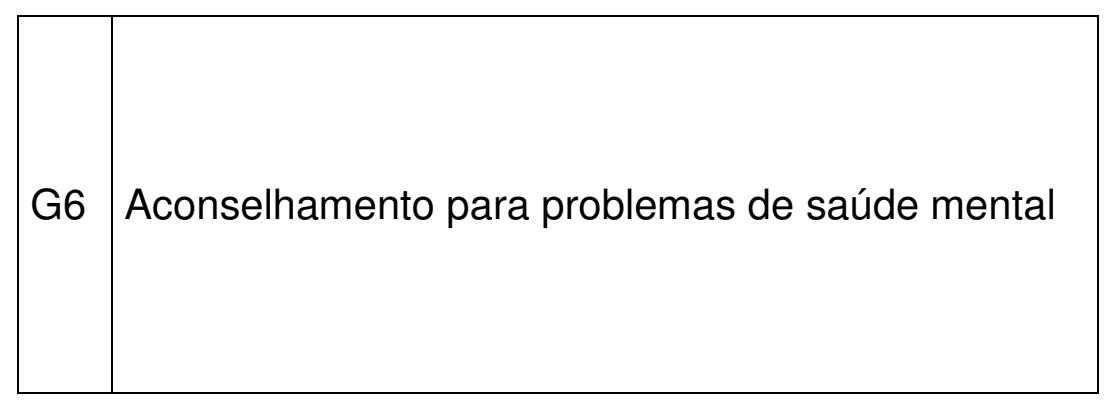

\begin{tabular}{|l|l|}
\hline G7 & Sutura de um corte que necessita de pontos \\
\hline
\end{tabular}

G8 Aconselhamento e solicitação de teste anti-HIV

G9 \begin{tabular}{|l|}
\hline Identificação (algum tipo de avaliação) de problemas \\
visuais (para enxergar)
\end{tabular}

Com certeza, não. 1

Provavelmente, não 2

Provavelmente, sim 3

Com certeza, sim. 4

NS/NR
Com certeza, não

Provavelmente, não

Provavelmente, sim

Com certeza, sim.

NS/NR
..1

Com certeza, não. 1

Provavelmente, não

Provavelmente, sim .2

Com certeza, sim. 3

NS/NR

Com certeza, não. 1

Provavelmente, não 2

Provavelmente, sim 3

Com certeza, sim.

NS/NR

\section{H - INTEGRALIDADE - SERVIÇOS PRESTADOS (USE O CARTÃO RESPOSTA)}

Vou Ihe falar sobre vários assuntos importantes para a saúde dessa criança. Quero que você me diga se nas consultas com o (nome do médico/enfermeiro da criança), alguns destes assuntos foram conversados com você.

Em consultas ao (nome do serviço), algum dos seguintes assuntos sobre essa criança já foram ou são discutidos (conversados) com você? 
Orientação para manter essa criança saudável, H1 como alimentação saudável, boa higiene ou sono adequado

Segurança no lar: como guardar medicamentos com segurança

Mudanças do crescimento e desenvolvimento da $\mathrm{H} 3$ criança, isto é, que coisas você deve esperar de cada idade. Por exemplo, quando a criança vai caminhar, controlar o xixi...

$\mathrm{H} 4$

Maneiras de lidar com o comportamento dessa criança

Maneiras para manter a criança segura, como: evitar H5 tombos ou quedas de altura ou mantê-la afastada do fogão
Com certeza, não. 1

Provavelmente, não

Provavelmente, sim 2

Com certeza, sim. 3

NS/NR 4 9

Com certeza, não. .1

Provavelmente, não 2

Provavelmente, sim 3

Com certeza, sim. 4

NS/NR 9

Com certeza, não 1

Provavelmente, não 2

Provavelmente, sim 3

Com certeza, sim. 4

NS/NR

Com certeza, não. 1

Provavelmente, não

Provavelmente, sim .2

Com certeza, sim. 3

NS/NR 4 9

Com certeza, não. 1

Provavelmente, não 2

Provavelmente, sim 3

Com certeza, sim. 4

NS/NR 9 


\section{I - ORIENTACÃO FAMILIAR \\ (USE O CARTÃO RESPOSTA)}
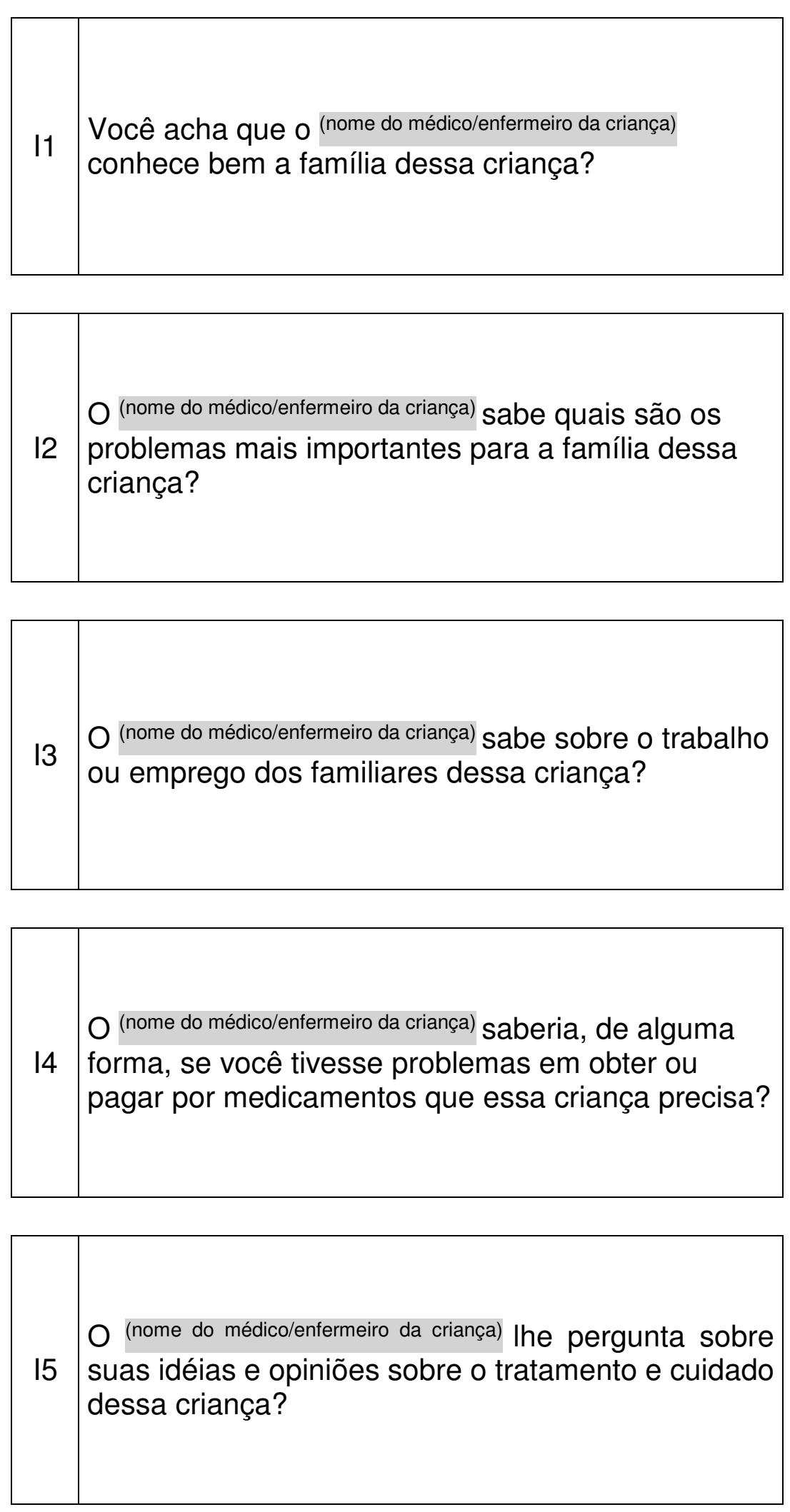

Com certeza, não.

Provavelmente, não 2

Provavelmente, sim 3

Com certeza, sim.

NS/NR

Com certeza, não. .1

Provavelmente, não 2

Provavelmente, sim

Com certeza, sim. .3

NS/NR

Com certeza, não .1

Provavelmente, não 2

Provavelmente, sim 3

Com certeza, sim 4

NS/NR

Com certeza, não .1

Provavelmente, não 2

Provavelmente, sim 3

Com certeza, sim 4

NS/NR 9

Com certeza, não. 1

Provavelmente, não 2

Provavelmente, sim 3

Com certeza, sim. 4 NS/NR 


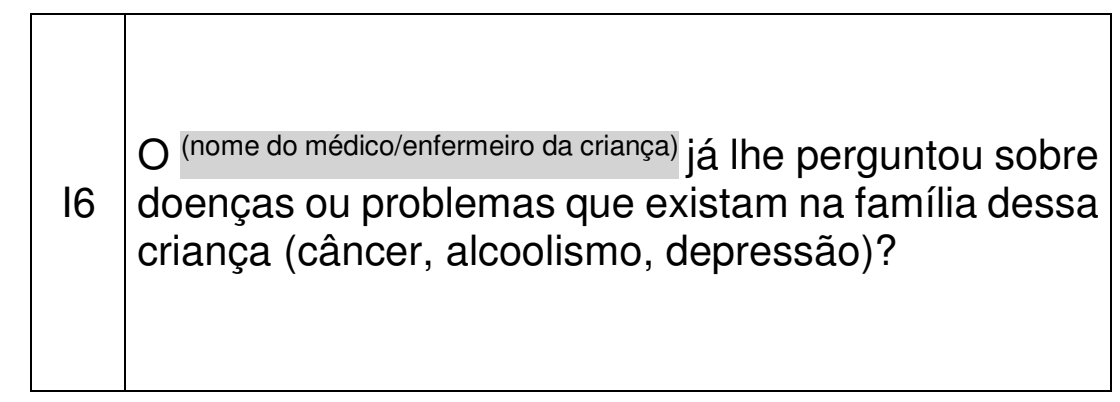

Com certeza, não. 1

Provavelmente, não 2

Provavelmente, sim 3

Com certeza, sim. 4 NS/NR

\section{J - ORIENTAÇÃO COMUNITÁRIA (USE O CARTÃO RESPOSTA)}

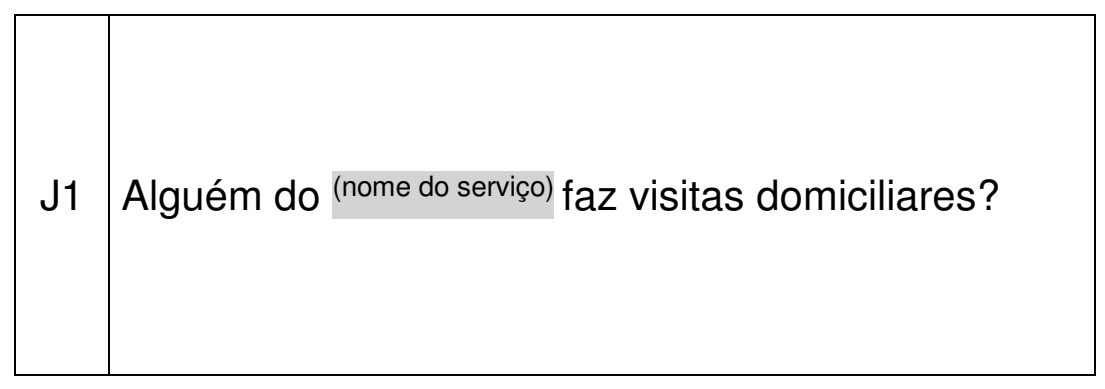

\begin{tabular}{|l|l|}
\hline J2 & $\begin{array}{l}\text { Alguém do (nome do serviço) conhece os problemas de } \\
\text { saúde importantes da vizinhança dessa criança? }\end{array}$ \\
\hline
\end{tabular}

Com certeza, não.

Provavelmente, não

Provavelmente, sim

Com certeza, sim.

NS/NR 1

Com certeza, não. .1

Provavelmente, não .2

Provavelmente, sim 3

Com certeza, sim. 4

NS/NR

\section{A seguir, são listadas formas de avaliar a qualidade dos serviços de saúde. 0 (nome do serviço)} realiza alguma destas atividades?

J3

Faz pesquisas na comunidade para identificar problemas de saúde que ele deveria conhecer?
Convida membros das famílias a participarem do Conselho de Usuários)?

Com certeza, não. 1

Provavelmente, não

Provavelmente, sim 2

Com certeza, sim. 3

NS/NR 4 .9

Com certeza, não. 1

Provavelmente, não .2

Provavelmente, sim .3

Com certeza, sim. 4

NS/NR 9 


\section{APÊNDICE C \\ TERMO DE CONSENTIMENTO LIVRE E ESCLARECIDO}

Título da Pesquisa: Análise hierarquizada para a identificação de fatores associados à hospitalização por pneumonia, em menores de cinco anos de idade: estudo caso-controle.

Pesquisadores responsáveis: Juliana Coelho Pina: Enfermeira, Especialista em Laboratório da Escola de Enfermagem de Ribeirão Preto da Universidade de São Paulo (EERP/USP). Profa. Dra. Débora Falleiros de Mello: Enfermeira, Professora Associada do Departamento de Enfermagem Materno-Infantil e Saúde Pública da EERP/USP. Profa. Dra. Suzana Alves de Moraes: Médica, Professora Associada do Departamento de Enfermagem Materno-Infantil e Saúde Pública da EERP/USP.

$\mathrm{O}$ (a) $\mathrm{Sr}$ (a) está sendo convidado(a) a participar de uma pesquisa que tem por objetivo avaliar os motivos da hospitalização por pneumonias, em crianças menores de cinco anos de idade. Se estiver de acordo, o(a) $\operatorname{Sr}(a)$ e a criança que o(a) acompanha participarão da pesquisa, da seguinte forma:

- o(a) $\operatorname{Sr}($ a) responderá a um questionário sobre essa criança, a casa e a família dela e sobre a qualidade do cuidado recebido no serviço de saúde que ela usa;

- essa criança será pesada e terá sua altura será medida por pessoa treinada para isso;

Para conseguir essas informações, contamos com cerca de 40 minutos de seu tempo. Se essa criança fez uma radiografia de tórax (Raio-X do peito), o resultado desse exame poderá ser escolhido, por sorteio, para ser avaliado por um profissional especialista. Gostaríamos de sua autorização, desde já, para avaliar esse exame, se ele for escolhido. Lembramos o(a) $\operatorname{Sr}(a)$ que a criança não vai precisar fazer outra radiografia de tórax para essa pesquisa, a sua autorização é apenas para que o especialista avalie o exame já realizado.

Toda nossa conversa será mantida em segredo (ou seja, o anonimato de vocês será garantido), as informações serão usadas somente para esta pesquisa e serão divulgadas apenas em revistas científicas, documentos científicos e congressos. Não aparecerá seu nome nem o da criança em nenhuma dessas publicações. Também não aparecerão, em nenhuma publicação, nomes da unidades de saúde, do médico e do enfermeiro que o(a) $\operatorname{sr}(\mathrm{a})$ me disser. A qualquer momento, vocês poderão deixar de participar da pesquisa e isso não vai interferir no tratamento da criança; também não vai interferir no cuidado que vocês ou a família de vocês recebem nos serviços de saúde que costumam usar. Não haverá despesas, desconfortos e riscos para vocês, em qualquer momento do estudo. Também não haverá remuneração financeira ou benefícios diretos pela sua participação, ou seja, você não será pago para participar dessa pesquisa. Caso o(a) $\operatorname{Sr}(a)$ tenha alguma dúvida sobre a pesquisa, entre em contato com a Enfermeira Juliana Coelho Pina, na Escola de Enfermagem de Ribeirão Preto-USP, pelo telefone (16) $3602-$ 4756, das 8:00h às 12:00h, de segunda a sexta-feira. Agradecemos a sua colaboração e nos colocamos à disposição para qualquer informação que necessitar.

Atenciosamente,

Juliana Coelho Pina

Enfermeira e Especialista da EERP/USP 
$\mathrm{Eu}$, aceito participar da pesquisa "Análise hierarquizada para a identificação de fatores associados à hospitalização por pneumonia, em menores de cinco anos de idade: estudo caso-controle". Fui informado(a) sobre os objetivos da pesquisa e sobre minha forma de participação, bem como da criança que está comigo. Fui também informado(a) que, se essa criança fez uma radiografia de tórax, esse exame pode ser escolhido para ser avaliado por um especialista e autorizo essa avaliação. Sei que a qualquer momento posso pedir novas informações e deixar de participar da pesquisa, se assim o desejar. Recebi a garantia de que não seremos identificados quando os resultados da pesquisa forem divulgados e que essa divulgação acontecerá apenas em publicações científicas. Recebi uma cópia deste documento e pude tirar as minhas dúvidas em relação a ele.

Assinatura do participante

Data:
Assinatura da testemunha

Nome completo: 


\section{APÊNDICE D \\ TERMO DE CONSENTIMENTO LIVRE E ESCLARECIDO - Pré-Teste}

Título da Pesquisa: Análise hierarquizada para a identificação de fatores associados à hospitalização por pneumonia, em menores de cinco anos de idade: estudo caso-controle.

Pesquisadores responsáveis: Juliana Coelho Pina: Enfermeira, Especialista em Laboratório da Escola de Enfermagem de Ribeirão Preto da Universidade de São Paulo (EERP/USP). Profa. Dra. Débora Falleiros de Mello: Enfermeira, Professora Associada do Departamento de Enfermagem Materno-Infantil e Saúde Pública da EERP/USP. Profa. Dra. Suzana Alves de Moraes: Médica, Professora Associada do Departamento de Enfermagem Materno-Infantil e Saúde Pública da EERP/USP.

$\mathrm{O}$ (a) $\mathrm{Sr}$ (a) está sendo convidado(a) a participar de uma pesquisa que tem por objetivo avaliar possíveis motivos da hospitalização por pneumonias, em crianças menores de cinco anos de idade. Se estiver de acordo, o(a) $\operatorname{Sr}($ a) e a criança que o(a) acompanha participarão da pesquisa, respondendo a um questionário sobre essa criança, a casa e a família dela e sobre a qualidade do cuidado recebido no serviço de saúde que ela usa.

Para conseguir essas informações, contamos com cerca de 40 minutos de seu tempo. Toda a conversa será mantida em segredo (ou seja, o anonimato de vocês será garantido) e as informações serão usadas somente para conferirmos se as perguntas do questionário estão claras e adequadas. Portanto, as informações que o(a) sr(a) nos der não farão parte dos resultados da pesquisa e não serão divulgadas, ou seja, não aparecerão em publicação nenhuma. A qualquer momento, vocês poderão deixar de participar da pesquisa e isso não vai interferir no tratamento da criança; também não vai interferir no cuidado que vocês ou a família de vocês recebem nos serviços de saúde que costumam usar. Não haverá despesas, desconfortos e riscos para vocês, em qualquer momento do estudo. Também não haverá remuneração financeira ou benefícios diretos pela sua participação, ou seja, você não será pago para participar dessa pesquisa.. Caso o(a) $\operatorname{Sr}(a)$ tenha alguma dúvida sobre a pesquisa, entre em contato com a Enfermeira Juliana Coelho Pina, na Escola de Enfermagem de Ribeirão Preto-USP, pelo telefone (16) 3602-4756, das 8:00h às 12:00h, de segunda a sexta-feira.. Agradecemos a sua colaboração e nos colocamos à disposição para qualquer informação que necessitar.

Atenciosamente, 
$\mathrm{Eu}$, aceito participar da pesquisa "Análise hierarquizada para a identificação de fatores associados à hospitalização por pneumonia, em menores de cinco anos de idade: estudo caso-controle". Fui informado(a) sobre os objetivos da pesquisa e sobre minha forma de participação, bem como da criança que está comigo. Sei que a qualquer momento posso pedir novas informações e deixar de participar da pesquisa, se assim o desejar. Recebi a garantia de que não seremos identificados e que as informações por mim fornecidas não serão divulgadas. Recebi uma cópia deste documento e pude tirar as minhas dúvidas em relação a ele.

Assinatura do participante

Assinatura da testemunha

Data:

Nome completo: 


\section{APÊNDICE E \\ TERMO DE AUTORIZAÇÃO PARA REALIZAÇÃO DE PESQUISA NA INSTITUIÇÃO HOSPITALAR}

\section{AC Responsável Técnico-Administrativo da Instituição Hospitalar}

Título da Pesquisa: Análise hierarquizada para a identificação de fatores associados à hospitalização por pneumonia, em menores de cinco anos de idade: estudo caso-controle.

Pesquisadores responsáveis: Juliana Coelho Pina: Enfermeira, Especialista em Laboratório da Escola de Enfermagem de Ribeirão Preto da Universidade de São Paulo (EERP/USP). Profa. Dra. Débora Falleiros de Mello: Enfermeira, Professora Associada do Departamento de Enfermagem MaternoInfantil e Saúde Pública da EERP/USP. Profa. Dra. Suzana Alves de Moraes: Médica Epidemiologista, Professora Associada do Departamento de Enfermagem Materno-Infantil e Saúde Pública da EERP/USP.

Prezado(a) $\operatorname{Sr}(a)$ :

Estamos desenvolvendo a pesquisa acima especificada, cujo objetivo é identificar fatores associados à hospitalização por pneumonias, em crianças menores de cinco anos de idade. Esta instituição hospitalar foi selecionada como local de estudo devido à demanda de hospitalizações por pneumonia, identificada por meio de um levantamento, realizado a partir do sistema de informações de altas hospitalares do Centro de Processamento de Dados Hospitalares (CPDH) do Departamento de Medicina Social da FMRP-USP, em 2010. Solicitamos vossa autorização para o desenvolvimento do estudo nesta instituição hospitalar, permitindo, aos membros da equipe de pesquisa:

- a realização de visitas diárias à enfermaria de pediatria, ao ambulatório e pronto-atendimento pediátrico;

- a abordagem aos usuários desses setores, para convidá-los a participar da pesquisa e coletar os dados;

- o acesso ao registro diário de internações e às radiografias de tórax das crianças com pneumonia, participantes do estudo.

Para viabilizar a operacionalização da coleta de dados solicitamos, ainda, autorização para que os profissionais da equipe de enfermagem forneçam aos entrevistadores informações necessárias para a seleção dos participantes do estudo, as quais são: 1) se dada criança está sob suspeita ou tem diagnóstico de pneumonia; 2) se dada criança tem pneumonia contraída após internação; e 3) se o diagnóstico de pneumonia das crianças selecionadas está confirmado por RX. Ressaltamos que esse profissional não seria deslocado de suas atividades normais, apenas estaria autorizado a fornecer essas informações, com base no prontuário ou no registro médico de atendimento, sem que haja transtorno em sua rotina de trabalho. 
Após aprovação do projeto no Comitê de Ética em Pesquisa, comprometemo-nos a enviar à direção do hospital cópia do ofício de aprovação.

Agradecemos a atenção dispensada e colocamo-nos à disposição para esclarecimentos.

Atenciosamente,

Juliana Coelho Pina

Enfermeira e Especialista da EERP/USP

$\mathrm{Eu}$, autorizo a realização da pesquisa intitulada "Análise hierarquizada para a identificação de fatores associados à hospitalização por pneumonia, em menores de cinco anos de idade: estudo caso-controle", nas dependências do hospital Fui informado(a) sobre os objetivos da pesquisa e sobre os procedimentos para a coleta dos dados, bem como os recursos necessários para o desenvolvimento do estudo.

Estou ciente de que os pesquisadores submeterão o projeto ao Comitê de Ética em Pesquisa e que, somente após parecer favorável, será iniciada a coleta de dados. Para isso, uma cópia do ofício de aprovação deverá ser entregue à Direção do hospital.

Recebi uma cópia deste documento e tive a oportunidade de discuti-lo com a interessada.

Assinatura do responsável

Data: 


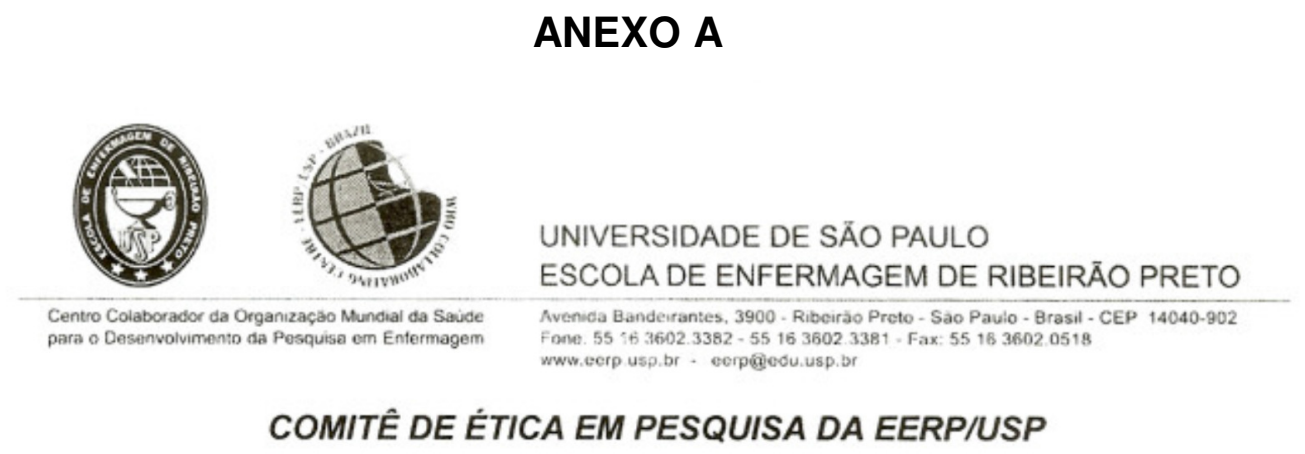

Of.CEP-EERP/USP - 475/2011

Ribeirão Preto, 29 de novembro de 2011.

Prezada Senhora,

Comunicamos que o projeto de pesquisa, abaixo especificado, foi analisado e considerado APROVADO pelo Comitê de Ética em Pesquisa da Escola de Enfermagem de Ribeirão Preto da Universidade de São Paulo, em sua 144 Reunião Ordinária, realizada em 29 de novembro de 2011.

Protocolo: $\quad n^{\circ} 1404 / 2011$

Projeto: $\quad$ Análise hierarquizada para a identificação de dos fatores associados à hospitalizaçäo por pneumonia, em menores de cinco anos de idade: estudo caso-controle.

Pesquisadores: Débora Falleiros de Mello

Juliana Coelho Pina

Em atendimento à Resolução 196/96, deverá ser encaminhado ao CEP o relatório final da pesquisa e a publicação de seus resultados, para acompanhamento, bem como comunicada qualquer intercorrência ou a sua interrupção.

\author{
Atenciosamente,

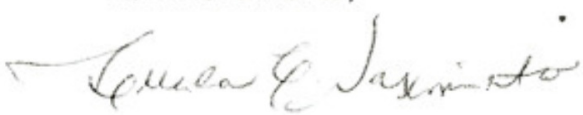 \\ Profa. Dr ${ }^{\mathrm{a}}$. Lucila Castanheira Nascimento \\ Coordenadora do CEP-EERP/USP
}

IIma. Sra.

Profa. Dra . Débora Falleiros de Mello

Departamento de Enfermagem Materno-Infantil e Saúde Pública

Escola de Enfermagem de Ribeirāo Preto - USP 